

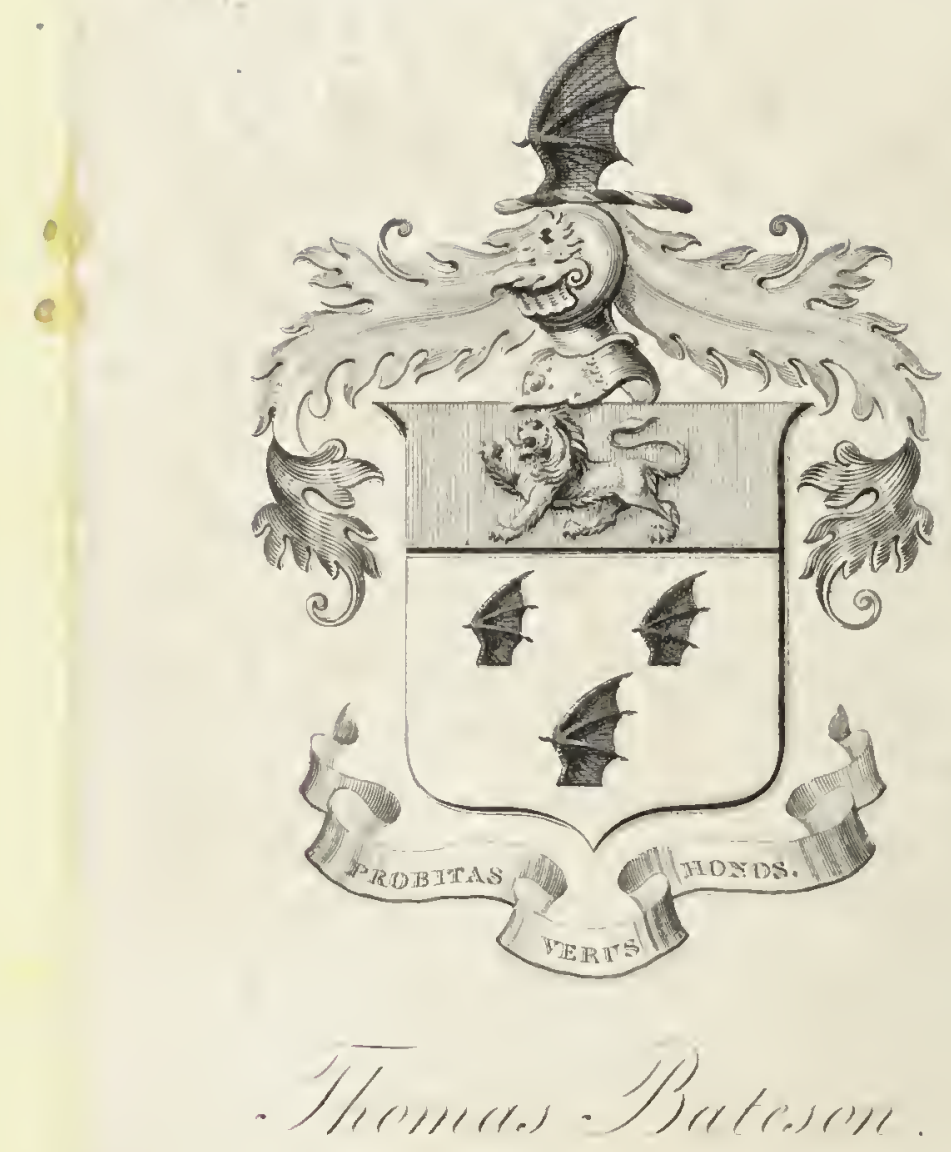




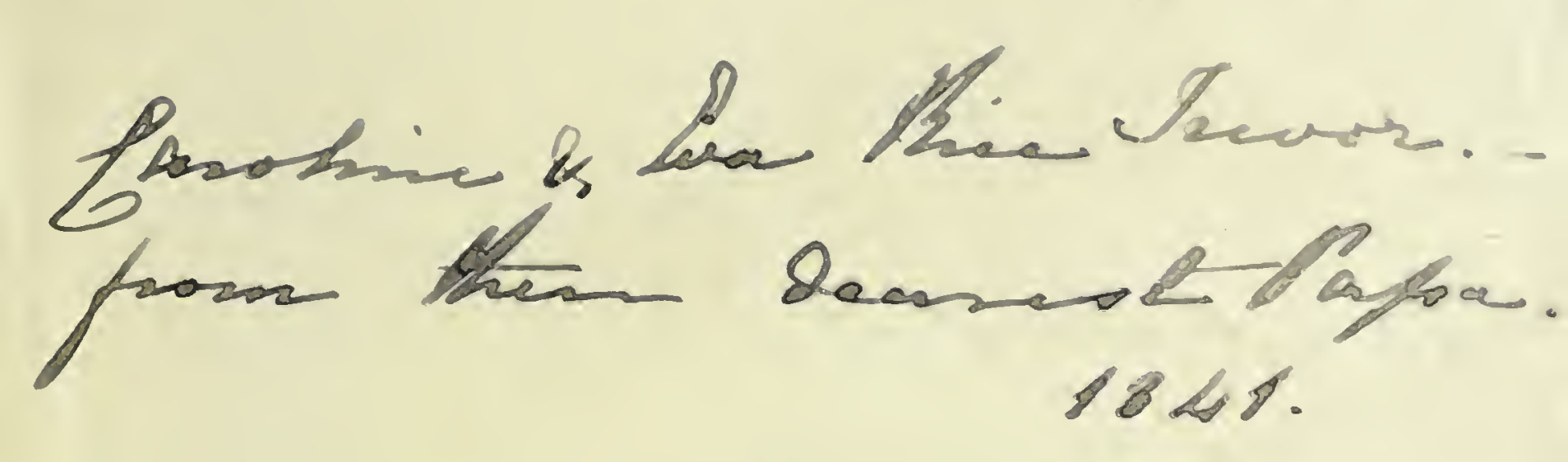




$$
\begin{aligned}
& 2 \text { vil } \\
& 2 / 2=0
\end{aligned}
$$


Digitized by the Internet Archive in 2018 with funding from University of Toronto 


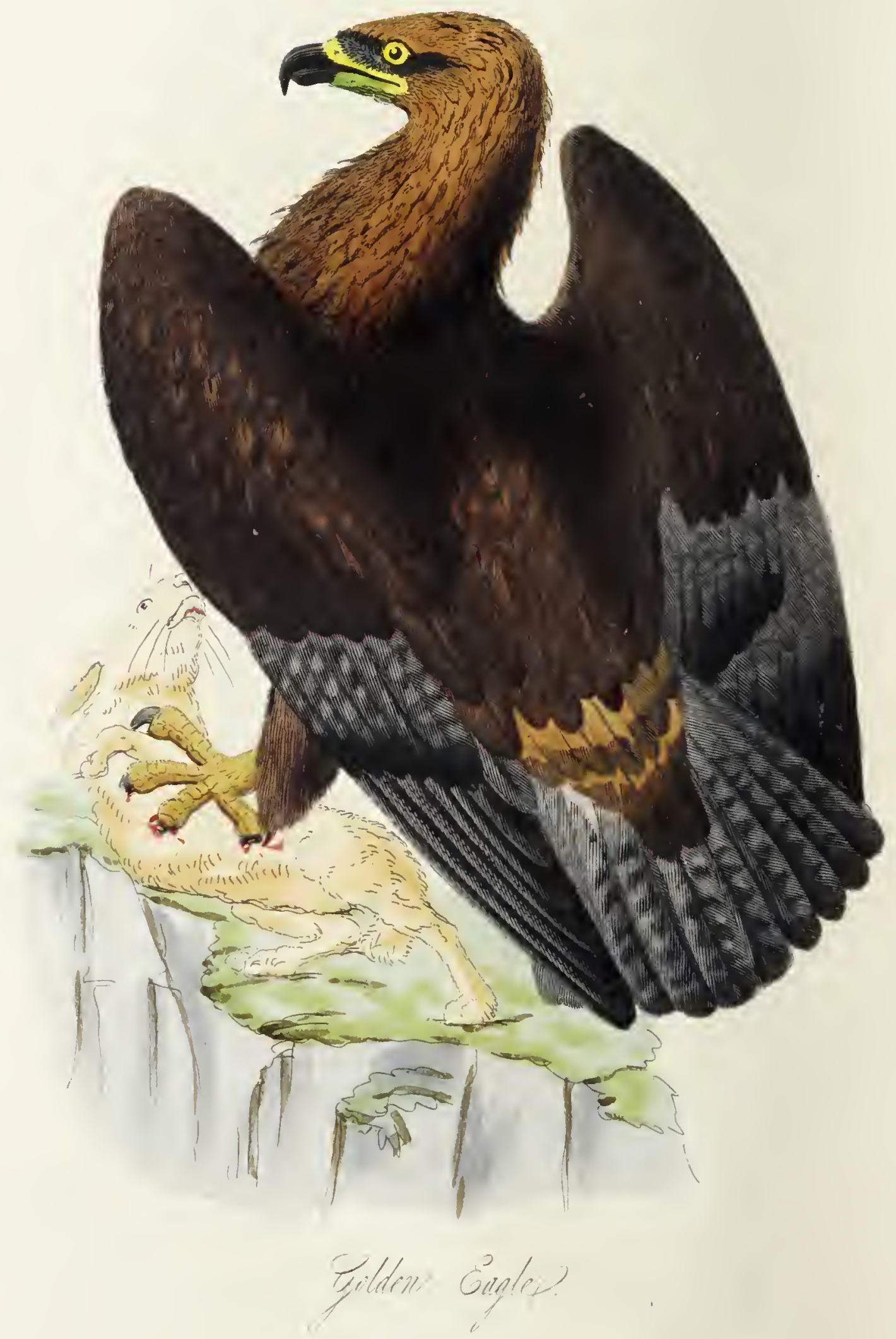


THE

\section{FEATHERED TRIBES}

OF THE

\section{BRITISH ISLANDS.}

BY ROBERT MUDIE.

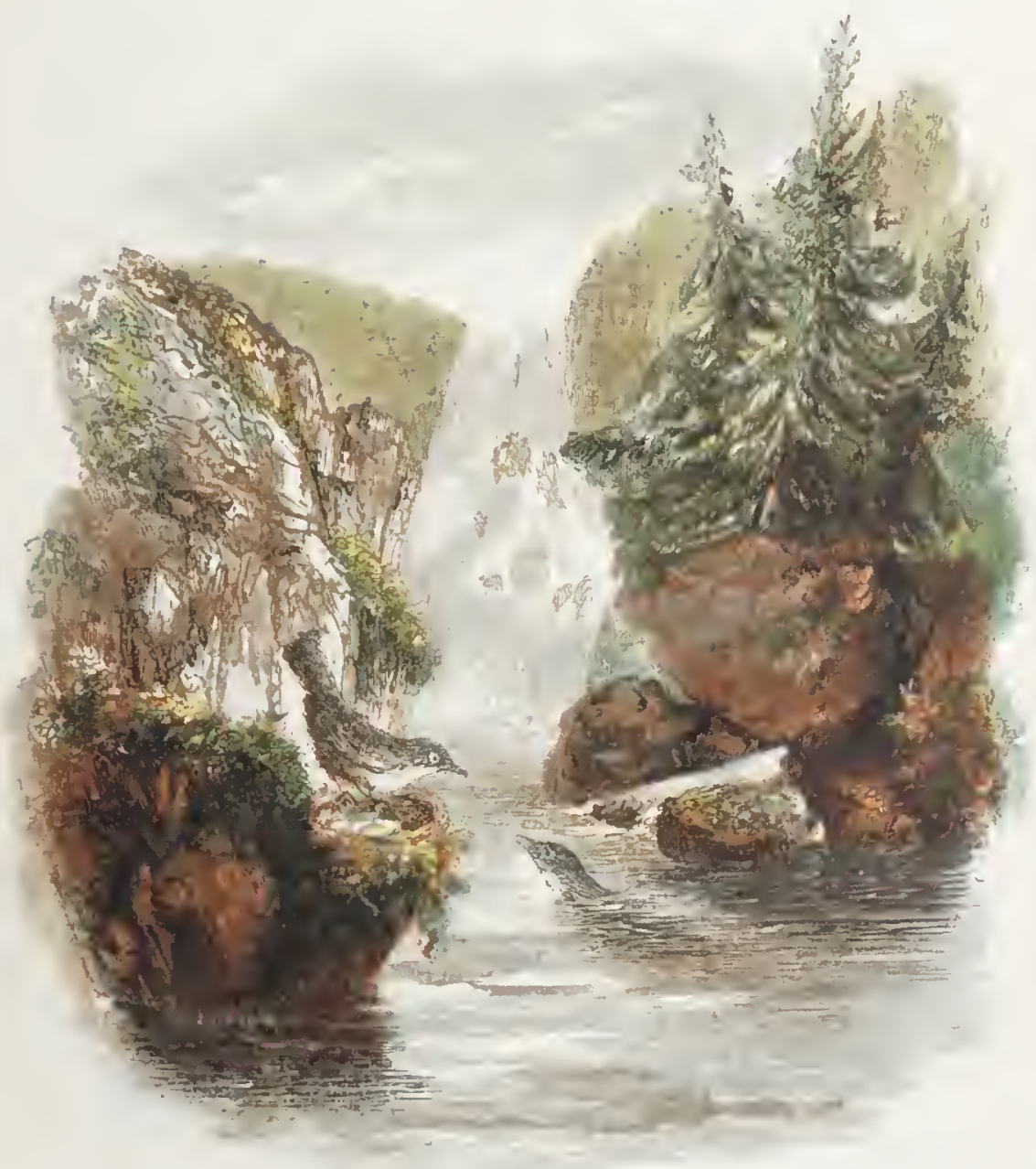

DIPPERS AND NEST.

VOLUME THE FIRST.

SECOND EDITION.

WHTTAKER \& CO., AVE MARIA LANE, LONDON: WAUGH \& INNES, EDINBURGI: AND JOHN CUMMING, DUBLIN. MDCCCXXXY 



\section{NOTE TO THE SECOND EDITION.}

Is preparing for the press this Edition of a work which has been received by the Public with that approbation which is the sweetest and the only satisfying reward of miental labour, I have not found much to add. The zeal with which natural science is now prosecuted has, however, enabled me to give notices of a few rare birds, which had not been previously mentioned in these kingdoms even as stragglers; and I have, with all the care that I could bestow, revised the whole work, so as to correct those errors, whether of the pen or of the press, which are perhaps unavoidable in the First Edition of a work wholly original. It would be too much for me to say that, even with all the care which I have bestowed upon it, (and only they who have written original works upon subjects $s 0$ multifarious and varied can know the amount,) the book is any thing like perfect; but if it shall continue, as I am told it has hitherto done, to send its readers to the haunts of the birds to observe and study them there, I shall have accomplished a task which is to me far more delightful than if I had won the greenest laurels which are to be obtained in the field of literature and science.

ROBERT MUDIE.

GROVE COTTAGE, CHELSEA,

May, 1835.

VOL. I. 



\section{P R E F A C E.}

In submitting these volumes to the public, to whom I have the feeling that I am bound to be grateful, I have not the vanity to suppose that $I$ have materially extended what is usually termed the science of Ornithology. I have formed no system, I have followed no systematist, I have drawn up no nomenclature of shapes or of colours, and I have not counted the feathers, or the scales or reticulations on the tarsi, of a single bird. Therefore, I conclude, that my little book is without the province of either the praise or the censure of the profound. I should also suppose, that most of what I have written, must appear so ragged and incomplete out of its connection, that my book will escape the inglorious martyrdom of being hacked and hawked in pennyworths, ere it has had even a chance for life.

My object is a much humbler one; but it is one which to me is more delightful, and, in my opinion-an opinion in which I am borne out by long experience-by no means less generally useful. It is simply, to entice my fellow Britons, of all ages, classes, and ranks, who are not too learned for relishing the beauties of nature as they stand displayed in nature itself, into the fields, that thcy may know and feel the extent of delightful knowledge, rational and even profound 
thinking, and useful hints for every department of science and pursuit, to say nothing of well-sinewed limbs, and hearts tuned for enjoyment, that are to be met with there, and met with in abundance by all who will but take the trouble of seeing with their own eyes and hearing with their own ears. It has been my wish and my endeavour to produce a book upon which the reader could lay his hand and say, "Herein I shall find a notice of every feathered creature which I may meet within the four seas, or on their margins, so expressed as to correspond with its appearance and habits in free nature; and by the help of which I shall not only know each bird when I see it, but, in some sort, borrow its wings, and soar with it and survey the glories and the wonders of that creation of which it forms so lively and so enlivening a part."

My first purpose was to attempt the accomplishment of this in a single pocket volume; but, in spite of all my efforts, it has extended to two; and even then, I have been again and again constrained to shut the door upon some of my favourites, before they had half told their story. The bird, too, is only a disjointed fragment, without the scene and the season or other cause which brings it to that scene; and when, in the contemplation of nature, we once begin to trace the relations between subject and subject, it is always difficult, and in some instances impossible, to stop the analysis, till it has carried us beyond the range of merely human reasoning, to that sublime field where we can but admire, and dare not restrain our adoration. The passages in which I have ventured to indulge in that strain, will be found to be few; but as it is the ultimate feeling in the study of nature, and the one which repays most fully and exquisitely the labour of all 
the rest, I have ventured, in those few passages, to extend the analysis as much farther than is usually done in such books, as to carry the ordinary reader beyond that point at which the half-informed stand in some jeopardy of falling into error, more seriously injurious to their happiness than any mistake that could be made in the details of Ornitholog: or of any other science.

In the narrowest view that can be taken of any natural subject, in such a way as to be popularly useful, there are three general points, each branching out into many subdivisions. First, there is the particular knowiedge of the subject itself, in all those characters by which it is distinguished as an individual; secondly, there are the relations in which it stands to the rest of nature, in place and in time, in subject and in event; and thirdly, there are the general rela. tions of nature to the Creator by whom it has been made, and to man by whom it should be studied both for bodily use and for mental information and pleasure. In pursuing the matter systematically, for the purpose of extending the light of science over these, it may, perhaps, be better to divide them,- - just as the constructing of a nice machine, a watch for instance, succeeds best when divided among many hands. But it is otherwise with the public, who want the machine or the science for popular use. When a plain man wishes to know how time passes, lie does not go to one handicraft for a spring, another for a chain, a third for a balance, and so on for all the several parts of a watch, he goes to the man who can furnish him with a watch in "going order," and prefers one even of rude workmanship, to the disjointed parts made by the first workmen in the kingdom. The popular desire for a book, and especially for a book upon Natural History, or any part 
of it, is nearly of the same description, though, as such books are neither so familiar nor so simple in their use as watches, people themselves cannot express so readily, or so clearly, what it is that they desire.

It may seem to be a little vain in me to offer even a tentatory example on the subject; but my chief reason for it is, that I am myself an instance of the class of persons to whom my volumes are addressed. I am not a naturalist in any of the common meanings of the term; but I have, for more than forty years, been an admirer of nature, having found it health in sickness, and a sure anchor to the mind when the current of life ran adverse or turbulent. During the whole of that period I have let slip no opportunity of noticing any one production or phenomenon in nature that came in my way; and during the greater part of it, my opportunities have been both numerous and varied. How they have been improved must be judged of by others, from the execution of these volumes, which are upon one of my favourite subjects, where it is likely that a man would, at least, try to do his best. Whatever else there may have been in my experience, there is certainly thus much, that I never proceeded in it upon any body's system, either with a view to the establishment or the overthrow of any hypothesis. I looked at matters just as I found them; and when I perceived that I should have to follow any subject or principle into a new field, I endeavoured to explore that field, however slight the connection might appear to be between it and the subject which had led me to it. All this was done without confederacy, consultation, or the least reference either to becoming scientific or to the writing of a book; for I knew not then, and I know not now, whether all who have had the 
same opportunities may not know much more of the matter in all its bearings than $I$ do.

I mention these circumstances for no ostentatious purpose, and they are indeed nothing to boast of, but rather the reverse. I mention them merely to ground upon them a claim to originality, such originality as there can be upon a subject, upon which so many have written, or to speak more correctly, upon which the same writing has appeared in so many different forms. Though I have laboured to avoid them all, yet, I would rather stand convicted of dulness, vanity, and error jointly, than have it said that I had appropriated, in any way, the labours of another man, how strongly soever I may have felt their value and superiority. An original book, be it ever so faulty in the plan, or feeble in the execution, always adds something to the mass of knowledge. A compilation always debases that which is already known; and, therefore, both the principle and the practice, by whomsoever they may be held, exercised, and encouraged, are to me equally revolting, as a robbery upon the parties from whom they are purloined, and a fraud upon the public, always the more mischievous, and therefore the more base and contemptible the more influential the party under whose sanction it is perpetrated.

We are all debtors for knowledge to those who have preceded us, and it is one of the advantages of that most valuable of all possessions, that it descends to the world generally, and not to kindred or heirs that can be named in the will of the bequeather. But still, I am not aware that, in the course of these volumes, I have appropriated any man's words without acknowledgment; and even with it, I have not been lavish in quotation either from others or from any thing that I myself may formerly have published-which is as much a 
fraud upon the public as the appropriation of that which they have already in the works of another.

Still, I feel myself under numerous and weighty obligations, some of which I am not at liberty to acknowledge. But I cannot pass without notice those which I owe to Mr. Yarrell, whose name is so well known, and whose talents and labours are so justly esteemed, by all who possess the love and are conversant with the knowledge of nature. That most acute and truly scientific zoologist is not, however, answerable for any one point, debatable or not debatable, which appears in this work; but yet I must sayand I say it with pride-that his museum and stores of knowledge, his sound judgment and candid opinion, which are far more valuable than any museum or collection, have been freely open and liberally afforded to me, and that they have sustained me in several instances where, through the imperfection of my own experience, my confidence might otherwise might have broken down.

So much for the general purpose of these volumes; and though the execution must speak for itself, a few words of explanation may not be altogether unnecessary. A complete system is quite incompatible with an account of the birds of a single country of small dimensions; and to dwell much upon system, would have been out of keeping with the purpose and character of the book. There are some good points and some imperfections in all the systems which have been promulgated; and therefore I have sometimes followed one and sometimes another: but I have followed them no farther than I could, by some general remarks under the orders, genera, and groups, save repetition, and thereby have more scope for the characters and relations of the species. 
In one order, the first in the second volume, or that of birds which feed mostly upon vegetable substances-at least at certain seasons, I have used a name at which the fastidious may cavil, namely, the word graminivora instead of granivora; but I have done so advisedly, in consequence of the limited meaning of the latter term, and also of its being sometimes applied to substances which are not vegetable; and if the general name, Botany, which is expressive of all plants, be derived from a root that signifies " to graze," surely a word of similar import and origin may be applied to those birds whose food is chiefly vegetable. But, even without this explanation, the name cannot mislead, as there is nothing founded upon it.

In the details, whether of appearance, character, habit, or haunt, I have aimed at giving truth and force rather than elegance and grace, and so far as knowledge would bear me out, I have endeavoured to apportion the length of the articles to the importance of the subjects. But that is a matter of opinion; and as I have followed my own, it may appear faulty to others.

In various places of both volumes, there will be found lints, and sometimes short disquisitions, of more extensive range than the mere history of birds; and of these, several will be found to be new : but they have been studiously introduced in the least ostentatious manner possible, that they might not alarm the ordinary reader with the parade of science, which is always more formidable than the reality.

$\mathrm{As}$, in works of instruction generally, and especially in popular works, one main object ought to be to please, and if possible, to delight the reader, controversy, and especially any thing bordering upon acerbity, is sadly out of place. 
Therefore, though I have not, in one or two solitary instances, been able wholly to conceal what I felt, I have endeavoured to express the feeling in the shortest and gentlest terms possible. One cannot help a little turning away of the countenance from cupidity, arrogance, or even gratuitous error ; but still, one's bowels yearn over that "frailty of the flesh," through which such things occur. These matters, though in themselves, neither profitable nor pleasant, yet afford a strong and striking proof of the advantages of the study of nature, inasmuch as all mankind agree, as far as they understand the facts, and dispute only about their own supplemental or substitutional assumptions.

The illustrations will speak for themselves, and may be depended on for fidelity of expression and accuracy of tint. I could have wished that they had been more numerous, extending to all the species; but that would have vastly increased the cost of the book, and also thrown the author into the shade. More figures, in an inferior style, might possibly have tempted into larceny those whose natural instinct needs no spurring; and who, since a late unadvised outbreak of charity for the destitute, or haply of that fatherly $\Sigma_{\text {roo }}$ in, before which equity and justice are of course but as cobwebs, stand in more peril than heretofore.

I should mention that the Vignettes on the Title Pages are novelties, being the first successful specimen of what may be called polychromatic printing, or printing in " many colours" from wooden blocks. By this method every shade of colour, every breadth of tint, every delicacy of hatching, and every degree of evanescence in the outline, can be obtained; and fifty thousand fac similes of a painting may be produced with perfect uniformity and at a moderate expence. 
The advantages to books, of which a large number is to be sold, will be very great, not only as removing the cost of tinting by hand, which is the same for the last thousand as the first; but by making the copies more alike and more durable, and rising more above the reach of the ignobile pecus of imitators. In these Vignettes, Mr. Baxter had no coloured copy but the birds, which are from nature. I made him work from mere scratches in outline, in order to test his metal; and I feel confident that the public will agree with me in thinking it sterling. In carrying this very beautiful branch of the typographic art successfully into effect, Baxter has, I believe, completed what was the last project of the great Bewick, but which that truly original and admirable genius did not live to accomplish.

It now remains only to notice the synoptic list which is prefixed to the first volume, and serves as an index to both. The indications there given are only approximations; but they are more numerous and varied than those given in any similar enumeration.

Having said thus much in the way of explanation, apology, or whatever else it may be called, I must now leave the work to its fate, in the anxious hope that some readers may derive, not from its perusal, but from that study of nature to which it may lead them, some portion of the same pleasure which I have enjoved in that prolonged course of simple observation, of which it is one of the results.

But having thus spoken of myself, or of my production, (which is of course nearly the same,) I may perhaps be permitted to say a few words to others. These I say, not with the dictation of a pedagogue, but with the anxious desire of a scholar, trusting that they will be received as such. They 
are these: the nomenclature of science, more especially of natural science, is an absolute chaos, of good materials I grant, but in perfect confusion, huddled together, not only without organization, but absolutely without that polarity which belongs to the smallest and simplest atom of mere matter. Over this chaos I wish the spirit of the learned to brood, and to turn it to a systematic world of light and of life: by fixing, at their first national meeting, (if they can as soon make up their minds,) an ENGLish NOMENCLATURE of SClence, which shall be classical, by issuing from under the authority of the combined talent of the nation. Such an act would not surely be difficult for so many: and besides enabling observers and inquirers, in all parts of the empire, to understand each other, it would repress, if not utterly destroy, that " calling of names," which, on the part of the lower orders in science, is as offensive as similar practices among lower orders of any other description.

The circumstances of the times render the fixing of some nomenclature a duty equally imperious and pleasing. Whether the establishment of Zoological Societies be the cause or the effect, I leave to be settled by others; but it is certain that there is a spirit awakened all over the kingdom, to the love and the study of nature, of which we have had no example in modern times. Till lately, the Country Gentlemen of England knew nothing of their estates save the rent which they yielded, and the animals that were hunted as vermin or as game; and the consequence was, that they did not want the people, except as administrators to the furnishing of food, clothing, and the trappings of state. The result has been that, ever since the breaking up of the feudal system, by 
which Baron and vassal were linked together in war, there has been an estrangement of the different ranks of society from each other, - a state of things which has every day become more and more unwholesome; and for which, much as has been said and written on the subject, there is no political cure. One can easily see that such must have been the result. The different ranks had no relation to each other but that of bargain and sale; and consequently they rated each other at a money price, and nothing more. But the feelings of the human heart cannot be made chattels; and they have consequently lain dormant.

The study of nature will, however, bring the different ranks together again, and unite them by a bond far more secure than any thing feudal. The owner of an estate will enjoy it all, not merely levy and spend the rent, but claim kindred with, and derive pleasure from, the plants and the animals. Without the love and the knowledge of nature, he can be said to inhabit only the mansion-house, and that but for a portion of the year; but with these he will inhabit the whole domain, however ample; and instead of his importance being rated by the thousands that he can spend in the year, it will be rated by the fields, the forests, the groves, and the waters, which lie around him, as a lovely and an everopen book; and he and his family will find their delight there, and they will cleave to their country and their countrymen, with heart and soul, and their countrymen will cleave to them, and the whole nation will be linked together by that " cord of nature," which God has made; and sustained by that, all the charities and all the gratitudes of the heart will be excited, and peasant and peer, while they preserve the ranks which civilization assigns them, will be brothers in 
nature, and each will vie with the other in striving who shall do the first good office.

This is not the doting dream of a Jover of nature, but a plain and philosophic truth. In the city, people of different ranks stand scowling and apart; but when they go to hunt, to fish, or to any other sport or occupation in the fields, they are fellows. Nature thus makes brotherhood; and if all mankind would study nature, all mankind would be brothers.

This is a truth which often forced itself upon me while sickening with disgust in the turmoil of politics; and, now that I have "'scaped the Stygian pool," I sarnestly and respectfully recommend it to the attention of my fellow countrymen.

ROBERT MUDIE.

GROVE COTTAGE, CHELSEA,

Feb. 14, 1834. 


\title{
ALPHABE'TICAL LIST
}

\author{
OF \\ B R I T ISH BIRDS,
}

\author{
WITH A SYNOPTIC VIEW OF SOME OF THEIR LEADING \\ DISTINCTIONS.
}

EXPLANATION.

N.AMES.

The first column contains the common English names, and the second column the generie and specifie systematic ones. The former are arranged alphabetically; and the only cxplanation they require is, that when the name contains an adjective or epithet, that is put first, but the epithet "common" is omitted.

\section{CHARACTERS.}

The third column, heared c. expresses the character of the bird, and rcquires attention to these particulars, -

R. means a resident bird, or one which is found in some part of the country all the year round.

$\mathrm{S} v$. means a summer visitant, $W \mathrm{~V}$. a winter visitant, $O \mathrm{~V}$. an occasional visitant, and s. a straggler not belonging to a regular migration.

The italies prefixed qualify the eharacters; $c$. means common, or that the bird is generally distributed, $l$. means local, and $r$. means rare : but the application of these eamnot be very preeise; $e$. or $w$. prefixed to an occasional visitant or straggler, means that it belongs to an eastern or a western migration.

\section{HABITS.}

The fourth column, headed H. refers to the habits of the birds in feeding. There,-

A. means acrial birds, which seek their prey on the wing; $h$. prefixed mcans that they fly ligh, m. moderate height, and $l$. that they fly low.

13. means branch or bush birds, which find their food on trees or bushes; $t$. prefixed denotes that they seek it on the twigs and leaves, and $b$. on the bark. H. means that they seek their food on herbaceous plints.

G. means a ground bird; $r$. is prefixed if a runner, and $s$. if they search the earth either with the bill or by seraping with the feet.

$w$. means a water bird; $w$. that it wades, $a$. that it fecds on fishes on the wing, s. that it swims, and $d$. that it dives. 
HAUNTS.

The fifth and sixth columns, headed s. and w. mean the summer and winter haunts; and the following are the leading distinctions, though they are necessarily vague,-

M. indicates a mountaineer, or bird which inhabits elevated places only.

H. means a hill bird, or inhabitant of the moors which have considerable elevation.

c. means a bird of the commons, or open wastes less elevated.

F. means a field bird, or one which inhabits the cultivated grounds.

W. means a woodland bird, whether of brake, copse, grove, or forest.

G. means a garden bird, or one which inhabits near houses.

B. nneans a bank bird, or one which inhabits the margins of lakes, streams, or pools, in reeds, or otherwise.

N. means a fen bird, but it is applied to marshy places generally.

s. means a shore bird, or one which is found on the beaches.

R. means a rock bird, or one which inhabits bold clifts, but no birds find much of their food in such places. The swallow tribe are properly speaking rock birds; they do not inhabit chimneys and steeples, because these are built by man.

P. means a pelagic bird, or one which is discursive orer the sea.

The column s. refers to the breeding haunts of the birds; and the qualifying italics have the following meaning: $s$. that the birds are social, or breed many in the same place, $d$. that they are dispersed apart from each other, and $\hbar$. that they breed hidingly.

The column $w$. refers to the winter haunts; and $f$. means that the birds flock, $p$. that they remain in packs or coveys, and $s$. that they are solitary.

The numerals prefixed and affixed to either of these, point out the numbers of the months, counting from January as 1 , between which the bird may be looked for; but they are vague, varying with both the place and the season.

\section{NESTING PLACES.}

The seventh column, headed N. points out the nesting places; T, means in high trees, B. in brakes or bushes lower down, G. on the ground but concealed

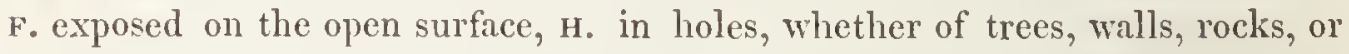
the eartl, and $\mathbf{L}$. on cliffs or ledges of rocks. The kind of surface is, in some measure, determined by the haunt; and no bird deposits its eggs on a liumid surface, as the evaporation would be proportional to the heat, and the eggs could not be hatched.

The italics in this column denote the character of the nest; $o$. that there is no formal one, $r$. that it is rude, $n$. that it is neat, and $e$. that it is elaborate.

These characters might have been extended; but too many columns would be apt to breed confusion.

\section{PAGES.}

The last column marked $P$. indicates the page; and when $i$. is prefixed, it is in the first volume. 
When any columm against a particular species of bird is blank, it implies that there is little reason to expect any character or habit of the species as British answering to that column; and when it is marked by the character? it is understood to be doubtful, and as such worthy of further investigation; the place to be sought is sometimes nuarked, but it is, of course, only guess-work; as, where there is not positive knowledge, there can be no certainty.

\begin{tabular}{|c|c|c|c|c|c|c|c|}
\hline ENGLISH NAME. & SYSTEMATIC NAME. & c. & H. & S. & W. & N. & P. \\
\hline Alpine Titling & Accentor Alpimus. & $0 \mathrm{~V}$ & & & & & i 289 \\
\hline ulture & Vultur perenopterus. & es $\mathrm{s}$ & & & & & i 1.51 \\
\hline American Bitteru & Botuurus lentiginosus.. & $w \mathrm{~s}$ & & & & & 150 \\
\hline Arctic Skua ...... & Lestris parasiticus ..... & $r \mathrm{R}$ & $a w$ & $\mathrm{R}$ & $\mathrm{P}$ & $L$ & 348 \\
\hline Aretic Tern... & Sterna Aretica... & $l \mathrm{~s}$ & & & & & 376 \\
\hline Ash-coloured Harrier & Falco cineracens... & $l \mathrm{R}$ & A $l$ & H & ? & B $r$ & i 102 \\
\hline Ash-coloured Shrike.. & Lunius excubitor... & $e \mathrm{~s}$ & A $l$ & & F & & 234 \\
\hline Baillon's Crake & Crex Baillonii & $e \circ \mathrm{V}$ & ? G & B & & ? & 218 \\
\hline Barn Owl & Strix flemmea.. & $e \mathbf{k}$ & A $l n$ & G & G & B & i 148 \\
\hline Bar-tailed Godw & Limosa rufa... & $w v$ & $20 \mathrm{~W}$ & & $\mathrm{~N}$ & & 202 \\
\hline Bean Goose... & Anas segetum .... & $l \mathrm{R}$ & $s \mathrm{~W}$ & ? & ? & $\mathrm{N}$ & 284 \\
\hline Bearded Tit.. & Parus biarmicus.. & $l \mathrm{R}$ & $\mathrm{H}$ & $\mathrm{N}$ & $\mathrm{N}$ & $\mathrm{B}$ & i 376 \\
\hline Bee-eater..... & Merops apiaster.. & eoov & A $l$ & B & & $\mathbf{H}$ & i 213 \\
\hline Bernacle Goose & Anserbermicla... & iv V & $s \mathrm{~W}$ & & $?$ & & 286 \\
\hline Bewick's Swan & Cygmus Bcuickii....... & $0 \mathrm{~V}$ & $s \mathrm{~W}$ & & w & & 293 \\
\hline Bimaculated Teal & Querquedula glocituns & w s & & & & & 306 \\
\hline Bittern .............. & Botaurus stellaris ..... & $l \mathrm{R}$ & $s \mathrm{G}$ & $\mathrm{N}$ & $\mathrm{N}$ & B & 131 \\
\hline Blackbird & Turdus merula... & $c \mathrm{R}$ & B & wh & G & B & i 2.51 \\
\hline Black-cap Warbler & Curvea atrierpilla. & $e \mathrm{~s} \mathrm{~V}$ & B & 4 в 8 & & $B$ & i 337 \\
\hline Black Grous ...... & Tetrao tetrix......... & $l \mathbf{R}$ & $s \mathrm{G}$ & $\mathrm{H}$ & $\mathrm{H}$ & G $o$ & i 36 \\
\hline Black Guillemot & Uria grylle.... & $r \mathrm{R}$ & $d w$ & $\mathbf{R}$ & $P$ & $L$ & 267 \\
\hline Black-headed Gull & Lamis atricillus & $o \mathrm{~V}$ & & & & & 361 \\
\hline Black Redstart ... & Sylvia Tethys ... & $0 \mathrm{~V}$ & & & & & i 325 \\
\hline Black Scoter . & Oidemia nigra. & $\mathrm{WV}$ & $d \mathrm{w}$ & & $P$ & & $30 !$ \\
\hline Black Stork ... & Ciconia nigree... & $e \mathrm{~s}$ & & & & & 154 \\
\hline Black-tailed Godwit & Limosa melanura. . & $l \mathbf{R}$ & $w w$ & $\mathrm{~N}$ & $\mathrm{NS}$ & N $h$ & 201 \\
\hline Black Tern............... & Stema nigra ..... & $\mathrm{s} \mathrm{V}$ & $a \mathrm{~W}$ & $\mathrm{~N}$ & & $\mathrm{~N}$ & 373 \\
\hline Black-throated Diver & Colymbus ureticus ...... & IWV & $d w$ & & & & 262 \\
\hline Black-wiuged Stilt..... & Himantopus Melconop- & & & & & & \\
\hline Blue-breasted Warbler & Syleia Suecica.......... & $\begin{array}{c}e s \\
8\end{array}$ & & & & & i 231 \\
\hline Brown-headed Gull & Lames cepristratus. & $\mathrm{ov}$ & & & & & 362 \\
\hline Blue Tit .......... & Purus caruleus ... & $c \mathrm{R}$ & B & $\mathrm{B}$ & G & $\mathbf{B}$ & i 370 \\
\hline Brake Warbler & Curruce garrula... & $\mathrm{ls} \mathrm{v}$ & B & $4 w 8$ & & B $r$ & i 326 \\
\hline Brent Goose $\ldots$. & Anser bientu.... & $l \mathrm{R}$ & $s \mathrm{~W}$ & $\mathrm{~N}$ & $\mathrm{~N}$ & G & 288 \\
\hline Brown Long-beak .... & Macrorhamphusgriseus & $\mid w s$ & & & & & 185 \\
\hline Buff-breasted Tringal. & Tringu rufescens .......... & $w \mathrm{~s}$ & & & & & 183 \\
\hline Bull-finch ............ & I'yrrhule volguris .. & $c \mathrm{R}$ & $B$ & w & w & 13 & 64 \\
\hline Bunting .............. & Limberizu miliurics.. & $e \mathrm{R}$ & H & $F$ & $\mathbf{F}$ & G & 19 \\
\hline Burgomaster Gull. & Larus Glancus ...... & ov & & & & & 352 \\
\hline Bustard .......... & Otis terda ..... & $l \mathrm{R}$ & $r G$ & $\mathbf{F}$ & $\mathrm{F}$ & G $o$ & i 53 \\
\hline Buzzard & Falio buteo...... & $\mathrm{R}$ & A $l$ & w & $\mathrm{F}$ & Tr $r$ & i 104 \\
\hline Carrion Crow & Corrus enrone. & $c \mathrm{R}$ & G & w & $\mathrm{F}$ & $\mathrm{T}$ & i 163 \\
\hline & & $e s$ & & & & & 370 \\
\hline Chaftinch ............ & Ir ringillu colebs ........ & $e \mathrm{R}$ & B & G & $\mathrm{F} f$ & B & 40 \\
\hline Chinney Swallow. & Hirunds restice ......... & $c s \mathrm{v}$ & $A m$ & $4 G 9$ & & н & i 217 \\
\hline Chough ...... & Pyrohocorede grecedus. & 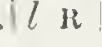 & $s \mathrm{G}$ & H & $\mathrm{H}$ & H & i 178 \\
\hline
\end{tabular}




\begin{tabular}{|c|c|c|c|c|c|c|c|}
\hline ENGLISH NAME. & |SYSTEMATIC NAME. & C. & H. & $\mathrm{S}$. & W. & N. & \\
\hline & & & & & & & \\
\hline & & $l \mathrm{R}$ & $\mathrm{H}$ & $\mathbf{F}$ & $\mathrm{F}$ & B & \\
\hline 9 & Park & $c \mathrm{R}$ & B $l$ & w & G & H G & \\
\hline & & $e \mathrm{~s}$ & & & & & \\
\hline or & & $c \mathrm{R}$ & $s \mathrm{~W}$ & $\mathrm{~N}$ & $\mathrm{~N}$ & G & \\
\hline & & $c \mathrm{R}$ & $d w$ & $\mathrm{R}$ & $\mathrm{P}$ & $\mathbf{L}$ & \\
\hline & Crex & $|c \mathrm{~S} \mathrm{~V}|$ & $s \mathrm{G}$ & $4 \mathrm{~F} 9$ & & G & \\
\hline & Grus cinerca .... & $e \mathrm{~s}$ & & & & & \\
\hline $\begin{aligned} \text { rear } \\
\text { foo }\end{aligned}$ & Cursorius Isabelli & & & & & & \\
\hline & Certhic far & $c \mathrm{R}$ & B $b$ & G & $\mathrm{T}$ & $\mathrm{H}$ & \\
\hline & & $l \mathrm{R}$ & $d w$ & $\mathrm{~N}$ & $\mathrm{~N}$ & G & \\
\hline & Ar & $\mid c o v)$ & W & B & & $?$ & \\
\hline & & $l \mathbf{R}$ & B & W & w & $\mathbf{T} e$ & \\
\hline & & $0 \mathrm{~V}$ & B & $w$ & w & $?$ & \\
\hline & & $|e \leq \mathrm{v}|$ & B $t$ & $4 w 8$ & & $?$ & \\
\hline & & $c \mathrm{R}$ & $s G$ & $\mathrm{H}$ & $\mathrm{s}$ & $\mathrm{Gr} r$ & \\
\hline Curle & & $l \mathrm{R}$ & $s \mathrm{G}$ & $\mathrm{N}$ & $\mathrm{s}$ & ? & \\
\hline & & $l \mathrm{R}$ & $\mathrm{B}$ & $\mathrm{C}$ & ? & B $\hbar$ & \\
\hline & & $l \mathrm{R}$ & $r \mathrm{G}$ & B & B & & \\
\hline & & $\mathrm{S} \mathrm{V}$ & $s \mathrm{G}$ & $\mathrm{H}$ & $?$ & G $l e$ & \\
\hline 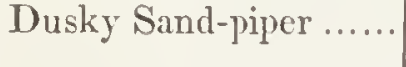 & Totanus fuscus.. & $l_{\mathrm{R}}$ & $s \mathrm{G}$ & $\mathrm{N}$ & $\mathrm{s}$ & $\mathrm{G} h$ & \\
\hline & & $l \mathrm{R}$ & $d \mathrm{w}$ & 2 & $\mathrm{~N}$ & G & \\
\hline Eider & Somateria mollissima.. & $l \mathrm{R}$ & $s \mathrm{w}$ & $\mathrm{R}$ & $\mathrm{P}$ & $\mathbf{F}$ & \\
\hline & & $l \mathrm{R}$ & & & & & \\
\hline & Tut & $e w v$ & $s \mathrm{G}$ & & $9 c f^{5}$ & & \\
\hline & & $l \mathrm{R}$ & $s \mathrm{~W}$ & $\mathrm{R}$ & $\mathrm{R}$ & $\mathbf{L}$ & \\
\hline & pillus & $l \mathrm{R}$ & B & w & w & $\mathrm{T} e$ & \\
\hline & Uria troile ....... & $c \mathbf{R}$ & $d w$ & $\mathrm{R}$ & & L & \\
\hline & $\begin{array}{c}\text { Thalussidroma Bul- } \\
\text { loekii ................. }\end{array}$ & $l \mathbf{R}$ & $a \mathrm{~W}$ & $\mathrm{R}$ & $\mathrm{P}$ & $I$ & \\
\hline Fulmar P & Procellaria glacialis ... & $l \mathrm{R}$ & $a \mathrm{~W}$ & $\mathrm{R}$ & $\mathbf{P}$ & $\mathrm{H}$ & \\
\hline & & $w V$ & & & $N$ & & \\
\hline & & $c \mathbf{R}$ & $w \mathrm{~W} \mid$ & B & B & G & \\
\hline & & $l \mathrm{sv}$ & B & $4 w^{9}$ & & B & \\
\hline & ircia.. & $\mathrm{Wv}$ & $s \mathrm{~W}$ & & & $?$ & \\
\hline & & $e \mathrm{~s}$ & & & & & \\
\hline & & $l \mathrm{~s} \mathrm{v}$ & A $l d d$ & 5 F 8 & & G 0 & \\
\hline & pillus & $c \mathrm{R}$ & B & W & W & T $e$ & \\
\hline & & $l \mathrm{R}$ & 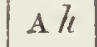 & M & M & L $r$ & \\
\hline & & $W \mathrm{~V}$ & & & & & \\
\hline & & $e \mathrm{~s}$ & & & & & \\
\hline & & $c \mathbf{R}$ & H & F & F & $\mathrm{B} e$ & \\
\hline & & $w \mathrm{~V}$ & $s \mathrm{~W}$ & & $\mathrm{P}$ & & \\
\hline & & $l \mathrm{R}$ & $A m$ & W & H & $\mathrm{T}$ & \\
\hline arbler & & $\operatorname{ls\mathrm {v}}$ & B & 4w8 & & B & i 3 \\
\hline & $A$ & $l \mathrm{R}$ & $d w$ & $\mathrm{R}$ & $\mathrm{P}$ & H & 2 \\
\hline & & $l \mathrm{R}$ & $a W$ & $\mathrm{R}$ & $P$ & & \\
\hline & & $\mathrm{ov}$ & & & & & \\
\hline & $F$ & $c \mathrm{R}$ & $\mathrm{H}$ & C & $\mathrm{F} f$ & B & \\
\hline & Paru. & $c \mathbf{R}$ & B $t$ & W & $G$ & H & i 3. \\
\hline & & & & & & & 19 \\
\hline 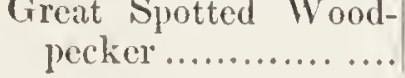 & & & B $l$ & W & $W$ & н $\pi$ & 19 \\
\hline
\end{tabular}




\begin{tabular}{|c|c|c|c|c|c|c|c|}
\hline ENGLISH NAME. & SYSTEMATIC NAME. & C. & H. & S. & W. & N. & P. \\
\hline $\mathrm{H}$ & & e s ? & & & & & 147 \\
\hline & Froungille chloris... & $c \mathbf{R}$ & H & $F$ & C & 13 & $3 i$ \\
\hline -piper & Totanus ochropus. & l. $\mathbf{R}$ & $s G$ & $\mathrm{~N}$ & $N$ & $\mathrm{G} r$ & 164 \\
\hline reen-slianksand-piper & Totenus glottis ... & $l \mathrm{R} ?$ & $s G$ & $?$ & $s$ & ? & 167 \\
\hline Green Wrood-pecker ... & Picus viridis ..... & $\rho \mathbf{R}$ & 136 & W & $w$ & II $h$ & i 189 \\
\hline Lap & Squatorala cinerea. & $l \mathrm{R} ?$ & $s \mathrm{G}$ & H ? & $\mathrm{s}$ & G? & 121 \\
\hline G & Anser palustris .... & IW V? & $\therefore W$ & & & & 282 \\
\hline & Perdrix rufie ...... & $l \mathrm{R}$ & $s \mathbf{G}$ & F & F & $\mathrm{G} l$ & i 47 \\
\hline Grey Phal: & Phalaropus lobatus. . & $r \cdot w V$ & $s W$ & & & & 237 \\
\hline rey $W^{r}$ agtail & Motucillu boamela.. & $l \mathrm{R}$ & $s \mathrm{G}$ & B & B & H $l_{\ell}$ & $i 276$ \\
\hline $11 \ldots \ldots \ldots \ldots$ & Lai & $l \mathrm{R}$ & $a \mathrm{~W}$ & $\mathbf{N}$ & $P$ & G & 356 \\
\hline 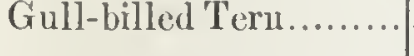 & Sterna Anglica ... & $c \mathrm{~s}$ & $a \mathrm{~W}$ & & & & 367 \\
\hline & Clangule & $O V$ & $s W$ & & & & 321 \\
\hline & Fringillu concotherceustes. & $l \mathrm{l} \mathrm{R}$ & $\mathbf{B}$ & W & W & $\mathrm{T}$ & 62 \\
\hline 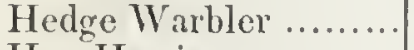 & a hippolais ...... & $\operatorname{ls} v ?$ & B & $3 w 9$ & $r \mathrm{~B} ?$ & B & i 335 \\
\hline & Falco cyun & $c \mathbf{R}$ & A $l$ & $\mathrm{C}$ & $\mathrm{C}$ & B $r$ & - i l01 \\
\hline & Arden & $c \mathrm{R}$ & $20 \mathrm{~W}$ & B & $\mathrm{B}$ & $\mathrm{T} r$ & 126 \\
\hline & Lecrus argentutus .... & $c \mathbf{R}$ & $a \mathrm{~W}$ & $R$ & 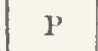 & $\mathbf{L}$ & 353 \\
\hline Ho & Fulco subibuteo.......... & $l \mathrm{~s} v$ & A $/ \ell$ & $4 F] 0$ & & $\mathrm{~T} r$ & i 87 \\
\hline d & apivorus .... & e o v & A $l$ & W & & & i 107 \\
\hline & Co & $l \mathbf{R}$ & $s \mathrm{G}$ & $\mathbf{H}$ & $\mathrm{F}$ & B & i 160 \\
\hline & ullatus ... & $s$ & & & & & 324 \\
\hline & Upupu epops ............ & $c o v$ & & & & & i 207 \\
\hline & rnutus ...... & $l \mathrm{R}$ & $d \mathrm{w}$ & $\mathrm{N}$ & $\mathbf{N}$ & G & 251 \\
\hline & bica ..... & $c \mathrm{~s} \mathrm{~V}$ & A $m$ & $4 \mathrm{G} 10$ & & $\mathrm{H}$ & i 219 \\
\hline House Sparrow ... & Pyrgita domestica ... & $c \mathbf{R}$ & $s \mathrm{G}$ & $\mathbf{G}$ & G & $\mathrm{H}$ & 33 \\
\hline & & $\mathrm{OV}$ & & & & & 352 \\
\hline & La & $\mathrm{OV}$ & & & & & 35.5 \\
\hline & & $c \mathbf{R}$ & $s \mathbf{G}$ & $\mathbf{R}$ & $F f$ & $\mathbf{H}$ & i 169 \\
\hline & opax gallinula ...... & $l \mathrm{R}$ & $s G$ & $\mathrm{~N}$ ? & $\mathrm{N}$ & $G$ & 196 \\
\hline & Garrulus glandurius ... & $c \mathrm{R}$ & $s \mathrm{G}$ & w & W & $\mathrm{T} h$ & i 175 \\
\hline & Fulco Islandicus.......... & 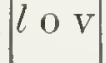 & A $h$ & & & $?$ & i 81 \\
\hline & & $l \mathrm{R}$ & $s \mathbf{G}$ & $s$ & $\mathrm{~s}$ & Fo & 110 \\
\hline & innunculus ... & $\mathbf{R}$ & A $l \ell$ & F & F & $\mathrm{T} \boldsymbol{r}$ & i 92 \\
\hline & spectubilis... & $l \mathrm{R}$ & $s \mathrm{~W}$ & $\mathrm{R}$ & $P$ & $G$ & 318 \\
\hline K & pida ........... & $l \mathrm{R}$ & A $l$ & $\mathbf{B}$ & $\mathrm{B}$ & $\mathrm{H}$ & i 209 \\
\hline & Fulco millus . & $c \mathbf{R}$ & $A h$ & $\mathrm{C}$ & C & $\mathrm{T}$ & i 107 \\
\hline & & $l \mathbf{R}$ & $\iota \mathrm{W}$ & $\mathbf{R}$ & $P$ & $\mathbf{L}$ & 358 \\
\hline Knot Tringa ............. & Tringu Cunutus .......... & $c \mathbf{R}$ & $s G$ & $\mathrm{~N}$ & s & ? & 179 \\
\hline & & $c \mathbf{R}$ & $s \mathrm{G}$ & $\mathrm{H}$ & $\mathrm{S}$ & Go & 118 \\
\hline Li: & a culcurata. & & & & & & \\
\hline ing Gull .. & Larus ridibundus ... & $l \mathbf{R}$ & $u W$ & $\mathbf{N}$ & $\mathbf{P}$ & G & 359 \\
\hline $\begin{array}{l}\text { Lesse } \\
\text { Gul }\end{array}$ & Lamefuseus & $l \mathrm{R}$ & $a \mathrm{~W}$ & $\mathbf{R}$ & $\mathrm{P}$ & $\mathbf{L}$ & $35 \%$ \\
\hline $\begin{array}{r}\text { Lesser Spotted Wook- } \\
\text { peeker ................ }\end{array}$ & & & & & & $1 h$ & \\
\hline - Redpole ... & villa linaria... & $l \mathrm{k}$ & $G$ & C & F $f$ & B $n$ & 46 \\
\hline Le & Sterna minuta...... & $\mathrm{S} \mathrm{V}$ & $\| \mathrm{W}$ & $\mathrm{s}$ & & $\mathbf{F}$ & 372 \\
\hline & & $c 0 \mathrm{~V}$ & & & & & \\
\hline & $O t$ & $e \mathrm{~s}$ & $r G$ & F & & & i 60 \\
\hline & Crexpusilla..... & $l \mathrm{~s} v$ & $\mathrm{H}$ & $\mathbf{N}$ & ? & ? & 219 \\
\hline ed Hero & Ardea garzetta ....... & $e \mathrm{~s}$ & & & & & 147 \\
\hline & Podicrps minor ....... & $l \mathrm{k}$ & $d w$ & $\mathbf{N}$ & $\mathbf{N}$ & G & 252 \\
\hline & & $O \mathrm{~V}$ & & & & & 363 \\
\hline
\end{tabular}




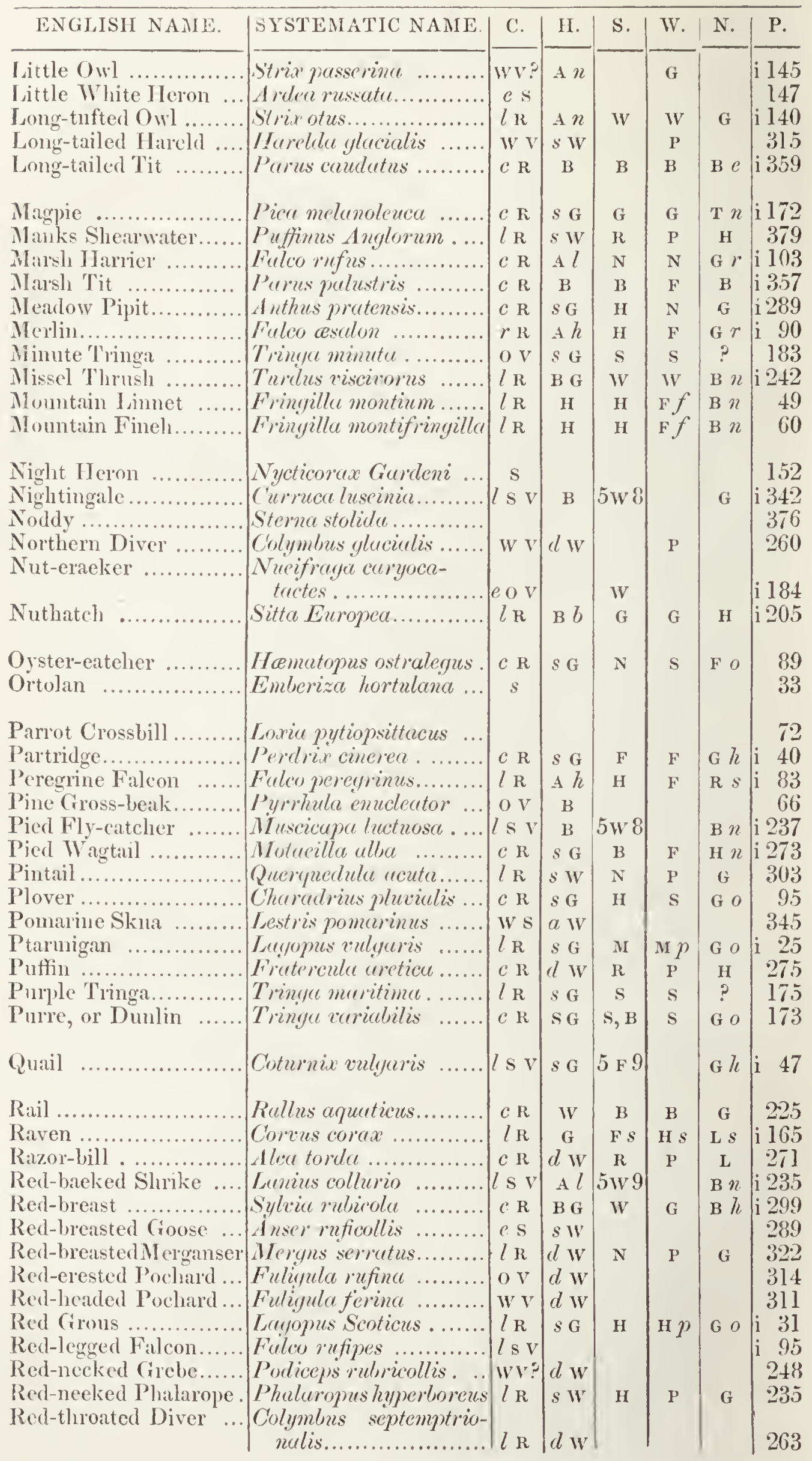




\begin{tabular}{|c|c|c|c|c|c|c|c|}
\hline ENGLISH NAME. & |SYSTEMATIC NAME. & C. & H. & S. & W. & N. & $P$. \\
\hline , & & $e \mathrm{R}$ & 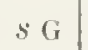 & $\mathrm{N}$ & s $s$ & Gr & 163 \\
\hline arbler .......... & Cumare phrenicurus .. & $l \leq v$ & $B$ & $4 w 8$ & & H $n$ & i 321 \\
\hline Red-wing Thrush ... & Turdusitiacus............ & W V & $s \mathrm{G}$ & & $9 c f 5$ & & i 258 \\
\hline Reed Bunting... & Emberizu schaniches... & $\begin{array}{lll}c & \mathrm{R}\end{array}$ & $\mathrm{H}$ & 13 & $\mathbf{F}$ & B & 21 \\
\hline Reed Warbler... & Сиюиси armalinacen... & $l \leqslant v$ & $\mathrm{H}$ & $5 \mathrm{~B} 8$ & & $\mathrm{~B}$ & i 318 \\
\hline Riclards's Pipit ...... & Anthus Richerreli......... & $l \mathrm{~s}$ & & & & & 1295 \\
\hline Richardson's Śkua ... & Lestris Richardsoniz ... & $c \mathrm{~K}$ & $a \mathrm{~W}$ & $\mathbf{H}$ & $\mathrm{P}$ & $G$ & 346 \\
\hline ng-Dove .......... & Columba palumbus ...... & $c \mathrm{R}$ & $s G$ & W & W & $T r$ & 64 \\
\hline orel. & 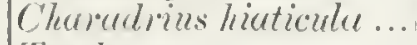 & $l \mathrm{R}$ & $\& G$ & $\mathrm{~s}$ & $\mathbf{s}$ & Fo & 10.5 \\
\hline Ring 'Thrush & Turdus torymutus .... & $l \mathrm{~s} v$ & $s \mathrm{G}$ & $4 \mathrm{H} !$ & & B & i 252 \\
\hline Rock Dove... & Columba livia ....... & $\ln \mathrm{R}$ & $s G$ & $\mathrm{~F} f$ & $\mathrm{R}$ & $\mathrm{R} r$ & i 68 \\
\hline Rock Grous.... & Tetrcio rupestris ......... & $e \mathrm{~s}$ & & & & & i 31 \\
\hline Rol & Coracias yarrulus ..... & $e \mathrm{~s}$ & & & & & i $18: 3$ \\
\hline Rool & Corvus fingileyus. & $e \mathrm{k}$ & $s G$ & $\mathrm{~F} . f^{*}$ & $F f$ & $\mathrm{~T} s$ & i l 155 \\
\hline Roseate Tern ........ & Sterma Dougallii... & $l \mathrm{R}$ & $a \mathrm{~W}$ & $\dot{s}$ & & G & 373 \\
\hline Rose-coloured Pastor & I'astor roseus ........... & 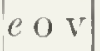 & & $\mathrm{F}$ & & & i 184 \\
\hline Rotcl & Mergulus melunoleneos & ov & $d w$ & & & & 268 \\
\hline h-legged Buzzar & Fulco lagopus........... & $e \quad 0 \quad r$ & & & & & i 106 \\
\hline ldrake ... & Tadoma rutilu .. & $\mathrm{s}$ & $s \mathrm{~W}$ & & & & 297 \\
\hline Rufï..... & Machetes puynax & $\mathrm{sV}$ & $s G$ & $\mathbf{N}$ & $\mathbf{N}$ & G & 212 \\
\hline & & OV & & & & & 364 \\
\hline Snipe... & Scolopax Sabini.. & o $v ? ?$ & $s \mathrm{G}$ & $?$ & $?$ & $?$ & 195 \\
\hline not & Colidris arenaria & $l \mathrm{k}$ & $s \mathrm{G}$ & $s$ & s & Fo & 114 \\
\hline urtin ......... & IVirundo riperia..... & $C \& V$ & $\Delta l$ & $\begin{array}{lll}5 & 13 & 8\end{array}$ & & $\mathrm{H}$ & 221 \\
\hline Sill & Totanus hypoleueos.... & $c \pi$ & $s G$ & B & $\mathrm{s}$ & Fo & 169 \\
\hline lı Teril .... & Sterna Boysiz......... & $l \leq \mathrm{V}$ & $a w$ & $\mathrm{R}$ & & G & 371 \\
\hline Pochard ..... & Fuliynla marila........ & W V & $d \mathrm{w}$ & & & & 312 \\
\hline rocet. & Recurvirostia arocetta. & $l \mathrm{R}$ & $u \mathrm{~W}$ & $\mathrm{~N}$ & $\mathrm{~N}$ & $\mathrm{G} h$ & 203 \\
\hline fted Owl & Strix s & ov & $A n$ & & & & i 143 \\
\hline ch Owl ...... & Strix strirlula .......... & $e \mathrm{R}$ & $A l n$ & G & G & $\mathrm{B} h$ & i $146^{\circ}$ \\
\hline Eagle ........... & Fuleo albicilla.......... & $l \mathrm{R}$ & $\iota W$ & $\mathrm{R}$ & $\mathbf{R}$ & $\mathrm{L} r$ & i 122 \\
\hline Sedge Warbler ... & Curmen phragmitis & $\operatorname{ls~} \mathrm{v}$ & $\mathrm{H}$ & 4 в 8 & & $\mathrm{~B} h$ & i 316 \\
\hline Sh: & Carbo grueulus ...... & $l \mathbf{R}$ & $d \mathrm{w}$ & $\mathrm{K}$ & $P$ & $\mathbf{L}$ & 333 \\
\hline Sheld & Tadrina vulpunser... & $\ln$ & $s w$ & li & $\mathrm{P}$ & I. & 296 \\
\hline Slio & Anthus aquatious ... & $\ln$ & $5 G$ & s & $s$ & G & i 291 \\
\hline tufted Owl & Strier bruchyotos ....... & $l_{\mathrm{R}}$ & $A \|$ & $w$ & wV & $\mathrm{T}$ & i 141 \\
\hline Sh & Sputhuleu clypeutu .... & $r \mathrm{R}$ & $s \mathrm{~W}$ & & & & 298 \\
\hline & Fringilla spinuts ...... & ov? & & & & & 57 \\
\hline Skil & Lestris eutaractes ... & $\ln$ & $a W$ & II & $\mathbf{P}$ & G & 342 \\
\hline -lark & Alumda arvensis...... & $\because R$ & $s i$ & $\mathrm{~F}$ & $F f$ & G & \\
\hline Sill & Mergus allsellas ....... & WV & $\& W$ & & & & 325 \\
\hline Sni & $x$ garlinugyo. & $c \mathbf{R}$ & $s \mathrm{G}$ & $N$ & $\mathrm{~N}$ & G $h$ & 183 \\
\hline Sint & Emberiza nivalis. & WV & & & H & & \\
\hline Sinc & Strir myctea....... & $0 \mathrm{~V}$ & & & & & i 143 \\
\hline Sol & Sula Basserna... & $l \mathrm{k}$ & $u W$ & $\mathrm{R}$ & $\mathrm{P}$ & L & 334 \\
\hline Thrush & Turdus musicus ....... & $c \mathbf{R}$ & B & $w h$ & $\mathrm{~F} f^{\circ}$ & B & i 247 \\
\hline & P"ffinus fuliginosus. & $s$ & & & & & 378 \\
\hline Spintow Hawk & Fulco nisus. ............ & $e \mathbf{R}$ & $A h$ & $F$ & $\mathrm{~F}$ & $\mathrm{~B} r$ & i 97 \\
\hline Spr & Crear porzcura .......... & $\mid \mathrm{S} V$ & $s G$ & 31310 & & $\mathrm{G}$ & 218 \\
\hline Fly-catcher & Mnscicup)a ypisola ..... & ls $v$ & $B$ & $5 w 9$ & & В $n$ & i $2: 39$ \\
\hline S & macularius. & $u \mathrm{~s}$ & & & & & 167 \\
\hline H & rulloides ..... & $e \mathrm{~s}$ & & & & & 148 \\
\hline & Stmrnus vulyaris...... & $r k$ & $r G$ & H & c $f$ & H & i 180 \\
\hline tock Doye & Columber aenas....... & $l \mathrm{R}$ & $s G$ & WV & $r f^{\circ}$ & 13 & i 67 \\
\hline & ode rubirola ...... & (c) $\mathrm{R}$ & $s(i$ & $\mathrm{C}$ & $\dot{C}$ & В $n$ & i 261 \\
\hline Petrel & Thalassidromen pelayiea & $l \mathrm{R}$ & a w & $\mathrm{R}$ & $\mathbf{P}$ & $\mathrm{H}$ & 389 \\
\hline & Oidemia pervpisilla..... & $\mathrm{OV}$ & $d \mathrm{w}$ & & & & 310 \\
\hline wift .. & Cypeches upus............ & s V & A $h$ & & & H & i 293 \\
\hline
\end{tabular}




\begin{tabular}{|c|c|c|c|c|c|c|c|}
\hline ENGLISH NAME. & SYSTEMATIC NAME. & c. & H. & S. & W. & N. & P. \\
\hline & $Q$ & $l_{\mathbf{R}}$ & $s \mathrm{~W}$ & $N$ & $\mathrm{~N}$ & G & \\
\hline & & $\mathrm{sv}$ & $a \mathrm{w}$ & $\mathrm{s}$ & & G & \\
\hline Tringa & Tringa Temminekii .. & $0 \mathrm{~V}$ & $s \mathrm{G}$ & s & & & \\
\hline & Ediencmus erepitans... & $r l \mathbf{R}$ & $r G$ & $\mathrm{C}$ & c? & $\mathrm{F} O$ & \\
\hline & Accentor modularis ... & $c \mathrm{R}$ & B & $\mathbf{F}$ & $\mathrm{F}$ & $\mathrm{B} h$ & \\
\hline & s ardoreus & $\mathrm{S} \mathrm{V}$ & B & $\mathrm{F}$ & & G $n$ & \\
\hline & & $l_{\mathbf{R}}$ & $s \mathrm{G}$ & $\mathbf{F}$ & F & $\mathrm{H}$ & \\
\hline & Fuligula & $\mathrm{w} v$ & $d \mathrm{w}$ & & & & \\
\hline & & WV? & $s \mathrm{G}$ & $?$ & $\mathrm{~s}$ & & \\
\hline Turtle & Columba turtur ... & $l \mathrm{~s} v \mid$ & $s \mathrm{G}$ & w & & $\mathrm{T} h$ & \\
\hline Velvet $\mathrm{Se}$ & Oidemia fusca..... & $\mathrm{w} v \mathrm{v}$ & $d w$ & & & & \\
\hline & & $e \quad 0 \quad \mathrm{v}$ & & & Ff & & \\
\hline & Som & $\mathrm{s}$ & & & & & \\
\hline & Ma1 & $W v ?$ & $s \mathrm{~W}$ & & & $\mathrm{~N}$ ? & \\
\hline & Sux & $c \mathrm{~s} \mathrm{v}$ & $s \mathrm{G}$ & $4 \mathrm{c} 7$ & & Н $n$ & \\
\hline & $N u$ & $c \mathrm{R}$ & $s \mathrm{G}$ & $\mathrm{H}$ & $\mathrm{s}$ & G $r$ & \\
\hline & Sax & $|\mathrm{s} v|$ & $s \mathrm{G}$ & $|4 \mathrm{c} 9|$ & & в $n$ & i 2 \\
\hline & Cyg & WV? & $s \mathrm{~W}$ & & $\mathrm{~N}$ & & \\
\hline & pinus & $l \mathrm{~s} \mathrm{v}$ & & & & & \\
\hline & Fuli & $\mathrm{ov}$ & $d w$ & & & & \\
\hline & Anse & $w v$ & $s w$ & & & & \\
\hline & Pla & ov & & $\mathrm{N}$ & $\mathrm{N}$ & ? & \\
\hline & Cicon & $\mathrm{ov}$ & & & & & \\
\hline $\mathrm{r}$ & Cur & $c \mathrm{~s} \mathrm{v}$ & Al $l$ & $5 \mathrm{~F} 8$ & & B $h$ & i 3 \\
\hline & & $c \mathrm{R}$ & $s \mathrm{~W}$ & $N$ & $\mathrm{~N}$ & G & \\
\hline & $C u s$ & $\operatorname{lsv}$ & $\mathrm{B}$ & 4 в 8 & & G $e$ & i 3 \\
\hline & & $e \circ \mathrm{V}$ & A $l$ & $5 w 8$ & & B $n$ & \\
\hline & Aluuda arbor & $c \mathrm{R}$ & $s \mathrm{G}$ & $\mathrm{C}$ & $\mathrm{C}$ & G & \\
\hline & & WV? & $s \mathrm{G}$ & w & w & G & \\
\hline & sglureola.. & WV? & $s \mathrm{G}$ & & & & \\
\hline & & $l \mathrm{~s} \mathrm{v}$ & B & $4 w 8$ & & B & \\
\hline & Troglodytes vulgaris & $c \mathrm{R}$ & $\mathrm{B}$ & $w$ & G & В $e$ & \\
\hline & Yunx torquilla ....... & $l \mathrm{sv}$ & $\mathrm{B} b$ & $4 w 8$ & & н $h$ & i 19 \\
\hline & & $c \mathrm{R}$ & $\mathbf{H}$ & $w$ & $\mathrm{~F} f$ & $\mathrm{~B}$ & \\
\hline & Notacilla flav & $\mathrm{S} \mathrm{V}$ & $s \mathrm{G}$ & B & & н $h$ & \\
\hline
\end{tabular}




\section{LIST OF PLATES.}

\section{VOL I.}

\begin{tabular}{|c|c|}
\hline & \\
\hline Frontispiece. & Bullfinch \\
\hline ippers and Nest & Feet of the Woodpeeker and \\
\hline oller & Nuthatch. \\
\hline tarmigan ........ & Woodpeeker. \\
\hline$i b$. & \\
\hline ib. & I. \\
\hline heasant ........ & val- \\
\hline Goatsucker & \\
\hline g Feet- & \\
\hline Ring-dove and Little Bustard... 55 & \\
\hline$s-$ & \\
\hline nd $\mathrm{Owl}$ & \\
\hline Peregrine Faleon .................... & \\
\hline Eagle Owl............................ ib. & Stoneehat \\
\hline ng Feet- & Feet of the Lark and I \\
\hline Golden Eagle and Osprey ...... 115 & \\
\hline (2) & ed-Start \\
\hline Blatry & Golden-crested in \\
\hline
\end{tabular}




\section{LIST OF PLATES.}

\section{VOL II.}

\begin{tabular}{|c|c|}
\hline PAGE & PAfiE \\
\hline he Gannet .............Frontispiece. & Grebe's Foot \\
\hline ittle Grebes and Nest .....Vignette. & Puffin $\ldots . . .$. \\
\hline Dotterel....................... & Teal. \\
\hline apwing ............................ ib. & Shag \\
\hline Jaek Snipe $\ldots \ldots \ldots \ldots \ldots \ldots \ldots \ldots \ldots$ ib. & Cormorant's Foot........ \\
\hline Sand-piper....................... ib. & Cormorant........... \\
\hline Kentish Plover .................... 110 & Skua-Gull.... \\
\hline Phalarope ........... & Eider Duck \\
\hline Turnstone ....... & Fork-tailed Petrel \\
\hline Pratincole ....... & Diver............... \\
\hline Bittem ........ & Kitty-rake \\
\hline urlew & Tern . \\
\hline rake & Storm Petrel........ \\
\hline
\end{tabular}




\title{
FEATHERED TRIBES
}

OF THE

\author{
BRITISH ISLANDS.
}

\section{INTRODUCTION.}

Birds are the most interesting division of nature's living productions: the elegance of their forms, the delicacy of their covering, the beauty of their colours, the element in which they live, the variety of their motions, the labours which they perform, the songs which they pour forth, and the indications which they give of the vicissitudes of the seasons and the changes of the weather, are subjects of observation, continually varying, but always delightful—so much so, as to have commanded the attention of mankind, in all ages and under every degree of civilization.

When the infant first begins to notice that creation which is to be its support, and should be its stury through life, birds are the fondest subjects of its admiration; and, long before it can use its feet, it will stretch its little hands, and strain to be out of the nurse's arms, in eagerness to catch the sportive tenants of the sky; and when the bird tunes its melody, the child is hushed into a repose apparently as fascinating as that which it derives when listening to the lullaby of the fondest mother. 
When the wind of winter is up, - when the forest howls to its fury, driving the twitterers from the sprays, and forcing them to take shelter in clefts of the trees and crannies of the earth, - when the sky is darkened by the congregated flakes of snow, which throw their protecting mantle over the earth, but compel the inhabitants of the cottage to remain within, and merely eye the storm which rages without,-it is then that the door is left a-jar, and the little red-breast comes lopping in for his crumbs, welcome, and well-beloved by the very boys that make the plundering of nests a portion of their summer's sport ; and the memory of his winter visit of familiarity, his chirp of gratitude for his pittance, and the early song with which he serenades his benefactors before taking his seasonal departure for the coppice, remains; and the boys spare the robin's nest, in order that the winter visitant may return again with confidence.

When the winter relents, - when the snowy mantle is dissolved, so that the early flowers display their colours, and the icy fetters of the waters are broken, so that the early waterflies begin to sport in the sun,-when man first feels the genial breath of the young year, away from the smoke of the town, or the shelter of the country habitation,- - the song of the lark, soaring to the zenith, and thrilling the atmosphere, is more gratifying to the sense, and inspires more uplifting of the spirit, than all the skill of the orchestra.

Indeed, in all places wherein man can hold converse with nature, or derive pleasure from the contemplation of it, the bird,- the inhabitant of the life-giving atmosphere,-is that which imparts the finishing touch to the enjoyment.

At the base of some wave-beaten cliff, which rises bold and rugged into mid air, cutting off the landward view, it is pleasant to sit on some jutting point, or to recline in some little niche which nature's own hand has scooped out, and look upon the glorious expanse of water which girdles the globe. It is one of those mackerel-breezy days on which the surface of the water just dances and dimples, to show its obedience to the air. Before one's feet, it sports in turn all the tints of the 
rainbow; but it softens off in the distance, and so blends its beryl with the subdued sapphire of the horizon sky, that the line of their separation is obliterated, and the observer feels linked to the universe.

On such days, the fishes sport so near the surface that their multitudes are ever and anon whitening the water, and impressing you with a feeling of the vast productiveness of that wide and wonderful element.

But if, in the midst of your contemplation, the gannet should come prone down, like a fragment hurled from the summit, dashing into the water till the ripple closes over him, and again bounding upwards with the reward of his daring in his bill,-then the cliff, the sky, the sea, and the fishes, would ail be forgotten, and your attention would be wholly and irresistibly absorbed by the bird. Even the dismal sand, where land and sea are equally void of interest, save the melancholy interest produced by the bleaching fragments of ships, which remain to mark the spots where they were stranded, and, it may be, their crews enshrouded in the flood;-even there, the scream of a curlew, the whistle of a sand-piper, or the wail of some sea-bird on the wing, will bring you back to animated nature, and your imagination will soon people the dreary waste with subjects of pleasure and admiration. Go where you will, be the scene and season what they may, be the sky serene or be it in storms, there is always a bird to be found, and that bird never fails to be interestiring, as well to the unlearned as to the learned. Thus, the study of birds is not only one of the best and most certain sources of rational enjoyment, but it is one which leads more directly than any other to the love, and consequently to the study and the knowledge, of all nature, and of nature's Author.

Nor can the natural history of birds be regarded as merely a subject of intellectual enjoyment, high as it ranks in this respect; for the elements of much practical science, and the foundations of many of our most useful arts, may be traced in the economy of birds. The doctrine of motion is one of the most useful branches of knowledge, and nowhere can that 
be studied so easily, or under so many varieties and modifications, as in the feathered tribes. The birds move through the air in all directions, upwards, downwards, and horizontally : they run upon the earth over all sorts of surfaces, on firm ground, over quagmire, or on long grass; and some of them, aided by the action of their wings, walk the waters, and row themselves by their feet, while the weight of the body is suspended on the air. They swim, they dive, they run along on the bottom in the shallows, or through the water in the deeps; and, in short, they perform every species and almost every rate of motion that can be imagined, from a velocity which surpasses the hurricane in the utmost of its fury, to gentle gliding, barely perceptible by the eye. All these varied motions are performed by means of organs adapted so much more nicely to their purposes than even our finest mechanical contrivances, that they may be said to differ from these in kind more than in degree; and, though we may take many useful hints from them, they are far above our imitation. That the same bird should be able, without any change of substance, and by the action of its mechanical structure alone, to ascend and descend at pleasure, either in air or in water, is in itself a subject well worthy of the most profound investigation.

Nor are the uses of the birds, not merely in wild nature but in conjunction with man as he cultivates the garden and the field, less worthy of being observed and admired. We, in our ignorance, often regard them as pests, and as such destroy them in the most assiduous manner, deeming every feathered creature which we deprive of life as so much certainly added to the produce of our horticulture and our farming; but we little know, while we are acting thus, that we are sacrificing the guardians of our vegetable wealth, and giving protection and scope to its destroyers. The whole of nature is so replenished with the germs of small life, in a condition ready to be developed the instant that the state of heat and moisture accords with their development, that a means for preventing their extraordinary increase, more efficient both in itself and in its application than any thing of human contrivance, is absolutely 
requisite, in order to preserve that relative balance which is essential for preserving the system of nature, and which no part of that system is without.

Every bud, every crevice in bark, very many roots, all the pools and slow streams, and all animal and vegetable matters in a state of decay, are full of the rudiments of small animals in some state or other, and those rudiments are awakened so easily, and by causes so little open to common observation, that, if there were not some counteracting power, our gardens might, in the course of a single season, be left without a blossom, our forests without a leaf, and our fields without a blade of grass, a spike of corn, or an esculent root. If this once took place, vegetation would be gone, save the poisonous fungi which might be nourished by the remains of the destroyers.

We have partial experience of this almost every season. When the wind of the early year is soft, and the showers are genial, the leaves and the blossoms are perfect in their forms, and rich in their colours; they are also cool in their temperature, and their sap is astringent. If this state of things continues, the year is one of abundance; but if, in the midst of the verdure, the east wind should dry the surface of the leaves, and the unclouded sun, co-operating with the wind, at the same time raise them to a certain temperature, the juice which is in them would become saccharine, as it does in ripening fruits; and, as that is the proper food of the larva, or caterpillars, of insects, these would appear in myriads, as if they came by magic, or rode on the wings of the destroying wind. Those reverses are part of the system of nature's economy, and inseparable from a climate so variable, and by that means, so favourable to continual cultivation as ours; and they produce the most serious effects when they come upon the vegetable tribes in the most active and vigorous growth. Nor is there any season during which they would not destroy the produce of the gardens and orchards, and greatly diminish that of the fields, were it not for the birds.

Almost all birds feed upon insects, molluscous animals, B 3 
(such as snails and slugs,) and worms, though many have recourse to other food, particularly at certain seasons; and many retire from Britain when their favourite food becomes scarce. But even those birds which feed upon the smaller seeds are of service; and the flocks which throng to the cornfields and pastures during the winter, pick up the seeds of various plants, which, if allowed to remain, would spring up during the following season, and choke the more valuable species.

The organs by which the various races of birds get at that species of food which is best suited to their natures, are admirably suited to the functions which they perform. If the bird is to procure the larvæ from the earth, as the rooks do in clearing the land of those of cockchaffers and other insect pests, the bill is formed like a sort of mattock, for digging into the soil ; if the food be soft insects and their caterpillars, the bill is soft and weak; if seeds are part of the food, the bill is of stronger form and firmer texture, in order tha: ${ }^{*}$, may clear the kernels of the seeds from their exterior husks, which are either indigestible or afford very little nourishment; if the food is more strongly enclosed, as when it is the kernel of a nut, or some insect or larva which burrows under the bark or in the decaying wood of trees, then the bill is a chisel, an awl, or a pair of pincers, or forceps, according to circumstances, all of which are worthy of observation, not only as distinguishing characters of the birds, but as important facts in the general economy of nature. Indeed, the various organs with which birds are provided for arriving at the places where their food is, for seizing it when they are there, and for fitting it for being converted to the purpose of nourishment after it is seized, are so varied and so curious, that it is impossible to enumerate them in any other way than by reference to the individual species. 


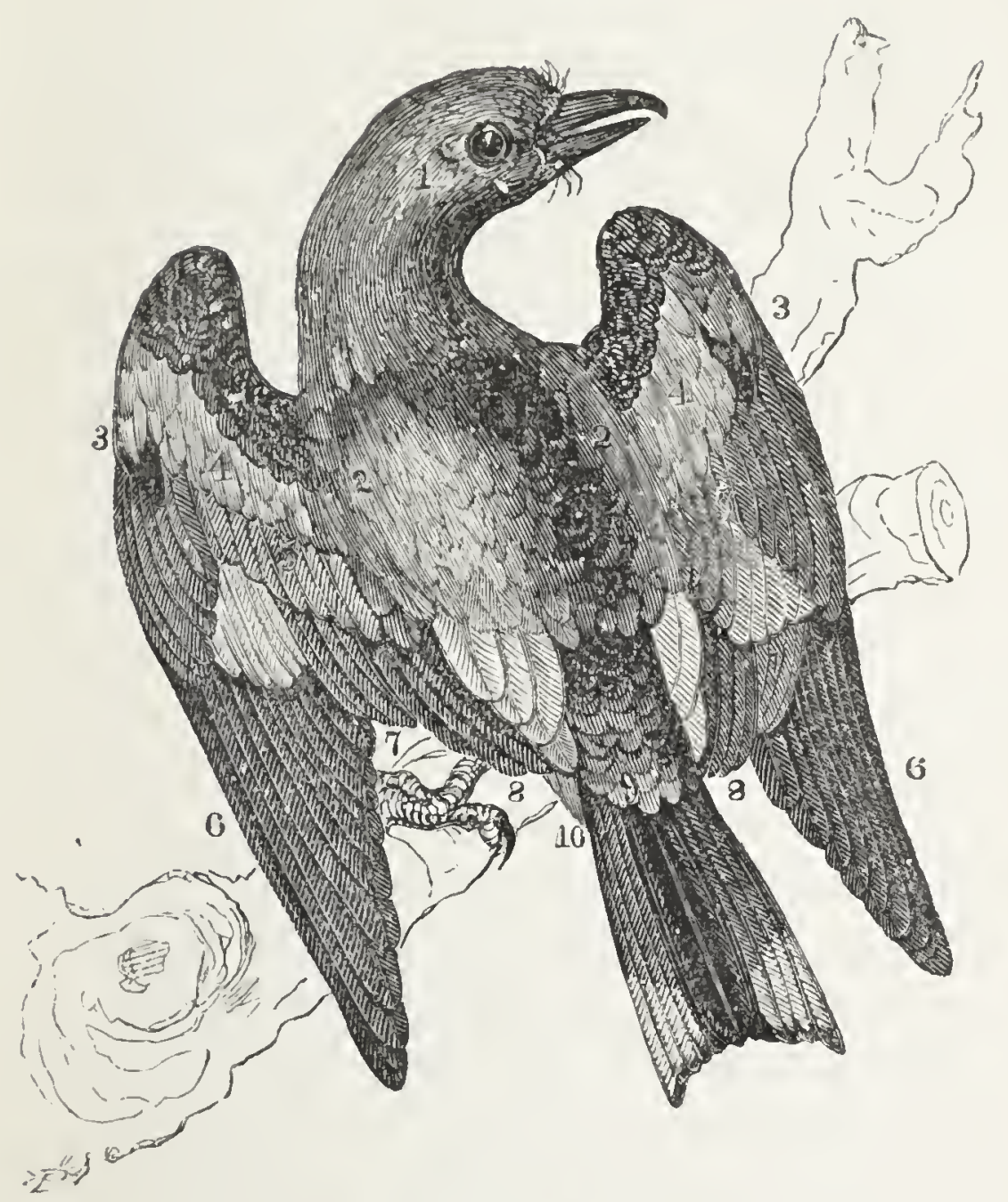

The Roller.

The popular study of birds being properly that of them when living and in a state of nature or undomesticated by man, the external parts only are those which chiefly interest the ordinary observer. The common parts of a bird, with their names, are so familiar to every body, that they require no explanation; but there are a few, upon the variations of which the distinguishing of one bird from another so much depends, that it may be necessary very briefly to glance at them, referring to the systematic works for more minute particulars. 
The cut at the head of this section represents a bird which is so rarely seen in this country, that it hardly deserves to be considered as a British bird; but, as it is one in which the different feathers are very distinct, it answers better for an index to the more remarkable parts than most birds with which we are more familiar. Of course it is possible to represent only half the surface of a bird by any one figure, and as the back is the most interesting part, and the one most generally seen, it is given in preference.

1. Is the ear covert, which consists of certain soft feathers that cover the external organ of hearing. They vary considerably in birds of different species, and on that account they are of considerable use as means of distinction.

2. The scapulars, or feathers which cover the shoulders and shoulder bones, and the places where the humeri, or first bones of the wings, answering to the bones of the human arm above the elbow, are articulated. They unite without much distinction with the common feathers of the back, and also with those of the wings and the sides. The scapular feathers serve only as clothing to the parts which they cover, but they form a thick and comparatively a downy covering, which, while it admits of easy motion, preserves the important joints which it covers from the variations of the weather.

3. The bastard wing. This consists of a greater or smaller number of feathers, bearing some resemblance to the quills of the true wing. They grow from a little bone, which is united to the third or wrist joint of the wing ; and they, and the bones by which they are supported, are generally strong, in proportion to the power of flight in the bird. Indeed, there is generally a development of all that part of the wing which corresponds to the hand, proportional to the power of flying. Thus, in the wing of the jer-falcon, which may be considered as being the bird of finest and most graceful flight, the thumb consists of two distinct bones, and even a marking, as if the last were two united; and the four fingers may be traced, the first in a long bone, the second in a small one, and the third and fourth in two ribs united by a very 
thin plate of bone. The use of the bastard wing is not very well known, because the action of the different parts of the wing, during flight, is not easily observed; but it is probable that it prevents the wing from turning upwards, and even gives the point of it a downward motion, in the contrary direction to that in which the whole wing is moved, and thus propels it forwards.

4. The lesser wing-coverts. These are the first parts of the plumage of the wings which, in all birds, take the form of definite and firm feathers. There are generally several rows of them; and there are under-coverts, which answer to them, and line the under or inner sides of the wings, but these are more slender and downy in their consistence, and, generally speaking, they have less colour.

5. The greater wing-coverts. These lie under the lesser ones, and are still larger and stronger, stretching a considerable way over the quills or flying feathers, and being supports to these for a greater part of their length than the lesser coverts. They are also much stronger in proportion to the coverts which answer to them on the under sides of the wings.

6. The primaries, or principal quills. These form the termination of the wing, and are the strongest feathers on the bird. They rise from the hand, or that portion of the wing which is below the wrist joint, and which, though it sometimes contains three distinct bones in its length, is frequently called the first (or third) bone of the wing. These feathers are numbered in order; the outer one, or that which is foremost in the expanded or lowest in the closed wing, is the first. Considerable differences in the form of wings arise from the various lengths of the feathers; and these are accompanied by corresponding variations in the style of flight. If the first or second of these feathers be the longest in the wing (and when the second is longest the first comes underneath and supports it) the bird can turn in the air with greater ease than with any other form of wing. Birds which hawk flying, or catch their prey while on the wing, whether they catch other 
birds as the falcons, or insects as the swallows, have their wings of this construction. The pigeons, which are also birds of excellent wing, have the second feather longest; but the lapwing, which is remarkable for the variety of its motions in the air, has the longest feather farther into the wing.

7. The secondaries, or second quills of the wings. They arise from that part of the wing which is commonly called the second bone, and which answers to the fore arm in man. They arise from it toward the wrist joint, and admit of a folding of the wing between them and the primaries when the wing is closed. When the wing is open, they sometimes appear a continuation of the same curve with the primaries, and at other times they form a distinct curve of their own.

8. The tertiaries, or third quills of the wings. They arise chiefly from the same bones as the secondaries, but nearer to the elbow joint. In some birds, especially those which are in the habit of running very swiftly with the wings partially opened, the tertiaries are often so long and come so to a point, that thc bird appears as if it had four wings, or rather had a double wing on each sidc. This form of wing answers some important purposes in their economy, which can be more satisfactorily noticed in the particular accounts of those birds in which it is found.

From the manner in which the several coverts support each other and the quills, the wing is a finer combination of lightness, strength, elasticity, and stiffiness, than could be produced by any other means. The different coverts support each other, and admit of motion upon each other, not unlike that which takes place in a coach spring, which is about the best of our mechanical contrivances for rcndering motion smooth and free from jolts, at the same time that the compound spring is much less liable to bc broken than if it were formed of a single piecc, containing the same quantity of metal.

9. The rump feathers and upper tail coverts. The first of these are a continuation of the covering of the back; and the sccond support the tail feathers on the upper side, and are strong in proportion as these are adapted for action in flying. 
In birds which use the tail as the means of support in fixing themselves upon upright surfaces, as is the case in the woodpeckers, the upper tail coverts are very strong and close, and so thick in their array, as to give that organ the same stiffness as a powerful wing. In those birds also which have to take wing from the water, and yet have not the feet webbed and placed far backwards, so as to support them when rising, the tail coverts are peculiarly strong, in order to support the tail feathers, which are the principal fulcra from which the bird gets into the air.

10. The vent feathers, and under tail coverts, which cover the hinder part of the bird; and, in those birds in which the tail feathers are long and stiff and much used in the act of flying, support the under side of these feathers, in the same manner as the under coverts support the quills of the wings. In those birds which have a habit of flirting up the tail, the under coverts are longer and stronger than in those which have no such habit.

The tail feathers require no reference. They vary much in their numbers and length, and also in the form of their terminations, and the motions which the bird can communicate to them. In some birds the whole, or at least great part, of those feathers appear to be merely ornamental, which of course means nothing more than that their uses have not been observed. In general, however, they act both as a rudder in flying, and as a means of directing the motion upwards or downwards. Analogy would indeed lead us to suppose that their chief use is in the upward and downward motion, because their greatest surface is generally horizontal. That analogy is further confirmed by the fact, that many of the low-flying birds have the breadth of the closed tail in the vertical plane, though these also can, in general, spread it out like a fan when they fly.

The other feathers are to be considered rather as the clothing of the bird than as active instruments in its flight, or as auxiliaries in its motions upon the land or the water. But still they are not less worthy of notice, both in the distin- 
guishing of one bird from another, and in tracing how well all the parts of birds are adapted to their general habits and their haunts. These ordinary feathers are imbricated, that is, they are placed one over the edges of two, as slates or plain tiles are in the covering of a roof. By means of this arrange. ment, all the parts of the bird are equally feathered, and so they are equally proof to the action of the atmosphere. The lines in which the several rows of feathers are placed form very curious curves, and their shafts diverge or converge so naturally, and with so perfect agreement to the surfaces which they cover, that no line of separation can be traced.

The feather's of birds, the coverings of the featherless parts, and even the beaks and claws, are all, chemically speaking, formed of nearly the same materials, and nearly the same with the hair and cuticle of all animals, and even with the epidermis which covers living shells. This material is coagulated albumen, or nearly the same substance as white of egg when consolidated by heat, in which state it better resists the action of water than almost any other flexible substance. This substance is, especially in the upper or more coloured and glossy parts of the feathers, combined with oils and metallic substances in very minute portions; but in the down and the light-coloured feathers it is nearly pure.

The under part of the clothing feathers, and also a small portion of almost all feathers near the tube or barrel, consists of down, but the exposed surfaces even of the softest feathers are smoothed, so as to throw off the water. This is the case even in those water birds which pass the greater part of their time with the under part of the body immersed in water. On them, the down is abundant in proportion as the habits of the birds expose them to cold, and the external surface is waterproof from its glossy texture, and (possibly?) also from the oil with which the bird anoints it by means of its bill : but, in all birds, there is an external surface, adapted to prevent decomposition; and an inner downy matter, as a protection against changes of temperature. The down is partly on the root-ends of the feathers, and partly on the skin in the intervals between 
them, but the material is in all cases substantially the same; the difference is in the form or in the colour, which generally approaches nearer to white in the down than in the feathers. When the bird remains all the year round in situations where there are great differences in the heat of the seasons, the down increases in quantity during winter; and when birds of a warmer climate are domesticated in a colder one, they become more downy. The form which the down assumes is often characteristic of the habits of the bird. In the ostrich there is none; in some birds it is a mere tuft at the origin of the webs, in others it is a second feather originating there; and there are all the intermediate states in different birds, and very considerable seasonal differences in the same bird.

Different birds find their food in different states, both of the atmosphere and the waters; and very beautiful corresponding differences in their plumage may be traced. The plumage upon the raven, which braves the storm in the wilds, is very different from that of the gallinaceous or poultry races, which a slight shower drives to their cover or their perch; and ducks and other water birds, which seek their food peaceably on the banks or by swimming in the shallow waters, have very different plumage from those which hawk about on the wing in order to catch what the troubled sea brings to the surface. If the habit of the bird be to steal softly on its prey, then the feathers are fined off to exceedingly delicate points, so that it can glide silently through the air.

MOULT AND MIGRATION.

The feathers of birds, while they remain perfect and firm in their connexion, are really parts of a living animal, and as such they must be regarded as organs of feeling. They do not probably in themselves feel pain, but they are in intimate connection with parts which do. The epidermis in no animal appears to feel pain, even in those parts of the animal which are regarded as being more immediately the organs of sensa- 
tion ; but they very speedily transmit impressions to the parts that do feel. It is the same with hair, and with all the appendages of the cuticle, such as nails, claws, hoofs, and horns. The horse feels his footsteps in the dark, even when his hoofs are shod with iron; and he feels not only the touch of a wall, a gate, or any other obstacle, but he feels the dif. ference which such objects cause in the resistance of the air, and that enables him to avoid touching them.

The horse feels his way by means of the hair; and birds must in like manner often feel their way by their feathers. Such must be habitually the case with owls and other nocturnal birds, which can fly darkling through thick woods and other intricate places; and though the owls have the eyes directed forwards, and not laterally, as many other birds have, they are by that means less capacitated for avoiding by sight, even admitting that they can see with the smallest possible portion of light, those obstacles which it would be the most awkward to encounter-those of course which would injure, entangle, or impede their wings. If one wing were to come in contact with a tree, or even with a leaf, the bird would be upset, as certainly as a man is when, in walking heed. lessly, he places one foot over a pit or ditch, while the other is on the ground.

The necessity of feeling with the feathers, is not confined to nocturnal birds, but is essential to the safety of all the winged tribes; the feathers must therefore always be in a state of great perfection. Now, though the shafts of many feathers, and the larger ribs of the webs or vanes of not a few are of considerable substance and strength, all feathers are subdivided till the ultimate ramifications are exceedingly minute. Consequently they produce very large surfaces to the air in proportion to the quantities of matter they contain.

Feathers are thus very much exposed to atmospheric action, which dries them and renders them unfit for the functions that are required of them. They are also apt to be broken or torn, in the flights, the wars, and the labours of their owners. They are therefore periodically shed and repro- 
duced; and the reproduction usually takes place in such a way, as that the bird shall be in best feather at the very time when it has the greatest labour to perform.

The resident native birds of countries where the heat of the year is comparatively uniform, moult gradually; and the same may be said of those that have their haunts in regions that are always cold, and where the food is comparatively limited. Such birds are seldom so denuded of feathers as to be unfit for pretty vigorous flight. Birds which migrate from region to region, moult more periodically; and in cases where the migration is extensive, it will perhaps be found, upon further examination, that the bird moults twice in the year : though in most instances the spring moult is less general than the autumnal one, being in many birds, the males especially, rather a change of colour than of all the feathers. Birds which migrate polarly, or for the purpose of breeding, generally receive their nuptial colours, if not their plumage, after they arrive; but when they migrate equatorially, they change their plumage before they begin their journey.

The vernal change in the plumage of birds is owing to the same cause as the change of their voices from the chirp or cry to song; and in a state of nature the two cease together. This change bears some analogy to the blossoming of plants, while the autumnal moult more resembles the fall of the leaf.

That the migration depends much upon the state of the atmosphere, is proved by the fact, that the number is augmented with an augmentation of that state which we suppose makes them leave the country from which they came. Our winter migrants are always most numerous when the season is most severe in the countries from which they come; and there are some rare species which reach our shores only in very severe winters.

With our summer migrants the state of things is just the reverse. Warm weather in the places whence they came sends them to us sooner and in greater numbers; and cold weather in the autumn makes them sooner quit our shores. A very mild year will, on the other hand, induce some stragglers to remain 
the whole winter. The differences between the appearance and habits of these and those of their brethren that have performed the two migratory voyages in the interim, are well worthy of attention.

The long flights which the migratory birds take, are of course much affected by the winds; and it is worthy of notice, that at the season when our birds are migrating northward, south winds are most prevalent, and north winds are most prevalent about the time that they are coming southward. But though these are the predominating winds, they are not the only ones; for the times of the migration of birds, both the spring and the autumn, are times when the weather is unsettled, and severe gales often blow from the cross points. These winds cause the numbers and also the species of migratory birds to vary in different seasons. An easterly wind, at either season, will cause the birds to be more numerous, and also bring stragglers of those which, though common on the continent, do not regularly visit Britain. A west wind will, on the other hand, lessen the number, and keep away the stragglers. We have not so many summer stragglers on the west side of the island as we have on the east, when the wind is from the west during the time of migration, because the Atlantic is wider than the mere lee-way which any land bird, guided by meridional impulses, is likely to make. In the autumn the numbers that straggle from that side are greater, because the absolute distance in latitude is less toward the north; but the stragglers then are principally rare birds, and they seldom come farther than the western coast. Upon examining the position of Britain on the map, it will be apparent that the summer migrants must be more abundant in the south-east of England than in any other part of the country, while winter migrants will be the least abundant there. Throughout the whole island, the summer birds may be looked for in the greatest abundance near the lines of shore, or of mountain ridge, that are inclined to the south; and the winter birds near those lines which are inclined to the north. Thus, on the east coast of England there are more 
summer birds in proportion from Dover to the Spurn, and more winter birds in proportion from the Spurn to the Tweed. In Scotland, Fife, Forfar, and Kincardine have more summer birds in proportion than the counties along the southern shores of the Moray frith, or even than the Lothians; but the counties on the Moray frith and Aberdeenshire have probably a greater proportion of winter birds. The migration of birds, not only with regard to its general nature, hut as it is connected with the different states of the weather in different seasons, is a subject well worthy even of popular observation, not only as part of the natural history of birds, but as capable of throwing much light upon that subject of universal interest and speculation-the weather.

\section{POPULAR DISTINCTION AND CLASSIFICATION OF BIRDS.}

Colour, size, and shape, are the most simple and obvious appearances by which to know one bird from another. Colour is, however, rather a variable character; and though there never can be any doubt that two birds, of which the colours are of the same tints and marked in the same inanner, belong to the same species, and may be called by the same name, yet the colour of all birds changes a little with differences of age, and that of very many birds changes at different seasons. The immature bird is very generally differently coloured from the mature one, and one in the full vigour of life from one which is beginning to decay. There is no positive law for these differences, but the young bird is in general, though not always, more mottled than the mature one; and both in the young and the decaying bird, the tints are less perfect and the gloss is inferior. With very few exceptions, the male bird has the finest plumage; but the young male is not easily distinguished from the young female: and in the mature bird the distinguishing colours, and also the peculiar and often supplemental feathers in which those colours appear, are most conspicuous about the pairing time. That is, indeed, the very best time for studying birds, as they are then seen and heard to the 
greatest advantage; while the general activity and freshness of the season have the charm of novelty, heightened by the remembered contrast of the gloomy winter, which is just over. The popular descriptions of birds are perhaps, however, too much dependant on colour, and too little on the size, shape, and especially on the structure and habits of the birds.

Size is, in so far, a very good means of distinction; but, in many instances, it is more vague than even colour. Many of the small birds which frequent the gardens and shrubberies, and are in consequence the most convenient for general observation and study, and so nearly equal in size, that it is not easy to say which is the largest, and which the least, unless when the different ones are seen at the same time and nearly at the same distance.

Shape, or form, is a good means of distinction, because there is a resemblance in form among all the birds that have the same general habits, even though they differ ever so much in colour and size; and though there are variations in the details (as no two species of birds have exactly the same habits), yet the similarity in form runs through all the parts of the bird. Birds have, however, so much power over their attitudes, and the outlines of their form change so much with the changes of these, and are, taken as a whole, so different in the living and the dead bird, that the characters are much more easily understood than expressed. It would be very difficult to find names for all the curves that are found in the outlines of birds, and still more to point out the differences. It may be observed, however, that the bodies (the necks, heads, and feet vary to suit other purposes) of fast-flying birds are like fast-sailing vessels, compact and round forwards, and diminished to the hinder extremity. This is so remarkable in the hawk and swallow tribes, that one who has seen any one species on the wing, can know at first sight any other of the tribe, whatever may be the species. It is true that there is the style of flying, or the attitude in repose, and also the haunt of the bird, if in a state of nature, but still the form is an essential element in judging. 
The haunts and habits of birds are certainly the best means of distinction; but the perfect or detailed knowledge of them requires an acquaintance with the bird, which includes the whole of its natural history as a species, and therefore a few of the more remarkable haunts and habits are taken as indices to the rest, - or general heads, under which the others may be arranged as they are found out.

Of haunts, land and water are the most obvious distinctions. Land birds, with few exceptions, can walk and fly, but they cannot swim. Water birds can, in general, walk and fly and swim, but in many instances they are bad walkers. The bird is always best fitted for the performance of that kind of motion which it most habitually performs; and therefore, when we have seen in one bird the organization and the haunt, we may, from similar organization in another bird, infer that the haunt is similar; and the same inference may be made from the organization to the habit. These inferences are, however, merely general.

Birds are also distinguished by the times of their appearance. Those which remain in the same country all the year round are resident birds; those which come in the spring and depart in the autumn are summer visitants; those which come in the autumn and depart in the spring are winter visitants; those which do not come every season are occasional visitants; and those that are seen rarely, only one now and then, are accidental visitants, or stragglers. The resident birds and summer visitants may both be considered as natives; because, although visitants that are not hatched in the country may come with those that are, there are always more of every species hatched in the country than can be expected to live and return to it. The winter visitants and stragglers are not natives; and the occasional summer visitants are only partially so. It is common, however, to call every bird that is found in Britain, without having been brought there by artificial means, a British bird, and to distinguish them as common or rare in their occurrence in respect both of place and of time. 
The finding of food for themselves and their young is the grand object to which all the organizations and habits of birds tend, when we consider them merely in themselves, and without any reference to the rest of nature; and therefore these objects must be kept in view in the study of the birds, and also in the arrangement of them. But almost all birds can subsist on different kinds of food, and some have a very great range, so that it becomes necessary to consider the place where the food is found as well as the food itself, before the general character and habits of the bird can be determined. The bill, the feet, the wings, and (though in a less degree) the tail, are the parts of the bird most essential to be studied for that purpose; but to these we must also add, the strength and the spirit of the bird. The kestrel, for instance, is a larger, and to common observation a stronger bird than either the merlin or the sparrow hawk, and it does not appear to be much inferior in beak and claws, yet the kestrel follows humbler game than these do.

Having made these few general observations, we shall proceed to give short notices of the different British birds, and the places where and the times when they are most likely to be found, beginning with the land birds, as those with which the majority of people are most familiar. 
The distribution and even the numbers of the feathered tribes which inhabit the British islands, or resort to them periodically to breed in the summer, or to avoid more inclement skies in the winter, are points upon which no precise statement can be made; because we are ignorant of the habits of many of the species that make their appearance occasionally, and very recent experience shows that some which were formerly considered as stragglers remain in the country the whole year round, though they are generally concealed both by their habits and by the nature of the places in which, especially in the breeding season, they take up their abodes. In round numbers, however, there may be stated to be between two hundred and ninety and three hundred different species of British birds, that is, of birds which by natural means have at some time or other found their way into the country and been taken alive or killed; and this exchusive of the species that have been imported, or the varieties into which those species have been broken by those differences of treatment of which unfortunately no particular note has been taken, but which, if that had been judiciously done, would have very much assisted in determining in how far climate and food influence the characters of birds in the wild state.

The distribution of the feathered tribes is as indeterminate as the numbers; for though there no doubt are birds which belong to certain localities and not to others, some regulated by climate, other's by situation, some apparently by drought, others by humidity, some by the covert of woods or other tall vegetation, and some by open places and naked ground; yet the lines of demarcation between the localities of those birds are not drawn with any thing like precision, so that one species 
is often found, at least seasonally, upon those grounds which we would be apt to suppose belonged exclusively to another.

The common distinction of land birds and water birds is, indeed, a very imperfect and unsatisfactory one. All birds deposit their eggs on land, and therefore, if we consider only the places of their nativity, they would all deserve the name of land birds; and if we attend to the places in which they seek their food, these are so varied, and often so varying in the individual, that they cannot be made the foundation of any general arrangement: thus we are under the necessity of considering the haunt along with the genus, or, in many instances, along with the species.

The proper element of all birds is the air ; and as nearly all birds, and certainly all British birds, can transport themselves from place to place by means of that element, they are enabled to shift their localities with changes of seasons, or of the circumstances of different places, so as to be always in that part of the country which is the best adapted to their habits. Wherever there is food for a bird to be found, a bird comes to consume that food; and as most of them can make their escape into the air, they can venture to seek their food more in the light of day, and in the presence of man, than the wild quadrupeds.

Birds are thus distributed from the verge of perpetual snow on the mountain top, to almost the farthest range at sea; from the depth of the forest to the bleak and treeless hill; from the marsh to the arid waste; and, in short, in all the extremes of surface or of climate which the country presents. Also, when places change with the seasons, from one cha. racter of surface to another, the birds change their habitations; and if the season does not leave within the country any place adapted for them, they take wing, and emigrate to another; and the extent to which they perform those changes is so varied, that it cannot be reduced to any general law ; therefore the natural history of birds becomes necessarily a matter of detail, except in so far as it derives some little assistance from the arrangement of them into orders and genera. 


\section{ORDER I.}

\section{GALLINID E.}

GALLINACEOUS BIRDS, OR POULTRY.

Birds of this order are the most useful to man as food, and they have been longest and most completely domesticated, though none of the domesticated species are originally British birds. There are five of them; the common fowl, originally from Asia, but the particular locality undetermined, the small variety improperly called the Bantam, is of more recent importation, and from Japan; the peacock, also from Asia; the guinea-hen, from Africa; the turkey, from America; and the pheasants, from Asia,- - the common ones from the western parts of that continent, and those of finer plumage from China. It is only those which are in a state of complete domestication that are called poultry, the common name of the wild ones is game.

\section{GENERAL CHARACTERS OF THE GALLINIDÆ.}

The body bulky, the head small, and the legs so placed as to balance the body, and leave the head free. Three toes before, united by a membrane at their bases, and one behind articulated on the tarsus, or foot-bone (often called the leg), above the articulation of the front toes; so that in walking, which is the principal motion of the order, as they feed on the ground, the front toes are chiefly used. Claws hollowed on their under sides, and adapted for scraping in the soil. The tarsi of some of the males armed with a horny spur, which 
they use in their combats of gallantry. Legs and tarsi strong, and of moderate length, and the former more muscular than in birds which are more on the wing.

Bill rather short, but strong and convex, the upper mandible bent wholly or at the tip, and projecting over the under one. Nostrils lateral, protected by a scale, and sometimes by feathers, wings mostly short in proportion to the weight of the body, and very concave on their under sides; hence the flight seems laborious and fluttering, and is performed with a peculiar noise, arising from the rapid motion of the short and hollow wings.

Tail consisting of from ten to eighteen feathers; and in the male birds often highly coloured, and with ornamental feathers.

Eood, very indiscriminate,-seeds, grains, berries, buds, insects, and succulent vegetable substances and soft animal ones of all kinds; but varying of course with the haunts of the different species.

Eggs, generally numerous, and much relished as food, as is also the muscular fibre, which is sweeter and more wholesome than that of any other order of birds. The young, when they first appear, are covered with down, and they are at once able to follow the parent birds, - some, as the common field partridge, with a portion of the shell upon the body.

Their habits are, to seek their food generally, if not exclusively, upon the ground; to deposit their eggs there in very rude nests, though some few nestle in trees or bushes; to feed in the morning, and again towards sunset: to scrape, and roll and bathe their feathers in the dust, while basking in the mid-day sun; and to squat upon the ground, or perch on trees, during the night. Some of them pair for the season, and the family keep together in a covey till next pairing time; others are polygamous, or have a number of females associating with one male; the males, especially of the polygamous kinds, fight courageously for and in defence of their femaies, but, even in those which pair, the labours of incubation and of defending the young devolve chiefly upon the female; and she 
often becomes so courageous in their defence, as to beat off quadrupeds as well as birds of prey. The young are gathered under her wings for protection botl from the inclemency of the weather and from enemies.

Their haunts, in consequence of the wings being fitted for short flights only, are better defined than those of many other birds. They are, or at least were, the mountain top, the mountain side, the mountain forest, the hill, the field, and the margin of the waters; but some of those which frequent the latter places are of stronger wing than the others, bear some resemblance to the running birds, and are migrants.

It does not appear that there are any migrant gallinidxe among British birds, though the quail has become so rare in most localities, that it is usually considered as a migrant, But they are said, on what may be reckoned good authority, to be far from rare on the Surrey hills; and individuals have been found in that county, and also in Bedfordshire, in the winter months, within these few years, and also a nest not five miles from London bridge. Therefore, the native Gallinidx of Britain are, Grous, Partridges, and Quails, and there are no species entirely migrant.

\section{GROUS.}

There are two divisions of Grous, (Tetrao, Lin.) those which have the tarsi and toes feathered, and those which have the tarsi feathered, and the toes bare.

\section{With the TOES FEATHEREd (Lagopus).}

These are the mountaineers, and get the name of Lagopus, or "feathery foot." Of them there are two species, ptarmigan and red grous.

\section{ptarmigian (Lagopus mutuo).}

Sce Plate opposite, where the bird is represented in its winter plumage, one sixth of the natural size, in lineal dimensions. It may save trouble and prevent mistakes, to observe, 
that the surface is as the square of the lineal dimensions; thus, the figure of the ptarmigan, being one sixth or two inches to a foot, is one thirty-sixth of the natural surface of the bird; and if the bird is to be considered as a solid, the solidity will be as the cube of the lineal dimensions, or the figure one two hundred and sixteenth of the natural size. The proper understanding of the figure therefore is : the ptarmigan diminished six times in line, thirty-six times in surface, and two hundred and sixteen times in solidity or bulk.

When, with weary steps, you have gained the summit of one of our loftiest mountains, say of Ben-Nevis, wbich overlooks the valley of Lochaber, the wide desolation of Rannoch moor, and the glittering Atlantic, spotted with its isles and islets; or of Cairngorm, to look down on the one hand on the dark pine forests of Strath-Spey, and on the other to look onward to the summits of the neighbouring mountains, equally sublime, and even more cliffy and desolate than that on which you stand; - when you have so ascended, (and if the day is fine, wondered at so much of the earth being displayed at one view,) remarking the silence and the apparent death which, on a tranquil and sunny day especially, appear to reign there, you begin at last to feel alone, severed entirely from the world of society, of life, and of growth, and committed to the solitude of the ancient hills and immeasurable sky. The snow lies thick on the side of the summit, and even peers over the top, defying the utmost efforts of solstitial heat. There is no plant under your feet, save lichen on the rock, apparently as hard and stony as that to which it adheres-it can hardly be said to grow-and moss in some crevice, undistinguishable from the dull and cold mud into which the storms of many winters have abraded the granite. You are above the reach of all sound from the inhabited parts of the country; and as one cannot think very long upon bare rocks and blue skies, however sublime they may be in themselves, or howerer novel the visit to them may be, there is a wish for some living creature, to share even that unproductive scene along with you. 


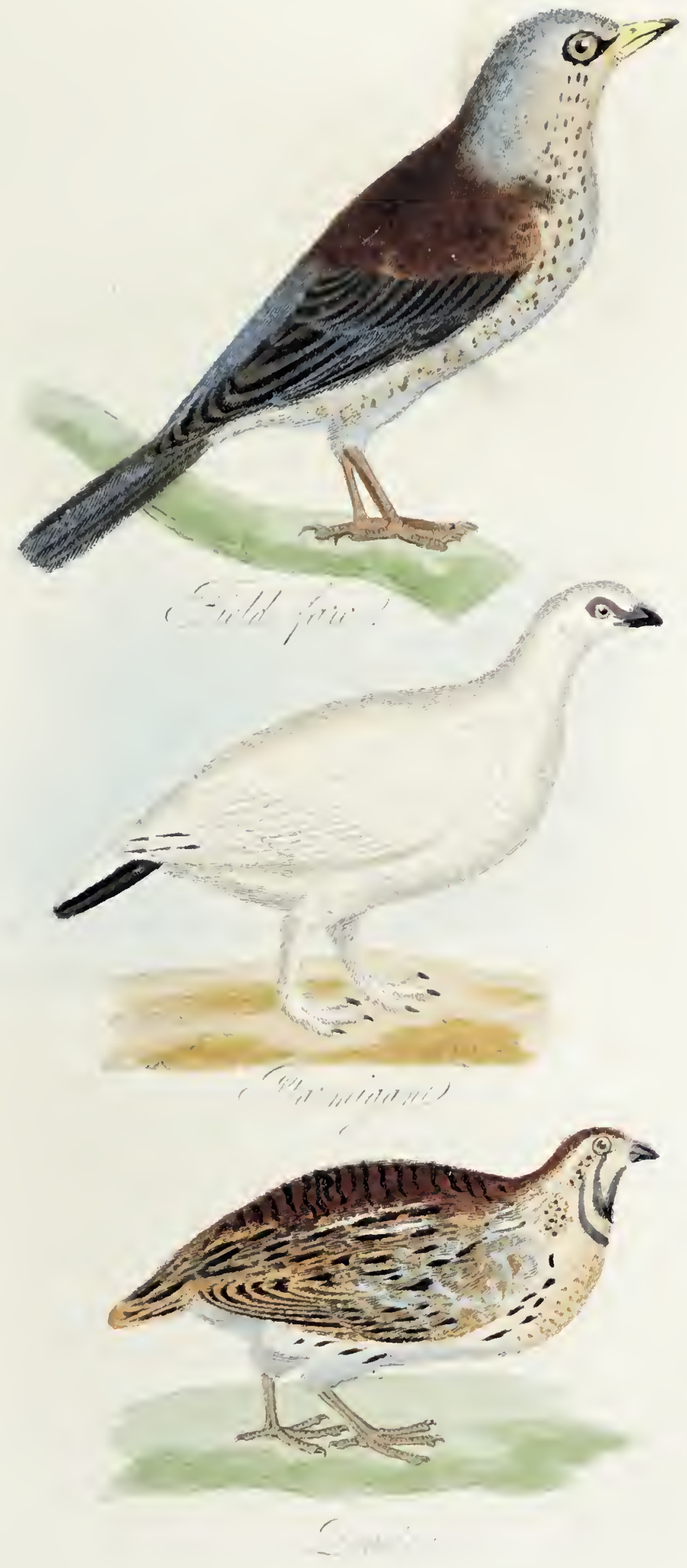



A few mottled pebbles, or at least what appear to be sucl, each about twice the size of your hand, lie at some distance, where the decomposed rock, and the rudiments of what may be called the most elevated mountain vegetation, just begin to ruffle the surface. By and by, a cloud shadows the sun, the air blows chill as November, and a few drops fall, freezing or melting in their descent, you cannot well tell which. The mottled pebbles begin to move: you throw a stone at them, to show that you can move pebbles as well as the mountain. The stone hits beyond them; they run toward your feet, as if claiming your protection: they are birds,-ptarmigan,- the uppermost tenants of the island, whom not even winds which could uproot forests, and frosts which could all but congeal mercury, can drive from these their mountain haunts. It has often been observed, that of all the human inhabitants of the earth, the mountaineer, be his mountain ever so barren, is the last to quit; and the same holds true of the mountain bird.

The ptarmigan, though not only constantly resident in the country but constantly resident in very nearly the same locality, is perhaps less seen than almost any of our permanent birds. It is not nearly so often seen in the dead state as the red grous, because it is much less abundant, and its flesh is less juicy and of inferior flavour. It is, however, a very interesting bird, both from the peculiarity of its haunts, and from what may be called the simplicity of its habits. Enemies, in its native regions, the ptarmigan has comparatively few. It is above the range of the fox, the mountain cat, and the martin; and generally speaking, above that of the raven and the eagle. It is true that the raven does prowl on bleak elevations; but even in summer, he seldom goes to the highest mountain-tops; and though he frequently may make a meal of those ptarmigan which are beaten to the earth by mountain storms, and rolled down the slopes by mountain floods, he does not commit so much positive havock among ptarmigan or their nests, as he does among the red grous, which inhabit lower down. The eagle too, though her eyrie 
is in lofty and lonely-situations, seldom has it in the cliffs of the very highest mountains; and though she may be oecasionally observed soaring far above the loftiest summits, the most favourite and frequent seenes of her hunting, are the valleys farther down, in which animal life is more abundant; so that the grand enemy of the ptarmigan, is the inelement situation which it inhabits.

And it is in every respeet well adapted for that situation. It is more eompaet in its form, and stands more firmly on its legs than any of the other gallinidx, and its general attitude presents less resistanee to the wind. Its haunts being in a great measure free from vegetable cover, it does not require that elevated position of the body, in looking around it, whieh is found in those speeies that inhabit more fertile plaees. Its feet and toes, down to the very claws, are so eompletely and closely feathered, that they are proof to almost any degree of cold; and thus, as water does not stagnate on mountain tops, the ptarmigan is always in a eondition for using its feet.

The full grown ptarmigan is about fifteen inehes in length, and nearly two feet in the streteh of the wings. Its weight is about a pound and a quarter. The bill is blaek and strong (black bills and elaws are always firmer than those of any other colour,) and well adapted for erushing the hard berries, heath-tops, mosses, lichens, and even, as some say, pebbles or gravel, on whieh it feeds. We may observe, in passing, that it is a general habit with the gallinidre to swallow gravel, more especially when they are fed on dry and hard vegetable matter; but the proportion found in the stomaeh of the ptarmigan, perhaps, exeeeds that found in the stomach of any other bird.

The head of the ptarmigan appears stupid or simple, indeed there is little eharaeter or expression in the heads of any of the order. From the gape of the bill to the eyes a black streak extends, whieh not only remains when the general plumage ehanges to white, but at that season stretehes along the upper part of the ear eoverts. That band is wanting in the female. A naked searlet spot over the eye, in the form of a erescent, is another character of the male bird. 
The summer plumage is very beautifully mottled with brown, grey, and white; the quills of the wings, of which there are twenty foul, have black shafts, and pure white webs, which give a curious streaky appearance to the extended wing. Of the tail feathers, which are sixteen in number, seven on each side, and the shafts of the two centre ones are black, the webs of the latter two are mottled with brown and white.

As autumn advances, the plumage begins gradually to change, the black and brown giving way first, and then the grey, till by the time that the winter is confirmed, the whole bird, with the exception of the eye streak in the male, the outer tail feathers, and the shafts of the middle ones and the quills, become snow white. Those changes do not take place in consequence of a moult, or separation of the coloured feathers to be replaced by white ones, but by an actual change of colour in the feathers themselves. No doubt new feathers grow towards the autumn, and some of the old ones are thrown off; but there is no general moult in the feathers at that season, and probably not at any season, the moult being gradual, just as the shedding of leaves is upon some evergreen trees. In winter, they congregate in family parties or packs, live peaceably together, and shelter themselves in holes in the earth or in the snow, through which last they contrive to scrape down till they can subsist on the scanty vegetation which it covers. At the commencement of summer, (for in their haunts spring is a season of snows,) that is, usually about the month of June, they disperse in pairs (they are monogamous), a little further down the mountain than their winter haunts, and there scrape a circular nest, in which the eggs, varying from six to twelve, or fifteen, the average being about ten, ale deposited. The young are covered with down, which bears some resemblance to the general tint of the summer plumage, but is less mottled, and lighter in the tints. The eggs also partake of an admixture of the sime colours.

That the autumnal change of colour in the ptarmigan, and probably also the summer change, is a change in the same

$$
\text { c } 3
$$


feathers, and not the effect of a moult, is proved by many circumstances. In the first place, the birds have more powerful flight during the time that the change is taking place, than at any other period of the year. In the second place, two moults at least would be necessary; for, with the exception of the ear-coverts, the prevailing tint of the whole bird is grey in autumn, and brown in summer. Thirdly, the decay first of the brown, and then of the grey, is gradual over the whole bird. Fourthly, the change to white is complete, in proportion as the place and the season are cold.

The plumage of the ptarmigan is thus a sort of natural thermometer; and as the plumage becomes a bad conductor of heat in proportion as it whitens, and the evaporating power of the air diminishes with the cold, it is probable that the birds may feel as warm while burrowing in the snow, as while basking in the sun.

The ptarmigan being the bird which, both from its haunts and its habits, is the most exposed to changes of temperature, and the seasonal variations in its plumage being greater than those in any other, we can in it see the causes of those more partial variations, which, to a greater or less extent, take place in all birds which remain the whole year in exposed situations in variable climates. The sun has less influence on the winter plumage: there is less evaporation and waste from that plumage; and the bird fattens with less food than it requires in summer.

It is no doubt in order to find more abundant food, and more especially to find insects for the newly hatched young, that the ptarmigan descends, and, contrary to the general habit of birds, chooses during the breeding season a region having the temperature a little higher. But their descent subjects them to greater dangers than they meet with in their more elevated regions; and therefore the old birds, not only figlit desperately for their young while they remain on the slopes, but lead them to the mountain tops as soon as they can follow. While the female is sitting, and indeed as long as they remain in the lower places, the male is constantly on the watch, and, 
on the appearance of danger, gives his alarm call, which is harsh, and has some resemblance to that of the missel thrush. They do not give the alarm on the passage of a human being, or that of a large quadruped; so that a person may search the last short heath upon the mountains long enough without finding any ptarmigan, even though there may be numbers quite close to the path. But when they are in the exposed situations, they are just as little anxious to hide themselves; and therefore, the sportsman who meets with a pack, may shoot them one by one, without those that remain after each discharge making any attempt to get out of the range of the shot. Instances are mentioned of ptarmigans having bred in confinement; but they are certainly not, by their habits, adapted for the purposes of domestication; and the birds are best studied in those lofty regions, of which they are a very peculiar and very characteristic ornament.

Though the summits of the Grampians (the eastern part of the great central ridge especially) be the principal places of the British Islands where ptarmigan are met with, there are a few, and but a very few, on the highest mountains of the north of England and of Wales; but they are hardly numerous enough in any place to render the shooting of them a regular field sport. It has been mentioned, that for the table they are inferior to the red grous, but that applies to birds which have wintered in the mountains, and borne the severe cold, and subsisted on the scanty food of that season. The young, if taken in the autumn of the same year, are very delicious.

A single specimen of another ptarmigan (tetrao rupestris of authors), which was killed in Perthshire, is now in the collection of Lord Stanley.

RED GROUS, OR MoOR-Fowl (Lagopus Scoticus.)

The red grous is a little larger than the ptarmigan, though the difference, except in the length of the wings, is inconc 4 
siderable. Many of the habits are also the same in both birds: but the grous is always found farther down the hill than the ptarmigan. The bill also is shorter, and less pointed; and there is a white circle round the eyes, and a white spot at the base of the lower mandible. The scarlet spot above the eye is fringed along its upper side. The general colours of the feathers are, red, different shades of brown and black; and the quills of the wings and external feathers of the tail, which both in number and arrangement bear a considerable resemblance to those of the ptarmigan, are black. The attitude of the body is also more erect: and the male is larger and more gay in plumage, as compared with the female. The cry of the male bird is very different, being lively, and often repeated, while that of the ptarmigan is a sort of croak.

To the lovers of wild scenery and daring excursions, the haunts of the red grous are not nearly so interesting as those of the mountain bird: they are the slopes and flats, where the heath is of considerable length, which renders walking over them very fatiguing. There is no danger, however, of being lured into bogs and quagmires in the pursuit of grous, as the birds always keep the firm ground. Their feet are not adapted for soft places; and as their security from birds of prey is in the heather, and not on the wing, they do not rise, except at the sight of men or quadrupeds, and not always then. As they are much more generally distributed in Britain, and more abundant than their upland neighbours, they encounter more visitors, and are more on their guard; and even when the pack are basking during their noontide repose in the sunny days of autumn, a keen and experienced eye, or the assistance of a pocket telescope, may observe the heads of one or more of the males elevated just so much above the cover as to be able to see in all directions. The visitor is soon espied, a short call-note is uttered, the heads disappear, and the whole pack lie close till the stranger passes. So difficult is it to raise them, especially when the season has been rather un.favourable, and they are not in good feather, that one who 
has little knowledge of the moors may wander for days, in the places where they are most abundant, and not see a single bird.

On the other hand, when the season is very early and favourable, and the birds are strong on the wing, they rise too readily, so that the sportsman cannot get within range of them, though he sees them in considerable numbers. When the young have acquired their full strength of feather, which is commonly in November, but sooner or later in the month according to the season, the families, or broods, which then kept apart, mingle with each other, and flock in packs of two or three families. They are then strong, and range to greater distances, sometimes approaching the stubble-fields of the upland farms; but they are shy in proportion. But even then they never remain long on the wing, but make their journeys by short stages. Their flight is low and peculiar, and apparently performed with considerable effort. It is well expressed in the lines of Burns:-

"The moorcock springs, on whirring wings,

Among the blooming heather."

When the winter is very severe, they descend in considerable flocks, and many of them remain, and breed rather lower down the next season; but in these cases they rather avoid the plantations; and when they begin to pair, or rather to fight for the females, for they are polygamous, which is as early in the season as the snow will admit, the call of the male bird, which is heard at a very early hour, and afterwards all the night long, till the young are hatched, is always heard from the open moor, and from the centres of those detached tracks of heathery waste, which they continue to haunt in the lowlands.

Their natural enemies, the birds of prey, - for, like the ptarmigan, they have not much to dread from quadrupeds, the few of which that remain are in the brakes and copses,--have been much thinned; the seasons have been rendered milder in their haunts by the progress of cultivation in the neigh- 
bouring parts; the practice of burning the heather in closetime, which, though forbidden, could not be altogether prevented, has been given up; and the throwing of much of the country into sheep-walks, has given them more repose in the central highlands, than when the lower glens abounded more with cottages, and the upper with sheilings. But still, their boundaries have been circumscribed, and the pasturage of sheep tends both to destroy their favourite heather, and to disturb them in close-time; so that with more preservation than formerly, it is probable that the numbers are considerably diminished. The heather is the only good cover that they have, both from the weather and from enemies; it defends the nests and sitting-birds from the rain and the snow, showers of which are not uncommon in the early part of the season; and its colour conceals them from their foes, the most common, and therefore the most destructive of which is the hooded crow, which is very common in the Scotch highlands. Ravens are by no means common, and even the carrion crow is not very abundant. It is possible that the general introduction of sheep may have increased the number of ravens.

The Welsh mountains, and the heights and moors in the south of England, though bleak enough, are not well adapted for grous, from the absence both of cover and food. The hill bogs of Ireland are better; but still they are too retentive of moisture; and the dry central mountains of Scotland are therefore the proper places.

It is probable that the superior juiciness, and even flavour of the red grous, is owing to their having a greater proportion of insect food than the ptarmigan, and their not feeding in so humid places as the black game; for insectivorous birds are always sweeter than those that live on vegetable substances, and both insects and vegetables are better flavoured in dry places than in moist. The difference of flavour thus arising is felt in differences of season, and appears in fishes as well as in birds. Grous, partridges, and all the gallinaceous birds, are finer flavoured in dry seasons than in rainy ones, 
though they fly earlier, are stronger on the wing, and therefore more difficult to be procured. They also continue longer sweet when the weather is dry.

TOES BARE, OR NEARLY SO, BUT THE TARSI FEATHERED.

(Tetrao.)

Of these there used to be formerly two species-black grous, black cock, or heath cock, and wood grous, cock of the woods, or capercailzie ; the third name being merely a corruption of the Gaelic for the second. The last is now extinct in the British islands, and has been so for the last seventy years, though still abundant on some parts of continental Europe.

These birds inhabit still further down than the red grous, the feathery or downy foot being always characteristic of a mountaineer, or an inhabitant of cold climates, and exposed to the violence of the atmosphere. The Bantam fowls might be considered as an exception, if they were not natives of a country which sets all the distinctions both of animals and of plants, that are attempted to be founded on differences of latitude, at complete defiance. They are from Japan, and many of the natural productions of Japan are tropical in their appearance, and yet can bear the winter in cold latitudes better than even the native productions of those latitudes; we must not, therefore, object to the rule, because one of the Japanese gallinidx is an exception.

Both of these species have the feet adapted for perching; and though the toes are not feathered, they are margined or fringed on the sides, so that they enable the birds to walk more easily in soft and miry places, and also to retain their perch better on trees than the mountain birds.

Their general habits also more nearly resemble those of common domestic poultry. The males are polygamous, each of them procuring, often by desperate combats, in the early part of the season, a number of females, to whom they are not so attentive, in the time of incubation, as the formerly 
noticed species. The male is also larger as compared with the female, and has the plumage finer in proportion, and the external feathers of the tail more developed; and though, as we descend the mountains, the birds become more shy of the visits of man, they come more to his cultivated grounds and his habitation. The only British species now is

\section{BLACK GROUS. (Tetrao tetrix.)}

Black grous is a much larger bird than the former species, though far inferior in size to the wood grous. It is nearly two feet long, and three feet in the expanse of the wings; and the weight, when the bird is in good condition, is from three to four pounds: these are the proportions of the male bird, the female being considerably smaller. As the tail is more produced, the length is greater in proportion than in the red grous; but the forms of the birds have (the tails ex.cepted) a considerable resemblance to each other, and the weights bear the same proportion to the extent of the wings.

The bill is black, and so are the upper parts of the body generally; but they are finely varied with blue, purple, and deep bronze-green reflections. The blue is brightest on the nape of the neck, terminates at the scapulars, which are black with purple, and appears again on the rump, passing into purple, black, and a shade of green on the upper-tail coverts and tail feathers. The lower part is pitch black without reflections, with the exception of the under.tail coverts, which are pure white. A spot on the wrist-joint of the wing, the tip of the bastard wing, the roots of the primary quills, with the exception of the first four, and the tips of the secondaries, are also white-the last marking the closed wing with an oblique line of white, and the others with two white spots. The toes and feathers on the tarsi, with the exception of a portion at the upper joint, which is white, are dusky; which is probably also the colour of the ear coverts and the necks of the primaries. There are two quills more in the wings than in the red grous, and sixteen feathers in the tail, the outer 
ones mueh produced and reeurved, so that the tail appears forked. The naked spot over the eye is bright searlet, granulated on its surfaee, and deeply fringed along the upper edge.

The female is about two-thirds of the weight of the male, and the dimensions are nearly in the same proportion, only the length is less, the tail not being so much produeed. The eolour is brown, of various shades, darkest on the baek, and everywhere very beautifully mottled with black. The tail is a little forked, but it is short, and the external feathers are not recurved. The scarlet pateh orer the eye is in the female a mere line.

These birds inlrabit the lowest slopes of the hills, lonely heaths, and the banks of marshes; but they eome upon the stubble fields in winter, when these are near their haunts. They also frequent sequestered woods and eoppices, perehing on trees during the night; and in the eold weather living upon the buds of such trees as have them of considerable size, suel as the pines and wild alders. In autumn they feed much upon wild berries, and the seeds of wood and marsh plants, though they eannot swim, and do not fly or wade for the latter.

During the latter part of autumn and the winter the males live together in floeks, and in a state of the most perfeet harmony; but when the warmth of spring begins to be felt, and their plumage, which had beeome rather dull during the winter, begins to shine in all the beauty of its glosses, they separate from each other, fight stoutly for their females, and when each has obtained his number, seatter themselves over the waste. These operations begin at different times, aceording as the place and the season are more or less early; but it is with us seldom earlier than Mareh, or later than April.

They are then on the alert by early dawn, erowing, making a harsh and grating sound, like the whetting of iron with a rough stone; and as the day dawns, showing off the beauties of their plumage in a great variety of attitudes and gestures.

This pugnacity of the males, in the early part of the breed- 
ing season, is common to all polygamous animals, whether quadrupeds or birds; and even among those that are not hostile to each other, there is a tacit separation. The tendency is a very essential one; because, when they are occupied with their young, they have less time for seeking their food, and have the young either to feed in the nest, or lead to the pastures. Hence each can the more easily provide for itself, when the whole are distributed over the surface, in proportion to its productiveness. The nest is always formed with care, very nicely proportioned to the time that the young are to use it as a habitation. It is a mere hatching place with gallinaceous birds, and therefore it is rude, and placed where the female can easily find food during the time of incubation. When the young have all come out of the shell, the female leads them to new pastures, and returns no more to the nest; but gathers them under her wings in the first shelter that presents itself, when the day becomes too dark for their feeding. The number of eggs is less than that of either of the former species, the average being about eight, though sometimes more, and often fewer, especially in a second brood, after the first has been destroyed by any casualty. The female nestles on the ground, and never attempts to perch, till the young be so far grown that they are able to perch along with her; and while they are immature, the male never quits the neighbourhood, but acts as a sentinel, watchful for the safety of all his families, but occasionally perching for that purpose. If the male is killed in the early part of the season, the females join the packs of those whose cry they can best hear; but if the nest of the female is destroyed, she only shifts her ground, continuing in the pack of the same male. The differences of sex appear in the young birds when they are about half grown; and by that time the males are generally beginning to flock together, until they are again separated by the impulses of another year.

The black grous being a bird of lower situations than the red, it is found in more places of the British islands, being 
found wherever there are wilds of sufficient extent, with heath or coppice, or tufts of grass and rushes, to afford cover; but it is not any where met with in such numbers as the red grous are on the Scottish moors.

WITH THE TARSI NAKED.

There are two genera of British gallinida with the tarsi naked of feathers, partridges (perdrix), and quails (coturnix), the former resident birds, and the latter summer visitants, though a few sometimes remain in certain warm situations, near the shores of the Channel.

In the general form and attitudes of their bodies, and also in the ground-colour of the greater part of their plumage, the partridges and quails bear some resemblance to each other; and they also so far correspond in their haunts and habits, as to form a division of gallinaceous birds different from those that have been mentioned; but still they are so different, that the one can never be mistaken for the other. If we except the pheasant, which, though abundant in many places, is an imported bird, and which is the gallinaceous bird of woods, coppices, and thick brakes, replacing in the lowlands the cock of the woods which has become extinct in the highlands, the partridges and quails inhabit next to the black grous. This grous inhabits down to the verge of cultivation, and the partridge takes up its abode within that verge, seeks its food where man cultivates, and inhabits so near his dwellng, that it borders closely upon the domesticated poultry, and sometimes mixes with them in their excursions. The quail seeks its food in similar places, but it comes not quite so near the habitations of man, is less generally distributed over the country, and remains only for a season.

The general characters are: the bill short, strong, naked at the base, the upper mandible curved, and the point extending downwards over the under one, well adapted for pecking in the ground. The opening of the nostrils naked of feathers; but, as is the case in all birds that run among herbage, lateral, 
and defended by a scale. The body compact, but fusiform, or curved above, below, and laterally, tapering to both extremities, borne horizontally in running, and thus presenting the least resistance to the air, and gliding in the easiest manner through the herbage. Feet with three toes before, united by membrane as far as the first joint; the hind toe articulated farther up the tarsus than in grous; and the whole foot better adapted for running upon soft ground. The tarsus with tubercles in the partridge, and smooth in the quail. Tail very short in both, somewhat square in the partridge, but rounded in the quail, and containing four feathers fewer. Wings different : those of the partridge concave and rounded, with the fourth quill the longest; more extended and pointed, with the first feather longest, in the quail; the one fitted for short flights only, the other adapted for considerable distances. The extent of the wings is double the length of the body in the quail, and only one and a half times in the partridge.

\section{Partridge (Perdrix.)}

There are two British species of partridges, the common, or ash-coloured (cinerea), and the Guernsey, or red-legged (ruf $(a)$; but the latter is not abundant in the isles in the Channel, and it is rare on the mainland, yet it is said to be increasing in Sussex and Suffolk.

COMMON PARTRIDGE.

The common partridge is so well known, that description is hardly necessary. Bill and naked parts, with the exception of the spot behind the eye, which is red, bluish grey. Throat, cheeks, and over the eyes, reddish orange. Neck and breast silver grey, with fine zigzag black lines. The same colour continued to the flanks; but the markings larger and brown. A large reddish brown horse-shoe spot on the belly. The scapulars and coverts have the shafts bright yellowish brown. and the webs darker and mottled, but lighter at the edges, 


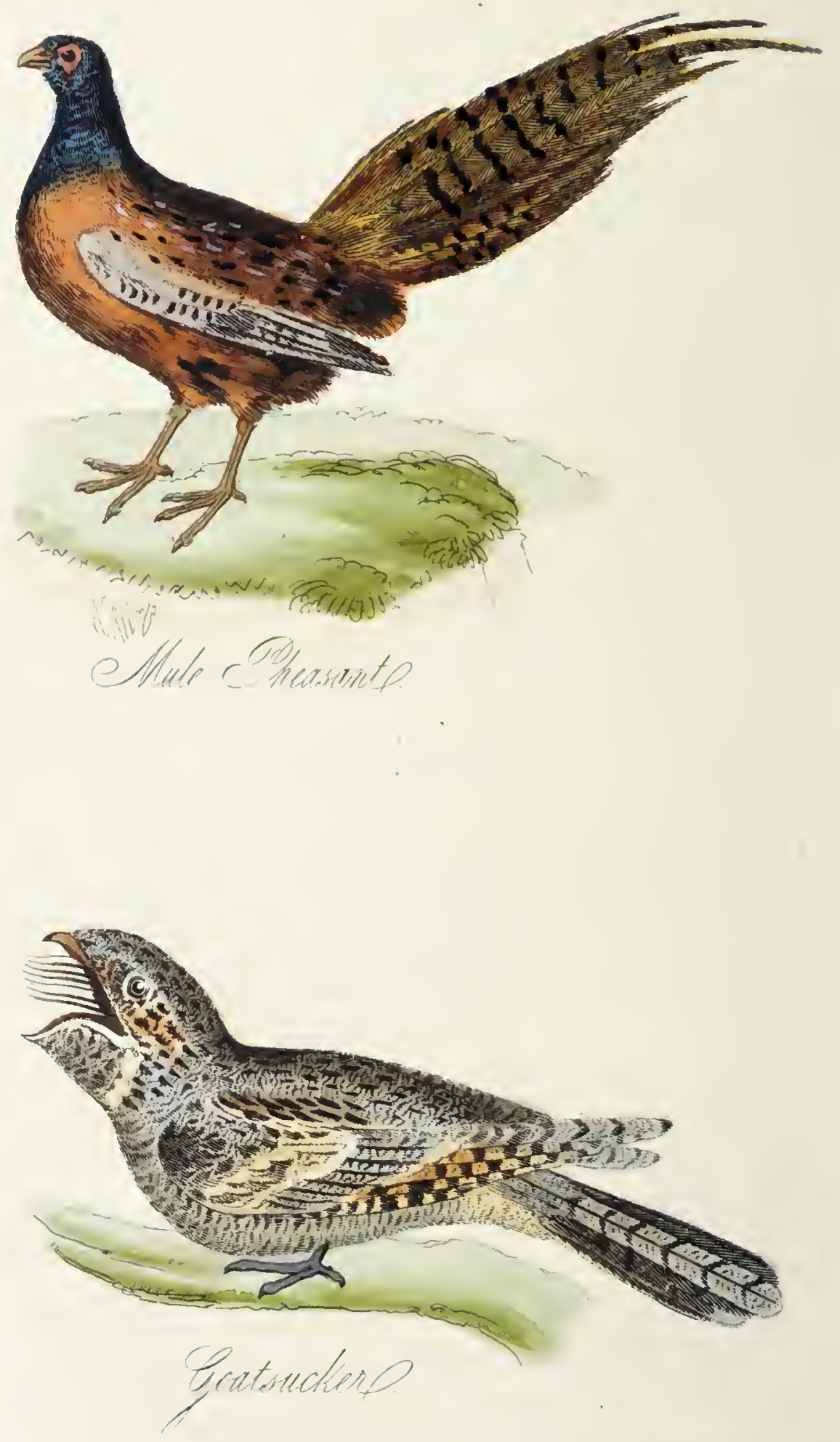
which gives their feathers a very distinct and neat appearance. The quills are greyish black, leaved with brown. The back, rump, and middle feathers of the tail, are mottled with black lines and spots, the outer featliers are the same brown as the others, but without mottling. There are twenty-three quills in the wings, the fifth the longest; and sixteen feathers in the tail, of nearly equal length. The female bird is smaller, has the orange brown on the throat pale, the feathers on the head edged with white, the belly spot less defined, and the back more minutely mottled.

As might be expected in a bird, which, although not domesticated, yet follows cultivation, and appears to depend upon it, the partridge is more affected by local circumstances, than those birds that avoid the neighbourhood of man. Where cultivation is most successful, and the fields most productive, partridges are most abundant, largest, and of the finest plumage; and the difference between those which are found in the rich agricultural counties, and in the moors, is so great, that the latter has sometimes been considered as a distinct species, or at least a variety, under the name of the moor partridge.

This is partly to be accounted for by the large broods which partridges rear; they are the most prolific of the wild gallinidx, the eggs being often as many as twenty, and never fewer than twelve. The nest is merely a hole scratched in the dry mould, generally under the shelter of some bush or tuft of grass; and during the incubation, which lasts three weeks, the female sits remarkably close, and not only does not rise when her nest is approached, but is not easily driven from it. During this period, and more especially toward the close of it, the bird offers a bold resistance to winged foes, and will drive off crows, magpies, and other plunderers of nests. On the other hand, if quietly approached, and gently handled, the bird and her eggs may be removed, and she will continue to sit, and hatch her brood in confinement, but depart with them to the fields as soon after as possible, This is exactly the reverse of the domestic hen: she will often 
retire to the coppice to perform her incubation, but she leads her brood back to the farm-yard with an air of triumph, as soon as they are able to follow her. They are monogamous.

The male partridge takes no part in the labour of incubation; but, as is the case with all birds that pair, he is attentive to his mate, and joins with her in defending the brood; he also practises many arts to entice visitors away from the nest. The young can leave the nest the instant that they break the shell, and generally do it the same day. At that time their legs are as strong in proportion to the weight of the body, as in the mature bird, but the wings are barely developed. There are few more interesting sights than a family of partridges. The young feed on small insects, larvæ, and insects' eggs; and the old ones lead them to the places where these are deposited, and scrape away the mould. An ant-hill in friable soil is a fat pasture, and myriads of the eggs and larvæ are eaten by the young partridges. In the northern parts of the country, the large ant-lills which are in the scattered plantations, more especially those of pines, attract the partridges farther from the cultivated fields, than they are found in places farther to the south; and though those that are bred there are small or " hill-partridges," they are superior in flavour to the more bulky ones obtained on the rich lands. It seems to be a law of nature, to which there are few exceptions, that the smaller any production runs, it is, if equally perfect, always the most delicate. Hill mutton, hill grain, and hill vegetables, are so many proofs, and hill partridges are another.

Whether they are tending their young, or relieved of that, and only mindful of their individual safety, the partridges feed only in the morning and the evening. All the gallinaceous birds feed by sight only. If they have the sense of smelling it is weak, and does not appear to assist much in guiding them to their food; and their bills are so hard, and their feathers so close, that they can hardly be guided to the place or the substance by any thing that we can call touch. Hence they feed only in the daylight-in the morning and the 
evening; and they bask during the heat of the day, or roll themselves in the dust to free their plumage from the nirmides with which they are infested. When the brood is very young they feed to a later period of the day, in order to seize the eggs and larvæ of the ants; but when the young have begun to eat grains and seeds, the morning's feeding is sooner over. The night worms and other small animals, which are the food of some of the grallidæ, have mostly retired into the earth before the partridges leave their "jugg," or sleeping place, in the centre of the field; but there is a succession which comes with the sun, and retires when that becomes strong, returning again when the evening begins to cool, and the shadow begins to lengthen; and to keep down the redundancy of these is the business of the partridges and their congeners.

All birds that feed upon the ground, live almost exclusively upon insects, (it is to be understood that the word insect is used in a popular sense for all animals which are not birds, quadrupeds, reptiles or fishes, and we shall use it in that sense, in order to avoid a number of technical names which we are not called on now to explain,) when they are young, and at all periods of their lives prefer insects to any other food. Hence, if we had a good account of the diurnal and seasonal appearances of those insects, we should be in possession of a key to very many of the habits of birds, which would, in very many instances, lead us to invite that which we banish, and cherish that which, in our ignorance, we are zealous to destroy.

Among these, the partridge would, without doubt, be found to hold a very conspicuous place. The partridge follows the march of cultivation; it multiplies exceedingly; and no persecution can drive it into the wilderness. The covey will rise, and wheel about, and alight, again and again; but thin them as you may by the gun, the remainder will continue in the same turnip field, or on the same clover-matted stubble, as pertinaciously as ever a mountain tribe of human beings clung to their fastnesses in a war of extirpation. Naturally 
speaking, the partridge is therefore part and parcel of our agriculture; and though the farmer may see it only as an evil, in the portion of grain that it destroys, yet it must have good in it, and that good must counterbalance the evil-must be a positive surplus for the advantage of man. The weevils, the cynips, and the tipulce, come along with cultivated grain and cultivated vegetables and roots, in countless myriads, to consume those surplus seeds and grains which, if man did not take them for his use, would choke all else and each other. But as man takes the produce of the vegetable, the partridge and the other birds which frequent the cultivated field, come and consume that which, but for them, would deprive man of his produce, and do it in a way which he could not prevent, or very materially check. It is true that, when the insects have disappeared for the season, and those seeds which the birds have been so instrumental in preserving are matured, the birds take their share; but, in justice, why should they not?--they are the preservers of the whole.

It is the same with the whole winged creation. The sparrow does not follow man wherever he lives, and twitter around the cottage for mere mischief; neither do the birds of summer come from a far country, and carol from the groves, or hunt in the garden, as the enemies of man. Even in wild nature, man has no enemy; and that which invariably accompanies improvement, is, we may rely upon it, necessary to improvement. If we could reckon up how many caterpillars two sparrows pick from the trees and buds in the course of rearing one brood, we should deem the sparrow on the house-top as much our servant, and as worthy of his little reward, as the domestic under the roof.

No doubt we should be impartial, for even the caterpillar has its use, within certain limits; and it is only within certain limits that any creature or thing is useful. Our art in so far renders the labour of the bird less necessary than the supply which its power of increase can afford; and therefore, if the surplus is useful to us, we may freely take and use it. When the birds of the season have 
come to maturity, they are far more than the winter could support. Many would, in consequence, die of starvation; therefore while they are in season, go by all means to the field, inhale the bracing air of autumn, to fortify yourself against the cold of winter, and fire away. That is your direct use in the partridge; and though not half so important as the indirect one which you do not see, still it is a delicious use; so take it, and enjoy it freely. But be a wise sportsman, and do not exterminate: the farmer who eats the seed corn gets no more crops. Be an honest sportsman, and "bide your time." From the time that the coveys pack, and you can with difficulty get within shot of them, to that when the next brood are on the wing, the birds are doing you nothing but good, and you can do them nothing but harm. Man may not observe you, and you may evade the punishment of those laws which, whether wisely or not, he has enacted; but do not on that account both injure and degrade yourself. Take your use with knowledge, but be not an ignorant or a wanton plunderer of that store, over which for the greatest good of all, the eye of Omniscience keeps watch.

Children, unless they have been schooled in the vice of mere hoarding, always break or pull to pieces those toys of which they know not the use; but they are just as happy, nay, far happier, in preserving those of which the use is known: and we may all derive an important lesson from that. We are among the works of nature, what children are in the toy-shop, only the things of which we know not the use are more numerous in proportion. While ignorant, we most destroy; and we can destroy nothing that is natural without injury to ourselves; so that to use we must first know, but to know is to enjoy. That which, if it remained, would injure the rest in our legitimate portion; and such is the productiveness of nature, that it is in all cases not only sufficient, but the maximum of what we can permanently obtain.

In the case of those birds which are desirable as food, whether they reside with us always, as the partridge does, or tarry only for a season, nature points out when our portion 
can be most safely and advantageously taken, with as much certainty as it points out when the crop of the field may be reaped, or the produce of the orchard gathered. The culm and the twig bend to bring the ear and the apple within our reach; and the birds flock that we may use the net, and take short and whirling flights, in order that we may use the gun. They do so when they are in the very best season for our use, and when the removal of the superabundance will tend most to the preservation of that which is left. They do not so at other seasons; and therefore to attack them then is much the same in principle and in profit as it would be to pull the green ears in the field, or the half-grown fruit in the garden.

Partridges begin to pair in February, about which time there are often fierce combats between the males, obviously for the purpose of dispersing the pairs which have been congregated during the winter. The eggs are not, in general, dropped till toward the end of May; and the young break the shell about Midsummer. The time of dropping the eggs is thus rather longer than that spent in incubation; but the times and the operations are both accelerated by heat and drought, and both retarded by cold. The hill partridges in the north are at least three weeks later than those of the rich agricultural parts of the south.

Partridges are easily tamed, but do not breed in confinement, though instances have been mentioned of females in that state producing eggs. Addled eggs are, however, produced by many birds under circumstances where there is or can be no progeny. In some places it is customary to collect the eggs of partridges, hatch them under domestic hens, and then turn the broods into preserves for the purpose of stocking them. That method may in so far answer, and it is the only one by which birds can be readily accumulated in places where they are not native; but in the case of partridges, it is probable that the increase in the one place is not so great as the decrease in the other. A stock may be good up to a certain point, but an overstock must always be kept up at a loss. 
The Guernsey partridge is stouter, heavier and longer in the wing than the common partridge; it has also two quills more in each wing, which mark it as a distinct species. Its colour is more red than that of the common sort, and its gait bolder. It has been introduced into many preserves, from which pairs have escaped or been driven; so that it is becoming gradually more abundant in the open fields of the southern counties. It differs from the common grey partridge in some of its habits, as well as in its appearance; as for instance, it sometimes perches on trees.

\section{QUAIL. (Coturnix).}

A figure of the common quail (Coturnix vulgaris) will be found on the plate facing page 26 . It is there represented at one-third of the lineal dimensions, or half as much diminished in line as the ptarmigan.

Though quails are now both local and rare as British birds, yet it is probable that they are more numerous in some of the southern counties than appears to common observation. Their extreme closeness during the day, appears to be the principal cause of this. They are best known to the night poachers, who are well acquainted with their cries, and dexterous in catching them; but, during the day, the birds are as silent as they are still. Those which do migrate to Britain, which are few as compared with the continental migrants, usually come about the end of April. Their long flights are understood to be performed during the night; for though, like the other gallinidre, they feed in the morning and evening, they, contrary to the practice of most of these, sleep at mid-day; indeed, during the greater part of the day. They squat at these times, and do not "flush," or take wing, till a dog be quite among them. The males are polygamous, and fight desperately in the early part of the season, so much so, that in 
some countries thcy are trained in the same manner as game cocks. The call-note of the male is a trice-repeated whistle, and makes rather a pleasant variety among the many songs of the active season. The response of the female is made use of as a decoy-note in catching the malcs alive, though they will come to the male call, as if it were a challenge to the fight. Their nests, and the number of their eggs, are nearly the samc as thosc of partridgcs. Quails are very abundant on the continent of Europe, and in most parts of Asia. In the former, thcir summer migrations extend as far as Lapland; but in the latter, they do not reach the extreme north of Siberia. They linger during the winter in more localities than almost any other migratory birds; but such is their productiveness, that they return cven to the north of Africa in vast flocks, though very many of them are captured in the places whcre they halt by the way. When at rest from migrating, and not busied with the care of their broods, quails get very fat, especially on pastures that afford them a plentiful supply of oily seeds; and when in good condition, they arc highly esteemed as food, Their straggling appearance, however, and thcir short stay, render them less interesting to ordinary obscrvers of British birds, than those genera which regularly summer and wintcr in the country, and are generally distributed over it.

DOMESTICATION AND CHANGE OF PLUMAGE.

If we leave out of the question the wood grous, which, as a British bird, is extinct, and the quail, which is both rare and local, we have, in our native galline, a regular succession of inhabitants, from the highest mountain top, to the closc vicinity of the most warm and sheltered dwelling, all mingling a little with each other on the confines, but still each preserving its locality, while the character of that locality rcmains unchanged, more decidedly perhaps than any other birds. All birds straggle a little at times; but still it is rarc to find ptarmigan any where but on the mountain, 
grous any where but on the moor, black grous but in the wild dell, or partridges but on or near the cultivated field. Thus we know where to find any of these birds at all seasons; and, according as we ourselves are situated, we can study their habits with much certainty.

We find the ptarmigan on the height, changing by nature with the seasons, and braving the very excess of the winter. In the grous we have a bird, in the dry cover of the heath, which affords it shade and protection in the summer, and shelter in the winter, while the short but firm stems support the covering of its snow-house, which, in many instances, remains unmelted for half the year; the tops of the same heath, and the mosses and lichens which are growing under it, dcspite the snow, serving the birds for food during the time of their confinement. The heath thus serves to equalize the temperature of the seasons to the grous, in the same way that the transition from house to tent, and from tent to house, equalizes them for the rude inhabitants of high latitudes; and hus, the change in the colour of the plumage not beirgo necessary, that does not take place.

The black cock has the shelter of the bush when the naked wind blows, and the thicket when the rain falls, or the snow drives; and as the places which it inhabits are more productive than those of the others, it can range more easily for its food. The habitation of the partridge requires still less shelter, as the winds are not so strong, or the snows so heavy. The seerls on the fields also supply it with a greater abundance of winter food; and, when hard pushed, it comes to the stack-yard for a meal.

It may seem singular that, whilc the natives of Asia, Africa, and America are domesticated with us in so great numbers, and so many varieties, our own native gallinidx, should be all still in the wild state, or domesticated, or rather tamed, only in partial instances of the individual, but not in any way in the race. But the difference between our climate and the native climates of these foreign birds, is really the cause why they have little or no tendency to go into the wilds! while the influences of

VOL. I. 
season and climate, very little different from those to which their natures when wild are adapted, are constantly, acting upon, and tending to lead back to the state of nature, those individuals of our native genera which are occasionally bred in confinement, or taken and partially tamed.

In these birds we can trace a sort of resemblance to the general colour of the places which they inhabit, though we know not well the cause of the colour in either case. The ptarmigan is mossy rock in summer, hoar frost in autumn, and snow in winter. Grous are brown heather, black game are peat-bank and shingle, and partridges are clods and withered stalks, all the vear round. We do not mean to say that these correspondences of colour with situation are intended to hide the birds from their enemies, because, at Nature's table, the goshawk is as free and as well provided for as the grous, and the harrier as the partridge. Still, the correspondence of colour show a correspondence of cause, whether we shall ever be able to find out that cause or not; and when, by domestication and change of circumstances, we break the connexion, the colour falls into varieties, so that we have various colours in the same brood. The regions which ptarmigan inhabit vary the least in locality, and those of the partridge vary the most. We find the same in the colour of the birds. The ptarmigan has always some stage of its own changing colour; the partridge varies much, being found with the upper part brown without mottling, and also with nearly the whole body white. But the individual ptarmigan is subjected to far greater changes of temperature than the partridge, and therefore the one has seasonal varieties of colour, and the other few or none.

In many of the gallinidæe, the plumage of the male is much finer than that of the female; but the gaudy livery appears brightest on that plumage which the male is to wear in pairing time; and the more sober plumage of the female, which is of considerable service to her while she sits, remains only so long as she retains the capacity of being a mother. Common pullets, when they become barren, acquire part of the plumage, and also the crowing note of the male bird; and in the plat 
opposite there is a figure, copied from nature, of what is very inaccurately termed a "mule" pheasant. A mule is a hybrid between two distinct species of the same genus, incapable of continuing the mixed race, but readily breeding back to the pure blood; whereas the bird figured, and many more of the same description, are females, in which the peculiar functions have prematurely ceased; and cases are mentioned in which some of these have changed so far as to have one spur on the tarsus.

It was once supposed that these changes of plumage were the consequences of old age, and that they would take place in all females of the species in which they occasionally appear, if these were allowed to be old enough; but it has been satisfactorily ascertained that age has nothing to do with them, any further than as it may be one of the causes of sterility. When that is in any way produced, the change of the plumage is always a consequence; and the change is more complete, in proportion as the sterility is more absolute.

The popular adage of the unprofitableness of " crowing hens," might have at once led to the same conclusion which has been arrived at by actual cbservation, as the adage would not have gained currency, if the fact that the crowers did not lay eggs, had not been one of common occurrence. But the voice which the sterile female acquires is an unnatural voice, wanting the vigour of that of the male, and having no meaning as to time. The male calls the colony to their labours in the morning, and also proclaims triumph when an enemy or a rival has been driven away.

The sterile female, on the other hand, has no discrimination of time or of purpose in her crowing, which is attempted without any assignable cause. The following passage (Philosophical Transactions, 1827) by Mr. Yarrell, the sagacity of whose remarks is as valuable as the accuracy of his observations, is worthy of being quoted:- "It is probable that they (the barren females) do not live many years after the commencement of the change, since so few are found to arrive at any great degree of splendour. Of the many I have had 
opportunities of examining, none possessed either the fullsized broad scarlet patch round the eye, the fine blue zone at the end of the red feathers of the breast, or much of the bright straw-coloured mark on the scapulars and wing-coverts, one specimen alone excepted; nor have I seen a female pheasant with spurs; and a bird belonging to Mr. Leadbeater, (the one represented in the plate,) which is by many degrees the finest I have ever seen, is also without any."-The subject is one of much interest, and merits farther investigation. 


\section{ORDER II.}

\section{CURSORES.}

RUNNING BIRDS.

AlL the gallinidie run, some of them very swiftly, and many other birds are fleet-footed; so that "running" is by no means a very distinctive epithet. Running is, however, the principal motion of this order; and there are some very important species, such as the ostrich and the emu, that cannot fly. Two species only can be at all considered as British birds; these are the bustards, the one resident, but exceedingly confined in locality, and few in number; the other, one of our rarest straggling visitants.

\section{GREAT BUSTARD-(Otis tarda. $)$}

One is at a loss whether most to deplore the total extinction of the wood grous from the forests of Scotland, or the impending and, as it seems, approaching disappearance of the great bustard from the plains of England. It was once not uncommon in various parts of the country; and as it is a bird of powerful wing, and can fly to considerable distances, notwithstanding its great weight, it occasionally visited the northern parts of the kingdom. One was shot on the lowlands of Morry in 1803.

Ten years previous, I saw two birds in the parish of Carmyllie, in Forfarshire, (a place famous, by the way, for migratory birds, in their passage to Strathmore and the Grampians,) which I have no doubt in my own mind were bustards, 
although, from the little knowledge I then had of the names even of these local birds, which were absolutely teazing me to study their habits every day, and the length of time that elapsed before I saw even a tolerable representation or description of a bustard, I cannot venture to record my belief as an authentic instance. The place consisted of a wide extent of very bleak and bare surface, half moor, half marsh, but so constituted both ways, that neither could claim it wholly. It was surrounded by "outfields" of barley, which was choked in the shoot-blade, or oats, which seldom got white till helped by the frost; but at one place a dell, with a succession of pools, formed a sort of drainage, and there the sward was a little more kindly. I was on the one side of these pools, and near the other was the termination of the cropped land, fringing the summit in a way, but not coming over it. The wind had been keen and hollow from the east for some days (an east wind in such a place often makes May cut up April and March): but it had veered round, rain had fallen, and all was beginning to be green. It might be the end of May, or the beginning of June, and an hour or two after sunrise. I saw two brown birds of great size, by the edge of the cover, and very distinctly made out against the sky. They might have been about a quarter of a mile distant, so that I could not see the markings or minute parts; but they certainly were larger in size than any of the common birds, more especially than any that appear in the summer. The pools formed a perfect barrier, and I am not sure whether then I should have approached to take a nearer view, even if there had been no impediment in the way. After a little while they stalked off out of sight, by descending the other side among the corn, and I did not see them either alight or take wing, so as to observe the wings suspended half closed for a time, which is one of the characters of the bustard when alighting, or rising undisturbed; neither did I again see them, or any birds like them.

The bustard is really a splendid bird. The male, when full grown, is four feet in length, and nine in the extent of the wings; and the weiglit is from twenty-five to thirty 
pounds. The bill is greyish; but the legs, which are not feathered quite down to the tarsi, are black; and the three toes are all turned forward, but with an elastic pad as a heel. In form, the foot does not differ much from that of the little bustard, which is represented in the following figure :-

\section{Walking and Running Feet.}

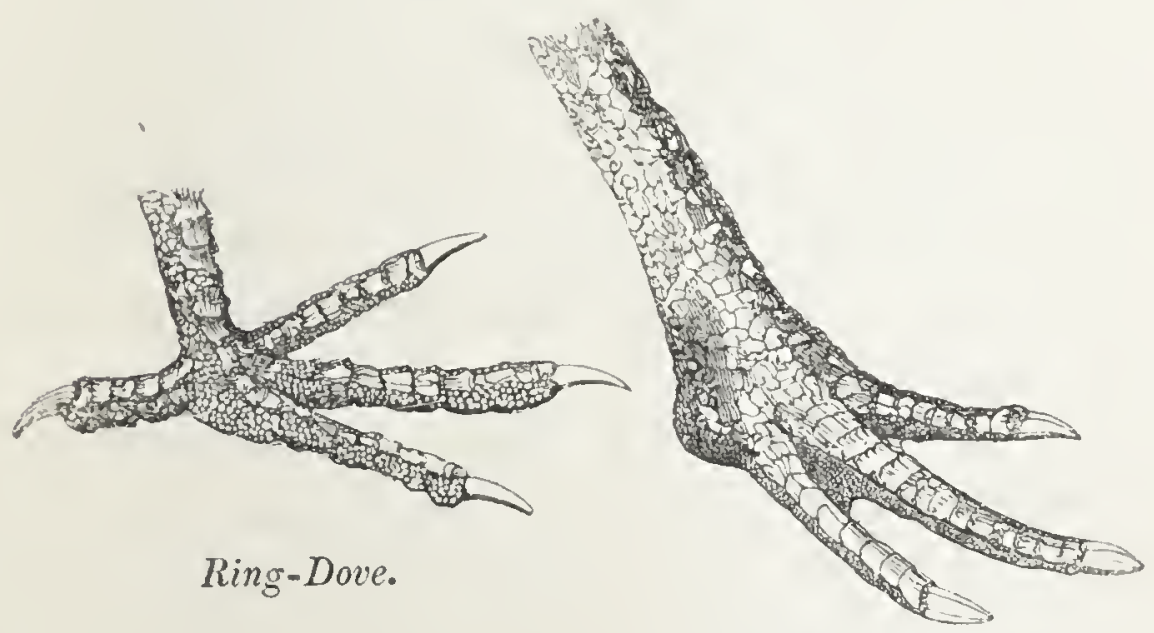

Little Bustard.

The hinder toe is wanting, as in all the running birds, in consequence of which the rest of the foot acts as a complete and free spring, and projects them forward without any pause or interruption, so that they acquire a momentum, and by that means run fast with comparatively little exertion.

The plumage is strongly marked. The head is of an ashengrey, with the exception of a black streak along the middle. The feathers on the chin are long and wiry, and at the base of the lower mandible form a tuft on each side, which hangs eight or nine inches down the neck. These feathers, in some attitudes conceal and in others disclose naked spots of a violet colour on the sides of the neck. The lower part of the neck passes into a fine reddish orange, which is also the prevailing ground colour on the upper parts of the bird, but lighter on the scapulars, and inclining to grey on the lesser wing coverts; and there is a tuft of down at the articulation of the neck inclining to grey. The greater coverts, and part 
of the secondaries are bluish, and the primary quills brownish black with white shafts. The tail feathers are white toward their bases, and generally also at the tips; but the other parts are brown with black lines, which form a regular band across all the feathers. The tail feathers can be spread out like a fan. All the upper part of the body is finely barred and spotted with black, the lines in general crescent-shaped, and sometimes with a narrow line of the same colour running parallel to their convex side, or side next the point of the feathers. On the fore part of the neck, and having its opening under the tongue, there is a membranous bag or pouch, capable of containing about half a gallon, and covered externally with a bluish-black naked skin, of nearly the same colour as the legs. The use of that pouch in the economy of the bird is not very well known.

The tarsi of the male bustard are about six inches in length, and the other part of the legs are nearly one foot, so that, when the bird stands up for observation or on the watch, its total height is about four feet. Its walking gait is erect and stately, and its running pace, in which it lowers the head and partially rows with the wings, is exceedingly swift. The female is not above half the size of the male, wants the wiry mustaches and pouch, has the grey on the head and upper part of the neck darker, the upper part more uniformly mottled, and the mottling continued to the tail, which is less produced than in the other sex, and without the regular black bar.

Like most of the gallinaceous birds, the bustard makes no nest, but drops her eggs on the bare ground. These are only two in number, produced rather early in the season, and requiring four weeks' incubation. The young are of a pale yellowish brown, mottled with darker and black, and follow their parent as soon as they break the shell. The female sits close during her incubation, and cannot be raised without difficulty; the young also squat close down upon the ground on the appearance of danger.

Independently altogether of its size, and the quality of its 
flesh, which is highly prized, the bustard is a very interesting bird. But unfortunately it is one of which the recorded history is exceedingly fabulous, and it is now so rare, that it is not easy to correct the errors and supply the defects.

The bustard does not come very accurately into any of the orders, into which systematists arrange the winged tribes. It cannot, with any regard to natural character, be classed with the grallida, because the bustard never wades, but keeps the open and dry plains, and seldom drinks. As little can it be classed with the cursores, or running birds, though we have placed it there, for want of a more appropriate niche. Its most powerful motion is not running, but flight, for which, heavy as it is, its large wings well adapt it. That it can walk well and run swiftly is true, but it combines these with the power of flight in a degree much superior to any other very large bird. The bustard combines so many characters, that it stands alone,-in structure as well as in locality, dif-ferent from any other genus. The circumscription of its haunts, as a British bird, and the decrease of its numbers in those haunts, are, on that account, doubly to be regretted. Though not, like the African ostrich, a bird of the desert, it is naturally a bird of bleak and desolate places; and therefore a natural decay in its numbers may have been occasioned by the different system of agriculture which has been introduced. That has been especially the case in those sandy and dry tracts of Norfolk, where the remnant is still to be found. Drill husbandry in general, and turnip culture in particular, which bring so many people into the fields for hoeing and other summer labour, disturb the female bustards in their incubation. The eggs too, are tempting to the rustics; and even if these are spared, the female, once raised during the day, is shy of sitting again. Such is probably the natural progress toward extermination.

But there have been other causes. The bustard, especially the male bustard, was always a temptation to the sportsman, who slew away for glory or for lucre (bustards of course always sold dear), without considering how slowly these birds 
breed, compared with any of the common game birds. Lat. terly, those who are called " amateur naturalists," have accelerated the extermination. One does not know whether cupidity for the pot, or cupidity for the cabinet, be the vice most destructive of the beauties of nature; but it is certain that those caterers for the museum, who go about shooting every rare bird they see, do no small mischief to our ornithology. A stuffed skin is something without doubt, but it is dearly purchased at the expence of a living race; and now that the bustards are become too rare for being objects of regular pursuit by sportsmen, it will not redound much to the credit of our prudence in matters of natural history, to have the skins of a few native bustards perishing by the worm in our museums, while we must go to other lands to study the cliaracters and habits of the living bird.

In other places of the country the more general pasturage of sheep has no doubt had its effect in destroying the bustards; but in all cases the extermination has been hastened by the desire of possessing the bird. It may be too, however, that cultivation has produced some climatal change which is unfavourable to birds that affect dry and lonely wastes. In that case there is no remedy: we might with justice forego the rarity at the table, and the marvel in the museum, for the sake of seeing so majestic a bird stalking about at its ease and in safety; but our desire of that ought not to interfere with the rational progress of those arts on which the people depend for bread. If the result is to be turnips in place of charlock, or oats and rye in place of thistles, by all means let the bustard go,-only keep him as long as possible.

The food of the bustard is, like that of the gallinidx, very miscellaneous. Insects and earthworms are the favourite food, and the food of the young; and the birds are early astir, in order to capture the night worms before the light and heat of the day drive these into the earth: they also eat reptiles, mice, small birds, and garbage, swallowing the small animals alive. In addition to these, which may be considered 
as dainties in the places which the bustard chicfly frequents, it eats vegetables; and, except at particular seasons, trefoils and other succulent leaves, and the tops of green corn and the grasses are its principal dependence. In the autumn it lives a good deal upon seeds, and in the winter upon roots. Its stomach is membranous, and of great capacity.

The pouch (which is wanting in the female, and opens under the tongue in the male) has been conjectured to answer many purposes, such as a reservoir of drink for the bird that wears it, or for the female and the young; or, again, as a sort of water engine which the bird discharges against itsfoes. The fact of the bird not drinking, which has been tolerably well ascertained, and the pouch being found in the male only, are against the first of these conjectures, and the second is probably no better founded than the old fable of the excellent sport that was procured by coursing the young bustards with greyhounds,instead of which, until they can fly, which is late in the season, the young birds squat so close that it is not difficult to take them with the hand. When plumed they take wing more easily than many lighter birds.

In Norfolk, where only the birds are now found in England, they frequent the large corn fields in summer, and the turnip grounds in winter. If the winter is severe, they sometimes migrate nearer the coast, at which times they appear in little flocks; but they are usually persecuted in their journey and in their temporary abode. They are polygamous; but notwithstanding, it is said that there is a deficiency of male birds. They are much more abundant in some parts of France than in England, and in the dry wastes of the south of Russia, toward the Black Sea, they are still more plentiful; but they are always found on the dry wastes, and never in the marshes, or even where the surface is soft. The fact is, the structure of their feet adapts them only to firm land, and as they cannot perch, and are not well formed for making thcir way among bushes, they are never found but in the open country. The epithet tarda, or slow, which was applied to the great bustard in the time of the Romans, and now forms its specific 
name, is not used with reference to the common motions of the bird, but to the pertinacity with which the young and the female bird, when hatching, retain their place on the ground.

the Little Bustard. (Otis tetrax.)

The little bustard is a very rare straggler in Britain, and when one does make its appearance, it is generally in the autumn and winter. Above it is beautifully mottled with brown and black, with a tinge of pale rose colour on the breast, the under part is white with black spots. The full grown male has a black collar in the summer, which is wanting in the female and the young male, and it is supposed to disappear at the end of summer and to be resumed again in the pairing season. The bird is about one-third of the length of the great bustard, with the wings rather shorter in proportion; but it is a thicker bird, and instead of being one twentyseventh of the great one, which one third of the length would give in similar birds, it is about one twentieth; the weight is about a pound and a half. The haunts and habits resemble those of the former. When a straggler does make its appearance in Britain, it is always near the coast; but it is one of those birds, in quest of which it would be vain to set out.

As the bustards feed readily, and are very miscellaneous in their feeding, they can be made to live in a state of domestication, at least for some time; but it does not appear that they have ever bred in confinement, so that their domestication as races is more to be desired than expected. 


\title{
ORDER IIT.
}

\author{
COLUMBA.
}

COLUMBINE BIRDS-PIGEONS OR DOYES.

THESE are birds which have, in all ages, claimed much of the attention of mankind; and the poets have chosen them as the type of all that is gentle, amiable, and affectionate. The mournful scund of their voices, the attachment of the pair to each other and to their young, the form, gloss, and colour of the birds, and the evolutions which they perform on the wing, all give them an interest to the lover of nature; while the rapid rate at which they breed, and the flavour of their flesh, have made them of consideration in an economical point of view. They are, however, very voracious feeders, and while the ripe grain and pulse are on the ground probably destroy more than they are worth; but at other seasons they are not without their uses.

The domesticated ones, of which there are many varieties, though all agreeing in their general character, are usually called pigeons, and the wild ones doves. It is with the latter only that we are in the mean time concerned.

The characters of the order are, the bill of moderate length covered at the base with a membrane in which the nostrils are pierced, and the upper mandible curved at the point; the tail containing twelve feathers, and the feet having three toes before and one behind, free their whole length, and all articulated to the extremity of the tarsus, so that they are equally adapted for walking on the ground, for perching, or for supporting the bird on tufts of regetation, of 
which it eats the seeds. Doves are much more elegant in their forms than the gallinidæ; and in all the British species the prevailing colours are mixed tints, very softly blended, in which blue, green, and red predominate, excepting in the quill-coverts and tail feathers, and these are more or less black. They are strictly monogamous, and pair for the season even in their wild state; but it is of course not true that in any of the species the survivor mourns in singleness in case of casualty to its mate, for when the season comes round the widowed bird pairs the same as ever; and the note, though plaintive to our ears, is a love song, and not a song of lamentation in the bird. Birds never sing in sorrow. They scream when in fear or in pain, and those that are in the habit of watching have a peculiar warning cry; but there is this much of charm in the songs of birds, independently of their music, that they are always songs of pleasure.

The doves are much more exclusively vegetable in their feeding than the gallinidæ, or indeed than almost any other order of birds. Seeds, and other vegetable substances that are farinaceous or succulent, are their favourite food. They join in the labours of the field; and while the rooks follow the plough, picking up the larve of cockchafers, and other insects, the pigeons are just as busy in eating the couch grass and other creeping roots.

They do not even feed their young with insects, as many birds do, while they themselves live more (at least at some seasons) on vegetables; and nature has provided them with the means of adapting that food to the tender stomachs and weak digestion of their fledglings.

All birds that feed much on vegetable matter have an expansible portion of the gullet which can be enlarged into a sack capable of holding a considerable quantity of food, which passes gradually into the gizzard or true stomach, after the bird has ceased to take in a supply by the bill. That dilatable portion is called the craw or "crop," and bears some resemblance to the paunch or first stomach in ruminat. ing quadrupeds. It is probable that the food of all birds, 
when requiring such a preparation, is moistened and macerated therc before it passes into the stomach. But in the columbr, there is a peculiar change in the organ for the feeding of the young,- - change which has some resemblance to the production of milk in the mammalia, only it takes place in both the parent birds. At that time the inner coat becomes covered with small glands, which secrete a peculiar fluid which acquires a consistency resembling that of soft curd. When the young first break the shcll, they are fed upon that substance, wholly or nearly in a pure state; but as they grow it gradually mingles with more and more of the food of the parent bird, which it reduces to a sort of pulp; and when the young are able to feed themselves, the sccretion disappears, and the glands that produced it arc inactive until they again are required for the feeding of another progeny.

The food which the pigeons thus prepare for their young, whether it be the curdy secretion of their own bodies, or food which they have picked up and prepared, is not given to the young by the bill, in the way in which the majority of birds feed their young. The old bird puts its bill half-opened fairly into that of the young one, and the food is brought up and dclivered to it by a peculiar action of the gullet.

That habit, approaching more ncarly to maternal tenderness than perhaps any other in birds, - the fact that there are only two young in a brood, and that these are generally a male and female; the attachment of the pair which, notwithstanding the disposition which pigeons have to flock (and in some countries thcy flock in countless millions), we have reason to believe they preserve through life; and their apparent fondness for each other, to which there is no parallel instance in the whole animal creation; - these circumstances, taken in combination with the beauty of the birds, and the gracefulness of their motions on the wing, justify that interest which they never fail to command; and so to command as that, unless it be for the purposes of the fancier of tame pigeons, there is no need of describing the birds, for every body learns to know a pigeon, almost as soon as to know any thing. 
But though the pigeons live more on vegetable food than most of the feathered tribes, they do not live exclusively on it. They eat various kinds of snails, generally shell and all; and they do so not only when seeds have become scarce in the winter, and they are reduced to beech-mast and other capsuled seeds, which they are unable to break with their bills, but also at the time when they have young. Nor, though they cannot be so well observed then, is there any doubt that the wood species, at the time of the hatching of their spring broods especially, wheri vegetable food adapted to them is not so abundant, pick up numbers of insects in the woods. The rock species, again, inhabit in vast numbers places where there is little vegetable food. They may be seen alighting in multitudes, and walking about on the beaches at low water, ever and anon picking at something; and though all the species are fond of salt, the probability is that animal food is the chief object sought on the beach. No bird that feeds exclusively on land vegetables takes up its abode on the rocks on the sea-shore, as thereby it would be cutting off half its pasture.

There are four species of doves found in a wild state in the British islands, though in different localities, and with differences of habit. Two of these, the ring-dove, and the stockdove are resident inhabitants of the woods; one, the rockdove, is a tenant of the rocks; and the remaining one is a summer visitant of the woods in certain places only.

\section{RING-Dove. (Columba palumbus.)}

The ring-dove, if not the most abundant in numbers, is the most generally distributed over the country; and it is every where a favourite, even with those farmers in the neighbourhood of woods, upon whose crops, their peas especially, it commits considerable ravages. It has in consequence many local or provincial names-the Wood-pigeon, the Quest, the Cushat, the Cusha-doo, and many others, all of which are favourite words in their localities. 
The ring-dove is, indeed, one of the most ornamental birds in the British woods. It is considerably the largest (British) bird of the order; and it is the most elegant in its form, if we except the turtle, which is much smaller, and a very local as well as a migratory bird. The ring-dove is about eighteen inches long, and thirty in the extent of the wings. It weighs about a pound and a quarter. The other species should, from their length, (about thirteen inches and a half,) weigh not more than ten ounces, if of the same proportions; but they weigh eleven, or more. Thcy are.more bunchy and less graceful at the shoulders than the ring-dove. The whole outline of the bird is fine, combining symmetry and vigour in an eminent degree.

The colours are also beautiful, and remarkably constant in the individuals. The bill is orange, the membranous portion at the base covered with a white mealy powder, similar to that found under the wings of most pigeons. The head, cheeks, and neck, are of a very peculiar changing grey, which inclines more to black or blue, according to the light in which it is seen; and there are obscure darker bars on the back part. The pale yellow irides of the cyes contrast beautifully with the general colour of the head and neck. 'Two spots of white, one on each side of the neck, near its insertion, almost meet behind, forming a collar or ring which occasions the name. The breast and belly are a purplish red with prismatic reflections, varying from green to deep purple. The lower part of the back, the rump, and tail coverts, are the same colour as the head, barred with darker, and passing into a purplish tinge on the coverts. The upper part of the back and the wing coverts are deeper grey, but of the same mixed and varying character. The quills are twenty-four in number: the first ten black, edged with white. The tail feathers are blackish, and edged with blueish grey, but they have very faint purple or bronze reflections. The tarsi and toes are pale red, and the claws black. In general, however, the colours pass so gently into each other, and reflect so many hues with so slight shades of difference, that few birds are more difficult 
to describe by colours; and these can be seen to perfection only upon the living bird when it turns itself about in the sunshine.

The notes of the ring-dove,-for there are four of them, two produced by modulation and two by difference of time,are soft and plaintive, but not melancholy, far superior to the monotonous croak (it is nothing better) of the domesticated pigeon. It of course varies with the season, but February is the month in which its song begins; and it gives the preference to pine plantations, especially when they are not too tall. As it repeats its notes in the early part of the season, and is itself unseen while it does so, there is much interest about it; and the young ornithologists often listen much and wander far in the coppice, and come home, after all, without seeing the cushat.

The nest is very rude, consisting of a few twigs laid carelessly together, and generally at a place where some of the branches are nearly horizontal; for, as the bird has feet adapted for walking as well as for perching, it can perch only across the twig, and awkwardly if that twig incline much. Hence, when there is a choice, the ring-dove always both builds and perches for the night in trees of which the branches set off at large angles. The upright poplar, the mountain-ash, and the willow, unless when the latter is pollarded, are no favourites with it. During the breeding season, which, as there are generally two, and often three broods in the course of the year, lasts the greater part of the summer, the ring-dove never perches high, or builds in tall forests where the trees have long branchless boughs; but in autumn and the early part of winter, when the birds collect from the places over which they were dispersed during the summer, and have nothing to do but find their own food, which they at that time find in ábundance, and are high in flesh and flavour, they perch for the night in lofty trees.

A figure of the ring-dove's foot is given on page 55, along with that of the little bustard, to show the difference between a foot adapted only for walking on dry and hard ground, and 
one adapted for walking on softer ground, and also for perching crosswise on a horizontal twig.

The ring-dove is a bird of very fine wing. As the second feather is the longest, it hovers neatly, and it sometimes displays curious gambols of ascent and descent. It dashes its wings upward with so much force, that they strike against each other with an audible noise; and the bird drops down so far, as if it were to fall to the ground; but a downward stroke, given with equal force, sends it up again. It displays these motions most frequently in the pairing season; but they are also useful to it in its short excursions for food among the trees; and when these are scattered, it may be seen leaping over them like a horse over hedges on a steeple chase, only it takes its leaps from the air as a fulcrum, as well as in it. But volumes might be written on the ring-dove, and still there would remain abundant materials for a fresh volunie. The bird will not live in a domestic state, unless by force; but in 1834, a pair built a nest in the Zoological Gardens, and two eggrs were produced.

\section{THE STOCK-Dove. (Columba QEnas.)}

That is a smaller species than the ring-dove, and in England it is rare, excepting in the midland counties. The southern parts of Europe are its principal haunts; but it is a roaming bird, and migrates in large flocks. It is a percher, and always nestles in holes of trees, or in tall bushes, which might have convinced authors that it could not well be the parent stock of those numerous varieties which live in pigeon-holes, and never perch or build in trees, though the pigeon-houses are in the middle of woods. If the domestic pigeon had been derived from the stock-dove (or the "bush-dove," as it is sometimes called with more propriety), we should certainly have found it resting upon, or moaning its note from the trees of the garden rather than the roof of the house. The only note of the stockdove is a hollow grunt. The same pair build for years in the same place. This bird has no white on the rump, no bars on 
the wings; it is thicker at the shoulders and on the breast than the domestic pigeon. The legs and feet are not so strong, the former are not so much feathered, and the claws are not so well armed on their under-sides with pads and tubercles.

THE ROCK-DOVE. (Columba livia.)

That is the true "stock-dove" from which the domestic ones are descended, whether those that were first kept in pigeon-houses in this country were natives of the country or imported. These birds do not of course build pigeon-houses, but they choose high cliffs, the acclivity of which may protect them from enemies: they nestle in the holes of those cliffs; they sit on the points and little ledges of the rocks, and never perch on trees. If a pigeon-house is built in a district where pigeon-houses are numerous, or near the native locality of rock-doves, it is soon stocked without exertion on the part of the owner; and if it be whitewashed, it is stocked the sooner. Hence the proverb, "Whiten the pigeon-house, and the pigeons will come," which is applied metaphorically, in order to show that, by neatness and regularity, friends will be most certainly procured. In the case of the pigeons, it is the utility and not the beauty of the whitened house that is the attraction. The females never hatch fewer than three broods in the year, and sometimes as many as twelve. The shells of so many eggs require a great deal of carbonate of lime; the lime on the whitened pigeon-house attracts the females, and as the rock-doves are constantly paired, the males of course accompany them. So decided is that attraction to them, that a whitened pigeon-house will entice the stock from those that are neglected, thus making the proverb a literal fact.

It is probably a similar instinct which leads the pigeons to cliffs on the sea-shore, in preference to inland ones. The shells on the beach furnish them with an abundant supply of lime. No doubt, the comparative uniformity of temperature during the year in the sea cliffs, is a farther inducement; and 
brings the habit of the bird of the rocks still nearer to that of the house bird. Indeed, the habits of common field pigeons are so little changed, and the change is so exclusively an act of their own, that they cannot be said to be in a state of domestication. They are rock pigeons still, only they are lodged better, and more conveniently for their food.

Whether on the rock or in the pigeon house, they are grega. rious all the year round; and, whatever may be the distance to which they may range during the day, they uniformly return at night. The certainty with which they return, notwithstanding the height at which they often fly, their passages at sea: where there are no marks to guide them, and the turning which they must make in cross winds, is one of those instincts, which we must admire but cannot understand. That they do in so far depend on sight, would appear from the fact that they are often bewildered in fogs; but still sight, in so far as we can judge of it, is not sufficient to explain the whole. We get to a place by experimental knowledge of the intermediate space, or by information which answers the same purpose; but pigeons, and indeed many animals, have, at least to the extent of their usual journeyings, an instinctive knowledge of the place of their abode, without any reference to the space that lies between. There are authenticated instances of dogs and of donkeys returring on foot for hundreds of miles, though the former had been removed in a close carriage, and the other had been on board a vessel which was wrecked. I knew an instance of a bullock that was driven west and south at least forty miles to a fair, sold there, and taken to his new pasture, fifteen miles from the old one, and with a wide and deep estuary of a river between. His new companions, as is very often the case with cattle for a time, shunned him, or rather combined to expel him. The pasture was on the shore of the estuary: he stood there some time nosing the wind; then dashed into the tide, although the ripple was high, swam gallantly through, and trotted off to his former pasture and companions, lowing as he went. Sight could do nothing in that case, because there were high 
grounds on the opposite side of the estuary, which limited the view to not more than one mile out of fifteen. When these things happen with quadrupeds, we may cease to wonder at, though we must on that account admire the more, the feats that are performed by carrier pigeons; and which are often at least sixty miles an hour. What messengers the swift-winged migratory birds would be, if we knew how to press them into our service. A discovery made in central Africa, might be printed in London, and sent by post on the very next evening.

The white rump, and the two dark bars on the closed wings, which are never wholly obliterated, even when the general colour is almost white, are strong indications of the descendant of the rock pigeon. The stronger foot, too, and especially the more spreading toes, so that the outer and inner act nearly against each other, and crosswise to the other two, cannot be mistaken. Farther, the perchers, the ring and stock-doves, may be confined as individuals but cannot be tamed as races; the rock-dove needs no taming.

Domestic pigeons are a tame study; but there is something more stirring in the observation of the rock-dove in nature's pigeon house, especially among the cliffs and caves of the Hebrides. On some glittering day, when the meridian sun lulls birds and breezes into repose, you row swiftly but silently into the portal of some giant cave, the entablature of which reaches the nid heaven; and, while you are contemplating silent naturc, the rowers, by a concerted motion of which you were kept ignorant, lift their oars, and simultaneously dash them against the sides of the boat. The echo is loud, but the sound of the wings which it wakens into action, is louder. It is as if the hollowed and craggy isle were falling to pieces about you, and the wide Atlantic were heaving and vibrating to its most distant shore. But we dare not begin the description,--from the length, and the pain of leaving off. Those who can, should go there, if it were but to see how far nature exceeds and beggars all description. 
THE TURTLE-DOVE. (Columba turtur.)

The turtle is the smallest British species; and in Britain it is a summer migrant, and as such, visits only the southeastern parts of the island, more especially Kent, the thick coppices of which afford it that depth of shade, and the rich fields that abundance of food which it requires. On the continent it ranges into much higher latitudes, although not to the extreme north or even within the Arctic circle.

When the winds of Autumn blow from the north-east or east, which is always the case when the rains fall heavy on the countries south of the Baltic, the migrating birds, which range farther north on the continent than with us, are frequently drifted to our eastern shores, not in straggling individuals, but in flocks, in the case of birds which are gregarious in their migrations. These form a sort of involuntary autumnal migrants; and as both the time and the exertion spent in contending with the cross wind, are probably as great as would have carried them to their journey's end with favourablc weather, they alight on our shores in a state of great fatigue. They must, in consequence, remain for some time to recruit themselves; and if they reach the coast far to the southward, and the season become very mild, some of them may linger for the wintcr and even survive it. Before we conclude, from the appearance of a specimen, or even of a flock in the autumn, that a bird is a pcrmanent resident in any part of the country, we must consider the range and the time of its migration on the continent, and the kind of weather that preceded its appearance. Our constant sojourners are best seen in the winter, because then they collect from the woods and wilds, and come in flocks near our habitations.

The turtlcs do not come before the latter part of April, or, if the scason be cold, the beginning of May. But though it is general among birds, that the male is the first to feel the genial influence of the season, yet turtles are, in this country 
at least, first seen in pairs. The turtles betake themselves to the thick groves, build the nest, which, like that of all the order, is slight and rude, hatch the two young, nurse them till they are nearly fledged, and are more frequently heard than seen, till the pods on the leguminous plants begin to swell. When that takes place, they come in little flocks to claim the reward of that sweet, though plaintive and even mournful melody, with which they have soothed the labours of their mates during the season of leaves and blooms. In August they collect in larger flocks, on the open places near the coasts of the channel, and soon after they disappear, except they happen to be brought by the wind in the manner that has been stated.

The turtle is a light and slender bird compared with the other species. It is only about two inches shorter, and two inches narrower in the wings, than the rock dove: and yet it is only about half the weight, being from five to six ounces, while the rock dove is from ten to twelve.

The colours vary a good deal with age, but in general the prevailing colours are brown, grey, reddish orange, and black, with the belly and tips of the outer tail feathers white; and in the male, some white on the forehead, and white margins to a patch of black feathers on each side of the neck; the breast, in the male, is tinted with purplish red; and the same colour blends very softly with the other colours of the neck, as they pass from the soft grey of the cheeks to the black and orange of the scapulars. The dusky black fading off through brown to bright orange, at the margins, renders the feathers on the upper part of the turtle much more distinct than those of any of the other doves. The patch of dull red under, behind, and partially round the orange iris is another distinction. The young birds are browner than the old ones, and want the ornamental patch on each side of the neck.

The bird is as mild in its manners as any of the others, and as assiduous in the care of its young. The constancy, and 
the mourning for its mate, for which the poets have given it crcdit, are qualitics for which there is of coursc only the poet's license. Though retired, timid, and shy, to pcrhaps a greater degree than any of the other doves, the turtle when caught is far more casily tamed than either the ring-dove or the stockdove.

The note of the turtle is a very soft and mournful coo, often dehivered when the bird is on the ground, and when it is in a close thicket it may be very closcly approached.

The spccies now enumerated comprise all the native pigeons of the British islands, whether resident or migrant. With the cxception of the turtle, they are all resident in nearly the same localities throughout the year, but the habits of some of the foreign species are very different, though not so much so in Europe as in other parts of the world. The grand places for them are between the Oriental Archipelago and New Holland, and bctwcen the northern and central parts of Ame.rica. The multitudes that migrate in those localities are absolutely countless; and the species which frequent the former are numerous, and some of them equal in the colours of their plumage to the very finest of the parrots. The American ones, as they migrate en masse, and are continental at both ends of their journey, are more numerous in the flock than those of the east and south. Their migration is different from the general migration of birds, as they move polarly in the autumn, when the wild berries are ripe. They find ample supplies in that Ultima-Thule sort of country which lies to the northrard of the great American lakes, and also in Canada ; but as the polar sea is approached, there is less food for them, and they are not so numerous. They are thus not sufficiently far to the north for being in the line of the north-west winds, and consequently they do not come so often to the British shores as their abundance would lead us to conclude. But notwithstanding the great difference of longitude, it appears that the principal species, the passenger pigeon (Columba migratorius), does sometimes stray across the Atlantic, for one was shot in Fifeshirc on the last day of 1825, and it evidently 
retained its social instinct, as it found its way to a part of the island where pigeon-houses abound, and was shot while perching on the wall of one.

The particular history of the several varieties of fancy pigeons which are known to the curious in these birds, does not come within the scope of these pages, as those varieties are not met with in a wild state. They are, however, probably all bred out of the same stock as the common pigeons, as they are all "house" pigeons and not perchers. The principal ones are the Barbary, the Biset, the Carrier, the Crested, the Helmet, the Horseman, the Jacobine, the Laced, the Norway, the Rough-footed, the Shakers, broad-tailed and narrowtailed, the Smiter, the Spot, the Tumbler, the Turbit, and the Turner, besides a countless number of mixed breeds. 


\section{ORDER IV.}

\section{ACCIPITRES.}

RAPACIOUS BIRDS, OR BIRDS OF PREY.

WE are now to notice birds of very different habits from those of the preceding orders. They, though some of them are courageous in their combats with each other, and most of them are bold in defence of their young, are peaceable toward the rest of the warm-blonded creation, whether living bird or quadruped. Instances have occurred of some of them killing mice, and even small birds, and the greater part of them will eat any animal garbage, or offal ; but they are killed in many more instances than they kill; and the flesh of all of them is not only eaten, but highly prized for its wholesomeness and flavour.

The birds of prey are, on the other hand, of no use to man as food, and they live by rapine and plunder, for the perpetration of which they are very powerfully armed by nature. They never use their weapons for mere purposes of gallantry and mastery, as is the case with many of the males among. the gallinaceous birds. They attack that they may kill; and kill for no other purpose than that of eating the slain. In a natural point of view, we cannot call them cruel; for it is no more cruel in an eagle to eat hares, than it is in a hare to eat green leaves, and no more cruel in a hawk to eat pigeons, than it is in a pigeon to eat pease. All the creatures which nature produces, obey equally the laws which nature has implanted in them; and for the purposes of nature, the fiercest bird of prey is as important as the gentlest warbler that sings in the grove. All work beautifully together and support one 
another, so as to produce and continue that glorious system which we see around us. The plant collects the first clements of organic life from the earth, the air, and the waters; and tempers them to the palates of the phytivorous animals, from the smallest creature that curls or discolours a leaf, to the tall giraffc and the stately elephant. Other races consume those. Some birds take the eggs of the insects, some the caterpillars, some the full grown insects; then follow the races which plunder the nests of birds, and fced upon their unfledged young; and lastly, come the birds of prey, feeding not merely on the other birds, but on the smaller quadrupeds and the inhabitants of the sea.

It may happen that the birds of prey interfcre with our plans, though it is probablc, that in their case as well as in that of many other birds, we know the evil but not the good; and consequently, in our eagerness to destroy the evil, we destroy the good along with it, and in the end lose much morc than our labour. We set a price on the brush of a fox, or the talons of an eaglc, but it is open to every man's observation, that those places in which foxes are not hunted or eagles shot, are not more impoverished than those in which both are destroyed with the utmost vigilance. Nature never sends any animal to inhabit a district, unless there be food and the other circumstances which suit that animal in that district; and when the food ceases or the circumstances are changed, the animal disappears, as fast probably as is necessary to the best interests and perfection even of our artificial system. The kite would doubtless be a plundercr in the poultry-yard, the osprey in the fish-pond, or the eagle in the rabbit-warren; and the owner might claim thcir lives. If we actually use any portion of the earth, then that portion is ours, and we may do with the wild creatures as we deem best. But we should not play the tyrant with that which is not ours. If we can show that it will be useful for us to destroy the kite in the wide moor which we neglect, and the eagle in the mountain ravine, which we can neither stock nor cultivate, then we may plead our privilegc as lords of the nether 
world, and slaughter them; but if we cannot, we are interfering with, and most probably marring, that which we do not understand, - acting much in the same manner as the owner of an estate, who should cut down the forests, when he could neither use nor sell the timber, nor yet cultivate any other crop on the land which it occupied.

The birck of prey are not merely a part of the system of nature, but one of the most interesting parts of it; and there are no birds, the haunts or the habits of which are more calculated to impart information and afford pleasure. In strength, in swiftness, in bold daring, in patient endurance, in attachment to each other and to their young, and in the utmost perfection of observing power and muscular strength, there are no birds equal to the birds of prey. Drive the eagle from the mountain, and half its sublimity would be gone; chase the owl from the ivied ruin or the hollow tree, and half its fascination, even to the unobservant rustics, would be destroyed.

SENERAL CHARACTERS AND DIVISIONS OF THE BIRDS OH

PREY.

The characters in which all rapacious birds agree, and by which, if any one is well known, all others may be determined, are peculiar and striking. The bill is short, strong, rather compressed at the sides, often bending for its whole length, and hooked at the extremity of the upper mandible. The limbs very strong and muscular, with the toes, three before and one behind, free, or only partially united by elastic membrane, their extremities armed with sharp crooked claws, generally retractile, and of firmer consistency than any horny productions, except the claws of those carnivorous beasts which catch or kill their prey with the paws. The bills are usually called beaks, and the claws talons. Sight keen and piercing, in some adapted to bear the strongest light of the sun, and in others to see in the twilight, or to our observation nearly in the dark. They are capable of enduring hunger longer 
than any other of the feathered tribes, and they rarely drink. They are strictly monogamous, the pair associating for life, and probably better deserving that praise for constancy which poetic fancy has awarded to the turtle. They never congregate in flocks; and the more powerful ones drive their progeny to a distance, obviously from an instinct having a purpose similar to that which make the males of the wild gallinæ fight and separate at the commencement of the breeding time. The female is larger than the male, sometimes much larger, and very different in colour. The young birds also are generally different in plumage, and some of them retain the difference so long that they have been described as distinct species.

As is the case with beasts of prey, and generally with all inimals whose nature it is to kill and destroy, the most powerful are found in the wildest places; but while the powerful beast lurks in the shade of the forest or the jungle, the powerful bird braves the elements, and is found in the cold latitudes, or if warm latitudes, in those wild places which are cold and bleak from elevation.

The following are sketches of the beaks of three of the order, in their gradation from those that strip their prey entirely of its feathers, to those that swallow it entire, and return the indigestible parts in balls called "castings."

RAPACIOUS BEAKS.

Hawk.
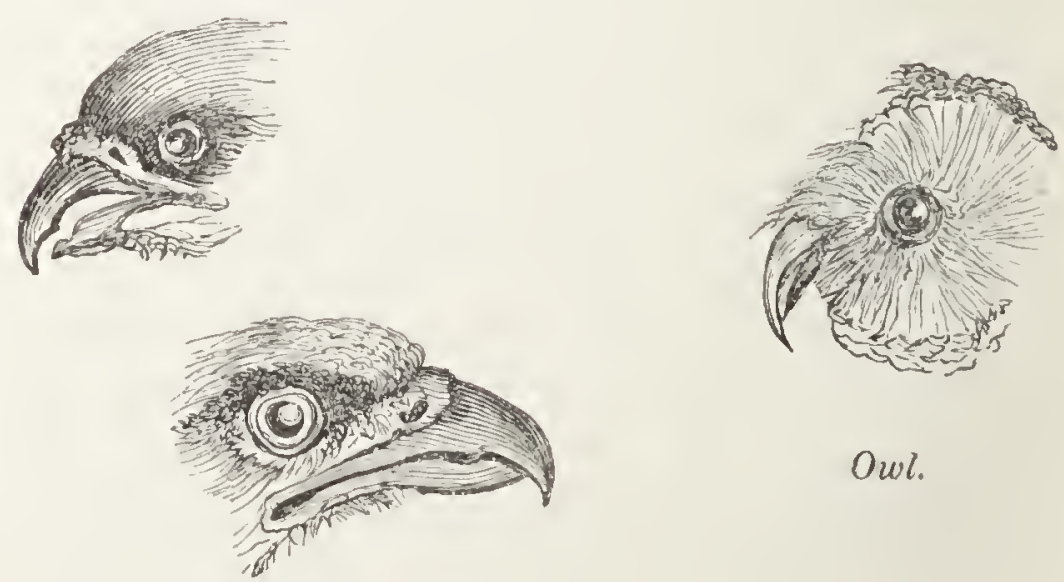

Eacrle.

Owl. 
The most obvious natural division is into preyers by day (diurne), and preyers by night (nocturnc). The former are falcons, known by different names, according to their structure, habits, and haunts; the latter are owls. The plumage of the diurnal birds is firm, strong in the individual feathers, and fitted for contending with the elements in bold and daring flight; that of the nocturnal ones is "fined off" at the extremities, into very delicate and almost invisible margins, so that they steal through the air without any noise. The former are free and elastic, and make the air rustle to the torrent of their course, and ring to the dash of their wings; the latter glide along as if they were muffled, and come upon even quickeared prey before it is aware.

There are about seventeen diurnal species enumerated as British, and eight nocturnal ones. Of the falcons, four or five are understood to be occasional visitants, and the others to reside permanently in some part of the British islands; but some are rare and confined to particular districts, while others are common. Six of the owls are inhabitants of the moorland; and two, which are arctic birds, and the most powerful of the whole, are found only in the extreme north, or in other parts of the country as mere stragglers.

\section{Falcons (Falco).}

The old division of noble and ignoble hawks, which was so well understood when falconry was a general field sport, is still of considerable use in distinguishing the species and also the habits of birds of prey. The noble hawks are longwinged, and have the second quill the longest, but it is supported to nearly its tip by the first, so that the point of the wing is peculiarly strong. These may be considered as the perfection of mechanism in birds, more powerful in the air than any others; and the daring of the larger ones is equal to the means with which they are provided for putting that daring into execution. The ignoble lawks have the wings E 4 
differently formed. They are, in general, shorter, and the third or fourth feather is the longest. As British birds they are more numerous and varied than the former; and comprehend, among others, the eagles, which though less gallant on the wing, are, all things considcred, the most powerful of birds.

The popular distinctions are, however, better for simple description, and certainly not worse for scientific purposes. According to it the divisions are, Falcons, Hawks, Eagles, Kites, Harriers, and Buzzards, all easily distinguishable from each other by their forms, their modes of flight, and many of their habits.

\section{FALCONS .}

The beak of the Falcon is short, very thick, and strong, the upper mandible bent from the base, and with a prominent tooth toward the top, which fits into a notch in the under mandible. The tarsi are short, and they and the toes are very strong. The talons are much hooked and exceedingly sharp, and flat ol groored on the under sides.

Their command of the air is truly wonderful. A few strokes of their powerful wings will send them up till they are hardly visible; or bring them from the top of their flight to within a short distance of the ground. At times they will ride motionless, as if they were anchored in the sky; and anon, with hardly any perceptible motion of the wings, they will shoot, with the rapidity of a meteor and the certainty of an arrow, -aye more certainly and at a farther range than ever shaft that human archer set on the string. The collision of their pounce is terribly effective. It is seldom the mere difference of velocity; for their habit is to rise above their quarry, and press their weight into the service of their wings by an oblique descent; but still that is no mean force which can break a wing, strike off a head, or burst a bird asunder, when it is not merely suspended in air only, but in rapid motion away from the striker. If the falcon misses, 
we need not wonder that the quarry eseapes before it ean again rally; and if the falcon comes upon the bayonet charge of the quarry, as is somctimes the casc when it stoops at the heron, we need not wonder that it is transfixed. The ballistic pendulum used in cxperimental gumncry, though suspended on hinges, grives way to the camnon shot; what then shall we say of the stroke of the falcon, which breaks bones flying away in air, and defended by fcathers. The keen point of the claw,--of that terrible claw on the hinder toe, which eoncentrates the whole momentum of the bird, and always strikes perpcudicularly and penetrates, - is the main instrument of the effect.

THE JER-FALCON, or ICELAND FALCON (Falco Icelandicus).

If, in eommand of the air, the faleons take the lead of all the feathered tribes, the jer-faleon unquestionably takes the lead of all the falcons. It is bred in the crags of the polar rocks, it is tempered to the fitful and furious blasts which rage occasionally in countries near the icc, and its native pastures are but thinly stocked; but a partridge on a warm and sheltered farm, or a pheasant in a judiciously situated preserve, is not better adapted for finding its food, than the jer-falcon is in the wastes of Iceland.

It has not becn positively ascertained that the jer-falcon brecds in any part of the British islands, neither can the fact of its so brceding be denied, because, in all places, its nest is situated so high among the crags of the rocks, that it is difficult to be seen, and still more difficult to be reached. But if it does not breed thcre, it pays occasional visits to the northern and wcstern isles, more especially to those places of them that abound with rock-doves; and few sights can be fincr than that of the jer-faleon driving through a flock of these. When the falcon eomes within sight of her prey, she bounds upwards, every stroke of the wings producing a perpendicular leap, as if she were climbing those giant stairs into which nature moulds the basaltie rocks; and when she 
has "got the sky" of her prey to a sufficient height for gaining the necessary impetus, her wings shiver for a moment as she works herself into perfect command and poise, and to the full extent of her energy. Then, prone she dashes, with so much velocity, that the impression of her path remains on the eye, in the same manner as that of the shooting meteor or the flashing lightning, and you fancy that there is a torrent of falcon rushing for fathoms through the air. The stroke is as unerring as the motion is fleet. If it take effect in the body, the bird is trussed and the hunt is over : but if a wing only is broken, the maimed bird is allowed to flutter to the earth, and another is marked out for the collision of death. It sometimes happens that the mountain crow comes in for the wounded game; but in order to do so it must proceed stealthily along the ground, for woe betide it if it rises on the wing, and meets the glance of the falcon. The raven himself never scoops out another eye, if he rises to tempt that one; and it is by no means improbable that, in the early season, in those cold northern countries, when the lambs are young and the flocks weak, and the crows and ravens prowl about blinding and torturing, the jer-falcon may be of considerable service to the shepherd.

Though the distance from Iceland to those parts of Scotland and the isles where the jer-falcon is seen be about five hundred miles, that is merely a morning journey for the bird, from which it can easily return the same evening. Its flight on long journeys is not so well ascertained, and probably not so swift, as that of the peregrine; but still it is certainly more than one hundred miles an hour; so that the bird can easily leave Iceland in the morning, dine and take its siesta in Sutherland or Ross, and return to Iceland before night.

Like the golden eagle, the jer-falcon is found only in the wilds, and therefore its habits in a state of nature are much less known than those of many of the tribe. In those parts of Scotland where it is most likely to be seen, it is difficult to say whether you would have longer to wait for a fair day or a jer-falcon. 


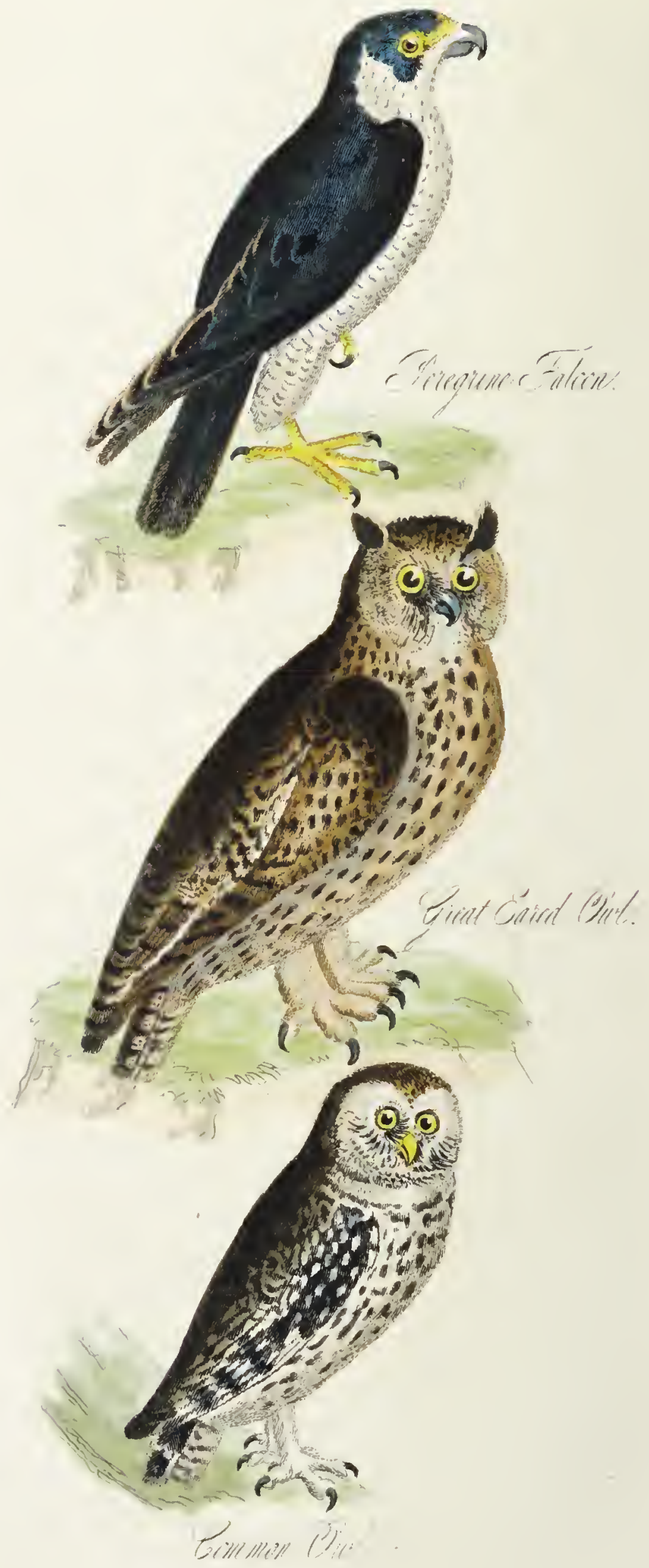


The jer-falcon is a large, strong, and rather weighty bird, very close and thick in its plumage, and altogether perhaps the most compact of the birds of prey. Its length is about twenty inches, the stretch of its wings nearly four feet, and its weight at least two pounds. The colour is very much like that of the lichens on its native rocks-white, dull grey, and dusky. The neck, breast, bclly, and long feathers on the legs are white, with dusky lines on the neck and breast, and similar lines, interspersed with arrow point spots, on the other parts below. The back and wings are dusky, the feathers margined with greyish white and having large spots of the same colour. The tail, which consists of twelve roundpointed feathers, and is rather long, is darker grey, with black shafts to the feathcrs, and about twelve regular dusky bars. The feet, cere, and naked space round the eycs are bluish yellow, in the mature bird, and inclining to blue in the young. The bill, which has the tooth less prominent than most of the falcons, and a sort of double, is bluish; but the tip is black and so are the claws, and the shafts of the more strong and decided feathers. The young are more dusky than the old, and have the naked parts so much more blue, that they have sometimes been considered different species. The eggs are two or four in number. Birds that pair uniformly, generally lay their eggs in even numbers, though there are, of course, casual exceptions.

The jel-falcon can live in any climate; and from its strength, its daring, and the certainty of its stroke, it is more prized in falconry than any other, but it is very difficult to train; and therefore, in the days of falconry, it brought a very high price.

It is possible that the jer-falcon which abounds in Norway, and the Iceland one, are different species: the latter paler in colour, and more powerful.

the PEREgrine falcon. (Falco peregrinis.)

On the opposite plate, there is a figure of the peregrine falcon (female), one-sixth of the lineal dimensions. 
It is much less than the jer-falcon, but more gracefully formed; and though less terrible and more docile than that, it is withal a very bold and powerful bird. The full-grown female is sometimes seventeen inches long, and more than three feet and a half in the extent of the wings. The male is two or three inches shorter, and narrower in proportion.

The head, nape, a patch under the eye, and the whole upper part of the bird, are dusky, inclining to grey in some parts, and to brown in others; the bends of the wings, and edges of some of the feathers, relieved by greyish white. The rump and tail coverts rather paler and bluer than the rest of the upper part. The tail feathers with rather obscure dusky lines, the one at the point the broadest. The throat, sides of the neck, and all the under parts white, passing into cream colour on the breast and into light grey on the long feathers of the legs, marked with bars and arrow-head spots of dusky. The quills are dusky; and the first one having very little outer web towards its tip, gives the point of the wing great firmness. The male wants the cream colour on the breast, and the upper plumage is more inclining to brown. Naked skin yellow, and irides dark brown; bill bluish, the tip, and the claws, which are very sharp, black. Bill strong, and tooth in it very prominent.

Among rapacious birds, the peregrine falcon more eminently deserves the name of the "poulterer;" because, though it flies at other game, it seems to be placed as the natural regulator of the numbers of these. It inhabits the wilds next in latitude and loneliness of situation to the jer-falcon, and seldom nestles in the low countries, and never in the marshy ones. But it is not so fortified against the cold as the jer-falcon, and therefore its nest is usually found on the sunny side of the mountains. Insulated rocks near the margin of the rich country, and even near the sea, are much more favourite retreats with the peregrine than the fastnesses of the mountains. Accordingly, we do not meet with it beating the summit ridges of the Grampians, but it is very frequently met with on those sccondary slopes where grous are most 
abundant; and it will sometimes take a dash over the farm, and levy its contribution upon the rabbit warren, or even the poultry yard.

The peregrine falcon is one of those birds that appear to be less numerous than they really are. It nestles in wild places; and as the powerful birds of prey are as remarkable for their repose when not preying, as for their boldness and activity when they are, it spends much of its time in quiet, and spends the more, the more abundant that prey is in its neighbourhood. Hence it lives the most in retirement in those places which are the best adapted for it; and, as the smaller hawks and kites are not very fond of it as a neighbour, it keeps its preserve in a great measure to itself.

Its onward flight, from the length of which it gets its name, is exceedingly rapid. Montagu says, as much as 150 miles in the hour; and probably that is not an over estimate; for there is no high-flying bird, of any thing approaching to its size, that gets so soon beyond the range of the eye, as the peregrine falcon. Its pointed wings, too, enable it to turn and double with much ease; so that escape from it by any bircl on the wing is exceedingly difficult. The peregrine falcon strikes with the beak as well as the talons, though not so generally as the smaller hawks; and it also strikes birds as well as small quadrupeds upon the ground; but its common habit is to strike them on the wing, and it often gives chase at very long distances. Its proper game, the gallinida, from the heaviness of their flight, and the difficulty they have in turning, are soon dispatched, and the chase seldom lasts a minute: but with pigeons and ducks, and other birds that have much command of themselves in the air, it is generally of longer duration, and has been known to extend, including doublings, to nine or ten miles, performed, including the turns, at the rate of about a mile in a minute, and at double that velocity, or more, upon the stretches. The heron is the hardest game for the falcon, because of the height at which the beron flies, the consequent difficulty of the falcon getting above him, and the smali power which it has over any bird 
that is not lower than itself. The heron strains hard to keep the sky of its enemy, because, while it can do so, it is perfectly safe; and when it is mastered in that, it has still the resource of charging by doubling back the neck, and projecting its sharp-pointed bill upwards behind the wing. That serves a double purpose, preserving the head and neck from the stroke of the falcon, and also presenting a point upon which, if the falcon should come, slee would be transfixed, and the heron escape in safety. In these cases, the falcon strikes at the wing; and if the stroke takes effect, and the bird descends, the falcon follows, and strikes again at the head or neck, and soon brings the heron lifeless to the ground. The rush of the peregrine is perhaps not so tempestuous as that of the jer-falcon, which has altogether more of the habits of the eagle; but its style of fight, especially when on the chase, is much finer. There are many instances recorded of the amazing power of flight in falcons; one of the most remarkable is that of one belonging to Henry IV. of France, which was found in Malta, 1350 miles from Fontainbleau, within twenty-four hours after quitting the latter place.

The peregrine, as possessing the greatest courage, power, and tractability jointly, is the falcon par excellence of the falconers. The fulcon always means the female, and the male is called the tercel. When one year old, and before the plumage acquires the grey that characterizes the mature bird, the female is called a red falcon, and the male a red tercel. When fully plumed and trained, (and she has not her full superiority over the male till in her mature plumage,) the female is the gentil, or gentil falcon,-so called, partly from her docility, and partly because she never turns " down the wind," or stoops to ignoble game, as some of the other hawks, and even the tercel peregrine, are apt to do. The name gentil, which is the opposite of "low" or "vulgar," was, however, applicd to all good hawks, even to some of the short-winged ones, such as the gos-hawk.

Most of the hawks, especially those in which there is much 
difference between the colours of the young and the fullgrown bird, are liable to eonsiderable variations in the general tint and marking of the mature plumage.

The peregrine is exeeedingly bold and daring, and so little afraid of men and $\log s$, that it will sometimes join the hunters in the lower moors, and, if no shots are fired, strike and carry off a portion of the game. It was, in all probability, that habit which first led to the training of it; and those who are fond of field sports must, in these eases, regret that the faleon is not, as in the olden time, their servant, and not their rival. As to the mere slaughtering of birds, the gun (with a tolerable shot) probably kills more in one day, than the faleon would in a week: but the falcon kills the birds when they are stronger on the wing, and in better condition; and the sport, from the beautiful aetion of the faleon, is much finer. One regrets, therefore, that it has beeome unfashionable in the real sports of the field. To let birds fly from the hand, in order that they may be pouneed by the faleon, is probably cruel, and eertainly vulgar, just as it is to turn out a tame buek to the hounds, or let the birds from the trap, at that most ignoble of all killing sports, a pigeonmateh; but, when the birds fly strong and the faleon is sure and true, in wild nature it is indeed glorious sport; though sport whieh those who are grinding the flesh of a lamb that fell by the buteher's knife feelingly designate as eruel.

the lanner (Falco Lanarius.)

Bears some resemblanee to the peregrine, but it is smaller. It is said to be abundant on the southern slopes of the Carpathian mountains; but its appearance in Britain, even as a straggler, is rather doubtful.

тне новву. (Falco subbuteo.)

The hobby is a bold and beautiful little bird,--the peregrine falcon in miniature, in form and habits, only more 
deeply tinted and rich in its plumage. In wing, it is proportionally even more powerful than the peregrine, the wings being a little longer in proportion, and when closed extending beyond the tail. Its length is about a foot, its breadth two feet three, and its weight less than half a pound.

The naked parts of the hobby are yellow, the bill a blacker blue than that of the peregrine, and the irides reddish orange, which gives the eyes a more fiery expression-an expression more resembling the eyes of the jer-falcon, than the brown irides of the falcon. The upper part of the bird is greyish black, the feathers relieved by a higher shade at the margins, and having a sort of bronzy gloss. The chin and throat are white, and the white is broken on the sides of the neck. The belly is dull orange, and that and the breast are, in the male bird, marked with pretty large dark spots, often crescent or arrow-head shaped, as is common in the markings on the under sides in all the hawks. The thighs and under tail coverts are buff-orange; the tail feathers are greyish black, with bronze spots on their inner webs; and the quills are dusky black. As is the case in the peregrine, the middle toe is very long and strong, and acts immediately against the hinder one.

The hobby is a summer bird of passage, and it is the only British bird of prey that is so. It arrives in April, and soon after begins to build its nest, which it does in lofty trees; but it sometimes arails itself of the deserted nest of some resident bird that builds earlier, such as the crow or the magpie. The eggss are from two to four, which appears to be the average minimum and maximum of the whole tribe. The young, which have more reddish orange or bronze in the back than the old birds, are fully feathered by the beginning of September, and in October the whole depart to warmer climes.

The hobby is a local bird with us, being confined to $\mathrm{Eng}$ land, and seldom reaching northward of the central heights of that part of the island. It is the contrast of the peregrine falcon in its favourite haunts, and is as strictly a bird of the 
cultivated land, as that is of the open wilds. It nestles in the wood, indeed, and often in the depth of the forcst if not very extcnsive; but it haunts in the fields, and though one would be apt to suppose that, as it comes with the summer birds of passage, it should fced on them, yet its favourite gamc is the lark, which it assails even at its grcatest height in the sky. That height is indeed often so considerable, and the one bird so intent on capturing, and the other on escaping, that their mancuvres can be better seen than most chaces by birds of prey. The hobby has to keep the lark both up and down; for if there is good cover on the ground, the lark can drop like a stone, and be safe; and if the lark can keep above the hobby, it is pretty safe also. On walking across a tufted field, or by the side of a common, one may sometimes observe a lark falling as if shot, only thcre is no turning, and no flutter of the feathers; and when it does so fall, although at a very little distance, (and one would be inclined to think that it falls near a person or an animal grazing, in order that these may scare the pursuer,) it cannot easily be seen; and if it is, it has squatted so close, and is in a state of such violent palpitation, that it may be taken with the hand. If a lark is found acting thus, there is very generally a hobby to be seen, darting off in that indignant manner which birds of prey show when they lose their game. At pairing time, the larks drop in a similar manner; but that is earlier than the arrival of the hobby : and when they alight they may be seen running along, or heard " churring" an end of thcir cxhilirating stave.

When the hobby so far gets command of the lark as to keep it to his height, and that is generally the case, the chace is often rather a protracted one. The lark is not, in proportion, so well winged as the hobby; for the lark has wings only for one tenth the wcight of that bird, and its weight is about a fifth; but still the lark is a bird of no mean flight. On a strctch, it would soon be overtaken; but it wheels and doubles, and often throws the pursuer out to a considerable distance. But the hobby has an excellent cye, and not only makes up rapidly, but actually turns the wheelings of the lark to account, 
by crossing to meet it on the return ; and as fear and exertion together wear out the lark, the hobby dashes in by a desperate effort, and the lark is no more.

The hobby also flies at snipes, young partridges, and many other birds. It is bold, can continue a long time on the wing; and, though light, it acquires no small force from the rapidity of its motions. The hobby was one of the noble hawks, and, for small game, a very favourite one.

\section{the merlin. (Falco cesalon.)}

The merlin is another of the small falcons, but, like the hobby, very bold and rapid on the wing; and it is more remarkable for the difference in colour between the two sexes, than any of those already noticed. The prevailing colour of the male on the upper parts is greyish blue, with black markings, and the shafts of the feathers black. On the under side it is white on the breast, passing into salmon colour toward the sides of the neck, and on the belly and long feathers of the legs marked with lines, arrow-head spots, and lines of dusky. The lines are most conspicuous on the under sides of the quills, the spots on the flanks and belly, and the sides of the neck. Tips of the tail-feathers white; about an inch within that, dusky black; the rest of the feathers bluish grey, with dusky bar's on the inner webs. The bars vary considerably in number, and, indeed, the colour of the whole plumage is subject to considerable variations. That might be expected from the difference that there is between the colour of the young and the mature bird; for when that is the case, the male plumage sometimes stops at one of the intermediate stages, and has often led to an unnecessary multiplication of the species.

The female merlin is quite a lady's hawk, and would remain so, if the dames of England were again to temper their beauty in the autumnal winds, and so secure the full life-rent of it undisturbed. It is a little and a light bird, and for spirit there is no comparison. The naked parts are lemon yellow, irides 
hazel, and the bill, which is beautifully shaped, dark blue; head mottled brown, with a white patch round the eye, divided by a longitudinal dusky line, which makes the upper part of the white appear like an eyebrow. The white on the neck nearly forms a collar, lined in front, and dropped on the sides with brown. The under parts, white, brown, and grey, with dusky spots, the markings continued under the wings. The upper part, grey brown, and dusky, finely mottled. The tail, which is peculiarly handsome, contains one dusky feather in the middle, those at the sides brown, with white tips, and very regular bars of very pale reddish brown. When the wings are half raised, and the tail partially spread, the merlin falcon is perhaps the handsomest of all hawks. The whole length is nearly the same as that of the hobby, but the spread of the wings is two inches less; the tail is, however, more than an inch longer, so that, weight for weight, the merlin is the better winged bird of the two. The weight is not six ounces, that of the hobby is about seven.

The merlin is a resident bird, and described as being rather rare, though probably it is more abundant than is generally supposed; its habits and its small size tend to make it less generally seen than many other birds, which, though they come more into sight, are really less abundant. In the breeding season the merlin frequents the bleak moor, and constructs its nest in stony places, and sometimes, though rarely, in a bush. Its eggs are more numerous than those of the larger falcons, being sometimes as many as six. The birds are not, however, numerous in proportion to the eggrs; and hence it is supposed that, in the absence of the female bird, they are sometimes destroyed by crows, and probably by weasels. The stony moors in the south of Scotland and north of England, with some parts of the Welsh mountains, where small birds are more plentiful than in more elevated and remote places, appear to be the favourite haunts of the merlin. But the time when the merlin is on the moors is the time when they are little frequented except by the shepherds, and they, though generally shrewd observers of the 
weather, do not pay much attention to natural history. By the time that autumnal sporting commences, the little birds have mostly flocked, and come down either to winter in warmer and more abundant pastures, or preparatory to their departure from the country. The merlins accompany them as far as the southern parts of England, and probably, in many instances across the channel; but they preserve their retired habits. As both prey and preyer fly rapidly at that season, the merlin is not very often seen, and as it gives chase in long flight, and does not beat like the short-winged birds of prey, it vanishes almost as soon as it is got sight of.

\section{THE kESTREL. (Falco tinnunculus.)}

The kestrel, though much less bold and noble in its hunting than the merlin, is a very beautiful bird; and it is one of the most common of all our birds of prey. It is also little, if at all, destructive of game, unless when they are in a very young state, so that its manners do not so much expose it to persecution, except that general persecution which it receives on account of being a hawk.

The kestrel is of the same weight as the hobby, and has the same extent of wing, but it is two inches longer, and altogether a more slender bird, and weaker in the beak and the talons. The female, which is the finer and larger bird, is reddish brown on the whole of the upper part, with arrowhead, dusky spots on the head, back and wing coverts, and dusky bars on the tail, the last one broad, and the tips of the feathers margined with cream colour. The quills which are twenty-two in number, are dusky, relieved by white margins. The under part is reddish cream-colour with indistinct dusky lines. The male, after the first year, during which it very much resembles the female, has the head and tail grey, the back brighter red and with fewer spots, and the under part redder, and the spots more distinct. It also has the feathers on the chin more produced, and a black stripe proceeding 
from the gape, which gives the light grey above the eye the appearance of an eye-brow.

The eye of the kestrel is peculiarly brilliant; the irides are rich brown, which contrasts well with the dark stripe and the pale feathers at the base of the bill and over the eye. The bill is very short, and the notch nearly obliterated, and there are two rows of small teeth pointing downwards upon the palate, not unlike those with which the tongues of the beasts of prey are besct. The whole structure of the bird indicates that it is less adapted for pursuing winged game, pulling feathers, and tearing flesh, than the other longwinged hawks, and its habits correspond with these differences of structure.

Popular names are often much more expressive of the lhabits of animals than those which have been adopted for scientific purposes, and that is peculiarly the case with the kestrel. Two of its popular synonymes are, the "stannel" and the "wind-hover ;" and these, which by the way have nearly the same meaning, are remarkably descriptive of the action of the bird in the air. "Stannel," or "stand-gall," as it is sometimes pronounced, is "stand-gale," and "wind-hover" is "hoverer in the wind," both of which express that wonderful power of poising or anchoring itself over a particular spot, despite the wind, which the kestrel possesses in greater perfection than any other hawk.

The kestrel is, altogether, an intcrmediate sort of bird; and though it flies moderately high, and of course generally in the day.light, it has some of the habits of the owls. It is, therefore, more worthy of the attention of those who wish thoroughly to understand the characters of birds than some of the more powerful and daring hawks. In onward flight it has not the dash and rapidity of these; but its power of hovering over the same spot, in defiance of the wind, is much greater; and, when that is necessary, it comes down in beautiful style. While it is hovering, the motions of the wings, when they do move, are exceedingly rapid, and the head is bent downwards and turned to one side, so that the eye com- 
mands a considerable circle of ground, over the centre of which it is hovering. We have no reason to suppose that the range of its vision is equal to that of the eagle, because it does not fly nearly so high, or command nearly so wide an extent of horizon; but it is so acute that not a mouse can stir within its range, without the kestrel being down upon it, and pouncing it with the most unerring certainty. Mice and unfledged birds, but especially the former, are the chief prey at which it stoops. It swallows them entire, and thus "casts" more than those hawks which pull feathers and tear Hlesh.

The kestrel continues its hunting to a later hour than those hawks which feed principally upon birds, and in the bright twilights, especially those that break up after showers, when the light is given back again by the clear drops upon the leaves, and the larger beetles are numerous on the wing, the kestrel may often be observed not hovering to stoop to the earth, but hawking on the wing. Selby, whose selfobserved facts are always worthy of confidence, was among the first to mention its exploits in thinning the numbers of that arch. enemy of the lawn and the meadow, the cockchafer; but it preys equally upon all the larger twilight bcetles and on some of the moths, which it clutches with the foot, and conveys to the bill without pausing in its flight. The smallness and distance of its general prey, require a wonderful power and certainty of eye in the kestrel, and as it preys chiefly upon those animals only which man considers as nuisances, and is anxious to destroy, it is less deserving of persecution than any of the other harvks, even from those who are most inconsiderately prone to persecute the whole race. The brightness of its colours, too, and more especially the gracefulness of its motions, render the kestrel a very interesting bird, and the one which of all birds of prey it is perhaps the most pleasant, and certainly the easiest to study. One would be almost tempted to believe that the birds of prey have an instinctive knowledge when, in the pursuit of their prey, they trench on the province of man. The eagle 
and the jer-falcon never come near human habitations, the peregrine comes rarely, and even the hobby and the merlin are comparatively solitary birds; but the kestrel will come near the dwelling, and if violence be not offered to it, it will hawk about over the lawn or the garden, and assist in the keeping of these. Nature is, indeed, altogether so beautifully arranged, that each creature comes only where it is wanted in order to contribute the most to the harmony and perfection of the whole.

The hitTle grey kestrel, or red-legged falcon ( $F$. rufipes), which is a bird of eastern countries, and very discursive in its habits, has, of late years, been occasionally shot in Norfolk. The male has the back deep ashen grey, and the belly and thighs red: the female has the back grey with black spots, and all the under part reddish.

HAWS.

The hawks are shorter winged than the falcons, and have the longest feather farther into the wing-the fourth being the longest and the first very short, and the wings when closed, seldom reaching beyond the middle of the tail. They are not therefore capable of such prolonged flight or graceful turning in the air as the falcons; but their direct flight is very rapid, though fluttering: they are bold and courageous; and they strike their prey upon the wing. Though not so far-sighted as the falcons, they see more perfectly within their reach, and their habit requires it, as they see their prey against the ground (which often resembles the prey in colour), while the falcons see theirs more against the sky. Their claws are much hooked and very sharp, and the middle toe is very long, as compared with the inner and outer ones; but the tarsi are, at least in some species, long and slender, and the whole body is less indicative of power than that of the falcons. They nestle more in trees, and frequent wooded places more than the falcons; but some also build in rocks. The notch in the hawk is not so conspicuous; but the beak is more used as a prehensile instrument. 
THE Gos-HAwк. (Falco palumbarius.)

The gos-hawk is an exceedingly bold and powerful bird, and in the days of falconry it was much used for flying at "low game," that is, game which remains on the ground, or does not rise very high above it, such as hares, rabbits, wild ducks, and the wild gallinidre.

The gos-hawk is a longer bird than even the jer-falcon, but the superior length is in the tail feathers rather than in the body; and it is shorter in the wings and altogether less compact and powerful, while it is not nearly so elegant as the peregrime; but still it is a very fine bird, and justly entitled to be considered as the model of the short-winged or lowflighted hawks. In the full grown female, the general colour of the whole upper parts, the ear coverts, and a streak contimued thence to the shoulder, is blackish brown, the back mottled, the edges of the ear coverts relieved, and the quills and tail feathers margined with light tints of reddish brown. Between the nostril and the eye is grey, and the rest of the under part white, with numerous arrow-head spots and lines of brown, which are very delicate on the long feathers of the legs, and obscure or wanting on the vent and under tail coverts. The tail and tail feathers are obtuse-pointed, and tipped with white. The colours though not showy are well contrasted. The naked parts are yellow, the irides grey, and the eye very quick and penetrating. The male has the top of the head and the neck much lighter, and a reddish tinge over the greater part of the body. The spots on the under part are also fewer, much paler, and generally of an oval shape. The male is not abore two-thirds of the length of the female, is not nearly so well shouldered or winged, and altogether a very inferior bird. The gos-hawk is not so prolific as the smaller falcons and hawks, the eggs seldom if ever exceeding four. The young are much more of a red or rusty colour, especially on the under parts, than the mature birds. They pass through sereral tints of plumage, and as is the case with most birds 
which do that, the permanent colour which they at last take is not uniform. Sometimes they are (the males especially) nearly white, and at other times the same sex is tawny with few markings.

The favourite dwellings of the gos-hawk are the extensive wooded dells of the mountains or the wild cliff's on the sea shore, where it can nestle undisturbed and yet be within reach of places abounding with the large birds and small quadrupeds on which it feeds. But it is one of those birds that flit before the progress of cultivation, and hence it never builds and is rarely seen in the Lowlands of Scotland, and more rarely in England. In inland places it builds in the forests, and is generally found near these, because large birds are much inore abundant there than on the open wastes. The remains of the natural pine forests, on the east part of the Grampians between the Dee and the Spey, in Strathglass, and in some of the glens that open irito the line of the Caledonian canal, are the favourite inland haunts of the gos-hawk. It is probable, also, that the extensive artificial plantations in Athol, Moray, and other places, may have brought it back, though not in great numbers. Where the gos-hawk abounds, it is very destructive to mountain game, especially in close time, when it kills the old birds, and the broods perish. The gos-hawk is docile, and not difficult to train. It was on this account called a "gentil" falcon, at least in some of its plumages. Though its action is not so grand as that of the falcon, there is a great deal of stir and energy about it, and it is nowise inferior as a "pot-fowler," if the ground for it be judiciously chosen. The gos-hawk is found in the wild parts of most countries, with the exception of low marshy ones.

THE SPARROW-HAWK. (Falco nisus.)

Though this hawk is bold and daring enough to come near the house for the purpose of killing sparrows, yet sparrows are not its only or even its favourite game. It is a 
very general and successful destroyer; and, in the female especially, by no means destitute of power.

The difference in size between the sexes is not quite so great as in the gos-hawk, - the male being only one-fifth less than the female, the length of which is about fifteen inches. The female is, however, a far more compact and powerful bird, and her additional weight is much more than in proportion to the length.

There is some resemblance to the gos-hawk in the general shape and air of the body, as well as in the general colour and markings of the plumage, and in the male being redder on the under part than the female. The upper part of the full-grown female is blackish grey, barred with darker, and mixed with brown on the back and shoulders; the ear-coverts and sides of the neck brownish, with a mottled white band passing from the forehead over the orbit of each eye (which is very prominent,) and nearly meeting on the neck. The under part is white, tinged with brownish on the belly, and marked with transverse brownish bars. The irides are bright yellow, and the naked parts pale, the tarsi being very long and comparatively slender. The male is nearly similar on the upper part, but wants the white on the head and neck. They build in thick bushes and low trees, sometimes forming a rude structure of twigs for themselves, and sometimes making use of the nest of some bird that breeds earlier. The crow tribe, and those other birds that agree with them in the habit of plundering nests, are among the earliest breeders, and have their young about the time that the generality of birds are laying their eggs. Birds that prey upon other birds breed later, and when they nestle in the same places as they hunt, as is in so far the case with the sparrow-hawk, they often occupy the deserted nests of the egg-stealers.

Sparrow-hawks, from their general distribution, their daring, and the voracity of their young, kill a vast number of birds, probably more than any other birds of prey; and 
these not merely little birds, but birds of large size and powerful wing, such as the lapwing, the snipe, and the pigeon. While the gos-hawk keeps to the large and lonely wood, the sparrow-hawk is the plunderer of the coppice, the hedge-row, and the corn-field; and it is more incessantly on the wing than any other bird of prey, and perhaps strikes more forcibly in proportion to its size and weight.

Both species of hawks are very indiscriminate in their slaughtering, and do not, it is said, spare even the weaker ones of their own species; for that reason, it is difficult to rear males and females in the same cage, as the latter are very apt to kill and eat the former.

The hawks resemble the falcons in many of their characters, and also in generally pouncing upon their prey on the wing; but they differ in their lower flight, their shorter and rounder wings, their bill not curving so sharply at the base, and being without the prominent tooth of the falcons. They differ little in activity, or if they do, the hawks are probably on the whole more active than the falcons.

There are two other divisions of rapacious birds, which agree with each other in their very low flight, and in striking their prey upon the ground, but differ essentially in many parts of their characters. These are Harriers and Buzzards.

\section{HARRIERS.}

The harriers are birds of considerable size, power, and extent of wing, very indefatigable in their hunting, and highly destructive of the feathered tribes, and also of rabbits. They have not the grandeur of the falcons, neither have they quite the vigour of the hawks; and they are not so powerfully armed as either of these. Their beaks and feet are more feeble, and their claws smaller; they fly very low, and strike their prey on the ground, that prey consisting more of young birds and of females when they are sitting, than that of the 
hawks, as the prey of the hawks consists of less powerfully winged birds than that of the falcons.

It is from this habit that they get the name of " harriers," which is synonymous with that of plunderers. They are also sometimes called "harpies;" and as they often beat the bushes so low that their feet touch, it is possible that they may have given rise to some of the fabulous accounts of griffins, one of the characters of which was supposed to be a combination of the functions of walking and flying. The harriers do not combine these; but they fly so near the ground, and have their feet so ready for assisting in the capture of any prey they may spy, that they often appear as if the feet were concerned in assisting their motion.

It was mentioned that the kestrel, which often pounces upon its prey on the ground, has more power in turning the head so as to take in a horizon all round it than those birds which strike in the air; and as the harriers fly lower than the kestrel, and consequently take in a smaller horizon, they are still better furnished with the means of narrowly scrutinizing that horizon.

The majority of the diurnal birds of prey have the eyes placed so far backwards laterally that they cannot see the same object with both eyes, unless it is at a very considerable distance; and cannot see right before them without turning the head. As their prey is also rather under them than otherwise, their eyes are, in consequence of the projection of the upper part of the orbit, better adapted for looking down than looking up. But in the harriers the eyes are placed so near each other, that both can be directed forwards; and they are provided with a concha, or circle of feathers radiating from the orbit, less produced and perfect than the same is in the owls, but something similar in structure and use. These appendages are most conspicuous in the hen harrier, which is the one that beats most about the furze, and other close and tangled bushes in which so many birds nestle and conceal themselves. The harriers have the wings and tail more 
produced than the hawks, the wings more pointed, and the tail rounded. There are at least three of them; but some of them are at times called buzzards, though they are far more active in their habits than these birds.

\section{THE heN HARRIER. (Falco cyaneus.)}

The sexes in this species differ so much, both in size and in plumage, that they have often been described as different birds, and some astonishment has been expressed that the female and nest of the grey one, (which is the male,) could never be found. Even in the same sex, the colours are not a little perplexing; for in all birds where there are remarkable differences of plumage in the sexes, and a passage from the plumage of the one to that of the other with the progress to maturity, as there generally is, there are not only always individuals in some of the intermediate stages of the plumage, but there are individuals in which the change never completely takes place, and others in which the plumage of the other sex is partially assumed. Colours vary also with differences of age, situation, and season; so that difference of colour is never a sufficient foundation for difference of species. Similarity of situation and habits are much more to be depended upon. There is, at least in some parts of the country, a further perplexity about these birds, arising from the fact that the ash-coloured harriers, though smaller birds, different in the general tints of their plumage, and local as compared with the hen harriers, have yet similar differences of appearance in the sexes.

The full-grown female hen harrier is about twenty inches long, and three feet and a half in the extent of the wings. The naked parts are yellow, and the irides dark brown. Brown and dusky white are the prevailing colours of the whole bird. The head is mottled brown on the upper part, and the concha round the eye is brown, immediately surrounding that organ, but terminates on a white eyebrow which reaches to the cere of the beak, and it is white below, but terminates in a brown 
border. That appendage gives enfoncement and expression to the eye, perfectly distinct from any other of the tribe. The feathers below are brown, with pale margins, and pass into white at the tail coverts: the upper part is brown, lightest on the scapulars and lesser coverts, and the margins of the feathers are lighter. The tail is brown, with dusky bars, and the quills of the wings very deep brown, inclining to black.

In the male, the breast, head, and all the upper part, are of a fine grey, lighter on those parts of the concha which are white in the female, and also where the brown is lighter in the upper part of that sex. The remainder of the under part is white, with very faint markings; indeed all the markings on the male bird are obscure and faint; but, notwithstanding this, and the difference of size and expression of the eyes, (the irides are yellow in the male, and brown in the female,) the shape and air of the birds correspond exactly.

Though the hen harriers fly low, their flight is very swift, and at the same time smooth and graceful; and they admit of a nearer approach, and can be better seen, than most of the birds of prey. They are not very numerous in any one locality, neither are they very prolific; but they are pretty generally distributed over the country, on the edges of the moors, where they may be seen beating the bushes with much assiduity. They pounce indiscriminately upon birds, reptiles, and small quadrupeds. They are very destructive in preserves, when these contain bushes in which it can nestle. They even pay visits to the poultry-yard, and pounce upon and carry off the chickens. The nest is on the ground, generally at the base of a furze bush, and it is rude, formed of a few sticks; the eggs are without markings, often four in number, but seldom six.

THE ASH-COLOURED HARRIER. (Falco cineraceus.)

The ash-coloured harrier has been observed only on the edges of the dry bleak moors in the southern counties of England. It is of the same length as the hen harrier, but 
has each wing about two inches longer, and is only about three.fourths of the weight. It is thus a bird capable of very powerful flight, and may be a summer migrant. The male is ash-coloured, with a tinge of brown on the upper part, and white below, with an orange-brown streak on the middle of each feather. Primary quills dull black, secondaries ash colour, with obscure dusky bars; tail ash colour, with the exception of the two middle feathers, which are brown. The female is deep chocolate colour above, with pale rusty margrins to the feathers, and a white spot on the neck; below, it is darker than the male, but the rump and tail coverts are white. Eggs not exceeding four, of a pure white, and deposited in rude nests under bushes. The young are similar in plumage to the female; but the sexes differ in size. Like the hen harrier, it is subject to varieties of colour. It is said to prey more on small birds, and to be less destructive of game. Whatever its colour may be, it is easily distinguished from the other harriers by the closed wings extending beyond the point of the tail, while about a third of the tail projects beyond the wings in the hen harrier, and about a fourth in

\section{THE MARSH HARRiER. (Falco rifus.)}

This is the largest and most powerful of the harriers. The female is sometimes about two feet in length, and nearly four and a half in the extent of the wings, weighing, when of that size, at least a pound and a half. The upper plumage is rich brown, with rust-coloured margins; the head, neck, and under part yellowish white, with rusty markings more or less obscure. It is subject to considerable variations of colour, the head and under parts being sometimes nearly pure white. The male is smaller than the female, lighter in the colours, and when old it often turns grey, which does not appear to be the case in the female. Nest generally on the ground, and the eggs pure white. These birds are not uncommon near extensive marshes; but the pairs live apart from each other, except 
sometimes during severe storms, when they resort to the sandy wastes along the sea shore. They fly very low over the marshes, and, from the great length of their wings, they appear larger than they really are. They prey on water birds, on the grallidx, on water rats and mice, on frogs, and even on fish when they can pounce upon them in the shallows. They will sometimes take a turn round houses, if situated near their haunts, and carry off chickens or tame ducks. They also eat carrion, especially the bodies of sheep that perish in the marshes. They are often found beating over rabbit warrens, when these are near marshes or the shores of the sea; and they choose the mornings, and the evenings after rain, when the rabbits come out, at which time they kill great numbers of both old and young. Their flight is rapid, however, and as the marsh is more easily beat than the brake, they are not so often seen, or seen so long at a time as the hen harriers. The mornings, at and a little before sunrise, when the grallidx leave their nests to feed on worms before these get into the earth from the sun, are the best times for observing the habits of the marsh harriers. They are pro. vincially known by many names, such as duck-hawks, moorbuzzards, harpies, and others. They seldom beat over dry places, and are never found at very great elevations.

\section{BUZZARDS.}

The buzzards have some resemblance to the harriers, but they are easily distinguished, both by their appearance and their habits. They want the concha of feathers round the eyes; they have no tooth in the upper mandible; their claws are short, and less hooked than those of any of the other sections; they have the feathers on the legs very long, and the tarsi much shorter than the harriers; and their whole frame seems loose and feeble; though they are bold and powerful birds. There are three buzzards mentioned as British birds; - the common buzzard, which is abundant in wooded districts; the rough-legged buzzard, which is a native 
of colder climates, and comes rarely to Britain as a straggler in the winter; and the honey buzzard, which also is by no means common, and though it brceds in some places, is, in all probability, only a summer visitant; indeed, as it seems to fecd much, if not exclusively, upon winged insects, provisions for it in the winter are but scarce.

the COMmon buzzard. (Falco buteo.)

The common buzzard is a large bird, more than twenty inchcs in length, and four feet in the stretch of the wings; but the wings are neither so well formed nor so fit for rapid flight as those of the marsh harrier. The bird weighs about two pounds; but it looks clumsy.

It builds in trees, the eggs being large, and seldom if ever exceeding four in number. As the places that it frequents abound in game, the buzzard finds its food with less labour than any other of the diurnal birds of prey. It continues perched on some hollow tree, and waits till the prey comes within its reach, and then it leaps down to secure and despatch it. It is, in fact, the only diurnal rapacious bird that preys in the thick of the forests and on the ground in these; and though, when we compare it with those hawks which drive through the air or beat the bushes or the waste, it seems an indolent creature, yet vigilance is its habit, and the only one that is well adapted to the places which it frequents. To beat a forest of tall trees by flying over it, would answer very little purpose, and to beat through the branches would be impossiblc for a day bird that depended on the light of the sun. The habit of the buzzard, thcrefore, though different from that of any of the other diurnal birds of prey, is just as finely adapted to the places which it frequents as that o any of the others; and the peregrine for all its speed, and the harrier for all its diligence, would find but a small supply in those places where the buzzard fares abundantly. The prey which it takes, too, is so situated that man 
could not easily take it; and therefore there would be a blank in nature, a want of something to preserve the balance between animals and their food, if the woodland were despoiled of its buzzards. But when the wood is cut down, and the animals over which the buzzard is set as a sort of regulator are dispersed or betake themselves to more open localities, they meet with new regulators and the buzzard disappears.

Buzzards vary a good deal in colour, but the prevailing tints are, rich brown edged with yellowish brown on the upper part, white on the throat, and yellowish white on the belly, the former marked with streaks and the latter with arrow-point spots of brown, the quills and tail feathers barred with blackish brown.

Besides the general rest and quiet of the buzzard, there is another circumstance recorded of it, which points out the general effect that plenty of food acquirable without much labour has on the habits of birds. The young buzzards are said to remain in company with the old ones for a considerable time after they have left the nest and are able to shift for themselves; whereas most of the other birds of prey soon desert their young, and many drive them away. In consequence of this social habit, the buzzard can be tamed, and, in France, it is said to have been trained to bring up chickens.

the RoUgh-LegGed Buzzard. (Falco lagopus.)

The rough-legged buzzard is a much smaller bird than the common one, lighter in the colours, and with the tarsi feathered down to the toes. It inhabits the pine forests of the north of Europe, and preys chiefly upon small quadrupeds and reptiles. It rarely visits Britain, and then only the eastern parts of the country, to which it appears to be driven by the winds, in the course of its continental migrations. It has not been noticed in Scotland, the coast of that part of the island being so far west, as to be out of the line of its passage. 
THE HONEY BUZZARD (Falco apivorus)

Seems also to be a mere straggling visitant; comes only in the summer, and is found (when found at all) in the southern parts of the island. Its native habitat appears to be chiefly in the eastern parts of the continent, where there are thick and extensive forests, interspersed with pools and streams of water, and abounding with the larger insects. It is more handsome than the common buzzard, with the wings rather longer. in proportion, and its habits are a little more active. It preys upon smaller game,-bees, wasps, beetles, dragonflies, frogs, lizards, and occasionally small birds. Its motion when hawking for its food, especially for dragon-flies near the pools and streams, is very light and gliding; and it slides through the branches of trees with more apparent ease than could be expected in a bird of so large size. It migrates on the continent, and, in all probability, passes the Mediterranean towards winter. Its nest has been seen in some of the forests of the south of England.

The buzzards are all woodland birds, and although they are adapted for and inhabit different latitudes, there is so much similarity and family likeness among them, that one who has seen the common buzzard, can be at no loss in knowing the others, if by rare accident they should come in his way.

KITES.

There is but one species of kite met with in the British islands, the common kite, or glead, (Falco milvus,) but it is by no means uncommon; and its form, the style of its flight, and the depredations which it commits, all tend to bring it into notice.

The lineal dimensions of the kite are very considerable; the wings of the female extend five feet and a half, and the length 
is nearly two feet and a half, but a considerable portion of that is occupied by the tail, the outside feathers being more than a foot long; the tail is also very broad, and much forked. The wcight is about two pounds and three quarters, which is less for the extent of the bird than that of any other of the predatory tribes. The male is considerably less than the female.

The ficathers on the head are dull white, with dusky streaks, which give it a grizzlcd appearance, and that is heightened by the feathers of the neck being pointed. The feathers above arc brown passing into reddish orange and buff toward the edges; the under parts are reddish orange, with dusk-brown stripes on the belly and thighs. Upper side of the tail reddish orange, with white tips; under side reddish white, with obscure brown bars. The female has the general tint of the plumagc more inclining to orange, and in some specimens it is even grevish; so that in some parts of the country, the male is called the " red glead," and the female the "grey glcad."

The kite builds in trees, the nest being concealed in a fork. It is a more carefully constructed fabric than that of most other predatory birds, being closely formed of sticks and the interior lined with wool or other soft materials. The nest is not very often seen, even in those places where the bird is most common. The eggrs are of considerable size, and seldom exceed two or three. The young remain a long time in the nest.

It is doubtful whether the kites are as constant in their pairing as many of the othcr birds of prey. In the early part of the season, males are not unfrcquently seen in desperate combat, thougl combat of no very dignified kind, but rather a sort of scrambling and scratching; and, as it is not the habit of the kite to attack any living creature nearly as large as itself, or indeed any creaturc that can show fight, it is not to be supposed that hunger is the cause of these combats; but that, however ungallant they may be in the style in which they are conducted, gallantry is the principle from which thcy proceed. 
The kite has, from the extent of its wings and tail, very great command of the atmosphere and possession of itself in that element. It does not beat along in straight lines, but wheels in curves, which it is constantly opening and closing, and always in a smooth and graceful manner, without any jerks; and if it were possible to trace a day's path of a kite, it would be a very fine specimen of looped curves. The kite can hover for a long time over the same spot, with very little exertion of the wings and though there is a fresh breeze; and there are times, (probably when it has lost sight of some prize on the ground, or discovered that the prize over which it was hovering was no prize at all,) at which it will " give itself to the wind," and drift to leeward in very beautiful style, and apparently with complete self-possession. Crows often do the same, especially upon the elevated moors, where prey is but scanty, and they have been long contending with the wind. Kites will also sometimes turn down the wind to escape the more powerful falcons, which though they do not attack the kite, often frighten it, and make it lose its prey; and as going down the wind is not a habit of the falcons, the kite gets away from them by the manœuvre. That manœuvre, though held in great contempt by the falcon, is by no means an ungraceful or uninteresting one : the bird rides lightly on the wind, but retains its self-command, so that it can take a new direction whenerer it pleases. The axis of its body is placed at an angle to the wind, which is smaller in proportion as that is stronger; and the windward wing is elevated, so that the wind takes the under side at an angle, and tends to riaise the bird obliquely upward, while its weight presses downward and counteracts. When looked at, the bird always has in these cases the appearance of descending as it drifts. But that is an optical deception; for all things that are higher than the eye, appear to descend as they recede, even though they are rising; and the kite may often be observed to have gained height, while thus appearing to float downwards. If on those occasions an alarn is given, the bird hauls closer to the wind, and makes off. 
A kite overtaken by a whirlwind, though not an every-day sight, is by no means an uninteresting one. The kite feels the first action of the revolving air as if it were a breeze, trims to it, and is borne upward in a spiral which gradually expands as it becomes elevated, till at last the bird escapes to straight flight, and takes its departure, as if not quite certain what may be the matter.

Though kites nestle in woods, they beat about in open places, and generally places where there is not much herbage on the ground. They are seldom seen over corn-fields, or places which are very thickly tangled with bushes, though they often hover on the margins of the brakes, to pounce upon mice, and also upon young birds when these first venture from the nest. The cold swards by the sides of the upland streams, and the upland farms, where the pastures are thin and bare, and any thing stirring on the ground can be easiiy discerned from the height at which the kite flies, are the places at which it is most frequently to be met with. In those situations, it is very destructive to the young of domestic poultry; and so intent is it upon that species of depredation, that it will very frequently carry off a chicken, in spite of the good woman of the cottage and her broom, and plenty of clamour to boot. But though the kite, after it has come in contact with its prey, is not easily driven off, and instances have occurred in which it has been knocked on the head, yet it will not face a brood hen, or even as is said a partridge, when excited in defence of her young. It is an adventurous and greedy thief; but as for courage, it must take its place among the " passive stout," that display their prowess more by suffering than by doing.

A country in what may be called a half.cultivated state, where the fields alternate with naked and cold wastes, and the portions out of crop are covered with scanty natural grasses, or in that state of slovenly and unprofitable fallow, which rivals the intended pastures in verdure-where ragweed and mountain daisies form tufts, equally forbidding to the nose and the palate of the cattle, though these have been 
so anatomised by storms and starvation that every bone in them may be counted, and the crow and the less frequent raven come hopping about as if they already scented carrion,these are the places for the kite. If there are woods in the vicinity, kites will nestle there; and if there are not, they will come from a considerable distance to the pasture. Kites used to be exceedingly numerous in those inland parts of Angus, Kincardine, and Aberdeen, where the land is cold and bare, and the cottages were arranged along the sides of the moors, the owners paying so many pullets as part of their rent. The pullets, with their broods, roamed freely over the cultivated patch of land, where the crop never entirely concealed the clods; and the kite was so common a visitor, that some of the children were generally posted on the watch to "sheu the glead," sometimes armed with a watchman's rattle to assist them in their vocation ; and when by any chance the marauder was caught, he was forthwith nailed upon the most conspicuous part of the hut, in terrorem of all forky-tailed hawks that might in future have the lawless audacity to diminish the sacred and rigidly demanded tale of " the laird's kain hens ;" and many times has the dame "o' gentil bluid" prayed inward maledictions upon the kite, as she sat tugging and planting tooth-ache in both jaws, over the matron pullet of twenty broods, which, in consequence of the alleged havoc of the plunderer, had been slipped into the laird's kain basket to make out the tale. But those days have gone by; the lands are better cropped; the uplands are under cattle and sheep; the laird resides at a distance, and wants not hens, but money; the "latcher-steds" of the cottages are but so many marks, a little greener, on the moor: there are no chickens now, and scarcely a mouse: so exit milvus - the kite is comparatively a rare bird.

And yet, one who has been familiar with such a place in its better days, (our young feelings bring finer weather on their wings than summer suns and south-west zephyrs, ) feels that there is a blank produced by the absence of the kite and the cottages; the more so that the country people are no more redolent of pullets for their own use, than when the kite and 
the laird were equally eager for ehiekens. The sight of a kite, quite at its ease, or at its labour if you will, on a fine clear day, and when there is not a spot in the blue dome of heaven but itself, is really a very fine one. It appears as if it had charmed the atmosphere to move it as it lists, and without any effort. The wings and tail are expanded, and yet they appear hardly to move, as the bird aseends and descends, and wheels and turns, now in wide and sweeping eireles, and anon dropping lower down it turns fairly round on the point of the wing as a pivot. After it has long beat over one portion of pasture without sueeess, and there is a hill, a wood, or any plaee not adapted to its habits, to be passed over before it reaehes the nest, the beauty and the easy smoothness with whieh it gets up are unrivalled. It elimbs eagle height, and without eagle effort, and from the very top of heaven surveys the land; then shoots away to some distant plaee, that may appear better adapted for its purpose.

The kite feeds not only upon young birus, and small quadrupeds and reptiles, but upon earrion and garbage of all sorts, in order to obtain whieh it will dare mueh when hungry. From the ease with whieh the kite ean keep the wing for a great length of time, it obviously could perform long flights; and though we have not aeeounts of the exeursions of kites in this eountry, a straggler sometimes makes its appearanee, and indieates a journey aeross the Atlantie, as one at least-that whieh is nearly white, with blaek wings and tail-eomes from America, and probably migrates there from Carolina to Brazil. The resident kite is subject to some variations of eolour, though less so than those speeies in which the sexes in their mature plumage differ more from each other.

EAGLES.

Eagles have in every age been the most celebrated of rapaeious birds; and in so far as power, strength, daring, and grandeur of situation are eoneerned, they deserve their celebrity. They are in all respeets the birds of the greatest eleva- 
tion. They frequent more lonely and secluded places than any of the others; they nestle in more elevated, wild, and inaccessible rocks; they rise much higher, and range much farther; and their stoop, when they come down on their prey from a great elevation, is perhaps the grandest display in the whole action of animated nature. They are much larger than any of the others; and though all birds are formed of nearly the same materials, these seem consolidated in a peculiar manner in every part of the eagles. Their bones are more solid and specifically heavy; and though, like the bones of all birds, they are hollow for the free admission of air, yet they are fortified by cross pieces extending from side to side of the tubes, so as to offer complete resistance to every strain of the naturally violent motions of the birds, and also to any casualties to which in the course of their daring lives they may be exposed. Their muscles are as firm as pieces of cable, and their tendons almost as rigid as dried catgut. Their very feathers have a firmness and strength in them that alone would tell the daring and enduring character of the birds. Those winds which cleave the oak, and rend up the mountainpine by the roots, do not ruffle the plumage of the mountain eagle, or drive her from her perch on the ledge of the rock. Firmly rooted in the powerful clutch of her feet, and defended by the plated mail of her stiff though elastic feathers, she defies the topmost bent of the elements, and, from the "munition of the rocks," looks down unconcerned upon the tempest which is sweeping the world below her with terror and devastation. The range of her eye is truly wonderful. Floating liundreds of feet above the summits of our highest mountains, - and she always soars aloft even there,-her horizon commands a hundred dells and valleys; and she spies a grous or a mountain hare from a distance at which the human eye could hardly discern an elephant. But as she dwells in power she also dwells in peace. There is no tumult or clamour in the eyrie of the eagle; she merely seeks food for herself and her young, and when that has been obtained she is at rest; and all under her dominion are safe, for even the boldest and 
swiftest-winged hawks keep at a distance from the retreat of the eagle, and when her shadow passes over the valley, not a wing moves but her own.

There are three British species of eagles, all differing in their haunts and habits, but all agreeing in their general characters of these powerful birds. They are pretty widely scattered, but they are nowhere numerous; and it is probable, nay it is certain, that independently of the price which is set on their heads, by those very considerate persons who would rather have ten sickly sheep punched and tortured to death by the crow than one lamb killed on the instant and borne off by the eagle, the numbers are every where on the decline.

One, the most powerful and the model of the race, dwells only in the wilds, and never visits the inhabited country, except it borders on those. It is very rare; and they who would enjoy the luxury of seeing it dashing away in pure nature (and it is a luxury) must pay the price in a very fatiguing, but at the same time a health-inspiring journey. That is the mountaineer; and like all mountaineers, it quits not its abode, but remains in the same haunt for life,- - and a long life it is, -and it resists all invasion, even by its own species.

Another which is rather smaller, not so powerful, and more generally distributed and more frequently seen, is either for the land or water, hunting or fishing as the one or the other promises to be most successful; not inhabiting so wild places, nor quite so chary in its food as the former, but in the absence of the mountain eagle, witlial a powerful and even a splendid bird.

The third more affects the waters, the banks of large rivers and lakes, and the shores of the sea, especially when they are wild and rocky, and distant from human habitations. It is considerably smaller than either of the others, but it is at the same time a bird of great power, and one of which the habits and action are well worth studying.

The tomia, or cutting edges of the beaks of eagles, form a sort of waving line, so that they can hold firmly; but they 
have not the prominent tooth which distinguishes the falcons and renders their beak so very efficient an instrument. The feet and claws are, on the other hand, more powerful in the eagles, and are generally speaking, the only instruments they use in the capture and killing of their prey, the beak not being brought into action until the prey has ceased to throb under the terrible clutch of the talons, The following figures represent a foot of the mountain eagle and one of the fishing engle.

\section{Clutching feet.}

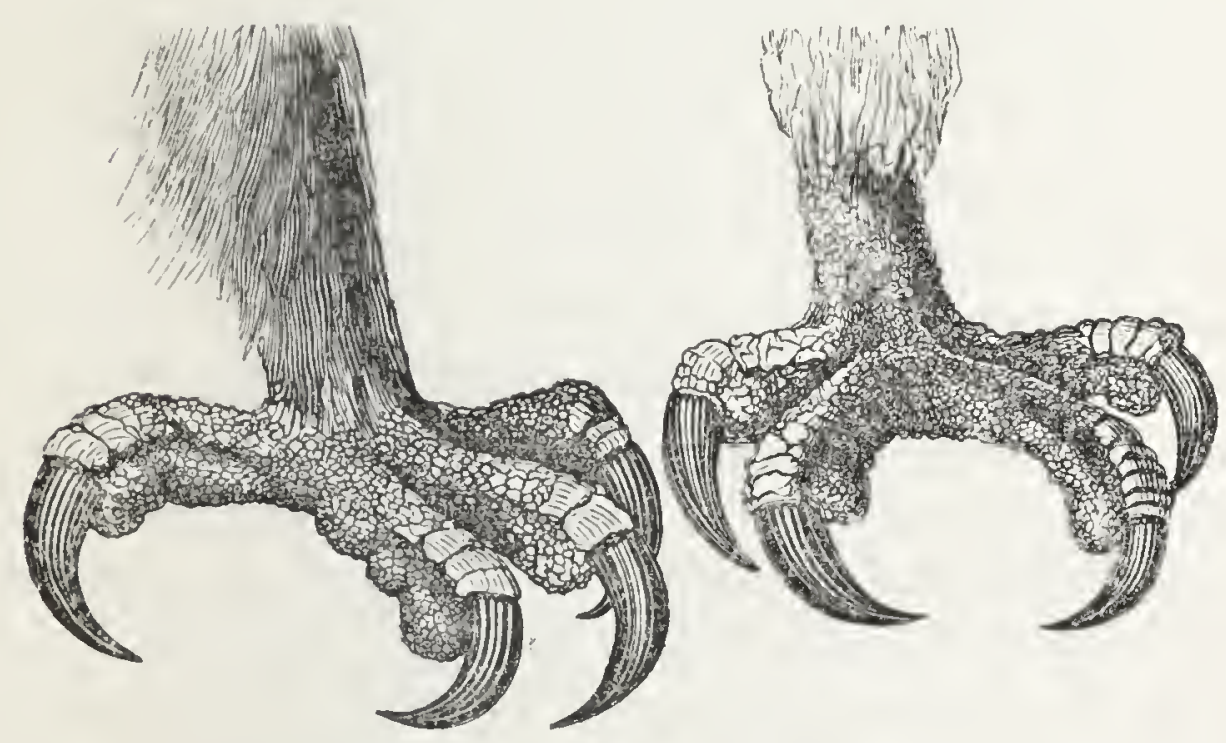

Golden Eagle.

Osprey.

The first of these is adapted for striking prey to the ground, and for griping it there till it be dead. The second for grasping fish in the water, and lifting them out of that element as the bird rises. For the latter purpose, the outer toe, which in the repose of the bird is turned forwards, admits of a reverse motion, so that two toes can act against two, and thus take a better lifting hold of the prey. The feet are also differently feathered, according to the difference of habit in the birds. In the mountain eagle, the feet of which are, from its habit, not much exposed to wet, but have often to endure a temperature far below 0 of the common 
thermometer, have the tarsi feathered down to the toes, by which means the powerful machinery by which these are moved is not stiffened by the frosts. The fishing eagle, which is not exposed to so intense cold, but must have the under part of the body frequently immersed in water, has the tarsi bare of feathers for the greater part of their length; and the one which preys indiseriminately on land and in the water, has them bare to an intermediate height.

\section{THL GOLDen EAGLe. (Falco chrysä̈tos.)}

On the frontispiece there is a figure of the female golden eagle, in the attitude which it assumes when apparently exulting over the prey which it has captured, and in the act of clutching to death. The figure is about one eighth of the lineal dimensions of nature; and it will give some idea of the attitude, though it is not possible to give the expression on so small a scale, or indeed on any scale. The spirit of an excited eagle can be felt only by those who are familiar with the birds (such familiarity as man can have with eagles) in their native haunts; and even then it must be imagined, for it cannot be accurately seen, or satisfactorily described. It is very difficult indeed to obtain even a tolerable portrait of one of these birds; for in order to get the eagle in perfection into an aviary, we would require to bring the mountain crag and the mountain glen along with her. The bird lives, no doubt, for it is a bird not easily killed, but its plumage is dull and its spirit more so. The rich browns with their peculiar metallic lustre, and the pointed feathers on the neck, shaded off till they arrive at the rieh orange at the points, and stand up when the bird is excited, as if they were so many scales margined with gold, are not to be obtained, unless where the bird has the free and unrestrained range of all its powers,can climb the pure air till it touch on the region of perpetual frost, and there dash along over a wide extent of country. Their feathers are tinted and tempered in the fury of the blast; and they acquire not their full depth and lustre till 
they have borne that for four successive winters; and so it would be vain to hope that we eould either obtain or preserve them in confinement.

The length of the full-grown female is upwards of three feet, and the extent of the wings between seven and eight feet. Specimens have been mentioned that measured as much as eleven feet, though the accounts of these may be a little exaggerated. It is very probable, however, that the ultimate size to which the birds attain depends, in a considerable degree, on the supply of food they receive when young, and it may be partially also on the climate. Henee, when the golden eagle had haunts more southerly, and in richer pastures than any which it now frequents in this country, it may have grown to a larger size.

The popular natural history of the eagles is more obscure than that of many less noticed and less interesting birds. All very large birds of prey that are seen flying at great elevations are regarded not only as eagles but as the golden eagle itself; and on the other hand, those who place the chief distinction in eolour, have multiplied the golden eagle into different species.

The bird with which the golden eagle has sometimes been confounded is the white-tailed, or sca eagle, which is of much more frequent oeeurrence; and, though the brown is not nearly so rich, or the points of the neck-feathers so well made out, and the bird seems altogether of a laxer and looser make when they are seen together, yet the general colours are so mueh alike, especially when the golden eagle is young and has white in the tail, that, to casual observation, the one may pass for the other. But upon comparison, the looser form of the head, the pale beak, the naked tarsi, and a comparative want of firmness and decision in all the feathers, and of eompactness in the body, show at once that the bird, however large it may be, is not the golden eagle. On the other hand, while the golden eagle is in the young plumage and the feathers of the tail are partly white, forming what has been called the "ring-tail," the bill, the down on the tarsi, and the deep brown 
bar on the end of the tail, together with the whole air of the bird, point out at once that it is the golden eagle. Give it but its form and expression, and no matter though the eolour were white, black, or even green, the golden eagle would never be mistaken for any other bird, any more than a friend, of whose person, air, and gait we had a complete knowledge, would be lost to our recollection, or changed to another person by merely putting on a diess of a different colour.

The golden eagle is now rare in England, if indeed it be found there at all; and even in the Highlands of Scotland it is by no means common, and its eyrie at least is confined to the most wild and inaccessible places of the mountains, and only in those places that are cliffy and precipitous. I have seen eagles beating about in the higher glens of the rivers that rise on the south-east side of the Grampians. I know that one pair, at least, nestle somewhere in the high cliff called Wallace's Crag, on the north side of Lochlee, and another somewhere in Craig Muskeldie, on the south side of the same. I have observed the four all in the sky at one time; and I for some time wrote with a quill which dropt from one of their wings in the autumn of 1819. An intelligent farmer who had resided all his days on the spot, assured me that the Wallace's Craig eagles had been known in the days of his grandfather, (the people there are rather famed for longevity, though the sun does not shine on the lake for several weeks at mid-winter,) but thosc on the south side were not such old settlers, and they were eonjeetured to be deseendants of the former, although driven off by their parents aceording to the general habits of the birds. I have seen them in Strathspey and Badenoch, in Stratherrick, and in the moor between Kiltarlity and Strathglass; and I onee saw one over Culloden moor, not far from the scene of the battle, though some of the land in the intermediate neighbourhood was under crop. Indeed, when the weather is very clear, and the eagles fly high, they continue their course in perfect indifference to any thing that may be happening on the ground; and I have been told, though I do not vouch for the faet, 
that they sometimes stoop down and carry off hens and even cats from the very doors of the cottages. I found, however, that eagles had been a sort of "lions" witl wandering tourists, and that any number of stories of their achievements might be had cheap. I never saw the golden eagle near the west coast, or in the islands, (though that is no proof of its not being there,) but I have seen the sea eagle and the osprey.

From what I have noticed of their habits, I am inclined to believe that eagles in general choose those rocks, where with an elevation and wildness which gives them the seclusion that they seem to like in their retreats, they have the command of a double pasture: a hill one, which they beat with a lower flight when the weather is dusky, and a lower and richer one, which they beat at a greater elevation when the weather is clear; - at all events, I have seen them on the upper moors flying low on dusky days; and again sailing majestically over the lower and richer valleys when the day was fine.

The eyrie of those magnificent birds, which is a dwelling as well as a cradle for their broods, is placed on some ledge of the rock, and rarely on a tree, unless when the tangled roots spring from the cliff, and offer a broad space which can be covered with sticks. The place is generally slippery with the refuse of their prey; and when the young are there, it is usually well stored with provisions, which consist indiscriminately of quadrupeds and birds. The eggs are seldom more than two, though some say that there are occasionally three, and that in such broods there are two females, one of which becomes an "odd eagle" and lives solitary, growing to a very large size, being very ferocious, and dropping addled eggs occasionally on the mountain tops; but the tale wants verification.

The eagle generally strikes her prey upon the ground, and the stoop is almost instantly fatal to any animal on which she pounces. The mere fall of a body of twelve or even eighteen pounds in weight, from an elevation of 1500 or 
2000 feet, would be powerful; but the eagle shoots down with a great initial velocity, and as she delivers the whole of her momentum with the claw, she not only dashes the animal to the earth, but plunges the claw into its body up to the toe, dislocating the spine or breaking the skull of the feebler quadrupeds, such as hares; and the death of grous and black game, which form a very large portion of the prey, is instantaneous. The view upon which the eagle proceeds must be a steady one, for on the ground she seldom misses ber pounce, though she often does when she attempts to hawk on the wing, as her broad wings and forward rush are both unfavourable to turning so as to follow the motions of the bird. If the prey is small, she has the power of slackening her speed as she descends, so as to temper the ultimate effect to the necessity there is for it, otherwise, strong as she is, she might be injured by the collision with the ground. An unrestrained stoop from her greatest height would be sufficient to dash even an eagle to pieces. If the pounce is not fatal, the clutch instantly follows, in the giving of which the whole weight of the bird-in the utmost excitement, with the head elevated, the neck stiff, the feathers of the head and neck erected, and the wings shivering so as to keep the pressure on the instruments of death-is upon the claws. With small animals, even when they show signs of life after the pounce, the clutch is given with one foot only and the bird is less excited; but in no case is the prey touched with the beak or even looked at until all motion in it has ceased. When the eye has guided the descent, and the talons have taken effect, the office of the eye is at an end, and the work of death is committed to instruments admirably fitted for carrying it into effect. In general the prey is borne off; but in some cases it is devoured on the spot, that taking place of course at those times when the bird has only herself to provide for.

In winter when her pastures are covered with feet or even with fathoms of snow, the eagle is often for weeks together without food. This may be one of the causes (for all pheno- 
mena, whether of birds or of any thing else, have causes) why she drives the young not only from the eyrie but from her haunt generally before the intensity of winter sets in; and it is said that she drives them lower down the country, where the chances of food are more numerous.

Thus the instinct which we are apt to regard as an unkind one, is the very best adapted for the preservation of all; and the eagle is, in her way, just as tender a mother as any other animal. As it is necessary for her brood to grow fast and get strong before the inclement season sets in, she is most indefatigable and most successful in supplying them with food, and equally daring in the defence of them against any intruders, that may have the temerity to invade an eagle's nest; and when they are so far matured that they can kill prey for themselves, she drives them down where prey is more easily obtained, while she herself remains to brave the winter at the very throne of its dominion. Herein we may see a beautiful instance of that balance and reaction which can be traced through all the works and operations of nature. Populating and cultivating narrow the bounds and diminish the number of eagles; but as there is a constant tendency in the eagles to spread and extend their territory and their numbers, that tendency instantly acts upon the withdrawal of the restraint; so that when the eagle becomes necessary in order to maintain the balance of races, and the perfection of the whole of nature, she returns by as unerring a law of nature as that which guides her to her prey.

Her strength of endurance also enables her to keep her footing and preserve her existence, under circumstances to which the powers and the life of almost any other animal would be obliged to yield. The same elastic ligament, which, of its own nature, and without effort from the bird, compresses her toes in clutching, enables her to cling to the pinnacle of the rock, and to cling the more firmly the ruder the blast. The claws are not used in those cases, as that would injure their points and unfit them for their proper functions; but the pads and tubercles hold on upon places where the VOL. I. 
foot of all else would give way; and the eagle sits with closed wings and close plumage, as if part of the rock itself, while the wind roars and the snow drives, tearing the bushes from their roots, sending them rolling over the precipices, and literally scourging the wilderness with ruin. The strength of the hill ox, the fleetness of the mountain deer, and the resources of the mountain traveller, are often un. availing; and when the storm breaks, the signal of the raven and the crow points out the place of their bones; but the bones of the eagle are not thus given by nature to be tugged at by ignoble birds. Queen of the tempest, she rides as secure amid its fury, as when, on a cloudless and breezeless day, she floats down the valley with easy and almost motionless wing.

Her endurance of hunger is as remarkable as her power in the storm. In confinement she is said to have lived five weeks without food; and yet as she was then taken with dead bait, to which she does not resort except in extremity, she must have been hungry when taken: so that, in her native freedom and with the cold dry wind around her, which diminishes the waste of the animal system, she may possibly be able to fast for a longer period; - and the one mentioned was killed and did not die of hunger. But I must leave lier to her haunts, apologizing to the reader, that I am obliged to confine my notice to a few desultory pages, which is as much out of nature as cooping up the living bird in a cage. In nature, the eagle requires a mountain, and if ever it be my good fortune to afford her a volume of description, she shall spread her wings.

\section{the sea eagle. (Falco albicilla.)}

This is the "erne" or " bog eagle" of the Scotch, in whose country, especially the parts of it in which there are wide morasses, it is still not rare. Like the former it is fond of wild retired and mountainous places; but it is far more discursive, and often ranges into England, and breeds in some 
of the wilder places of that country, where it is probably the only eagle that is now to be met with in a state of nature. It is most abundant on the rocky islands and rugged coast towards the north; and though it is sometimes seen considerably in advance over the cultivated grounds, it does not nestle there, neither does it get so far up the mountains as the grolden eagle. It is, however, the species which is most generally seen. Hence it is probable that it is " the eagle" of ordinary conversation in both ends of the island, and in all parts of the country, save those which only the others frequent; and that consequently many of the anecdotes that are told of the goldien eagle really belong to the present species.

It nestles in rocks and also in trees, or on the ground in thick bushes, and the number of its brood is nearly the same as that of the other. The eyrie is however less a dwelling for life than that of the golden eagle, because the bird is more a wanderer, and in all probability nestles in different places during successive years: that will, however, depend a grood deal on the nature of the locality ; if there is a sufncient supply of food, from field, marsh, and flood, upon all of which it levies contributions, the cause of migration diminished, and the migration itself becomes the less necessary. It is upon the same account less necessary for the sea-eagle to drive its young arvay from any particular launt, inasmuch as the old ones may cliange theirs. No doubt some of these birds con. tinue for years-many years, in the same places; but that does not establish a general habit in the race, for there have been instances of individual animals that belong to the most roving kinds attacling themselves both to persons and to places.

The roaming disposition of these birds, more especially before they arrive at their maturity of plumage, tended much to establish the old opinion, that the old and the young were different species. The general colour of the young is umber brown, with the margins of the feathers lighter, especially on the scapulars and lesser wing coverts, - the margins of the former being of a reddish straw colour, as is also the chin and 
upper part of the throat; and a number of spots on the under part of the bird, among which there are patches of white. The tail, at that age, is dark brown, as dark at the points of the feathers as the deepest brown of the golden eagle, but mottled with lighter brown on the other parts. The bill in that stage is bluish, though not so deep in the colour as the bill of the golden eagle. It is also larger, in proportion to the size of the bird, but softer and weaker, less uniformly curved from the base, and more completely without a tooth and notch.

As this bird advances towards its permanent or mature plumage, the changes which it undergoes are, in some respects, the reverse of those of the golden eagle. The feathers on the head and upper part of the neck become lighter, the bili changes from bluish to straw colour, the yellow of the cere and the brown of the irides acquire a tinge of red, the brown on the principal parts becomes more uniform, and the tail coverts and tail become white. There is, in fact, so much metamorphosis in the colour of the bird, that, until the change of the plumage had been actually watched, or the similarity of habits more closely observed than it is very easy to do in the case of eagles in a wild state, one cannot blame those who, being without the proofs, concluded that they were different. The young is often described as the ossifrage or " bone breaker," or the sea eagle, and the mature bird as the cinereous eagle, or white tailed eagle.

In the breeding season both old and young (for it is probable that all birds which take three or four years before they arrive at their mature plumage breed before then,) are found in wild situations, chiefly on rocky places near the sea or the larger inland waters. Whenever the shores are broken, bold, and rocky, and at the same time thinly inhabited, these eagles may be found as breeders, and often as general residents. They are seldom seen on the low shores of the agricultural parts of Scotland, though it is said that, in the south, they have been observed near St. Abb's Head. On the east coast they are not met with again, till the wild shore and equally 
wild adjoining district between Stonehaven and Aberdeen, is arrived at. Thence to the Ord of Caithness they are few ; but they are common there, and also around the whole of the rocky and indented coast on the north and west, and in both the northern and the western isles.

In the western part of Ross, about Lochbroom and Loch Maree, they are very abundant, the country being as well adapted to their habits, as the bold cliffs of the eastern Grampians are to the habits of the golden eagle.

The aspect of the country there is as wild as can well be imagined. Dreary black morasses on the heights, which present little save peat earth and pools of water; precipitous rocks, rifted into all manner of shapes, and often rising into sublime precipices and peaks; a shore, embayed and torn by the sea, till it seems an absolute fringe; arms of the sea full of jutting head-lands; lakes studded with the most picturesque islets; a sky, which is either dripping or pouring almost all the days of the year, so that the people are absolutely aquatic, and are said to catch cold whenever they come so far eastward as to get dry; a temperature as variable as the weather, but one which is never long severely cold; and a soil which is continually turned and ploughed by rains and floods, but which is never for any length of time deeply buried beneath thick snow. The consequence is, an exuberance of regetable action, which those who have not personally seen it, would not expect in so northern and remote a place. The green on the little swards is lovely; the verdure of the copses luxuriant; and some of the old trees, especially about Loch Maree, would do honour to the finest park in the richest county of England.

The law is, in fact, there demonstrated, that "where the waters are busy, neither vegetables nor animals can remain idle." Life is in constant bustle, - the podded plants, the mountain berries, the tops of the ever-growing mosses and heaths, furnish food for innumerable birds; and the soil, always moist, and never very cold or very warm, is the nursery of G 3 
slugs and worms. It has been observed, that where there is the greatest production of these animals on the land, there is a similar abundance of tlie corresponding ones in the sea. The rains and floods wash the land ones by myriads into the lakes and streams; the rivers roll them onward to the sea; and the tide casts them on the banks, or drops them in the eddies, mingled with other myriads of its own production.

The corsequences are, that the waters teem with fish, and the land abounds with all manner of living creatures, to which so moist a climate is at all congenial. Salmon, trout, herrings, cod, all the more valuable of the finny tenants of the lake the river and the sea, abound, to a degree of wealth which, if it were fully appreciated and won, would be very great; and if the people, who are every season leaving some part of that country and going to Canada, because they cannot dry oats in the rain, or ripen barley in the mist, would go to their wild shores, catch fish, plant potatoes, and breed ducks and pigs, they would have more than a Canadian reward, with nothing of Canadian peril or Canadian labour.

"Where the carcasses are, there will the eagles be gathered together:"-wherever there is grass, there will be browzing; wherever there is prey, there will be predatory animals; and among those of the district alluded to, the sea eagle is one of the most conspicuous. She strikes on the ground, she hawks, she fishes, and in short labours, and labours most industriously, by all the arts that an eagle can ply, to keep those classes of the population of which her natural instincts give her the charge, within the limits of their supply of food, with more than Malthusian assiduity. Seated on some rock that overlooks the waters, she views the salmon attempting to get over the shallow, or the salt water fish showing its back near the shore, and down she rushes, pressing the fish to the ground till her long claws are buried in it up to the toes, and then she rises and sails off in triumph, to eat her dinner or to feed her brood. If grous, sea-bird, or any large bird comes within the range of her telescopic eye, she speeds with 
equal alacrity, and though she is not by any means so expert on the wing as the falcons or hawks, she fails not in obtaining abundant prey.

Here we may remark, tliat the talons of the sea eagle, which are proportionably larger in size, are better adapted for lifting, though less so for laccration, than those of the golden eagle. Those of the golden eagle, and indeed of all that kill exclusively on dry land in day-light, are grooved on the under sides with two sharp cutting ridges so that as they clutch they tear and lacerate; but in the sea eagle the ridges are not so sharp, and thus not quite so killing, though as clutching.

In the lamoing season, which under that dripping sky is a hard one for the flocks, she beats over the sheep pastures, destructive both of lambs and of weakly and disabled sheep, and also of fawns in those parts of the country where there are wild deer. The extent of thesc excursions is not known, but certainly, although the straight-forward, or journey flight of eagles is not probably nearly so swift as that of the jerfalcon or the peregrine, from the Scotch Highlands to the border of England and back again would not probably be too much for a day.

As the sea eagle in her miscellaneous feeding, the form of her beak, and the looseness of her body, as compared with the golden eagle, has a slight leaning toward the characters of the vulture, it is probable that she may also have a trace of that wonderful power of scent which guides the vulture to its prey. The scason, and consequent diminution of food in her northern haunt, may be partly the cause; but it has been observed, that the sea eagle comes farther to the south and more inland, in those inclement seasons, when, from cold and deficiency of food, the deer in parks and forests, the hares in preserves, and the rabbits in warrens are weakly. On those occasions she avoids the cultivated and warm lands, and resorts chiefly to those places which have most the character of her native haunts.

The climate of Ireland is much more in accordance with the habits of the sea eagle than of the golden; and therefore 
it is probable that the eagles in Kerry, and other wild and rocky counties, of which so many stories are told, with pretty copious embellishments, are sea eagles, as those that are met with in the Hebrides generally, if not exclusively, are. The deeds of eagles, if there were a Macpherson to collect, arrange, dovetail, and build them up, with as much enthusiasm and labour and as copious supplies of stucco, would make as interestingly romantic a book as the poems of the son of Fingal; but, as is the case with these, we never should be able to find out the real historical character to whom the exploits belonged.

THE FISHING EAgLE (Falco haliaetus).

This is the species which is properly the sea or rather the water eagle of Britain, as the other preys more on land than in water, and when in water only in the shallows; but the name has been appropriated to the other, and the change of it is not worth attempting.

The fishing eagle partakes of the characters both of the eagles and the falcons. It agrees with, or at least approaches the eagles, in size and in the habit of stooping on its prey; and with the hawks in the form of the beak and the structure of the wings. But it has so many peculiar characters that, in a strictly scientific point of view, it belongs to neither.

The length is about two feet, and the extent of the wings five feet and a half, so that it is larger winged in proportion to its length than even the peregrine falcon; and if the weight of the birds be estimated as the cubes of the lengths, the structures pretty nearly correspond-the weight of the fishing eagle being often as much as five pounds.

This bird is often called the osprey, the fishing hawk, the fishing buzzard; and, from the white on the head and nape, the bald buzzard. Its flight sometimes resembles that of the buzzard, but that is almost the only character that they have in common; and the osprey can, when necessary, fly very 
differently. No bird of prey is better furnished than the fishing eagle. Its eye is remarkably keen, though it wants the suborbital bones. Its beak is of the most powerful form with a partial tooth, very much hooked at the point, and of that dark colour which belongs to all very powerful beaks. The tarsi are also very short and strong, free from feathers, but covered with scales; the under parts remarkably tuberculated, and the claws, more especially that on the outer toe, very large and strong; but all completely rounded on the under sides, and adapted for clutching, not for tearing.

The general colours are: the naked parts, the cere, tarsi, and toes, greyish blue; the irides yellow; the prevailing colour on the upper parts, with the exception of the back of the head and nape, blackish brown; and that on the under parts with the exception of the breast, which is marked with light brown, white, passing into dull grey toward the vent and tail. There is a streak of deep brown down each side of the neck, and the chin and front of the neck are marked by longitudinal spots of the same colour. The quills darker brown than the coverts; and the margins of the feathers in the latter are sometimes relieved by a lighter brown, which, however, wants the warm tint of the other eagles. The three middle feathers of the tail are wholly brown, and the others have white bars on their inner webs, the outer webs of the exterior ones, and also of the first feathers of the wings being very narrow and stiff. The feathers upon all the under parts, including the under coverts of the wings, are remarkably smooth and closely set, resembling those on the under sides of water fowl, indeed the very shape of that part of the body has some resemblance to that of a swimming bird. The feathers on the legs, which just clothe the upper joints of the tarsi, are pure white, and resemble fine straight hairs as much as ordinary feathers. The feathers on the upper parts are more those of a land bird; but they are not so decidedly so as the feather's of the other eagles.

The young birds are more varied in their plumage than the old ones. The brown on the back becomes uniform, or nearly 
so, in the mature plumage; and the brown and grey disappear from the under parts, leaving these pure white.

The feathering of the under part, the edges of the wings, and the tail, are all admirably adapted to the habits of the bird. Usually an inhabitant of the air, and of the air in places that are rather warm (for it is more abundant in the south of England and Ireland than in the central parts, and scarce in the north), and finding its food by sudden plunges into the water, at all natural temperatures above that of freezing, the under part of the osprey is exposed to more sudden changes of temperature, and also of element, than that of most other birds, whether of the water or the land. The sea birds that plunge from the air into the water, generally plunge head foremost, and seize their prey with the bill, so that they meet the cold, and also the resistance of the water, on both sides equally: but the osprey plunges down on the under part only, and seizes with the talons, the head being generally above water all the time. No doubt the wings, and also the tail, in part soften the dash, and the under sides of them are well formed for resisting the water, but still, both the resistance and the change of temperature come upon the under side of the body, the shape, and the texture of the feathers, defending it against the shock; and the downy compactness and white colour resisting the cold, as the bird is again in the air before the effect of the water can be transmitted through so close a covering of a substance which is so slow a conductor.

That texture and colour of the feathers are more necessary in the osprey than they are in a sea-bird, even if we were to suppose their habits the same; for the fresh water of the lakes and rivers, in which chiefly the bird fishes, is subject to much more seasonable variation than the salt water of the ocean. The scales upon the tarsi are reticulated, like those on birds which actually wade into the water in search of their food.

Nor is the arming and general structure of the bird less admirably adapted to its modes of life. Fishes are less sen- 
sible of pain in any part, save the head, than land animals; and from the transverse separations of the flakes or fascicul ${ }^{i}$ of their muscles, they can exert their powers of swimming, even though a considerable part of the flesh is cut through, if the spine be not injured. Hence it is much more difficult to kill a fish in the water than a bird in the air, or a quadruped on the surface of the earth; and thus, the talons of the sea eagle and the osprey (those of the latter especially) are fitted for lifting rather than killing their finny prey. The weight taken off by the buoyancy of the bird also diminishes the effect of its stroke, and to compensate for that, the outer claw can be reversed, so that they act two against two, which is the most effective position in clutching.

But if that toe had been permanently turned backward, it would not have answered so well upon other occasions. The osprey has to sit upon craggy points, from which it can command the fishing ground; and as the fish come most to the surface when the rocks are rather slippery, their prey being then most abundant and best seen, it is necessary that its foot should be firm; and, from the structure of its toes, it is equally well adapted for perching and for clutching.

The difference between the osprey and those birds of the same order, which live chiefly upon warm-blooded animals, affords a very remarkable instance of that wisdom of design which pervades all nature. Over its finny prey this bird is all-powerful; but its powers are for self-preservation, not for destruction. There is not, indeed, any destruction in nature ; or rather, all nature's destructions are preservations. Man has broken the law; but the benediction of the Creator is still upon all the rest-they are "very good." There is no wanton war but by man. The osprey is feeble in confinement where she cannot use her "stoop:" one at the Zoological Society's garden, was lately attacked and killed by an American red-tailed buzzard, which among land birds of prey is far from one of the most powerful.

When the osprey is merely passing from one place to another, its flight has sometimes the heary motion of the buz- 
zard, and at other times, when it flies higher, a very peculiar slanting or gliding motion, in which the wings take few strokes, compared with the progress made. But it is over the fishing ground, especially when of considerable extent, that the motions of this bird are seen to the greatest advantage. Its manouvres in the air are alternate wheelings and hoverings, the former to find where there is prey, and the latter to watch till that prey comes within reach. Whilst it hovers, it keeps the wings constantly in that rapid motion, which all birds of prey give them when preparing to stoop upon prey which is not on the wing; so that, when over the proper spot, it is always ready. The wheelings are performed with apparently little effort, the hovering motion enabling it to shoot away, in a manner something similar to that in which a stone is shot from a sling.

The short time that the fishes remain at the surface when they leap requires this activity. If the fish is a small one, and leaps instantly, the bird comes down with much swiftness, but checks itself near the surface, and either twitches out the fish with little more splash than the fish itself makes, or if it is too late, it abandons, wheels round and round for a turn or two, as if to wait till any alarm that it had occasioned is over, and then it hovers anew, probably over the very same spot. When it stoops in this manner for small fishes, it is never from any very great height; but if it come from a greater height, which it does only for better game, the exertion is more grand. The large fishes come less frequently to the surface to feed than the small ones; but when they do come they feed more determinedly, though more warily; and therefore they are longer near the surface. When the osprey has discovered one of these, which may be judged of from ber perfect stillness in place, and the increased vibratory motion of her wings, she dashes down more perpendicularly, and not less rapidly than the jer-falcon or the golden eagle. The rushing of her descent may be heard at a considerable distance, and the dash in the water is as if the lightning had smitten a cliff, and the fragment fallen from it in the 
lake. If, indeed, you have not observed her till the dash catches your ear, you are at a loss to know what is in the water, for the splash and spray hide the bird till the clutch of the talons is secure. But no sooner is that accomplished than she rises from the water, dashing the drops from her ample wings, and soaring majestically with her prey to the rock. If she misses in these her desperate efforts, she flies off (sulkily, as one would say,) either to a different part of the lake, or from it altogether. The lifting of herself, loaded as she is, and obliged to use her wings, not only near the water, but actually on it, is a vast effort, and could not be at all accomplished, if the under sides of the wings especially had not the water-proof properties of the aquatic birds. When the talons once clutcl, they do not quit their hold easily; so that if the wings were easily wetted, the bird would certainly be drowned, as is sometimes the case with the sea-eagle, when she strikes large fishes in deep water. The sea-eagle is not, however, weight for weight, so powerfully winged, and her wings have the water-proof property in a very inferior degree.

Though fishes are the chief prey of the fishing eagle, it also stoops at and often catches water fowl. But these though clutched with certainty, are not so easily borne off as the fishes. The mere fact of being lifted out of the water soon puts an end to the struggles of the fish, so that it is carried off as so much mere weight, into the solid of which the talons are struck. On the other hand, there is nothing to hurt the bird but the clutch of the talons; this is weakened by the thick plumage, and may not be inflicted so as not to do serious injury, and when that is the case, the bird may struggle and disentangle itself. Instances are mentioned of birds so disentangling themselves, and being retaken in their fall by the osprey, or borne off by other rapacious birds.

As a lake or river to fish in is the chief attraction for the osprey, the nest is chosen where it may be the most convenient for that. If the fishing is in a mountain lake, or a 
river that has worn a channel deep into the strata, the nest is placed in the rocks, but always as near the water as may suit the purpose of concealment. If the fishing place is a lake in the moors, or a river that runs slowly between fenny flats, then the nest is concealed in the reeds; and if the water pass through, or be situated among trees, the nest is constructed in one of these. In all situations it is a rude fabric of sticks, and rather a sort of platform than a hollow nest. The eggs, which are yellowish white with brown spots, are understood never to exceed four.

It has been already hinted that the osprey is more frequently observed in the southern than the northern parts of the country. It is also subject to winter migration, more especially in those places where the waters are liable to be frozen over, at which times it of course cannot fish. On these occasions, it sometimes betakes itself to the sea; but it more frequently passes into warmer latitudes, as the cold keeps down even the sea fish to a greater depth than that at which they swim in warm weather. Of course it is more a migrant on the continent of Europe than with us, as the summer is warmer, and the winter colder, it ranges over a much greater range of latitude, especially in the central and eastern parts.

NOCTURNAL BIRDS OF PREY-OWLS. (Strix.)

Some of the predatory birds of which short notices have been already given, seek their prey in different degrees of light. The common buzzard, for instance, watches in the twilight shade of thick trees, and feeds, in part, on those animals which are the chief prey of the owls: the kestrel, which is usually classed with the falcons, hawks for beetles and large moths after sunset; and the osprey, and the seaeagle (when it fishes) are constrained either to fish in the twilight, or, at some seasons, to fare but scantily; and though they, more especially the latter, can endure hunger for a long time, they at all times prefer food to fasting, if food can be 
obtained. The eye of the buzzard is protected from side lights by the concha of feathers round the eye, in order that these may not interfere with and confine the fainter light which comes from those shady places in which the prey is found, just in the same manner that the projecting upper part of the orbit in the sky hunting-birds protects their vision from the direct rays of the sun, and enables them to see better below them. The eyebrow in man answers a similar purpose; and, indeed, there is no animal which hunts in the clear light of the sun, in which the eye is not more or less defended by some such contrivance. The sea-eagle, again, can bring over the eye a peculiar membrane, which acts as a sort of curtain, in exchuding the level light of the twilight sky, and allowing the full power of the organ to the dimmer light from below ; and that instrument of twilight vision was regarded by Aristotle as a means of blindness. He is not to be blamed, or even wondered at, because the principles of optics were little known in his time; but those moderns who have repeated the assertion, are not so excusable.

The nocturnal birds of prey have the eye with a more ample and complete concha, and also the iris much more susceptible of motion than the day-birds-so much so, indeed, that a strong light appears to shut the pupil altogether, and the bird becomes bewildered, and cannot see its way. The sensibility will abate, however, under circumstances which render such an abatement necessary to the comfort of the bird. There have been instances of tamed owls (and owls are easily tamed, and docile when they are tamed) which, when kept in places where the air was confined, chose the window in preference to any darker part of the room, as a perchingplace, though eren in that state, they did not like the direct beams of the sun.

That delicate sensibility of the iris is necessary, in order that the eye may adjust itself to the variable degrees of light which they meet with in their nocturnal excursions. But still, there is not, either from analogy or from fact, the slightest reason to believe that any owl can see in black midnight, 
although even the blackest of that is far short of absolute darkness. The small quadrupeds, upon which chiefly the owls prey, have equally bright and sensitive eyes as their preyers, as it is while they are out of their looles and feeding that the owls capture them; but the action of their eyes is not so well seen as that of the eyes of the owls, partly because the eyes of the owls are so much larger, and partly because of the powerful motion of the nictitating membrane which the owl is always bringing to lubricate its eyes, when the light proves too strong for them.

Owls are remarkable for the softness of their feathers, and the great proportion which these form of the apparent bulk of their bodies. An owl, in its plumage, looks a thick, stout, and even clumsy bird; but strip off the feathers, and it is really nothing. The great owl, (strix bubo,) the size of which has been compared to that of the eagle, is not one-fourth of the weight.

The very name of the owl is a name of lamentation, expressive of the sound of its note, which is one of the most melancholy love-songs in the whole chorus of nature. Superstition has accordingly laid hold of the bird, as one of the instruments by means of which to bind the ignorant in the fetters of fear; and the circumstances attendant upon the owl, although they admit of being turned to better and even very delightful purposes, have certainly an aptitude to be so perverted.

Deep shady groves, hollow trees, crumbling ruins clad with ivy, steeples and churches with their associations of graves and ghosts,-all that seems dim to human reason, all that stands monumental of the works of nature, or of man and his works, - is linked to the owl by the closest and the most general associations. The owls, in such places, - often heard, but seldom seen: when heard, heard in the gloom and stillness of the night; and when seen, appearing with something of judge-like solemnity,-made them very readily convertible into a sort of "doom-birds."

The times of their appearance gave farther colour to the 
superstition. Gloomy days, when the congregated clouds hung low in the sky, but were kept up by the strong resistance of the warm earth and the breezeless stillness of the summer air ; murky days, when the sun "was sick to doomsday with eclipse;" all occasions when the heavens looked black upon the carth, but produced stillness rather than storm, borrowed the attributes of twilight, and so brought out the owl,--brought it out by perfectly natural and, according to the laws of its being, necessary causes, but causes which were not understood; and the event being striking and mysterious, was remembered, all concomitant mishap was remembered along with it; so that the owl, which came out simply to see if there was " a mouse stirring," got the blame of the whole.

But notwithstanding, owls are interesting birds, and the sounds which they utter, though deep and monotonous, have music for a well-tuned ear. The part which they act in creation is, moreover, an important part; and from the numbers of vermin which they destroy, there are few birds more worthy of protection in an agricultural country than the owls. The Athenians made them sacred to their patron goddess, for defending the labours of the loom; and if we cherished them about our farm-houses, they would do yeomen service in defence of the labours of the plough.

Nor is the superstitious dread of them wholly without its use, or would the abolition of it be unmixed gain. Mankind are all the better for some checks upon them at those times when they are not watched by their fellows; and the actual presence of the owl may have sometimes restrained the midnight plunderer from his purpose, as effectually as the mere thought of rural wisdom enwigged with office. If so, and there is little doubt of it, the owl was a cheap police-man, keeping back one set of marauders, and exacting, as his fee, the destruction of anotlier.

Of the many species of owls which are more or less frequently seen or heard in Britain, our notice must be very brief,-far more so than we could have wished,-and we shall 
take them as one genus, without regarding the more numerous and, it may be, more accurate divisions. We may remark in passing, that there are four that have produced feathers on the sides of the head, and are thence called "horned" owls; and four without these feathers, which are called "smooth-headed." The "horns" are not horns, however, in any other sense of the word, than their being, like all feathers, composed of nearly the same substance as horn, and their growing on parts of the head, something analogous to those on which the horns of ruminating animals are produced. As little are they "ears," as they are sometimes called, probably from their fancied resemblance to the ears of cats, they are "tufts," and such we shall call them. The ears of owls, which are as delicately sensitive as their eyes, are under these, and covered by the feathers of the concha.

THE Great-tufted owl, or Eagle-owl. (Strix bubo.)

A representation of this bird is given on the plate at page 83, immediately under the peregrine falcon, and on the same scale with that, namely, one-sixth of the lineal dimensions, or one thirty-sixth of the surface.

It is a very powerful bird, and, from its preying on the young of deer and sheep, and upon grous and other large birds, it merits the epithet of eagle. It is doubtful if it ever bred, even in the remotest parts of the British islands, though it sometimes, but very rarely, pavs a visit to the Orkneys, and also to the north coast of Scotland. On the continent, it is distributed over a wider range of latitude, in a general or partial state of residence; and it also migrates, especially in the central and eastern parts. As, from the vast mass of light feathers with which it is invested, it must make more lee-way than most other migratory birds, the east winds sometimes bring it to the shores of England, especially those to the north of Flamborough Head, and the south of the Thames, which are the most remarkable for the occasional appearance of continental migratory birds. It builds, in rocks or in lofty 
trees, a nest often three feet in diameter, but rarely containing more than two eggs. It prefers rocks, however, both for nestling and for perching; and, sallying fortli from these in the grey dawn, or the twilight, or on dark days, -in the northern regions all the night long,-it commits terrible havoc, especially among the grous, and more particularly when it has young, which, as is the case with all the owls, remain long in the nest, and devour a vast quantity of food. Its flying note is peculiarly deep and doleful, and the hissing sound which it utters when alarmed or irritated, is just as harsh and grating. The sound which many nocturnal birds of prey make when they fly, may possibly answer the same purpose as the roaring of the lion and other carnivorous beasts, namely, that of alarming the prey, and making it thereby reveal its hiding place to the keen ear of the preyer.

When it beats for prey, it flies very low, and often, by its large size and singular appearance, attracts the attention of kites, crows, and other birds, which follow after it with apparent astcnishment. Hence it is sometimes made use of to draw down the kite from her high flight, so that a falcon may get above her and dispatch her. It is also sometimes used in a cage, or otherwise confined, but visible, to attract and enable the keepers to destroy those birds which plunder the nests, and eat the young in pheasant preserves. Its migration flight is high, and not much inferior to that of the eagle, several of the characters of which it combines with those of the more common owls.

It is highly probable that many of those dismal sounds which have been reported as at times issuing from rocks or caves, or moaning along the solitary wastes, and which terror has imputed to supernatural agents, have been nothing more than the flight-cries of eagle.-owls, which came and departed (or died) unseen, but which were not silent or unoccupied during the time of their sojourn. About thirty years ago, there was an unwonted and very dismal sound heard occasionally on a wide and wild moor on the east of Scotland, to the total suspension of all walking by night--the more so, 
that the place bore the impress of ancient camps and battles, and contained the bones of some modern suicides, which then and there were not allowed church-yard burial, though the ground is not consecrated, and there is no burial service. But, if we could keep these birds when they do come, dismal as their sounds are, they would make a most interesting addition to our ornithology. In Norway, where they abound, they are guardian angels, from the countless thousands of lemmings which they destroy, in the desolating marches of those destructive creatures.

THE LONG-TUFTED OWL. (Strix otus.)

That is unquestionably the finest of our resident owls; and though not so plentiful as some of the others, it is pretty generally distributed over our islands, wherever the trees are thick enough to afford it that depth of shade in which it delights. It wants shade and shelter all the year round; and therefore it prefers the evergreen forest to the deciduous one, and the dark and thickly-clustering spruce to the more open branches and light foliage of the pine; but it is a bird of the champaign country rather than of the wild; and hence it is not met with at very great elevations.

It is a bird of considerable size, the female measuring about fifteen inches in length, and forty in extent of the wings; and weighing about ten ounces. The maie is smaller. The weight is in tolerably fair proportion to the dimensions, as compared with more formidable birds of prey, but it is small as compared with the bulk; and hence the bird steals as silently through the air as if it were altogether a bundle of soft feathers.

The plumage is rich in its ground colours, and finely and elaborately marked. The ground colour of the upper part is orange, and that of the under part buff. The upper is marked with black streaks, and finely and minutely sprinkled with white, grey, and black, lighter at the margins of the feathers, so as to give them distinctness and relief, but exquisitely 
marbled toward the shafts. The markings on the under parts are lines and arrow-head spots. The quills are orange brown, barred with blackish brown; and the tail feathers greyish orange, barred and spotted with black. The feathers on the tarsi and toes, which are without markings, are nearly the same colour as the tail. The irides are bright reddish orange, and give the eyes a very fiery expression, surrounded as they are by radiated concha, marked with white, grey, and black, the black contrasting with white at the inner angle, and giving an appearance of depth and enforcement to the eye. The ear-tufts, or horns, which the bird can move at pleasure, are about an inch in length, the feathers well defined, varying in number, but generally six or eight, sometimes ten, and black toward the shafts, with the margins grey and white.

The long-horned owl generally takes possession of the deserted nest of some other bird, such as one of the crow tribe, which nestle earlier, and thus have their broods out of the nest by the time that the owl lays. The eggs are seldom if ever more than six; white, and rather round in shape. The young are covered with very close white down; and as they have much plumage to acquire, they remain four weeks in the nest, the parents feeding them largely, and with much assiduity all the time. They even feed them longer; for the young birds "branch" for some time before they take wing and hunt for themselves; so that when they have disappeared from the nest, they may for a time be detected in the twilight, moaning for their food from some neighbouring tree. They very early show fight, by hissing and snapping with their beaks; and the old ones, if wounded, do the same, throwing themselves on their backs, and fighting determinedly with their claws.

The old ones are usually still during the day, or if necessity force them to hunt, it is in the depth of the shade; but they are active in the twilight, being voracious feeders, and though they prefer mice, they also prey on small birds, which they are said to clutch on their perches. The prey is taken with 
the talons, but the beak is used in breaking the bones, the only preparation which owls of any species are understood to give their food previous to swallowing it: that may be one of the reasons why mice are preferred to birds, the feathers being more untractable than the fur, both in swallowing, and in casting in pellets or quids.

THE SHORT-TUFTED OWL. (Strix brachyotus.)

This bird is of smaller dimensions, but stronger and heavier than the former, inhabits more exposed places, and in the course of the year undergoes greater fatigue. It breeds in the north, with us chiefly in the Orkneys, in so far as has been hitherto discovered, but it ranges southward over the greater part of the main land. During their migrations these owls are partially gregarious, roosting in small flocks, though they hawk singly over the fields; but in the breeding season they disperse themselves in pairs. Mice are their principal food; but they also swallow small birds; and when the weather is dusky, and they hawk during the day, they pursue, if they do not capture, larger birds, such as grous, partridges, and even pigeons. The feathers on their heads generally (as well as the eye-tufts) are much shorter than those of most other owls, so that the beak and shape of the head are better seen. Hence they are sometimes called "hawk-owls." The tufts are moveable as well as those in the former species. When in a state of repose they are barely visible; and in the dead bird they are laid flat and do not appear. Their prevailing colours are orange and dull yellow, with brown marking. The irides are yellow, the bill bluish, and the claws black; the latter much hooked and very sharp. It is a bold and resolute bird, and defends itself with spirit equal to, or greater than that of the former. The short-eared owl does not frequent the woods, but keeps the open fields. In its breeding places it nestles in heath, or tufts of grass, the eggs being understood to be rarely more than two; and when it 
ranges over the main land, its hiding places are similar. When disturbed it flies only to a short distance, where it eyes its disturber with a peculiar mixture of wonder and wisdom.

\section{THE SCOPS-TUFTED OWL. (Strix scops.)}

This is the smallest of the British tufted owls, measuring only about half as long as the last mentioned species. Its tufts form a sort of coronet across the head, marked by nearly a straight line on the under part, and most produced at the sides on the top. The colours are finely marked, and the form is more light and slender than that of most of the owls. Its tarsi and toes are bare, which shows it to belong properly to warmer climes. It is indeed of so rare occurrence in England, as a straggler, that though it is interesting to collectors, it can hardly be considered a British bird; and it certainly is one which common observers have not much chance of seeing.

The GReat white, or SNowy owl. (Strix nyctea.)

This species is by much the largest of the smooth-headed or tuftless owls, being two feet in length, and nearly four feet and a half in the extent of the wings. Its mature plumage is altogether snow white: but the young birds and females are marked with brown or dusky spots and bars. The tarsi and toes are very closely covered with long feathers, which partially conceal the claws; the claws are strong, sharp, and much hooked, and they and the bill are black, the latter with a tinge of blue. The concha around the eyes are very close and well formed; and the upper parts, which meet at a well defined angel over the beak, are directed outwards, and form a very close shade to the eyes.

The whole plumage is more compact and smooth than that of any other British species, and particularly more so than those which inhabit woods, and have the shelter of them in 
the inclement weather. Their covering is generally so con. structed as that they may glide through the sprays, yielding to these as they pass, and thus pursue a noiseless course in places where many of even the small birds would occasion a rustling. The snowy owl, on the other hand, is tempered to the storm, and perhaps better defended against the cold than any other bird. The only parts of it that are exposed are the tip of the beak, the points of the claws, and the eyes. Eyes do not feel cold, in consequence of the texture of the external parts, and the inferior conducting power of the substance of which they are composed; and the same may be said of the beak and claws. Every part of the owl that could feel cold, or have its power of motion benumbed, is completely muffled up in plumage, the colour, the texture, and the abundance of which all contribute to enable it to live, and not to live merely, but to seek its food safely and successfully in the utmost violence of those snow-storms witl which winter sets in on the Arctic lands.

It is chiefly found in those dismal countries, and performs not an unimportant part in nature's operations there. The long summer days, the rapidity with which vegetation proceeds under the continual action of a never-setting sun, and the vast production of insects and mountain berries which are the result, enable different species of grous to rear their broods more abundantly and more certainly than they do in climates farther to the south. Those products of the Arctic season which supply food to the broods of these birds would be lost if the birds were not so abundant; and it is a law in nature that nothing shall be lost. But the grous could not all, or nearly all, be supported during the long winter; and if they were not taken by the owl, the jer-falcon, and other predatory birds, they again would be lost. So, when the wind beats, and the snow drives, so that they would sweep the birds to destruction, out comes the snowy owl, clad in his armour of impenetrable fur, and riding on the wing of the tempest, keeps holiday amid the wildest turmoil of nature. Mountain hares and other small quadrupeds would meet with the same 
fate from the weather; and therefore they also become the prey of the owl. The number of those birds is, of course, tempered to the necessity that there is for them; and therefore the quantity of birds of which they make prey tend rather to preserve than to exterminate the species.

Time of the day is a matter of indifference to the snowy owl during the storms or the fogs. When the sun is hot, it takes shelter under some ledge of those wild rocks, in the fastnesses of which it nestles, and annually rears its brood of a single pair. But when the snow drives it is dim twilight all day long, and not very different during the fogs. At these times the snewy owl flies low, after the manner of the eagle owl, and the prey which it captures is so abundant, that it not only waxes fat during the storms, but retains its fatness when drifted by the winds to the distance of a thousand miles. It is found in the Orkney and Shetland isles, especially the latter, though not very abundantly, and generally in such obscure places that the nest is not often seen. Its principal food is birds upon the moors of those islands, and rabbits on the sandy banks by the margin of the sea. Countries in which snow dims the eyes or fogs cloud the vision of those animals on which it prey, appear to be the most congenial to this interesting bird. Accordingly it very rarely comes to the mainland of Britain; and when it does it is always during violent snow storms from the north, which also bring the northern birds not generally visitants of our shores. When it comes, it perches on the top of a wreath, or on some stick or other point jutting out of the snow, and as it is not very unlike a lump of snow itself, it causes but little alarm in the birds, and so captures them with ease. It feeds indiscriminately on game which it kills, and on carrion; and as those storms which brings the snowy owl into places where it is not usually found, in general prove fatal to numbers of birds and small quadrupeds, one of the functions which it performs is that of scarenger. 
The LitTle owl. (Strix passerina.)

A figure of this owl is given on the plate at page 83 , immediately under that of the great-eared owl, and on twice as large a scale in the lineal dimensions, that is on a scale of onethird of the natural size in line.

The little owl is only about seven inches long, and fourteen in the stretch of the wings. It is rarely seen in England, and if it breeds in the country its nest has not hitherto been met with. When seen, it is generally in the antumn, so that it may be blown across in the course of its autumnal migration, but it is worthy of remark, that it is not confined to the mere verge of the eastern sea, as European birds generally are when they drift, but has been noticed also on the west and south-west. The little owl resorts to the vicinity of human dwellings, and nestles, and generally hides itself for the day, in holes of old walls. It is an industrious and successful mouser, and though its wings are not very long, it is more quick in the use of them than some of the larger species. Its Hlight is not confined to the twilight, for though that be the time at which it is most successful in mousing, it hawks, especially on dark and cloudy days, during which it may be seen in pursuit of swallows, opposing a direct flight to their wheeling one, and endeavouring to meet them as they come round.

THE FEATHERY FOOTED LITTLE OWL. (Strix dasypus.)

Occurs in the south of England. It is rather larger than the former; brown with white spots, paler, and the spots larger on the under part; tarsi feathered; found in the woods.

SCREECH OWL, TAWNY OWL, OR BROWN OWL. (Strix stridula.)

That is one of the most sage-looking of the owls, which it owes partly to the much produced feathers round the face, partly to the bluish black irides, which make the eyes seem 
very large, and partly to the subched tone of colour in its plumage. It is a large, and rather a powerful bird. The female sometimes measures one foot three, by two feet eight, and weighs nearly a pound; the male is much smaller and lighter. The prevailing colours are tawny brown above, and tawny orange below, but minutely, and when closely inspected, beautifully mottled with brown, and spotted with white. The feather's round the eyes, which form a complete mask to the chin, and nueet over the beak (which is straw colour) at a very acute angle, are white, finely radiated with brown and grey, and having narrow irregular wings of brown on their margins. The tarsi are short and strong, and they and the toes and claws are brownish orange. The tint of the male bird inclines more to yellow, that of the female more to red.

The tawny owl is a bird of retirement, frequenting the depths of forests or groves, and nestling in the hollows of old trees. It will sometimes take up its abode in a single close tree near the house, in the ivy which covers old walls, or sometimes in a barn or in an out-house; but these latter places are not quite natural to it, and it is attracted to them chiefly by the abundance of game which their vicinity affords.

In the barn it is a most excellent mouser, but it is just as destructive in the pigeon-house, where, if it can find access, it commits great devastation. It is also very destructive to the young of rabbits, hares and partridges. It seizes its prey with great boldness, skinning the mice before it eats them, and tearing the larger game in pieces.

It is more strictly a night owl than many of the others, the light concha and the prominent eyes probably admitting too much side light into the eyes, or obliging it to close the pupil, by which means its vision is confused, so that it can with difficulty see its way; and when overpowered in the sunshine, it may be struck down with a stick. There is no doubt that the feathers around the eyes of owls, which are in general capable of partial erection, serve to collect and concentrate the light on which they fly as well as to exclude the side lights; and the eyes of this one, not being so deeply enfonced as those of 
most of the others, are not able to bear the solar light when collected by their own reflectors, and by the very convex external surface of the aqueous humour. People with prominent eyes are least able to bear strong light.

The tawny owl, though not very numerous in any part of the country, is very generally diffused in all wooded places, which are in the neighbourhood of an adequate supply of food. It is most partial to rank soils, overrun with vegetation, and containing decaying trees, tangled ivies, and unpruned bushes; because there it can find a resting place hidden to its heart's content, and also a more abundant supply of food, than in places which are either more open or better kept in order. "The screech owl shall lodge there," is no bad expression for the desolation and neglect of a place once carefully attended to; as, before it takes up its abode, the place must not only be in ruins, but vegetation must have made so much progress as to half veil the ruins from the day; and afford cover to those murine quadrupeds on which the screech owl preys.

Accordingly, it is the screech owl which, above all others, superstition has converted into a bird of horror and of evil omen. Its hooting, which is accompanied by a remarkable inflation of the throat, is deep and dismal, though solemn and impressive; and when the attributes of place and time are taken into the account, the effect which it produces upon the untutored mind is hardly to be wondered at.

\section{BARN OWL, OR WHITE OWL. (Strix flammea.)}

This is the most common, the most familiar, the most useful, and in its plumage perhaps the most beautiful of all the British owls. Instead of spurning the society of man, it courts the neighbourhood of his dwelling; and while it is more destructive of mice, in all their species, barn, field, and bank, than any of the other owls, it stands not accused of destroying any sort of game, even in the young state, though it sometimes does pursue small birds. It does not skin its mice, but breaks 
the bones, and returns these and other indigestible parts in pellets or castings, the quantity of which in a hollow tree or other cavity, which has for some time been the abode of owls, is very considerable.

The barn owl, though it has not the destructive habits of the tawny owl, and though the fact of its hooting like that and the snowy owl rests on the single testimony of Sir Wm. Jardine, yet merits the encouragement and protection of mankind; and in fact wants nothing but not to be persecuted, in order to make it both familiar and useful. The amiable, eloquent, and enterprising Mr. Waterton, of Walton Hall, has taken a colony of owls under his protection; and his paper on the subject in No. 23 of Loudon's Magazine of Natural History, is equally curious in its facts, and delightful in its spirit and naiveté. About 1814, despite the alarms of the old housekeeper, he founded a colony of owls, over the ancient gateway; for, whatever might be the fears of others, it is not to be supposed that he who, (vide his most romantic wanderings) in the wilds of Guiana, and to the admiration of men of all colours, rode triumphantly ashore on the back of a cayman, bridling the formidable reptile with its fore paws, would be timid of owls at his own threshold in England.

The owls have multiplied in a truly patriarchal manner, nestling not only in the original ivy, but in the neighbouring trees; and so familiar, without being either tamed or trained, that all their habits can be studied with the utmost ease; and those habits are evidently much more their natural ones than when they hide themselves on the approach of man. They admit of being visited in their nests and perching places, upon which latter they repose in an erect posture. They utter their stridulous cry, morning, evening, and all night long, whatever be the state of the moon; but up to the publication of his paper (January 1832) Mr. Waterton's owls had not hooted, though like others they hiss and snap with their beaks when violence is offered to them. The snoring noise is the complaint of the young for food; and the hearing of it in winter led Mr. W. to the discovery that owls have 
very late broods. It used to be repeated from one to another that owls snored in their sleep, but the structure of the breathing apparatus in birds is against that hypothesis, and corroborative of Mr. Waterton's observation.

These owls, as is the case with domestic birds, do not breed only at one particular season, but all the season over, as late as December, and many of them, no doubt, have two broods.

The number of mice that a colony of owls could thus destroy would be immense. A mouse every twelve or fifteen minutes, Mr. Waterton says, is the allowance brought to the young; and the (pair?) in the old gateway cast up a bushel of pellets in sixteen months, each pellet containing the skeletons of from four to seven mice. Thus, if owls were established at every farm, the caterwauling of cats, which is more unmusical than any other sound of animal, would be less necessary, the houses would be cleared of mice, and probably - eaten up by black beetles.

It may be further noticed on the score of the hooting, that the utterance of such a sound would be rather against the barn-owl in its mousing. The hooting, except in so far as it may be a love note, must be calculated to stir the game, and therefore applicable only to birds on the perch or lying close, which when they stir, stir into notice, and not to mice, which when alarmed stir out of both notice and danger. The familiarity of these owls is proved by one picking up a rat in sight of Mr. Waterton, not long after he had fired a shot; and he records some fresh instances of their fishing.

The barn-owl is about the same dimensions and weight as the tawny owl, only a little longer in the wings, as birds that fly in the free air are generally longer winged than those which inhabit forests. Its general colour on the upper part is yellowish brown, and on the under part white. The upper part is streaked, spotted, and sprinkled with white, grey, and dusky; and the concha are dusky round the eye, but passing into white at the margins. The sexes are equal in size; but the male has more grey above, and more buff on the under 
part. They are well defined; and as the dark line at their junction extends almost to the beak, the two when seen in front have something the aspect of a pair of large spectacles, while the single one looks a little like the cup of a convolvulus with a dark eye at the bottom.

Owls are supposed to be of use about dams and mill-ponds, by capturing the rats and shrews which bore into the banks. They are of use in churches, and other places which are only occasionally frequented; for though " church mice" are proverbially lean, they are on that account the more apt to attack and destroy whatever may either by accident or design be left in their way.

VUUTURES.

Vultures being birds which prey almost exclusively upon animals in a state of putrefaction, or upon those which have the weakness of disease and the "scent of death" upon them, are not birds adapted either to the course of nature, or to the state of the arts in Britain. They are found in wild places, where undomesticated animals perish by the casualties of the weather; on the margins of great rivers, where animals are drowned, and left by the subsiding floods; and generally in tropical, or at least warm countries, where the taint of their food can be borne far by the air. But as there is one which comes occasionally, though rarely, as a straggler, a mere notice of that one may be given.

THE ALPINE VULTURE. (Vultur percnopterus.)

This vulture measures about two feet and a half in length, and, in the largest specimens, between seven and eight in the stretch of the wings. The full grown male is nearly white; the female brownish, with the wing feathers very dark brown, margined with grey. The beak is long and narrow, the face naked, and the whole bird of an uncouth and ragged appearance. 
They come farthest when the weather is very hot and dry, because then the scent is not only strongest, but the wild animals get sickly or perish through the failure of the pastures. They very rarely visit England, though a pair was seen near Bridgewater in 1826 . They are light in proportion to their wings, and thus they are long flighted birds. They appear to be perfectly inoffensive to living animals, and are, no doubt, of great use in helping to keep pure the air on the margin of the great desert which extends from the west of Africa far into the east of Asia. That is their proper locality; and though to us they are rather repulsive, they are, in their own proper place, very serviceable birds.

Such are short notices of the whole, or nearly the whole, of the British birds of prey, the best defined as an order, and on many accounts the most interesting of all birds. Resident or visitant, they are adapted to all situations, all seasons, and all hours of the day. Those that feed upon animals which are valuable to man, court the desert and the depth of the wood, shun the dwelling of man, and flee at his approach. Others, such as the barn-owl, which destroy only those animals that are noxious to man, court his society, probably multiply as improvement and cultivation spread, are easily tamed, and if once tamed, show no disposition to wander when left at liberty to do so, but will even return to the house after being driven away. They in fact need no taming; for Mr. Waterton simply placed a stone upon which they could sit, planted an ivy in which they could find shelter, and forbade the molesting of the birds, and the destruction of their eggs, and they remained and multiplied, became familiar without being troublesome, and were diligent servants without expence. 


\section{ORDER V.}

\section{OMNIVORA OR OMNIVOROUS BIRDS.}

THE CROW TRIBE, AND BIRDS OF SIMILAR HABITS

Omnivorous is a vague, and not a very applicable expression; for there is not, of course, any bird or other animal that can eat " every thing," neither is there any species of bird that has not some favourite description of food, of which when it can be had the bird is fonder than of any thing else. Most birds, too, are somewhat miscellaneous in their feeding; and there are probably none which cannot, when compelled by hunger, subsist upon food which they reject when they have abundance of that which they like better.

But after the orders that have been already noticed, it is not very easy to select names descriptive of those particulars in which tribes of birds resemble each other,-too slightly, and with too many variations for allowing them to be included in the same genus, and yet having so much similarity that the description of one serves partly for that of the others. This is the practical use of forming birds into orders; and if the name can be made expressive of some very general and obvious property, such as that of killing prey in the rapacious birds, it is so much the bêtter; but when that cannot be done, a more vague term must be used, and rendered as definite as possible by definition.

It is in this sense that the term omnivorous must be taken. These birds are more miscellaneous in their feeding than any of the others. They eat most animal substances, carrion, insects, seeds, and other farinaceous and pulpy regetable 
substances, and some of them prey upon living animals, though generally weak ones, or when they are in an enfeebled state; and most, if not all of them, plunder the nests of other birds, eating indiscriminately the eggs or the callow young.

CHARACTERS OF THE: OMNIVORA.

Plumage close, firm, and glossy: the feathers 'jeing of hard and compact texture on all the exposed parts, with the exception of the head, which has sometimes loose feathers or a sort of crest. Colours strong and pure, uniform or with bold contrasts, Prevailing colour of those which are most decidedly British, black, with green, blue, purple, or bronze reflections of metallic lustre. Other colours, grey, white, blue, and green, rarely brown, and never red or yellow in any species resident in Britain, or regularly appearing as a visitant; though many foreign ones are very gay.

Bill of mean length, coulter-shaped, strong, ridged, pointed at the tip, and fitted for punching or digging, convex on the upper side, and often with a margin. The feet, formed for walking or for perching, have three toes before and one behind; they walk firmly, and many of them also hop with the assistance of the wings. The wings are of average length, firm in the feathers, and pointed at the tips.

Nestle in the tops of trees, in thick brakes and bushes, in the clefts of rocks, and in old buildings, or buildings that are elevated above ordinary reach, or in the hollows of old trees. They are all monogamous, but many of them live in large societies, even during the breeding time; and the more solitary ones also hold occasional assemblies. They range to considerable distances for their food, which they seek only during the day. They are rather noisy, but their noise is harsh and unmusical. Many of them frequent cultivated places, and are highly useful to man. Their flesh is hard, black, and bitter, though the young of some are eaten, being skinned before they are dressed. 
The omnivora, partly no doubt from the ease with which, in consequence of their miscellaneous and ready appetite, they can be fed, are all easily tamed; and in that state they are capable of very considerable attachment, both to places and to persons. They can also be taught to articulate words; and it is a curious fact in ornithology, that the birds which are the most easily taught to do that, are also the more remarkable for the roughness and harshness of their voices, and the absence of any thing that can be considered as natural song.

There are two divisions of them, the crows, properly so called, whose characters are well defined; and the other genera, to which no common name can with propriety be given, as they vary so much both in their appearance and their habits.

crows. (Corvus.)

Colour generally uniform; prevailing hue dark, generally black, of different shades and with numerous reflections. Bill very strong, upper mandible slightly bent at the tip. Tail of moderate length and rounded. Very numerous, found in all situations from the mountain top to the sea shore; but some prefer cultivated places, and others the wilds. The former are, generally speaking, the more social in their habits; the latter partake more of the characters of predatory birds.

THE ROOK. (Corvus frugilegus.)

Every body knows the rook; the dark, the noisy, and sometimes the nest-plundering, or, in the early fields, the contribution-levying rook; but still, notwithstanding, the cheerful, the orderly, the industrious, the discreet, the beneficent rook. There, in the aged and stately trees, he builds his wicker castle, chants his rude and monotonous cry the while, dwells among his brethren and his kindred, and looks 
down on the lord of the manor with as much self-possession as if it were he who suffered the wingless rustic to toil with heavy steps through the sticks that fall from the nest of his superior.

Nor does he loiter away his time in the manorial bower. He looks after the estate, and gives a very broad and at the same time pointed hint to others, if they would take it.

When the frost is severe and the snow lies thick, off he flies to the sea beach or the river side, and inter alia, inspects the embankments, weirs and dams, to notice if the teredo has bored into the posts, or any other injury has been done by small enemies, that can be productive of damage when the thaw and the flood come. Or he comes nearer the house, and examines the compost, in order to see that when you apply it to enrich the fields, you do not at the same time scatter insects which will eat up your young plants, and deprive you of your crop.

When the thaw comes, he hurries to the meadow, and examines the debris which has been cast there by the swollen stream; and if he finds in it the germ of any noxious thing he pulls it out, so that the blessing of the hill may come upon the valley, pure, wholesome, and without offensive addition. Next he goes to the autumn-sown wheat, and, by a curious instinct, kllowing those plants that are sickly, he delves down, and extracts the larva of the cockchaffer, or whatever earth caterpillar it may be which is only waiting for a few gleams of a warmer sun, in order to render your labour abortive, and compel you to plough and sow that field anew. Again, he is over the pasture, and every stool of grass and plant of clover undergoes a like patient and well-directed scrutiny; and, by the time that " the day is done," he returns to his perch, cawing to inform you that the labour is accomplished, and the labourer paid, in less time than you would take in considering how to do either the one or the other.

The great additional labour of the rooks is the preparing of their nests, and the rearing of those families which are to continue the society, and watch over the state of the fields, 
after age or casualty shall have given their own feathers to the winds and their flesh to the raven; and their early rising, their constant labour, and the order and police which they maintain, are all very curious. Their time of commencement is the first of March, a little earlier or a little later, according to the season; and, as the building of the nest and the instinct by means of which that nest is to be stocked come to maturity together; so, if the lapwing storm, which, raging on the shores, and in the low country, helps to drive these beautiful birds to the moors, be long and protracted, the nestbuilding is suspended till it blows over, and the rook contents himself in the interim with watching the safety of those sticks that are already placed.

But if the season goes cheerily on, and there is no interruption, the cawing and the bustle begin at the greyest dawn; and that man is most industrious that can get to his work before the rook. "Ask the beasts, and they shall tell; the birds, and they shall instruct." It is good, at that season, to be near a rookery. There is no lullaby in their cawing: you cannot sleep; and they will not allow you to be dozing and "losing thought" in bed. Rise you must, or suffer for it. But they do not annoy you at nights " Early to bed and early to rise" is the rooks' maxim, and if you follow them as far as that, the rest will follow of necessary consequence.

But their admonition does not stop there. The farmer's busy time is their busy time ; they feel that he is as necessary to their present profit as they are to his future; or they act as if they so felt, which in effect comes to the same thing. If he will not bring out his teams, turn the soil, and expose the worms and the grubs; they caw over his fields, and make the some sort of lamentation that a hungry man does when he knows that there is meat in the house, but the careless servant has lost the key of the larder.

But if the teams are all a-field betimes, slicing the sward or the stubble, and turning up the fresh and fragrant earth to be mellowed by the action of the sun, there is not a complaining note among all the fieldward rooks. Gallantly they 
strut and incessantly they pick up the larvæe and the worms, so that the returning plough cannot bury and so preserve in the soil a single destructive thing. And you would think that the memory of gratitude was strong in them, and that they know upon whose territory they depended, when their own was locked up by the snow and the frost. At that time, he resorted to the shores of the sea, and fed on the pastures of the gull; and now that it is his time of superabundance, the gull comes for a share, and the rook, instead of offering any resistance, mixes with the stranger on the most friendly terms. Even the pigeon comes from the cote or the wood, and the very poultry and ducks come from the farm-yard, and mingle in peace with the wild tribes, - such charms has the timely labouring of the ground.

The plentiful supply of food which, in the course of a few hours, the rooks obtain at this season, enables the one-half of them to be always, and the greater part of them to be sometimes, at work in the rookeries. It has been said, though after a good deal of observation I cannot verify it, that the strong sometimes help the weak in the construction of their nests; but it is certain that those which have been detected in filching sticks from the nests of others, are punished, not merely by the parties they have plundered, but by others. The attachment of the pair during the nestling time is the strongest of their attachments; but there is a feeling towards the society, and even the place, for if part of the trees are cut down, the rooks will accommodate each other upon the remaining ones, often so thickly as to contain two nests in the same fork, without any signs of hostility between either the old birds or the broods. In close time the male does not take turn in sitting, and when the action of the eggs has begun, the female is never long absent from the nest; but the male certainly does bring food to her, and appears as willing to bestow as she is grateful to receive. After the young are of such an age as that they can be left, both parents assist in feeding them; and as the working of the land goes on during the time, or if not, the larvæ come near the surface of the 
pastures, an abundance of food for the numerous broods (the average is five) is obtained without much difficulty. The feeding continues after the birds leave the nest, and "branch;" and when there are several broods on the same tree, cach parent appears to know its young, and each of the young its parent, with as much certainty as the ewes and lambs of a flock know each other, though the ewes are browsing and the lambs sporting indiscriminately over the pasture. The pairing attachment weakens, if it does not altogether cease, as soon as the young birds are able to shift for themselves; but the social instinct, which is the bond of union of the rookery, continues not only for life, but through as many generations as the trees continue; and if these are cut down en masse, the birds remove en masse to a new locality, generally as near the old ore as they can.

The treatment of orphan broods, and the disposal of widowed rooks, are curious points in the domestic history of a rookery; but they are points upon which, from the similarity of one rook to another, it is very difficult to get accurate information. There is little doubt, however, that when any casualty happens to the parents after the brood are of such an age as that they can complain, the others do relieve their wants. Indeed, it is very possible that all species of birds contribute at times to the support of orphan broods of their own species, otherwise, from the casualties to which the parent birds are subject, we should meet with many more instances of young that had died in the nest. As for the wirlowed ones, there is no doubt that they pair again the next year, so that there is never more than one odd bird in a rookery; and it has bcen asserted that one of the ways in which new rookeries are formed, is the pairing of the odd birds from existing ones. During the pairing season, one may often observe a rook flying about in a hurried manner, and cawing in a sharper and more anxious key, without carrying sticks, or taking any share in the husiness of nidification; but whether they be the odd ones it is not easy to say. Couriers sometimes pass and repass between the different rook- 
eries, upon terms that are evidently amicable, but the messages which they carry are known only to the rooks themselves. There is no doubt, however, that all birds which live in societies have some signals by which they recognise each other; for when the rooks of different rookeries feed together during the day, but go home at night, each party takes its proper course, though occasionally one or two will follow the wrong leader for a time before they discover their mistake. Rooks have a history which is neither brief nor void of interest; and they are so numerous, and found in so many places, that any one may study it.

It need hardly be added, that the rook is of a fine glossy black, of almost the only tint of that colour which is lively; that the sides of the head and neck are glossed with very rich blue, of which there are traces, but deeper and less perceptible, on the coverts. The beak is straight in the gape, with near equally similar outlines to both mandibles. The skin at the base which is light grey, is covered with black feathers extending over the nostrils, in the young bird, but these are wanting in the old. The common opinion is, that it wears them off in digging, which is not very likely, as much more laborious spade-work does not injure the fur of moles, or the feathers of some other birds. There is a power of reproduction in the bill, and if necessary there would be one also in the feathers which the young bird has at its base. The replacing of the feathers by scales, rather indicates a natural habit in the bird. The natural dimensions of a full-grown rook are, about nineteen inches long, and thirty.eight in the wings; and the weight is about nineteen ounces.

\section{THE HOODED OR ROYSTON CROW. (COrvus cornix.)}

This bird is larger than the rook, being an inch longer, an inch broader, and about three ounces heavier. Its head, wings, and tail are black, but less bright than that of the rook, though there are some blue and green reflections toward the sides of the neck; the rest of the body is of a dull 
smoke-grey. It is a stronger bird, but less handsome and less interesting in its manners. Its principal food consists of eggs, young birds, and carrion; and it may be described as a prowling and gross feeding bird, plundering all that it can find, killing all that its cowardly nature will allow it to master, and feeding greedily upon any garbage that comes in its way. Other birds seem to know and dislike it, for even the small ones fly about it, and beat it with their wings.

In England, the hooded crow is only a winter migrant, appearing in the month of October, and taking its departure about the first of April. During that time it is also most abundant in the richer districts of the Scotch lowlands, in which it seldom breeds; but as the latitude, and also the cold from elevation, increase, the birds are found more numerous; and in the high districts, and the Orkney and Shetland Isles, the hooded crow, or simply "hoody," as it is called, is the crow, and the rook and carrion crow are but little known.

When in the south, the hooded crows usually appear in small flocks, and come not only to the corn-fields but to the neighbourhood of villages and even of towns, gather any garbage that they can find, and play the scavenger in the kennels and at the lay-stalls. On the sea-shore they are not uncommon, where they pick up dead fish and birds, or any sort of animal substance, no matter how decayed or putrid, that may have been left grounded by the tide. They are also said to be adroit in opening muscles and cockles, and in twitching limpets off the rocks, or even in boring or hewing through the shells of such as they cannot detach. It is also said that the large limpets sometimes close upon their bills, till they are retained and drowned, which may be true, as the limpets hold on with the cloak, and not the shell; and there are limpets so large, that the adhesion is equal to a force of from twenty to thirty pounds.

They also prowl about the preserves, warrens, and pastures; and if they find any animal in a disabled or weakly state, they punch out its eyes; and if they are not able to kill 
it on the spot, leave it to perish, and return to the carrion at their leisure. In the north, they carry on similar depredations during the whole summer. The number of eggs and young birds of grous, and other species, which they destroy, is very great; and in some places of the Highlands and the northern isles, and especially in the Faroe Islands, they rob the ground of the seed corn and seed potatoes.

During their breeding time they disperse, because the uplands, where they have their nests, could not support a large colony of birds so voracious; but they do not pass immediately to the breeding places. They get back as they may, according to their powers of flight, and meet at some rendezvous; in all probability, near the place where they were hatched. There they assemble, and remain for some time in solemn deliberation (as some say) upon the conduct of the campaign, and make a solemn inquest into the southern " foray," with grave judges, brawling counsel, anxious clients, and all the paraphernalia of a court of justice, with the exception of witnesses, and of these even Landt maketh no mention. Some also are left for execution-no, left executed ; for the dead bodies are left on the place of meeting, as food for any creatures which may be fouler feeders than themselves.

But all this execution of the law for one campaign, and enacting of it for another, is, in truth, nothing more than the simple and natural operation of pairing, in the course of which, though they are strictly monogamous and constant, there is some rivalry, duelling, and bloodshed at the outset. The grave judges are, in reality, desponding lovers, rejected swains, and unwooed damsels, whose heads are weighed down, not with wisdom, but with woe; the wranglers are rivals, settling their affairs of gallantry; the anxious lookers on are the females, who are to fall to the lot of the conquerors; and the dead bodies are the remains of those who have, not ignobly, bled for all-conquering love.

When all is settled, the pairs wend their several ways over the wild, nestling in the rocks or trees as the one or the other 
may be most convcnient, building the external part of their nest with sticks, after the manner of the rooks, but, contrary to the custom of thesc, lining it with wool or hair, which they do not hesitate to pull from the back of a sheep or other animal; and if hc be wcak, lame, or laired (stuck in the mire), they punch out his eyes into the bargain, and take note of his carcass, as a substantial addition to the larder.

When one first meets them in scores upon a Highland moor, on a foggy day, having been previously familiar with the rooks of a less savage land, one imagines that the crows have been snowed on till thcy have become hoarse, their croak is so "inward" and laborious; but they have also a sharper sort of crowing notc-a kind of note that seems to belong, in some degree, to most birds that fight for possession of their females. The eggs are about five, which is indeed the usual number with all the crow tribe. As the season becomes cold, they migrate, or come down to the low country to pass the winter; and if that is more than usually severe, the grey upon them changes almost to white. When the snow falls heavy, they resort to the margin of the sea, and the very doors of the cottages ; but occasionally take an excursion to see if any creature has perished, or is perishing, in the snow; and if so, and the body is considerable, they soon come in a flock.

THE CARRION-CROW. (Corvus corone.)

The carrion-crow, though smaller in size, (about eighteen inches by thirty-six, and eighteen ounces in weight,) and diffcrent in colour, being wholly black, exccpt some greenish reflections on a few of the feathers, has so nearly the habits of the hooded crow, that doubts have arisen whether they ought not to be considered as varieties of the same species, produced by climate, the hooded one being whitcned by the cold. That the hooded crow bccomes whiter by exposure to intensc cold, is one argument, and the production of a mixed breed between them, is another, and would be decisive, if 
that breed were fertile in itself, and without any return towards the pure blood of either; but this has not been ascertained, and thus the mixed breed may be merely a mule, the same as that produced between the goldfinch and canary.

Independently of that question, which, being one of science and system, we are not called upon to discuss, there are, besides the mere size and colour, sufficient differences of appearance and habit to form a popular distinction. The carrion-crow has much more the air of the raven than the hooded crow; it is heavier in proportion to its length; it is firmer and bolder ; it frequents different situations ; and even when they are together for a time, the one race go one way, and the other another.

They nestle in ligh trees, but they prefer the neighbourhood of rich countries, and hence they are not found in the Highlands and northern isles. They prowl about even to the doors of the houses, and into the poultry yards, and are voracious devourers of eggs, young poultry, young rabbits, and young game, even more so than the regular birds of prey. They punch out the eyes of weak animals, hawk at birds on the wing, opens-shelled mollusca on the sea-shore; and there are modern instances in corroboration of the story of the ancient philosopher who was killed by a crow mistaking his head for a stone, and dropping an oyster on it in order to break the shell. One of these was seen by the celebrated Watt. A crow caught up a crab, rose with it to a considerable height, dropped it, not on the head of a modern philosopher-or he might have come more safely off than the ancient one-but on a stone, and descended to her feast.

Though not a very long winged bird, the carrion crow rises to a considerable height, higher than that at which the hooded crow is seen; and in defence of her brood she beats off the smaller hawks, the kite, and the raven. The brood remain with the parent birds till next breeding time; and though these crows collect in small flocks during the winter, they seem to do so rather from an accidental meeting in quest 
of food than from any principle or instinct of a social nature. During the breeding season, each pair keep within their own territory, which is of considerable extent, though at other times they associate during the night. When the spring begins to be felt, they separate: the hooded crows migrate, and the rooks collect together. These are, at least, distinctions of habit.

THE RAVEN. (Corvus corax.)

The raven, though in appearance and also in many of its habits very similar to the carrion crow, is much more a bird of prey. As is the case with the birds of prey, the female is larger than the male; whereas in all the other species of crows the male is larger than the female.

The raven is a powerful bird. It is rather more than two feet long, four feet in the extent of the wings, and more than two pounds in weight. Its colour is black, glossed with blue on the upper part; and it is one of those birds which inhabit almost all latitudes, and have their plumage unchanged by varieties of seasons or of climate. Under the line, and near the poles, in the northern hemisphere, and in the southern, under burning sun, and amid chilling cold, it is still the same dark, forbidding, and hoarsely-croaking raven.

The disposition of the raven is very similar to that of the carrion crow, only as it is much more powerful it carries matters with a higher hand. But as nature tempers and regulates her productions to each other with a degree and even a kind of perfection which man cannot imitate, the raven is much more a bird of the wilderness than any other of the crow tribe. It inhabits wild hilly districts, generally those that are between the low lands and the higher mountains; and though it can well endure the weather, it gives the preference to a southern aspect. Its nest is concealed in a thick tree, or in a cleft of a rock, but it gives preference to the latter. The nest is something after the fashion of that of the carrion crow, but larger; the eggs are five; but as the 
young are exceedingly voracious and restless for their food, that number is seldom reared, as some generally fall out of the nests. In some places, where a long range of precipice stands on the southern brow of a hill, in a district covered in many places with brakes, and abounding with birds and wild game, the ravens dwell in peace; but people occasionally gather up the young which they find croaking in the bushes under the precipice. When taken they strike with their bills, but the only taming that they require is being fed; and they make excellent warders, as few dogs, unless they have been trained, will go in upon a raven. The stroke is very powerful, and given not by the mere motion of the neck, but with the neck stiff, and the whole weight of the body thrown by a simultaneous movement of the legs and wings; and the bird comes on as if the whole of it were a sharp, feathered, and self-directed dart.

The hop of the raven suits his purpose well when he beats the long grass and bushes for eggs, young birds, and leverets. He flings himself into the air with wonderful ease; and when he has cleared the bush he lets himself down with equal softness, so that the feet slide to the ground but do not touch it. The raven thus comes more stealthily upon his prey than almost any other predatory bird; and though he does not repeat his hoarse and dismal croak till he discovers something stir the vegetation, in the act of hiding itself more closely, he comes upon it hopping, and before it is aware.

He moves from place to place on the wing, - and a bold and strong wing it is, less easily hurt by the storm than most others; but he does not beat so much while flying. He gains some high point, and there he sits surveying the whole horizon which it commands, till something promising appears. Then, away he wings, low and stealthy, and lets himself down softly before he arrives at it. Thence he hops, in a spiral or zig-zag, always appearing as if he were to pass in an oblique direction, but nearing his object at every hop.

One often wonders where he can come from; for you may walk the wild for hours without stirring a wing, more espe- 
cially a black one; but if you lie down, especially if you lie on your back, the raven will be close upon you in a moment, examining if you are ready for him. He appcars to know instinctively that the position of the lifeless or helpless body is on the back, with the eyes exposed to the punch of his bill, and therefore he comes more readily and resolutely upon the body in tliat position than in any other.

It may be that the position which the dead body assumes, generally on the back, (on the side in quadrupeds) and always with the eyes open and exposed, is partly assumed to accommodate the raven; for it is a law of riature to reclaim to other use the materials of every thing after it has ceased to be useful itself; and, in those countries where there are no vultures the raven is the consumer general of those carcases which would poison the air of the wild.

To lie down on your back, and lie still for some time, on an exposed part of the hill, is the best way to see and watch the motions of the raven, or to shoot him, if you are so armed and inclined. He is shy of man and of all large animals in motion; because though glad to find others carrion, or to make carrion of them if he can do it with impunity, he takes good care that none shall make carrion of him. If you are even sitting in any posture that indicates life he will not alight near you, though he may reconnoitre you on the wing. But if you lie on your back, he will come you know not whence, and, hovering round you on slow wing, examine you from all points. If you do not stir, he will drop down at a little distance, and begin to hop in an echellon fashion, bringing his shoulders forward alternately after a few hops on each line of the zig-zag. Sometimes he will utter his "crŭcq, crǔcq," and pause to see if that makes you stir, and if it does not he will accelerate his advance. If you allow him to come sufficiently near, his first salutation would be to dash himself at your eye; but if you have a gun you can make sure of him long before that; only "beware the beak," if he is merely winged or otherwise slightly wounded. Notwithstanding, if you take him home, feed him well, and heal 
his wound, he will not only forgive you, but become a faithful servant.

When the raven has young, his excursions are not carried on to such a distance over the wastes; and in very severe weather he comes farther down, prowling under the hedges, and even near the houses, and if he finds any animal in a weakly state, he helps it on its way. Rabbits find no quarter; and even the spiked armour of the hedge-hog is not proof against the thrust of the raven's bill, which is in some respects more formidable than the beaks of the rapacious birds, inasmuch as it stabs to death, and then cuts up the slain like a pair of great shears.

When there is " death on the hill," which there generally is at the time of the spring and the midsummer rains, of birds that are weak from long flights, or want of food during the first of these, and of nestlings unable to fly during the second, it is high feast with the raven; and while all else are driven to shelter, you may find him daring the storm, and beating about for its victims.

The extending of cultivation, and the greater attention that is now paid to the condition of stock, both cattle and sheep, during the winter, have diminished the food, and consequently thinned the numbers of the ravens. In the olden time, when the cattle went first to the hill, there were many of them so weak that they were unable to rise without assistance, so that part of the early morning's occupation for the people was to go round and lift the weakly cattle. The sheep did not absolutely need lifting on the level ground, but if they happened by any chance to get into even a shallow rut on their backs, they were unable to recover themselves; and both sheep and cattle stuck fast in places which stock in better condition could pass with ease. These were days of plenty with the raven, whose morning's work was to go round and punch out eyes; and then, though the animals were found, only the skin was useful to man; and so the raven, who generally sat at no great distance during the operation, soon came and claimed the carcase. In the im- 
mediate destruction of that, the raven was of service; because no browzing animal will feed near the carrion of its own species; and that he was able to begin the work, proved either that the pastures were on the whole overstocked, or that they were injudiciously managed. Indeed, the havoc committed by a predatory animal will always, if duly studied, be found to inrolve an admonition, which, properly acted on, will cure the evil produced by that animal, and produce a considerable reward for the labour it may require in additional and positive good. In those hilly districts where ravens are still to be found, animals are subject to more casualties than they are in the plains, or on the level moors: so that the ravens still have their use there, and the wanton destruction of them is, at all events, a matter deserving consideration.

THE JACK-DAW。 (Corvus monedula.)

The jack-daw is the only other British bird that strictly belongs to the crow tribe. It is a frequenter of the haunts of man, active, noisy, and familiar, almost to impudence; but it is a lively bird; and though at times it may take a little grain, that is far more than compensated by the number of insects and worms that it destroys in the course of the year.

The jack-daw is the smallest of the tribe, being only about half the weight of the rook; but the wings are larger in proportion. It is about fourteen inches long, twenty-nine broad, and weighs between nine and ten ounces, The bill, feet, top of the head, and wing coverts and secondary quills are black. The back of the head and nape smoke grey, and the irides the same but much lighter. The remaining parts black, with a greyish tinge on the upper side, and a bluish on the under. The black is variously glossed with blue and violet reflections. These are the ordinary colours; but like all birds that inhabit culcivated lands, and are of course affected by the differences to which cultivation gives rise, jack-daws vary considerably in colour, partly from age partly not; sometimes the grey is 
nearly white, at other times the bird is black all over; and there are many slighter and intermediate variations.

Holes and ehinks are the immediate places in which jackdaws nestle; but these must be elevated above the level ground, and the higher they are the bird likes them the better. It is probable that the original instinet is the protection of its eggs and young from the weasels. Rocks, the edges of neglected quarries, the projeeting parapets of bridges, torvers, steeples, ruins, the earth where it forms a very steep and crumbling bank, are all resorted to by the jack-daws; and one would imagine that the birds are fonder of the society of man than of having the loeality to themselves. But the fact is, that these birds court the vieinity of human dwellings for the same reason as the house-swallows, beeause insects are most abundant there. Fifty towers may be built in an insectless wilderness, and never a jack-daw would come to nestle in them.

In the winter months, the jack-daws and rooks floek together, and colleet their food on the same fields, and of the same kind, without any hostility; but in the spring, when the rooks return to the rookery or the trees, the jack-daws eolleet about the rocks and towers. Their habits are, indeed, very similar to those of the rooks, with the exeeption of the places in which they nestle, and the materials of the nest; both are generally of stieks, but the jack-daw uses a lining of softer matters. The differenee of their notes easily distinguishes the two speeies, even when they are so blended and distant that the sight cannot. The Seoteh names, "craa" and "kae," are perhaps as expressive of their sounds as names ean well be.

In some places, one would think that there is more in their winter assoeiating than merely accidental meeting on the same pastures. In the latter part of the season, when the rooks from one of the most extensive rookeries in Britain, made daily excursions of about six miles, to the warm grounds by the sea-side, and in their flight passed over a deep ravine in the roeky sides, or rather side, (for they inhabited the sunny 
one,) on which there were many jack-daws, I have observed that when the cawing of the rooks on their morning flight was heard at the ravine, the jack-daws, which had previously been still and quiet, instantly raised their shriller notes, and flew out to join the rooks, both parties clamouring loudly as if welcoming each other; and that, on the return, the time of which was no bad augury of the weather of the succeeding day, the daws accompanied the rooks a little past the ravine; then both cawed their farewell, and departed. What is more singular, I have seen, too frequently for its being merely accidental, a daw return for a short time to the rooks, a rook to the daws, or one from each race meet between, and be noisy together for a space after the bands had separated. With the reason I do not interfere, not being in the secrets of either party; but the fact is as certain as it is curious. In order that any one who pleases may investigate the matter, I may mention that the rooks were from the woods of Panmure, the daws from the den of Pitairley, and the feeding ground was the low part of the parishes of Monifeith and Barry, all in the county of Angus.

From the ease with which jack-daws can be observed, there are many stories of them, and also of the perils to which boys expose themselves in plundering their nests. One of the most extraordinary of the latter, is that of Murray, the Dundee barber. The battlement of the old tower there is about 150 feet above the pavement at the base. Murray (when a boy) went through one of the holes in the parapet, hung by one hand to a Scotch bonnet which another boy held from within, and with his other hand drew the eggrs and young birds from the nests, and put them in the bonnet. While thus employed, he kept warning his companion-" If you let go the bonnet, I'll give you none of the spoil." The jack-daw is easily tamed, and long remembers those who have paid attention to it; indeed it is almost tame in its natural state; but it is noisy and impudent, and not rery honest. 
There are two divisions of these, one with the tail long, and terminating in the form of a wedge, the other with it squared over. There is but one species of the former, the magpie, a resident. There are three species of the second that reside in Britain, and a good many that visit occasionally. All these birds are remarkable for the beauty of their plumage, and the ease with which they can be tamed, and taught to articulate. On these there is still no red or yellow, or even brown, in the plumage, though there is russet in the spots of the starling, and in the general plumage on the body of the jay, and red in the bill and claws of the chough.

the magie. (Pica Melanoleuca.)

Magpies are familiar birds, so well known to every body, that much description of them is not necessary. They associate in pairs, and are more prolific than the crows, the number of their eggs being sometimes eight. They do not chose the very highest trees for their nests, but they always, when there is a choice, select thick and bushy ones; and it has been remarked, that the tree which contains a magpie's nest is seldom uprooted by the winds, even in the violence of the winter. and when the birds are in a more sheltered habitation. By parity of reasoning, that house on the top of which the magpie perches, is in no danger of falling; but woe be to the beast on whose back it perches, for the magpie perches on dead beasts, and consequently, when it perches on living ones, it wishes, prophesies, and even dooms them dead! The magpie is thus a bird which excites very mingled and opposite sensations; it is a bird of hope and confidence, and of fear and despair; but the feeling towards it leans upon the whole, to the suspicious; and one set of the ignorant spare the magpies and their nests for the same reason that another class never mention the name of the devil, except in under tone, 
and with much respect, lest they should come by some heary or bodily harm! And the magpie filches away money and other little matters, and when they are again found, they have much of the peril of witches' money! Nay more ; the magpies actually take counsel together, conspire, and club their wits, for weal or for woe, as it may turn out. If there is an even number, and all are cheerily met, then happy times to the matrons, high hopes to the maids, and health and long life to all the family-or the parish, if the place of meeting is in or near the church-yard! but woe be to that house before which there is an assemblage, with an odd magpie sitting sulkily apart; and tenfold woe, if that sight crosses a lover on his path, or a party on their way to the altar! A black pig crossing the door of a fisherman's hut, or even a dead hare detected in his boat when at sea, is not more perilousnot half so much so; for neither lord of the manor, parson of the parish, nor (where these are effective) "bell, book, and candle," can cast out the evil spirit of the odd magpie!

These circumstances are not mentioned with a view to propagate superstition, and far less with a view to ridicule it; for ridicule is the hammer with which, as a nail in a sure place, it is driven home and rivetted. These superstitions are weeds; but, in every field of nature, weeds are the sure sign of fertility, and the certain guarantee that culture shall produce a crop valuable in proportion as the weeds are rank. The magpie is a very active and a very clever bird, having instincts which are very readily affected by changes of circumstances too minute for ordinary human observation; and therefore there is no question that, properly studied, the magpie would be a capital index to many of the phenomena of nature-a philosophical instrument, more delicate and more varied in its uses than any that man can construct; and if people knew but how to consult their magpies, (and it is a result within the legitimate province of observation,) they would find these better guides to the weather, - - the heat, the moisture, and the motions of the air, and the effects of these upon the earth,than any apparatus formed of dead matter. There is nothing so 
susceptible as life, and the magpie is probably one of the most susceptible of its winged forms.

It chooses the thick tree because that can best support and conceal its large nest, just as the eagle and the raven choose the cleft and ledge of the rock.

Most birds, by the way, nestle above their food; and though the magpie does not build so high as the rook, it builds higher than any of those birds whose nests it generally plunders. The magpie is one of the most villainous plunderers of nests, not hesitating to invade those of domestic poultry, especially when it has young. It seizes the eggs in the same way as the rest of the tribe, that is by thrusting the bill into them, and carrying them off. Boys sometimes play it a trick, by filling the shell of an egg with bird-lime, and leaving it as a bait for Mag. Mag thrusts the bill into it, and it goes up to the very bottom of the gape and further, so that Mag cannot see, but flies, bumping against the twigs, till she is fortunate enough to hit against one which breaks the shell, and then there is no small labour in clearing the bird..lime from the feathers at the base.

A thick-branched tree is also a firmly-rooted one; and so the tree is stable, not because the magpie chooses it, but because stability is a concomitant of that property in the upper part of the tree which suits the magpie. The nest is large, much larger than is necessary for the eggs, because it is walled and roofed, and the magpie must have room for its long tail while it sits, and facility of reaching all the young to give them their food; and hence the whole extent of it is much greater than that which is lined with grass or other soft matters. The nest is tolerably well concealed, and it is strongly built, and the eggs at such a distance from the door by which the bird enters, that they are safe from all spoilers except man.

Where these are but few, and no casualty occurs, the pair build for years in the same tree; but when they are nume.. rous, there must be marriage parties in the spring, as well of the young ones, as of those that have been left single by 


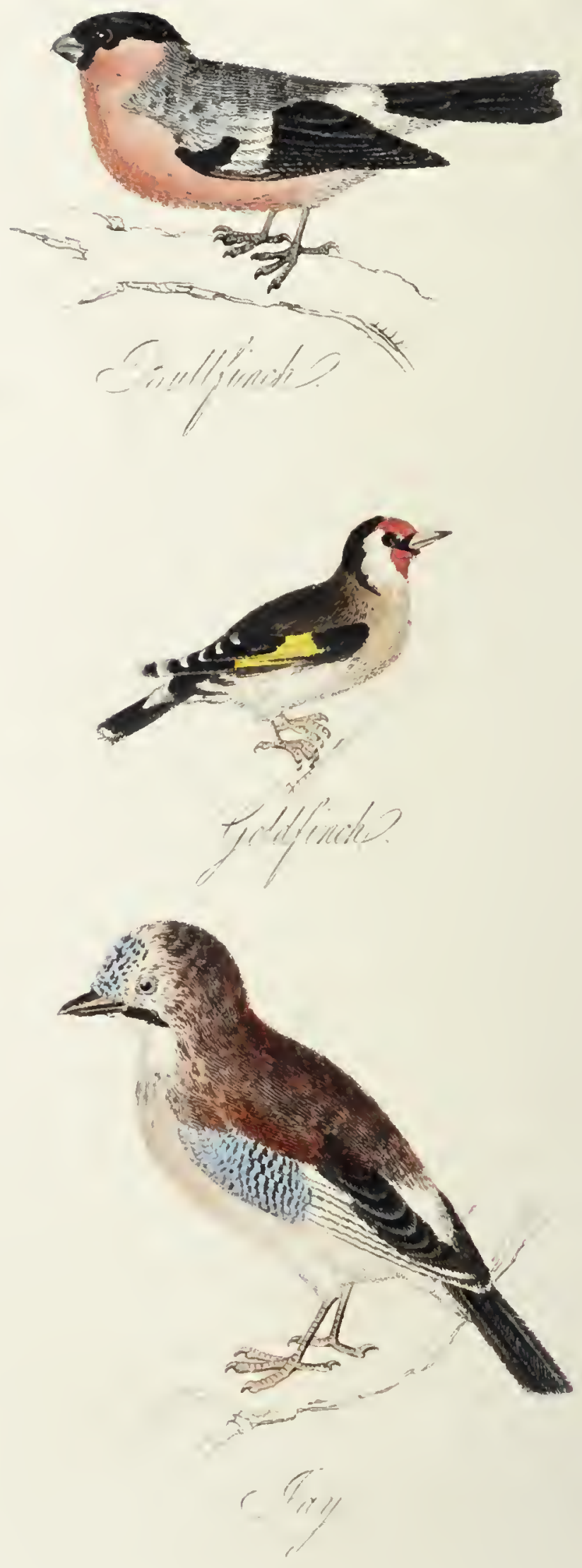
casualty. The meetings are for these purposes: the odd one is, of course, unpaired; and the rustic may very likely have brought the terror of it upon himself by killing its mate.

As to the houses, it will, I suspect, be found that magpies sit most frequently upon those that smell the most of " magpies' food." With beasts it is much the same. The magpie has many of the habits of the raven and the crow, and the whole race come most about sickly beasts, allured, no doubt, by the peculiar scent, though that scent may not be perceptible by man. It is certain that when, from bad food and improper treatment, murrain or any other general disease falls upon cattle, crows, and magpies, are as certainly attracted toward them, as vultures are to a field of the slain, and no doubt by a similar cause. In this matter, again, people might profit by observing and studying the magpie; and it is an interesting bird to study-neat in its form, beautiful in its colours, elegant in its attitudes, and smart and lively, but at the same time shrewd and cautious in its manners. Even the chatter of the magpie, though a note of alarm to the little birds when they have nests, is a social note: in a wild country, you may generally look for a cottage if you hear a magpie. The female magpie is rather smaller than the male, but the markings are similar. There are many pleasing stories of magpies; but we still want a good history of the bird, in combination with the circumstances about it, from the actual observation of one who is well skilled in the plain common sense phiiosophy of these circumstances in their connection. It is the same with all familiar birds: we know them, and we know them not.

THE JAY. (Garrulus glandarius.)

The jay, though not so handsome in its form, so familiar, or perhaps so interesting in its manners as the magpie, is one of the most beautiful of our resident birds. It is distributed over most parts of the country where there are groves and coppices, and especially where there are bits of thick and close 
plantation; but it does not occur in very great numbers in any one locality.

A figurc, one-sixth of the lincal dimensions, is given at the bottom of the plate opposite, from which a general notion of the form and colour of the bird may be obtained. The feathers on the head are, however, generally looser than it is easy to represent them in so small a figure: the white roots appear between the blue and black in the coverts; the bluish tinge is sometimes wanting in the forehead; and the upper part of the bird varies from brownish-purple to purplish-brown. When it is in a state of excitement, both the tail and the feathcrs on the crest are erected; and the pale grey iris of the eye, contrasting with the deep mustaches, gives it a ferocious, or at least an unsettled aspect.

The jay, though a showy bird, is much more frequently heard than seen, and it is not one of which it is easy to get a sight upon compulsion, as the more you follow it, it plunges the deeper into the thick of the coppice. The best place for observing it well, is where there are pease or cherries near its haunts, as it feeds greedily upon these, and may then be watched for a longer time than its wary habits will admit of under most circumstances.

Jays do not flock, neither have they meetings similar to those of the magpies and some of those crows that breed apart from each other; nor, though it has been observed in some instances, has it been fully established that the young remain with the old birds after they are fully fledged, and capable of finding their own food. That is rather against the general analogy of thcir naturcs, for they are much more predatory than the magpies, although considerably smaller They are equally, if not more destructive of the eggs of small birds; they catch mice, and they occasionally pounce upon birds, and kill and devour them.

One of their most remarkable qualities is the volubility of their sounds, and the readiness with which, when tamed, they can be made to articulate. Its alarm-note, which it utters upon the appearance of any thing that is dangerous, or even 
strange in its haunts, is peculiarly harsh; but it has a love note in the early part of the season, which is not only soft, but so low and apparently cautious, that it seems whispering to its mate, as if to hide their affections and their labours from the other tenants of the grove. Even there it is very imitative, and though it does not attempt the songs of the warblers, it is very adroit at bleating, screaming, neighing, and in short, imitating all the harsher sounds. What purpose these may answer, whether to scare or invite, or mislead other birds, is not known. The soft note is, in the warmer parts of the country, often heard again toward the latter parts of the season, because there the jays have often two broods in the year; and it seems to be in such places only that the family keep together during winter.

The first incubation is toward the end of May, the nest being begun about the first of that month. It is better built than that of the rook, but less carefully lined than the crow's, or generally than the magpie's, and it has no walls and roof like the latter. The platform is of sticks, and the immediate receptacle for the eggs, which is shallow, is of grass and roots. The eggs are about the same in number as those of the magpie; the incubation lasts about two weeks, and the young acquire their plumage in July.

The jay is, for its size, remarkable for the rapacity of its appetite, and the wideness of its swallow, and eats acorns, nuts, and chestnuts entire; but there are other substances of which it makes more of a bonne bouche. It is very partial to the flowers of the cruciferæ, which it pulls slowly and carefully, petal by petal. It is a restless and inquisitive bird, and sometimes gets itself torn, or jammed between branches, in its ramblings. When nests, and fruits on and under the trees fail it, it hunts among the fallen leaves, and often plunders the hoards of small quadrupeds; but as it does not come far from the woods, even in the coldest weather, it must be subject to many casualties, which accounts for the limited numbers compared with the fecundity of the birds. 
Words in which the letter $r$ occurs, are soonest learned, not only by the jay, but by most birds that can be taught to articulate. That is easily accounted for by the unyielding nature of the mandible, which forces the air to come out between the upper part of the tongue and the palate, on which that trills. A man cannot easily pronounce the $r$ in any but Northumberland fashion, if he grins the while: and those who use the tongue simpering and softly, merely touch, but do not pronounce it.

\section{THE CHOvgh. (Pyrrhocorax graculus.)}

The chough is as much a bird of the breeze as the jay is of the shade and shelter of the woods; and their different plumages are well adapted to the differences of their modes of life. The loose and comparatively downy plumage of the jay enables it to glide between trees, and softens its collision with branches, while the firm plumage of the chough enables it to bear the storm when beating against the rocks, in which it takes up its abode.

The chough is about seventeen inches long, thirty-four in the stretch of the wings, and thirteen ounces in weight: the female is smaller. The colour is all over black, but with finelyglossed reflections of blue and violet; the eye lively, with a light brown iris; and the bill and feet red-the former long, bent a little from the base, and very tapering; the latter with strong black claws, sharp and considerably curved. It is a handsome and lively bird, very active on the wing, and utters a shrill and wailing cry. It can be tamed, but it is restless and mischievous.

On the continent choughs migrate, but in Britain they remain in the same haunts all the year round. Their haunts are mostly confined to the southern and western coasts, on rocky shores, and where the surface of the adjoining land is irregular. They also nestle in ruined buildings, but not near the habitations of man, unless protected by a great elevation 
of cliff their nests are in the most inaccessible places, and the eggs are four or five in number. They eat grain, and sometimes visit the fields for that purpose; but their principal food is found among the rocks, and in the wilds, and it consists of meats or of seeds and berries, as may happen. It is probable that they also pick some substance from the rocks, because in bad weather they stay more closely there than appears to be consistent with the wariness of their feeding at other times. They come abroad only in fine weather, and fly high on their journey, but seek their food on foot, the form of their bills being well fitted for picking insects out of very small crevices. It is not true, that their flying far and feeding late, in itself portends the breaking of the weather; but it proves that they have scoured all the nearer pastures, till they have ceased to be very productive, which is saying, in other words, that there has been a long track of dry weather, the end of which must be change, more violent, and generally nearer in proportion as the drought has lasted long; and as pastures do not recover their insects any more than their vegetation while the drought continues, the choughs must extend their journeys more and more, till the rain comes; and thus they are necessarily further from home, and later on the wing, just before the weather breaks, but without any particular foreknowledge of the weather.

A change which is yet to happen in the atmosphere, can no more affect the present habits of a bird, than a gun which is yet to be loaded and fired, can at present shoot a partridge; but the present state of the weather, and the past state also, as being the antecedent of the present, do affect the habits of birds, and to these observation can always apply, and must, when rightly applied, be useful.

Those birds which, like choughs or rooks, live in societies, and go in bands to their pastures, must, in the nature of things, consume the produce where they feed; and whether their food be animal or vegetable, they must be driven to greater distances when drought (which, generally speaking, lessens the production of both) is of long continuance. As 
their journeys become longer, and their food less easy to be found, (for the abundance of food in the vicinity, tlough not the only element, always is an element in their choice of situation,) they must be later in getting home, until the change of weather comes. But that change, especially after long drought, often affects the earth, and the smaller living creatures, before rain begins to fall, or even before the sky is clouded; and thus those incipient changes which are not palpable to our observation, not only may, but often do, bring out the earth insects and earth worms; so that the birds which feed on them fare abundantly, and return earlier than before the change began. It is not meant to be said that that is always the case, but it is so frequent, that any one who chooses may observe it. And it is a wise and beautiful provision of nature. All Nature's provisions are wise and beautiful: the tempest which is to break in the night may confine the birds for days to their shelters without food; they want that, in order to recover from the fatigue of finding their food in the extreme of the drought; and the very resistance which the dry earth offers, finds them a hearty meal at the close of their severe labours, so that they can comfortably rest in their shelters and on their perches till the storm is over, and they can again come forth to enjoy plenty in their own neighbourhoods. Thus, when studied aright, the time and manner of the flight of birds, instead of being an idle augury serviceable only to the purposes of superstition, is fraught with practical information of the most useful kind ; and is more to be relied on as indicating natural changes, than the feelings or the conjectures of man, in an artificial state.

\section{the starling. (Sturnus vulgaris.)}

The starling is the smallest of all our resident birds allied to the crow tribe, and it is one of the least rapacious, confining itself to insects and seeds, (chiefly the former,) like the chough, and never killing other birds, or probably robbing any nest. It has been accused of breaking the eggs of pigeons. 
when it takes shelter in the pigeon-house from very severe weather; but as that would be a violation of the laws of hospitality, as of the customs of the starling, the friends of the bird very properly repel it as a calumny.

The starling is between eight and nine inches long, about sixtecn broad, and it weighs from three to four ounces. The ground colour is black, with rich reflections, varying from golden green to deep purple; the whole beautifully dropped with triangular spots like little "stars," white on the under part, and passing into cream-colour on the back. The quills and tail-feathers are greyish black, with reddish brown margins. The young of the first year are uniformly coloured of nearly the same brown as the margins of the quills in the mature bird, only lighter, and inclining a little to yellow on the breast; but after the first moult, they are more speckled than the old birds. The bill is lemon yellow, bluish at the base, and the legs are sometimes brown, and sometimes inclining to yellow; the bill of the male becomes yellow the first spring, that of the female, after two years. The spots, being on the extremities of the feathers, are sometimes to a considerable extent obliterated: hence old birds, as wcll as young ones, are sometimes mistaken for different species.

Like its congeners, the starling is not difficult to tame, or to teach to articulate; and Sterne chose the captive starling in a cage, with its "I can't get out," in order to depict pathetically the bitterness of slavery. The thought was not a bad one, for at certain seasons of the year, the starlings are among the most social of birds, and they also make great use of their liberty in ranging from place to place. They are found abundantly in all the lower parts of Britain, and in the most northerly of the islands; they mingle freely with most flocking birds, and do not hesitate to alight in numbers among domestic animals in the meadows and other pastures. They are partial to humid places, and do not much frequent the elevated and arid moors; and in the cold season they migrate in vast numbers to the low and warm countries, and to the shores of the sea. They are, at all seasons, very lively birds, 
whistling, chattering, and gliding about on the wing, which they generally do in curves, and with a smooth motion. On the ground they walk neatly, and with considerable velocity, but do not hop. Walking and hopping seem to depend a good deal on the kind of food which birds seek on the ground. If the food is large, and so visible at a greater distance, the birds hop, as in the case of ravens and magpies, and of thrushes, which feed on snails and slugs; but if the food is insects and their larvæ, and worms, as in the case of the rook and the starling, then the walk is smooth. When the weather is fine, starlings often hawk about on the wing in pursuit of insects, for hours together; but generally in the evenings.

Many birds fight at the pairing time, but the starlings are all play and good-humour; and after they have settled the preliminaries, they resort to the hollows of trees, holes in rocks, ruins, and walls, and there construct their nests, which are artlessly formed of dried grass. The eggs are never more than five; but it is possible, nay, probable, from the vast numbers of the birds, that they may, in favourable circumstances, have two broods in the year. All our resident birds that renew their song in the autumn have probably broods at that time, although in districts where the winter comes soon and suddenly, many of the later broods must perish. If the starlings can fly, they are exempt from many of the casualties to which birds that winter doggedly in their summer haunts are subject; they whisk away to places where there is plenty of food, while the lingering tribes perish of want.

When they are in the low districts, and in large collections, a flock of starlings preparing to lodge themselves in the tufts for the night, put one something in mind of a dog, preparing to lie down in a place to which he is not accustomed. They wheel round and round, first in the circumference of a circle, but that circle narrows, and the whole mass is revolving round a centre within itself, before it drops and disappears for the night.

Starlings not only associate with other birds, but imitate their cries-chattering with jack-daws, whistling with plovers, 
and screaming with sea-fowl. Their double voice causes them to be more frequently deprived of their liberty, their articulation being plain, and their whistle easily modulated into music.

OCCASIONAL VISITANTS OF ANALOGOUS GENERA.

There are at least five of these, of which specimens have been seen in some part or other of Britain, and they may be more frequent than has been ascertained; but still they are so little open to common observation, that we need do little more than mention the bare names.

THE ROLLER. (Coracias garrulus.)

About the size of a jay, beautifully marked with black, blue, green, and chestnut. Nestles in woods. Habits resemble those of the magpie and rook jointly. Common in the eastern and southeru part of the continent; very rare in Britain, and only seen in individual specimens. (See the cut at page 7.)

\section{THE WAX-WING. (Bombycivora Garrula.)}

A very beautiful bird, rather shorter than the starling, but of very graceful form and delicate plumage. Beak short and black, as are the eyes, a portion round them, the chin, (exeept a white line under the gape,) and the principal parts of the wing and tail feathers. Upper part and crest (which is long, silky, and handsome) of an indescribable colour, which is grey, brown, and purple, and yet neither of them; under part passing into a soft grey on the upper part, with reddish orange below. Coverts of the primaries tipped with white; tail feathers and primaries with yellow. Secondaries tipped with white, ending (in the mature male chiefly) in bright vermillion spines. Comes in small flocks toward the close of winter, but only occasionally; and while here, feeds on wild beries. Its nestling places and habits are little known. 
THE GOLDEN ORIOLE. (Oriolus galbula.)

Rather larger than the wax-wing, and less elegant in form, but a beautiful bird. Male golden yellow, with the wings and tail black; the margins white in the wings, and the tips, with the exception of the middle feathers, yellow in the tail. Female olive green above, grey below, with traces of yellow in both. A sumner migrant on the continent, but merely a rare straggler in Britain. The Orioles, with the analogous genus of American bird, Icterus, (of which the colour also is yellow in the males, and greenish yellow in the females and young birds,) exert more labour and show more neatness in the structure of their nests, than perhaps any other of the feathered tribes.

THE ROSE-COLOURED PASTOR, OR ROSE OUZEL. (Pastor roseus.)

This is another very rare straggler, about the size of the starling, but more compact. The head, (which has a large crest,) neck, wings, and tail of the male are black, and the rest of a pale rose colour, inclining to salmon colour, or nearly peach blossom, with the least possible "feeling" of orange in it. The black of the head, crest, and neck is intense and velvety, with exquisite, though rather obscure reflections of green and violet. The female has a shorter crest, and the body more inclining to grey or brown. The young are brown all over, mixed with grey, especially on the throat; they want the crest, and are somewhat like young starlings, but more round and compact. Their legs are dull brown, whereas those of the old birds are dull red. In Britain they are very rare stragglers, scen chiefly toward autumn; they are, indeed, only summer migrants in the south of Europe. In the countries which they do visit in summer, they and the orioles are of vast service in destroying the larvæ of insects. 
THE NUT-CRACKER. (Nucifraga caryocatates.)

Is also an exceedingly rare straggler in Britain, though abundant in many parts of the continent, even the cold ones. It is about the size of a magpie, of a rusty brown colour, palest on the sides of the head and neck; and is, especially on the scapulars, spotted with white, the spots larger and longer than those on the starling. It lives on wild berries, and kernels, and pips, the latter of which it digs out of their shells and cores with its powerful cultrated bill. It also lives upon insects, and digs them out of the holes of trees, upon which it can support itself in a manner similar to that of the woodpeckers. It has, indeed, something of the air, as well as the manners, of those birds; but it wants their peculiarly distinguishing characters.

These four species are all so handsome, so peculiar in their habits, and so different from our common British birds, that one regrets that they cannot be-at least have not been-enlisted among the dwellers in our woodlands. Our climate would preclude some of them, but not the nut-cracker or the roller, which are as common in the forests of Germany, as the jay is in our groves and coppices.

BIRDS CLASSED FIROM THE STRUCTURE OF THEIR TOES.

The old order, Passeres, "little birds," or birds of "the sparrow kind," contained so very many genera of different characters, that it was vague, and conveyed so little information, that it was nearly useless. The term Scansores, or " climbers," applied to certain descriptions of birds, of which there are but few British genera, and not very many species, was not much more definite, because those are not the only birds that climb-they only climb in a particular way, or by means of a peculiar structure of feet; and therefore the use of the word "climbing," as applied to them, was making a term, which is quite general and clear in itself, stand for one of its 
own peculiar meanings, in the same way as if the word "mo. tion" were applied to express some particular kind of motion that required a particular epithet, such as "flying" or "swimming."

The more judicious ornithologists have therefore founded the name on the organ itself, and not on the function of that organ; and as the organ is a substance, and the function only an act, the method is far more clear and satisfactory.

Of the birds already noticed, there are many that can perch on a stick, branch, or twig, or even on a blunt point; and they can walk, by stepping from stick to stick, or from point to point, without assistance from their wings. They can also walk along a round pole, if it be a thick one; but they cannot move lengthways on a slender one, in any other way than by shuffling sidelong, or hold their balance on it, unless they perch across. As little can they walk up or down a stick when nearly perpendicular, and especially not on the under side of one leaning over.

But there is food, and abundant food, for birds, that can be had only by perching and walking in the manner to which the birds noticed are not fitted. There are insects in the crevices of the boles and branches of trees adequate to the supply of many birds; and insects, too, which would do serious mischief to the trees, if there were not birds to thin their numbers. These birds require a peculiar structure of feet; and though they have other peculiarities for enabling them to filch the insects out of their lurking places, yet the feet, which enable them to get to those places, and remain at them till they catch the insects, are their proper distinguishing characters.

We have to do only with the mere external appearances of these feet; but they are wonderful pieces of mechanism, and show with how apparently little difference from that which answers one purpose, a very different purpose may be effected.

There are two distinct forms of these feet, the one called zygodactylic, or "yoke-toed," and the other anisodactylic, or 
" unequal-toed;" and on these are founded two orders of birds which agree in several of their habits, but differ in so many others, as to warrant the distinction. The following cut will illustrate both :-

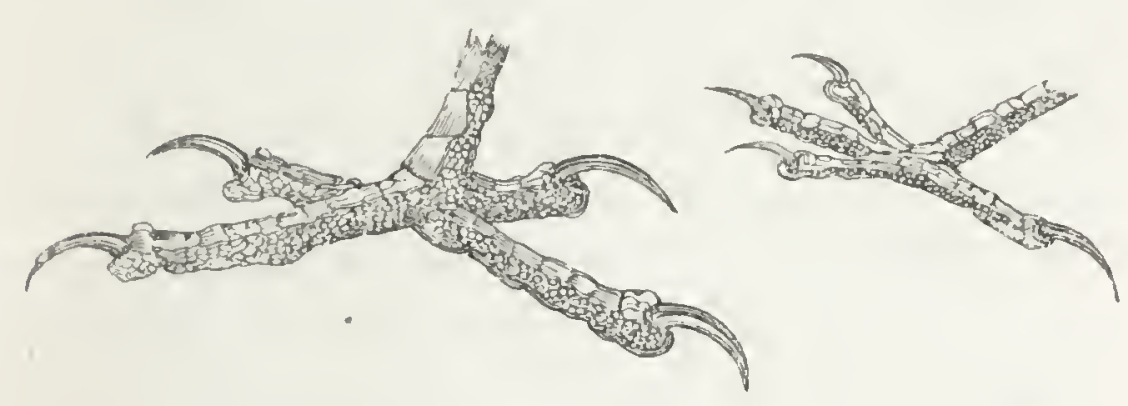

Wood-pecker.

Nuthatch.

The first or wood-pecker's foot, is zygodactylic, or " yoked," two of the toes being turned back, and two forward, and the two front ones are joined together at their bases. As that foot has two bearings in the front and two behind, it enables the bird to perch or to walk lengthwise on a branch; and, with the feet alternately holding on, and the tail bearing as a prop, to walk up the trunk of a tree, or even to move sidewise round it, though slowly. The legs are placed behind the centre of gravity, so that the weight of the bird both assists in compressing the claws into the fissures of the bark, and presses the tail against the tree under them; and while the centre of gravity remains higher than the feet, the bird is stable, without that exertion of the body which would prevent the use of the bcak and of the wings, if these should be necessary. But if the head were turned downwards, or the body even much out of the upward position, the principle of stability would be changed into a means of falling. Hence, though these birds can run upwards, they come down only backwards, and that rather slowly and awkwardly; and they can get round only in an ascending spiral : hence they beat and hunt the trees from the roots upwards. There are some very curious modifications of these feet, but as they belong not to British birds, they do not come within our province. 
The second foot (that of the nuthatch) is anisodactylic, or " unequally yoked," and is by far the more curious foot of the two, though at a cursory glance it seems not to differ much from a common foot with three toes before and one behind. It has, in fact, the power of two feet, and of two feet combined; so that the bird keeps its hold better with one foot, than other birds can do with two, and with the two, better than other birds could do if they had even four. The middle and exterior toes are united together at their bases, and admit of a position half reversed, or midway between the other two; the hinder toe is long and strong, and all the toes have strong claws. Thus the foot can adapt itself to any kind of surface, and the bird possessing it can run upon the trunk or branch of a tree in any direction-upward, downward, across, or obliquely.

The habits of the birds correspond. The British yoke-toed ones generally remain at places where there are insects, punch holes in the trees with their bills, and draw out the insects with their tongues, which can be far protruded, and are armed for the purpose. The British birds of the other order run over the bark with wonderful celerity, and pick out the smaller insects with their bills. The habits of both are exceedingly interesting. 



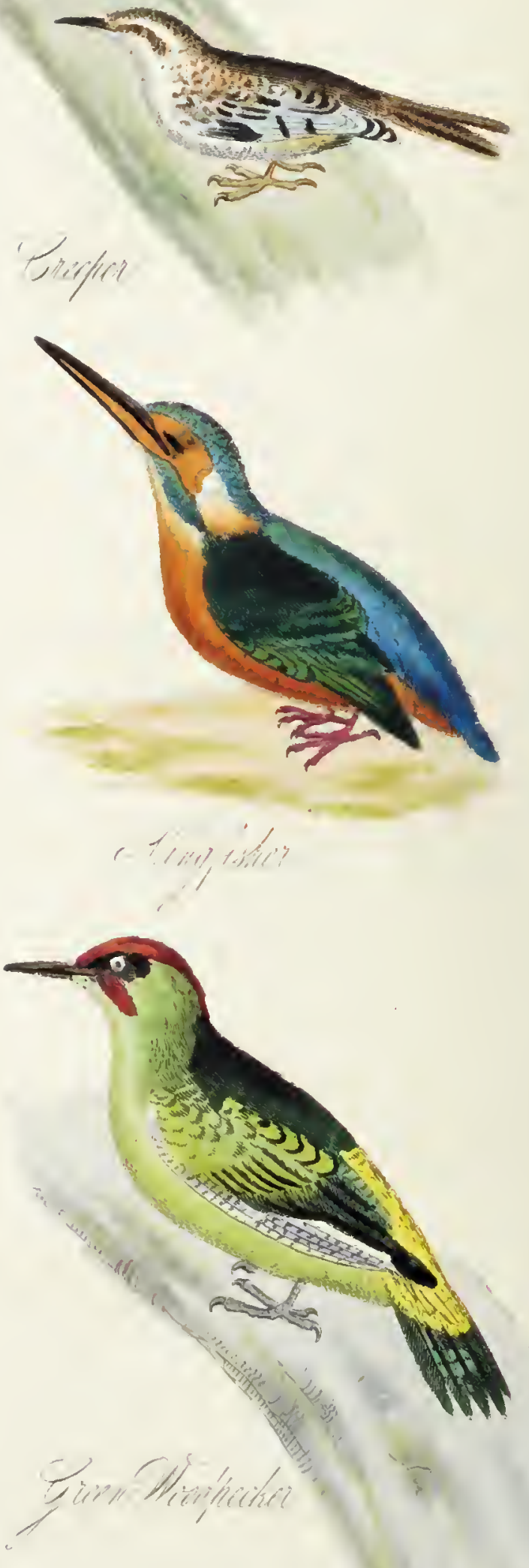




\section{ORDER VI.}

\section{ZYGODACTYLES.}

YOKE-TOED.

The foreign, especially the tropical, birds of that order are exceedingly numerous, and comprise the most curious and showy of the feathered tribes-the toucans, the parrots, the parroquets, the maccaws, and many others, which swarm in the forests, and hang on the trees like gorgeous flowers in colour. The British ones are but few-the wood-peckers, the wryneck, and the cuckoo: the last has a peculiarity in the structure of its feet, as well as in its mode of life. Three species of wood-peckers are resident in Britain, and some others come occasionally as stragglers. There is but one British wry-neck and one cuckoo, which are both regular summer visitants, but not equally distributed over the country. The wood-peckers are, the green, the greater spotted, and the lesser spotted,

the green wood-pecker. (Picus viridis.)

The lowest figure on the platc opposite, which is one-sixth of the lineal dimensions, will give an idea of the form and colours of the bird, and also of its attitude when in a state of repose. It will be seen that the upper tail coverts are very thick, and that the tail feathers are pointed at the ends; they are also very firm and stiff both in the shafts and the webs; and one of them, or at least two, can support the weight of the bird without bending.

The wood-pecker is especially a bird of the ancient forests. 
You do not find it in the hedge or the coppice, where so many of the little birds, especially the summer migrants, build their nests, and spend their mid-days, when the reflections of the sun come bright on all sides of the foliage, in picking the soft caterpillars from the leaves, or capturing the insects that resort thither for the purpose of depositing fresh myriads; and when they have thus secured the shelter and beauty of their habitation, farewell the evening, and again hail the morning, with their joyous songs: the aged tree is all to the wood-pecker, and the wood-pecker is much to the aged tree.

Whenever any thing that once had life dies exposed to an atmosphere which is not in the extreme of heat to torrefy or in the extreme of cold to burn, creatures come, true to the grand purpose, to win back the materials for new uses. The mosses and lichens insinuate their roots into the decaying bark, and the larve of countless beetles and flies mine into the lagging cumberer, where it lingers in life, and loses the acerbity of high health, or they drill through and through the dead and decaying wood. Of these, as well as of all things that nature produces, there is a surphs to meet extraordinary contingencies when they occur; and if there were not something to keep down that surplus on ordinary occasions, the old trees would speedily be destroyed, the races that prey on them would perish, and the place would be one step nearer to desolation.

But nature has appointed the wood-peckers conservators of the wood of old trees, furnished them admirably for their office, and so formed their habits, that an old tree is an Eden to them, fraught with safety, and redolent of plenty and fatness. So exquisitely are they fitted for their office, that the several wood-peckers vary in tint with the general colours of the trees which they select. If it is an alternation of green moss, yellow lichen, and ruby-tinted cups, with here and there a spot of black, then the green wood-pecker comes in charge; but if it is the black and white lichens of the alpine forest or the harsh-juiced tree, then we may look for the spotted race upon the bark. 
The tree is all to the wood-pecker; it is a castle, a pasture, a larder, a nursery, an alarm-drum, and a lute. When the renovation of the spring begins to be felt through all nature, and the fluids both of animals and of vegretables receive new action and new energy from that light and heat which the sun of the young year dispenses, the wood-pecker in the large hole of the tree, and the egg or the larvæ in the little one, partake of the renovation, and the wood-pecker creeps out, and tries till he comes to a place which is hollow, and upon that he beats the drum in loud and rolling taps, but yet without in the least perforating the tree. The instrument and the sound are rude, but the bird contrives to make the latter merry, and in some degree musical. The sound swells and sinks, and hurries and lingers alternately, so that at a distance it resembles the sound of rustic glee heard through the woodland: and if the wood-pecker's mate catches the sound, she answers to it, and the bargain is concluded, and the labour of the season begun; if not, the male glides on to another tree, uttering his short cry, $p l u-i, p l u-i$, upon which he again resumes his serenade; and if there happens to be an odd bird in the wood, this call of love may occasionally be heard, till the ardour of the summer sun has evaporated that energy which his coming in the spring inspired.

The sound is a rude one, and one which we would suppose but little suited for awakening the tender passion. But many of the love-calls of birds are harsh; and yet the croak of the raven, and the caw of the rook, answer the purpose of nature as well as the murmur of the dove, or the song of the nightingale. The subject is one of very nice investigation, and dangerous for theorizing; but really it seems that there are in the love sounds of birds (and of all animals) some implications of promised assistance, or implied capacity for the rearing and defending of the young. The cruwing of the male gallinx, which is their love-note, is also the song of victory, by which they make proclamation from the top of the dunghill, or a hillock in the field, that they have vanquished a rival, and so secured the pastures for their own females and 
their broods. Many other instances will occur to the reader, in which the love-note is also the expression of exultation at abundance; and the drumming of the wood-pecker on the hollow tree is an expression of the very same operation, by which a nest (if need be) is to be formed, and food is to be found. Indeed we may rest assured, that though the songs of the birds are delightful to us, that is not their use in nature, but that they are understood by the parties for and to whom they are poured forth, and that they are heard by these with understanding, or an inspiration of confidence; and further, that they have some very direct and palpable relation to the economy of the bird, which by careful observation we could find out.

If the tree affords no natural hole fit for the purpose of nidification, the wood-peckers set about excavating one with their bills. They do that by turns, and they do it with wonderful expedition, their bills, while they are at work, going so fast that the strokes cannot be counted either by the eye or the ear. They know the tree by the sound; and though they will cut through a few layers of perfect wood, they never mine into a tree, unless it has begun to decay in the interior. Such a choice would be inconsistent for two reasons; first, the great labour of making the nest, and secondly, the comparatively smaller quantity of food they would find on a healthy tree. Nature guides them to those trees where their labour is light, and they have plenty to eat.

They do not work with their bills as if these were pincers to tear, or chisels to detach pieces; they proceed in the same manner as a mason does when he perforates a block of granite with a pointed pick; they thump away with so much rapidity and force, that the timber is ground to powder; and they work in a circle no larger than will admit themselves. They generally burrow so deep that no spoiler can reach their eggs in their absence; and farther security is afforded by the opening being in some hidden part of the tree. The sound, which bears some resemblance to that made by the grinding of a thick piece of steel on a rather smooth stone, may be 
heard at a considerable distance; but though one proceed on the sound, it is not easy to see the birds. This arises partly from the uncertainty of the direction of sounds in forests, (which, by the way, prevents animals from being betrayed by their own notes, either into danger or out of their prey,) and partly from the ease with which the wood-pecker can glide spirally round and gradually ascend, always keeping on the side of the tree opposite to the observer.

There are seldom any materials carried in for the nest. If it is wholly made, it is made of the form and size, wanted and rendered soft by a part of the powder of the tree; and if there is a chink downward, that is filled up; but if there is one upward, which admits the rain, the nest is excavated in a lateral direction till the drip is escaped, or if that be impossible, the place is abandoned for another. The eggs are four or five, and the young come out, and ascend the trunk and branches, and feed there a considerable time before they can fly.

The wood-pecker digs its way to the insects which are in the tree with its beak, but it uses the tongue in extracting them. This organ is extensile, barbed with reflected bristles, and also supplied with a glutinous fluid at the tip, so that, whenever it can reach the prey, it draws out the larger as with a hook, and catches the smaller as with bird-lime. The surface insects it captures with the tongue only: and the number of those that it does catch, and the rapidity with which they are taken, are both truly wonderful. The number of ants that inhabit forests, especially pine forests in dry places, is very great; and these supply abundant food to the wood-peckers, not only when the ants are hunting for their prey on the trees, but when they are on the ground, especially on those beaten paths which they form in the neighbourhood of large ant-hills.

The wood-pecker does not subsist wholly upon insects. When the wood is ripening in the fall of the year, there is a pause in nature generally; and during that pause, most of the tree-eating insects are in the egg state or gone. At that

VOL. I. 
time the wood-peckers follow the same law as all our locallyresident birds that feed chiefly upon insects during the summer, and betakes itself to vegetables-to nuts, and other farinaceous and oily endowed kernels, which the structure of its bill enables it to get easily out of the toughest husks or the hardest shells.

In the miscellaneous plantations of the low country, the wood-pecker is fond of particular trees-the poplars, for instance, are favourites, because they are easily bored on account of their softness, and especially because they are overrun with insects. It is also fond of oaks, because of the natural holes that are in them, and the number of lepidopterous larva that are found about them. It is also fond of trees that are apt to contain numerous aphides, not for those creatures themselves, but for the ants which swarm thickly about them. Wood-peckers afford striking proofs of the effect which the quality of the soil has upon birds. They are much more plentiful on the clay to the north of London, where the trees grow rapidly and have soft wood, than in Surrey, where the soil is lighter and the wood more close grained and firmer.

The green wood-pecker has been called the " rain-bird," as have several other birds that are very active or that utter their cries before rain; and as, in the summer, all birds either eat insects or other animals that do, the term might be extended to all the tribes. Tame poultry and geese so far retain their natural instincts, as to feel that state of the weather which brings out their natural food, and also to express their feelings by louder, and apparently less causeless cries than they utter at other times. Now, if birds which feed on earth insects, feel that impulse, much more must birds that feed on tree insects. The trees are wholly in that air which rests merely on the surface of the earth; and when the drought begins to soften, and the larvæ can come nearer to the cambium of the wood, or otherwise feed without too great a pinching of their tender bodies by the drying wind, we might, as a matter of course, expect redoubled activity on the part of all the grove and forest birds. 
When in May, the wind blows long, cold, hollow, and dry, from the east, and the evaporation produces cold till the remaining moisture is congealed into hoar frost during the night and dissipated during the day, leaving the infant leaves black, and the more advanced ones sapless and shrivelledwhen the sap stagnates in the vessels of the trees, and curdles and becomes sugary, as if a premature autumn had set in, to produce the fall (no, not the fall, but the adhesion) of the blossoms instead of the fruit, and the congregation caterpillars, with which the birds do not much meddle, bring out their millions, spin their habitations of silk, and strip every leaf from orchard, coppice, and hedge, the birds become mute in the mournful groves. Many a weary wing is fluttered in vain; many a mother sits hungry over those eggs. the young of which, if they shall be produced at all, must perish of want; and many a nest is abandoned in despair, and the builders drop down among the arid clods, to seek the preservation of their own lives in that description of food to which they are fain to betake themselves in the rigours of winter. "The famine is" indeed "sore in the land;" and Sahara hangs suspended over the erewhile green pasture and gay grove.

But on some day, before there is a cloud in which the bow of Hope can limn its hues, the white flag of truce and mercy is hung out in the higher heaven, streaming in easy flexures from the south-west, in testimony of victory over the desolating east. And as the day declines, the little clouds flit joyously on varied winds, as if they were fetching the pitchers of heaven from the four corner's of the sky, to refresh the weary eartl, and renew the waning creatures. The sealed spring trickles out; the echo softens and mellows its tone; and the whole earth is tuned as an instrument by a skilful hand. Then, as the evening closes, the insects and the worms come out; the birds feed; new life returns; the tuned instrument is soon in use ; the groves are in song the livelong night; and that song ceases not even when the thunder peals and the rain pours, until the delivered tribes have expressed 
their gratitude.-Such is another instance of the augury of birds, and a very general one.

The female of the green wood-pecker has the head much paler, the mustaches black, and the general colour of the body inclining to brown and grey where that of the male is red and yellow. The young are also greyish, spotted on the breast, and have only a few red feathers on the head.

The great spotted wood-PECker (Picus major.)

The word "major" is not very happily applied to this species; for although it is the largest of the spotted ones, it is so far from being the largest of British wood-peckers, that it is not half the size of the green one. The spotted woodpecker is about nine inches long, twelve in the extent of the wings, and three ounces in weight. The green one is four inches longer, nine more in the wings, and weighs seven ounces. The spotted is therefore the least adapted for long Hights, and accordingly, it is not so generally distributed, being found only in the woods, and chiefly in the wild and lonely ones of the north, where the decaying pine is its favourite tree. But, with allowance for d:fference of situation, the habits of all the wood-peckers are the same, so that one description answers for the whole. The forehead, cheeks, ear coverts, scapulars, a patch on each, the neck, part of the coverts of the wings, the throat, breast, and belly, of the great spotted wood-pecker, are white; and there are white spots on the quills and tail feathers, except the two middle ones. The hind head is deep, the vent greyish red, and all the rest black, with the exception of the tarsi and toes which are blackish grey. The female wants the red on the head. The young have the crown of the head red and the hind head black; and as these colours are reversed in the mature bird, the old and young have sometimes been called different species.

THE Lesser spotted Wood-PECKer. (Picus minor.

This is a very little bird, only six inches long and twelve 
broad, and less than one ounce in weight. It inhabits the opposite parts of the country to the last species, being found only in the west and south of England. Its prevailing colour on the upper part is black, with dull red on the hind head and partially on the crown, white markings on the head, similar to those of the former species, white spots on the wings and back, and the outside feathers at the tail white, with black spots. Its form and habits at once show that it is a wood-pecker, and its diminutive size distinguishes it from the larger spotted one. Its babits are the same as those of the other wood-peckers.

Another species, the large black wood-pecker, with a scarlet head, about one half larger than the green, is met with in Britain, but it is as rare as the spotted ones.

\section{THE WRYNECK, (Yunx torquilla.)}

The wryneck is a very beautiful summer migrant, which comes regularly a little before the cuckoo, and distributes itself, though not abundantly, through all the south-east of England; but it rarely if ever passes the central heights, unless in single specimens as a straggler.

In its general shape, the wryneck has some resemblance to the wood-pecker; and it also a little resembles the smallest British one in the markings, though not in the tints of its colours. It is also just a little larger than that bird, though not quite so long in the wings. The ground colour above is yellowish brown, beautifully variegated with spots of brown and arrow-head hues of black, and a very distinct mural hue of brown from the nape of the neck down the back. The under parts are greyish white, with arrow-head dark spots, that form bars. The quills are brown, bound with black; and the tail feathers, which are long, but have not the stiffness of those of the wood-pecker, are mottled brown, also bound with black. The bill is more pointed, and not so strong as that of the wood-pecker.

The wryneck builds in the holes of trees, after the same 
manner as the wood-peckers; but it does not, like them, excavate a hole, though it enlarges, or otherwise adapts to its purpose, a ready found one. It seeks for one fit for its purposes, and then, almost without any preparation, deposits its eggs, which are nine or ten in number; so that, if it has not so much labour to undergo in building as the wood-pecker, it has a larger family to bring up. Neither its bill nor its tail, indeed, fit it for performing the same labour as the woodpeckers; the former not having strength for picking, and the latter not being stiff enough for propping up the bird, during a long labour. But the more flexible tail suits better as an auxiliary in moving about on the bark.

But the adaptation of the structure of the wryneck to its habits, is not inferior to that of the wood-pecker, or indeed of any other bird. Those warm, lowland, and, compared with the north and west of the country, dry regions, to which it comes, abound with the minuter insects, especially with aphides, and the smaller tribes of ants. These last are continually careering about on the boles and branches of the trees; and it is to them especially that the attention of the wryneck is directed, so much so as to have merited and obtained the provincial name of the "emmet hunter." These ants the wryneck catches with the tongue, an organ which it can pro. trude at least an inch, and retract again with the rapidity of lightning, so that when the ants are coursing about, they are picked up, one by one, without the capture producing any alarm, or even being noticed by the rest. They are captured, not only on the stems of trees, but on the ground, and they are even picked from their dens and hills-especially at those times when they are busy in bringing out the larvæ to the sun and air. Disturbing their dwelling readily brings out the ants at any time if the weather is dry, and the wryneck uses both its bill and the horny point of its tongue for that purpose; and when the little warriors mount the breach to reconnoitre and try if they can repel the enemy, the wryneck picks them up, soldier after soldier, till none are left, When it is engaged over an abundant supply of its favourite food, 
whether on the trunk of a tree or on the ground, the body is motionless, but the head is continually moving from side to side, and the dark mesial line on the back, twining like a serpent, the joints of the neck have so much motion that the posture of the head can be recovered. At those times the motions of the tongue are so quick, that they can hardly be observed. Indeed, the bird is altogether so shy and retiring in its habits, that it is difficult to be got sight of, unless one come softly upon it, at those times when it is basking on or near the ant-hills, while the ants are taking their siesta, which most of them do, though at different times, according to the variety.

The ants which the wryneck finds in those localities which it frequents, are exceedingly numerous when the weather is favourable; but they are rather uncertain, from their extreme sensibility, and the great degree in which the maturing of their eggs depends on the state of the atmosphere. Hence, though the wryneck continues with us only during those months that the ants are above the surface, and in a state of activity, it is often put to great straits; and that may account for the limited number of the birds as compared with the eggs in each nest. They remain too short a time in this country, however, for producing second broods; and they are probably as liable to suffer from contingencies in their winter retreats beyond seas, as they are with us during the summer. It is not ascertained that the wryneck ever has recourse to vegetable food, or indeed to any sort of insects save ants; and when the variable nature of our climate is considered, we can easily see that the fate of a bird which is, in a great measure, if not entirely, dependent on our summer production, and that production very much under the influence of the weather, must be often reduced to extremities.

Wrynecks are very abundant in many parts of Surrey. They are sociable in the early part of the season, and assemble at the call note, "peup peup," by imitating which, with a sort of mouth whistle, the London bird-catchers obtain numbers of them, they climb in the same style as wood- 
peckers, but not so often, though they often leap sportively after each other up the boles of the trees. When a wounded one is taken in the hand, it raises the feathers of the crown, flattens those of the neck, writhes that part slowly like a snake, and occasionally hisses. These birds, if captured, show signs of pugnacity or perhaps of fear; but their motions are slow and twining. They can be partially tamed, but do not live long in confinement. They usually appear in the southern countries in the first week of April and retire in October. They are very noisy in the early part of the season, but become silent toward the latter.

THE CUCKоO. (Cuculus canorus.)

Why the people of Scotland should have chosen their name for the cuckoo (gowk) as a synonyme for a fool, it is not easy to say, for there is more cunning about the cuckoo than about most birds, though its history, notwithstanding all that has been seen and imagined, and printed and spoken, about it, is still as obscure as it is singular.

Every body has heard the note of the cuckoo, or the imitation of it by a Dutch clock, though domesticated in the most birdless part of the city; and in the summer, it is difficult to be in any part of the country without hearing the cuckoo, and even seeing the bird as it flies hirriedly, and to all appearance heavily, from one tree to another, with generally a few of the smaller birds in its train. The cuckoo is about the size of the kestrel, only more bulky in the feathers, and about a fourth less in weight. The feathers of the belly and thighs are very loose and pendant, and the tail is large. The general colour is bluish grey, and the wings and tail black, with some white bar's on the exterior feathers. The lower part is greyish white, with transverse black bars, and the vent cream colour, with lighter bars of dusky. The feet and toes are feeble; and though the latter are yoked, the outer toe is reversible, so that there are occasionally three to the front and one behind. They are fit only for perching, 
not for climbing, and not very well for walking. The bill resembles that of the birds which live upon insects, but do not catch them on the wing. The bird has something the air of a hawk, but none of the powers, and it does not seem to have much of the disposition. Its food is insects and their larva, especially the larva of caterpillars of the lepidoptera; and, as many of these are highly injurious to trees, it is probable that the cuckoo is of great service, as it is with us at the very seasons when, if not thinned, these caterpillars would commit their depredations. It beats for its food in the trees, and it is probable that its peculiar feet, its long wings and great tail, and its soft plumage, enable it to hunt among the leaves, especially on the under sides of them, in places which the smaller insect-hunting birds cannot reach.

Analogy leads to the conclusion, that the cuckoo is a most avenous feeder, We have the example of the owls as compared with the other rapacious birds, to show that it requires more nourishment to supply feathers than flesh; and it requires more labour from the foster birds in whose nests these are found to feed one young cuckoo, than other birds of the same species require to raise a brood of five or six of their own species.

Considering the general distribution and the numbers of cuckoos, the eggs and young have been very seldom seen, probably not one to a million of the birds. When found, it has always been in the nests of other birds, at least in all those of the recorded instances that are received as properly authenticated; and little birds, pipets and others, have been observed most industriously feeding cuckoos after these had acquired their young or hair-brown plumage, and could fly. But before the habit can be considered as general, there must be numbers of young observed, bearing some nearer proportion to the abundance of the old birds, than have yet been found, although the cases that are recorded appear to be too many to be considered accidental; and the accident, too, is of a kind that rarely happens in the case of any other wild birds-that is, birds in a state of nature. The disproval of 
the old theory, that the bones of the under part of the female cuckoo were such that it could not hatch, throws at least a doubt on the universality of the habit, which would demand some additional proof on the other side, more than three or four isolated cases in the season: and that is, perhaps, nearly the usual number of young cuckoos that are seen in the nest.

Still, we may safely conclude that the absolvment of the cuckoo from nest-building and rearing young, which are the severest labours of other birds, is meant to answer, and does answer, some very important purpose in the economy of nature; and that purpose can be accomplished only by employing in some other way that portion of time in the cuckoo, which, in other birds, is devoted to nidification and nursing. That is the grand point to be ascertained: it can be ascertained only by observation of the most careful nature; and till it is ascertained, the history of the cuckoo, unquestionably the most curious bird that visits the island, must remain imperfect and mysterious; as such, we shall not enter farther upon it. Conjectures, in any quantity, may be had in the books. 


\title{
ORDER VII.
}

\section{ANISODACTYLES.}

\author{
UNEQUAL-TOED.
}

THE birds belonging to this order (of which the general character or peculiarity has been already noticed) are all small, and the British species are still fewer than those of the last; but some of the foreign, and especially the tropical ones, among which are included the brilliant and truly wonderful family of the humming birds, are equally remarkable for their beauty and their habits. There is little song among them, their voices being in general harsh, and in some instances absolutely grating, but loud in proportion to the size of the birds. There are three, or perhaps four, British species, all of different genera; one generally distributed and resident, one locally resident, and one a rare summer visitant.

\section{THE COMMON CREEPER. (Certhia familiaris.)}

The creeper is a most interesting little creature. With the exception of the golden-crested wren, it is the smallest of the British birds, weighing not more than a quarter of an ounce, being about five inches in length, and seven and a half in the stretch of wings.

A figure is given of it on the plate at page 189, along with the green wood-pecker and the kingfisher; the creeper onethird of the lineal dimensions, the kingfisher on the same scale, and the wood-pecker on half the scale, or one-sixth in line. The figure will show the colours and markings better than any description, as they are minute and delicate; it also 
shows the junction of the two outer toes at their base, and the length and strength of the claw on the hinder toe. It will also be seen, on comparing it with the wood-pecker, that the feet are placed farther forward, so that the centre of gravity is nearly in the centre of the base which they form. That may always be ascertained from the attitude of a bird: if the axis is nearly level, the bird is balanced on its centre, and can walk or run well; but if the head is inclined upwards, the bird is never a good walker, unless the elevation of the head is produced by the motion of the neck, and the body remains nearly horizontal. Thus any one can discover that the kingfisher is by no means so good a walker as the creeper. The tail feathers of the creeper, which are twelve in number, are stiff and pointed, and adapted for acting as a prop, like those in the woodpecker's.

Thus formed, and so light, the creeper runs over the boles and branches of trees in all directions, and with incredible celerity. It is most abundant in the forests, even in the depth of them, and far to the north; and it runs not only upwards, downwards, and across the perpendicular trunks, but with its back undermost, on the lower sides of the branches. Its object is to pick out of the smaller crevices of the bark those insects and their eggs which, though not observed by the larger birds, would, were they suffered to remain, do incredible damage to the trees. The bird is so small, that the most slender twig will bear it: so that it clears the terminal buds on the young branches when they are only partially formed.

It is so active and so generally distributed, that trees of all descriptions, and in all places, fall under its care. Woods, copses, hedge-rows, shrubberies, orchards, gardens,-_all places are visited by the little active creeper; and many a perfect flower, sound fruit, and vigorous shoot do we see, which, but for that little thing, would have been ugly and unpleasant in itself, and spread canker over the plant on which it grew. It has no song, but merely a monotcnous note, much resembling that of the golden-crested wren; but it amply repays the ob- 
server by the quickness and variety of its motions. It seems to feel that it is quite safe in its own resources; for, while you sit or stand under an apple tree, it will take a run over the whole, and clear it for you, and never be disturbed, though it should be only at the distance of a few feet. As it picks up those eggs of insects which are glued to the bark, or the buds, or inserted just below the surface, it removes an incredible number of destructive creatures before they can liave done any mischief; and as it looks after all trees, old and young, it is probably of more service to woody vegetation than any other bird.

The only coutribution which it levies on the trees in return, is to make its nest in some hole, and pick up decayed bark for the external fabric; and when it cannot obtain that, it uses dried grass, finishing the interior, in all instances, with feathers. The eggs vary, but nine is about the average number ; they are white, speckled with reddish brown. Altogether the creeper is a lively little bird, and has a pretty little nest, the plundering of which is absolutely treason against the majesty of nature in the wild woods.

It is understood that there is, at least in the southern counties of England, another species of creeper ; and indeed we want not a little research before the positive number of our woodland birds is decided.

тне Nuthatch. (Sitta Europea.)

The nuthatch, like the wryneck, is confined to the southern parts of England, but it is a resident bird; and as like the creeper, it visits trees in the garden, and even close to the house, it is as interesting to see, as it is easy to be seen.

It is about three times as heavy as the creeper, but only an inch longer, and the wings and especially the tail, are shorter in proportion. It is a stronger looking bird than the creeper : has a good deal of the shape, and also the beak of the woodpeckers; but the tail feathers are short and flexible.

The colours are, the upper mandible and whole upper side 
of the bird blackish grey, the base of the lower mandible and the throat white, breast and belly pale buff orange, sides and thighs brown orange, and vent and under tail coverts reddish brown; quills blackish grey; two middle tail feathers grey; the others black with a white spot and ash-grey tips. A black streak from the eye across the ear-covert to the neck. The feet strong, and the hind toe and claw very much produced.

During winter, the nuthatch, like the green wood-pecker, feeds at least partly upon vegetables. Nuts, it fixes in chinks and hews the shell to pieces by its bill ; and it seems to know at what places the shell is most easily broken, for it will turn the nut round after it has tried and failed. In ordinary cases, the stroke is given after the manner of that of the woodpecker, by moving only the neck; but as the nuthatch does not require the wood-pecker's stiff position of the body and tail in order to keep its perch, it can, in the case of a very stubborn shell, swing on the feet, and give the blow all the advantage of the weight of its body. It sometimes plunders the hoards of mice and other small grain-eating quadrupeds; and the evidence, though not absolutely conclusive, is rather is rather in favour of its hoarding.

It nestles in trees, and feeds on them; but it does not, like the wood-pecker, drum the tree when serenading its mate. Its love song is a sort of whistle, rether loud considering the size of the bird.

The nest is made in a natural hole of a tree, the deserted nest of a wood-pecker, or in a hole excavated by the birds themselves; in which case they make the entrance so small, that it will not admit any larger bird. If they choose a readymade place, they build up a wall of clay till the entrance is reduced to the requisite size; and should that be injured during the incubation, they instantly repair it. The interior of the nest is formed of dead leaves, those that are the most readily obtained, and the least decayed. The eggs are not more than seven, and the incubation takes place in May, the female being a very resolute sitter, hissing like a serpent, and 
striking furiously both with her bill and wings, at any one who offers to intrude. Even if her defence is disregarded, she will not desert her charge, but rather allow herself to be taken captive in their defence.

\section{THE HOOPOE. (Upupa epops.)}

The hoopoe is a singularly formed, but very beautiful bird, not uncommon in France, and plentiful in the warmer parts of Europe, as a summer migrant from Africa, where many of the summer visitants of Europe spend their winter, or rather their " other summer," for many of them pass beyond the equator. The hoopoe only comes straggling to Britain, driven, probably, by the east winds; but it comes occasionally to all parts of the country, even to the Orkney Islands, and sometimes continues and breeds, but disappears at the end of summer. One was shot in Cornwall, in December, 1834.

The length and slenderness of its bill indicate that it does not find its food in the same places as the creeper and the nuthatch. It picks up tadpoles, beetles, and other prey in moist and marshy places; but it builds in the holes of trees or of rocks. They are said to perch low, on the twigs of osiers and other shrubs that grow in marshy places; but in this country they are seldom seen on the perch. They have three calls, poon, slowly drawn out, and thrice repeated when they perch; boo, repeated the same number of times, is the love note of the male; and they have a sharp, half-hissing, halfgrating cry when they are alarmed or irritated. Five is about the greatest number of eggs, though there are seldom so many in their northern broods; but they are said to breed again once, and even twice, in the south. The young are very voracious; and as the substances on which they are fed are very liable to putrefaction, the nests are most offensive to the smell. That very circumstance shows, however, the value of the birds in keeping the air pure, especially in the hot countries, where they are so abundant.

The length of the hoopoe is more than a foot, the extent of 
the wings more than a foot and a half, and the weight about three ounces, The most remarkable external characteristic of the bird is its crest, consisting of two rows of orange feathers, tipped with black, extending backwards along the head, and capable of being elevated or depressed. The head, neck, and breast are brownish red, the upper part of the back, greyish brown, and the hinder part barred with black and white; the under parts of the bird are white, with longitudinal streaks of brown. The wings and tail are black, the former with fine regular white bars on each, and the latter with a chevron of white, the angle directed to the body of the bird.

The hoopoe walks well, and has the strut of some of the domestic gallinæ, and when dismayed, it erects its crest, and spreads its tail like a fan, in the manner of the turkeycock. Its flight through the air is by leaps, or undulatory, and, to appearance, performed with considerable labour; but from the long migrations which it makes, it must be capable of long continuance. 


\title{
ORDER VIII.
}

\author{
ALCYONES. \\ HALCYONS, OR KINGFISHER BIRDS.
}

There are only two British birds of that order, the one a resident, but by no means a common one, the other only a straggling visitant, though of late years more frequent, or more observed than formerly. They are birds of close and finely-coloured plumage, of powerful wing, and generally very graceful flight; but they are very ill adapted for walking, and thus prey on the wing. One of the peculiarities of their structure is the union of all the three front toes at the base, which makes one of the least powerful feet among all the varieties possessed by birds. The resident one is

THE COMMON KINGFISHER. (Alcedo ispida.)

The figure, one third the lineal dimensions, on the plate at page 189 , will give an idea of the form, colours, and altitude of this singnlarly shaped and exquisitely tinted little bird, when reposing with closed wings. It is an inhabitant of holes or burrows on the banks of streams, lives by fishing, and spends much of its time in the air near the waters, or perched on the bushes along the banks. Its food is not confined to fish, for it also catches dragon-flies and other water insects; and whatever prey it catches, it swallows entire; casting up the indigestible parts in pellets, after the manner of the owls.

Its ordinary motion is so rapid, and its colours so bright, that when it passes, it is like a gleam of a broken rainbow 
darting along near the surface of the waters. There are few sights in quiet nature more novel and pleasing, or that one wishes more to have repeated, than the first glance one gets of a kingfisher, darting along some reach of a clear but placid stream, which glides between soft banks, fringed with reeds and bushes. If one is not tolerably well acquainted with it from description, both in its hues and its habits, one is at a loss whether to think it a meteor or a bird. It passes so fast, and the rapid motion of the gay wings gives them so much the appearance of vapour, that it is rather a puzzle; and it is said, and may be true, that its rich hues when it hovers, which it often does after the manner of the hawks, attracts the small fishes to the surface, in the same manner as the lighted torch in "burning the water," attracts the large ones; and while they are, as it were, fascinated, it darts down like an arrow, and makes a certain capture,-though the colours can be seen from below only when the bird twitches round. When seen as it perches on some slender twig overhanging the water, it has the appearance of the gay flower of some rare and curious water plant; and the bird, as if conscious of the power of instant escape which is in his wingswhich appears to be felt by most birds so furnished-will allow you to approach tolerably near; and if you are quiet, and do not offer violence or make a noise, (for it is silence that the kingfisher loves, more than seclusion,) you may see its mode of doing business on the surface of the brook.

Its flight is rather low, and straight forward, but its eye must be remarkably keen, because it will, in the most rapid flight, halt, hover for a time, and then dart down, seize a little fish, a leech, or even a worm or slug by the bank, and instantly land with it. As it thus not only fishes wholly by the sight, but from the comparative smallness of its prey, requires to see very clearly, it is only at particular spots, and in particular states of the weather, that its operations can be successfully carried on. The water must be clear, and the surface smooth; and that is the reason why it is not found upon turbulent or brawling streams, or when wind curls, rain 
dimples, or mud darkens the waters. The days when evaporation has ceased, and a storm is impending, are those on which the atmosphere is most transparent, and the surface of the water most glassy. They are, consequently, the days which, above all others, are fitted for the successful operations of the kingfisher; and so are the clear blinks that break out, still warm and shiny, when the weatler is unsettled, and the process of evaporation is suspended. These are genuine "lialcyon days;" days on which the kingfisher is out and active : but the bird has, of course, no more to do with the producing of them, or of the storm which generally follows, than a Lapland witch has to do with the producing of that fair wind which she sells to the credulous mariner; and if the delivery of which did not often follow the sale, her trade would soon be at an end. Her experience leads her, from present appearances, to infer what is to come next, and therein the certainty of her success depends on the soundness and length of her experience. The kingfisher, on the other hand, comes on the water, because that and the atmosphere are in a certain state at the time, and the Creator of the bird has made that state the stimulus of the bird's instinct. The same state is that which precedes rain; but as the gay bird is more easily seen than all the circumstances of the weather that bring him out, the bird, which is merely one of the signs of the present state of the weather, is put for that state itself, and made the antecedent, or cause of the future. But where kingfishers are, the prognostic drawn from them is, from the very nature of their habits, a good one; and therefore we need liardly wonder at the superstition, or at the extension of it to other matters, against which much ridicule has sometimes been directed. But it cannot be too often repeated, that that ridicule is actually more injurious than the superstition itself. A natural superstition is merely a false application of a striking natural fact; and the business of true wisdom is to find out that fact, and apply it properly. The kingfisher is, in all senses of the word, a very "beautiful" subject. 
The kingfisher not only nestles, but generally reposes, in some hole in the bank; and as its feet, and even its bill, (which is a fishing spear,) does not adapt it very well for being an excavator, it generally selects one that is ready made; but whether, as has sometimes been said, it ejects the water rats, is not ascertained by any recorded witnessing of the actual ejectment, though the objection of the water rat eating the eggs and young, which is also conjectural, has nothing in it. A crow would eat the eggs or young of the eagle; but if Aquila should catch him in the fact, his doom would be as black as his feathers.

As it is only on particular days, and at particular hours, that the kingfisher can fish to advantage, he feeds abundantly at those times, and his gullet and stomach are ample in proportion. If the prey is very small and soft, he bolts it on the wing; but if it is larger, he goes ashore; and if it is large and lively, he beats it against a stone, and after swallowing it returns to his fishing : nor is it till after he has been gorged to the very throat, or the fishing tide is at an end, that he retires to his hole. There he digests and dozes, and often remains for days before he again sallies forth; and when all the soluble matter is separated, he ejects the bones in those castings which are found in his den, and which, as they contain nothing but that which is capable of resisting the gastric juice of the bird, do not decompose in the air, so as to occasion the least unpleasant smell. As the attachment of the kingfisher to its hole is a permanent one, and not limited to the breeding time, the plundering of the nest does not drive it away, any more than the annual shooting of the young on the branches drives the rooks from a rookery.

As the habitation of the kingfisher always opens toward the stream, and generally under some projection, and where there is not a path between it and the water, even in low states of that, as it flies low and near the surface, and can glide in without being observed, and further, as it spends much of its time in that habitation, its nest is rarely seen, in proportion to the number that actually exists. People find it 
fishing in lonely places, and thence they are apt to conclude that it dwells in places still more lonely, whereas it most likely has its loole not far from their own dwelling. Where a clear stream crosses the line of a hedge, and the gap, with high banks on each side, is secured by paling, is a good place to search for the nests of kingfishers, if the birds are observed upon any neighbouring part of the stream.

The nest, whether made for or by the bird, slopes upwards, as indeed all the nests which are made in banks by land animals do, otherwise, if they should ever by accident be filled with water, they would not easily get dry again ; as the creatures that inhabit them, and especially birds, though they can move solid substances, are by no means qualified for baleing out liquids: hence the offensive condition of those nests in which the droppings of the young are liquid, The eggs are from six to eight, and the young continue a considerable time in the nest, (they would indeed be helpless out of it till they are capable of flying,) and as they have their plumage to get, they are very clamorous for food, and consume a great quantity. The old ones feed them from the gullet; in all probability, from the stomach, and, most likely, in the early state, with food that has been partly digested in the stomachs of the parent birds; and, indeed, so long as the young are fed from the gullet of the old birds, their food must not only be partially changed, but also, to a certain degree, mixed with the gastric juice of these, which may assist the digestion of the young; and that will account for the difficulty of rearing them artificially.

THE BEE-EATER. (Merops apiaster.)

This is another beautiful bank-inhabiting bird, though it preys on bees and other winged insects, and not on fish. The forehead is yellowish white, passing into pale bluish green on the top of the head; back of the head and neck rich brown, passing through orange into dull yellow on the rump and tail coverts. The greater wing coverts of the same orange as the 
corresponding tints of the back; but the lesser coverts bright grass green. Quills bright blue, with a slight trace of green; feathers of the tail pale olive green; the two middle feathers about an inch longer than the rest, and pointed. Bill long and slightly tapering and black, with a black line from the gape across the eye and ear coverts, to a narrow collar of black round the neck. The throat, above the collar, very bright yellow, and the rest of the under part greenish blue. Irides red, which, with the contrast of the black, brown, and yellow, gives the eye a very brilliant appearance. The bird is, in fact, quite tropical in the texture of its plumage, and the richness of its colours. It is a common summer migrant in the eastern part of the continent; but, as the birds fly easily as well as gracefully, a few of them occasionally straggle to Britain. They are about the size of thrushes, that is, ten inches long and seventeen broad, As is the case with most finely coloured birds, their cry is harsh. They excavate holes for their own nests, and line them with moss. Excepting perhaps the kingfisher and the roller, they have finer plumage than any British birds; and in texture theirs is superior to the others, and the reflections on the blues and greens are prefectly unique. 


\section{ORDER IX.}

\section{CHELLTDONES.}

THE SWALLOW TRIBE.

THESE are a particular class of the insect-eating birds, which agree in so many characters, that they form a convenient group. They prey upon insects only; they capture these chiefly while on the wing, and their whole structure and manners are in accordance with that mode of feeding. Thus they are all summer visitants in Britain, because there are not so many insects to be caught in the winter as could support even the thousandth part of them. Again, their wings are very strong and long, and their tails produced in forky points, so that they can remain the whole day on the wing, and wheel round with very little diminution of their velocity, Their plumage also is exceedingly firm, so that the wind neither takes hold of, nor is apt to ruffle it. Their form is that which has been found to make the fastest sailing vessel,-full forwards, and lengthened and tapering backwards. They have small and weak feet, as they use those little, and they would be a weight to carry in flying; but the feet and the stiff points of the tail, and even the edges of the wings, are so formed, that they can cling to an upright surface, or even to an overhanging one, if there be roughness to hold their little claws. Their sight is exceedingly acute, so that they probably discern small flies at a greater distance than man can discern them. Their bills are flat, very wide at the base, and with the upper mandible hooked, and sometimes the lower recurved a little, so that the sides do not shut 
so tightly as to crush any soft substance that may be between them ; and that with the wideness of their gape and gullet, enables them to carry a cargo to their nests when they have young. These characters apply chiefly to those that feed by day: the twilight ones, of which there is only one British species, have their plumage much softer, and vibrisse, or hairs, dependent over the sides of the bill, with muscles attached to them, and capable of communicating impressions as well as receiving them ; these may help the owners to feel their way, and also to entangle the insects, as the birds cannot, from the extent to which the bill opens, and the position of the eyes, have much use of them in finding their way.

In some of the systems, these birds are classed as fissirostres, that is, "open bills," as the bill does not shut at the sides; but that is only one part of their structure, and one that is not an immediate or general key to their habits. The following figures will give some idea of the bills of the nocturnal and the diurnal Chelidonian birds, both of which differ from that of the bee-eater and other birds that pursue the larger insects upon the wing.

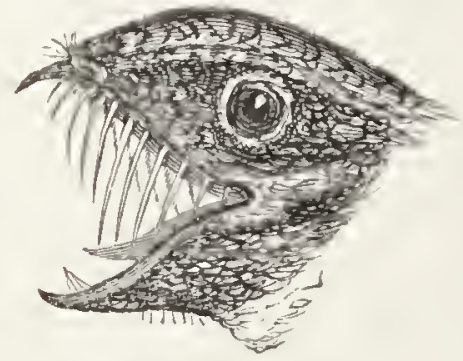

Goat-sucker.

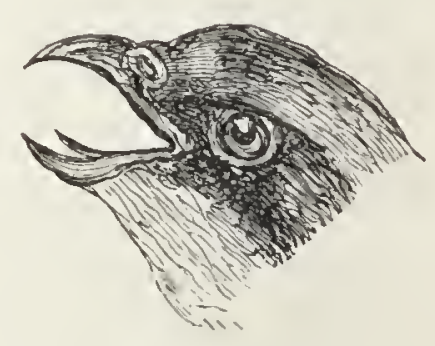

Swallow.

These birds fly for their food in the air, something in the same manner as the whales swim for theirs in the water; and as the goat-sucker feeds on the night-moths and gnats, which it probably does not see, the hairs, or vibrissa, at the sides of the bill probably answer a purpose similar to that of the baleen in the common whale; and it is not a little singular to find 
so near a coincidence of organ in animals whose element and size are so very different.

The swallow, the martins, the swifts, and the goat-sucker, are the only British Chelidonian birds : they all come to the cultivated districts, and while they remain, no doubt, perform the most important services to man, in the vast numbers of insects which they destroy, not when in the caterpillar state, and when the capture of one may be considered as only the destruction of one, but when they have passed all the dangers of the preliminary stages of their being, and are ready to deposit their eggs, and thus lay a foundation for future myriads.

THE CHIMNEY SWALlow. (Hirundo rustica.)

The forehead and the throat of the swallow are deep reddish brown; the belly and vent reddish white; a large white spot on the inner web of each of the tail feathers, except the two middle ones; and all the rest black, with blue reflections. Some individuals are grey, or even white. The length is seven inches, the breadth about twelve, and the weight an ounce. One remarkable character of the swallow is the great length of the external feathers of the tail, and the deep fork which they give to that appendage. The young of the same year have not the long tail-feathers.

Swallows perform their principal moult in warmer coun. tries about the month of February; appear in fine plumage in the south of England about the first of April ; and proceed northward, colouring as they fly, along all the places that are adapted to their habits, till about the end of the month they appear in the extreme north of the country.

The places which they select for their nests are, chimneys, barns, outhouses, steeples, ruins, rocks, and the sides of pits and quarries. The nest is constructed of mud, and lined with feathers, but open at the top : indeed, the length of the tailfeathers is such, that the construction of a domed nest would be very laborious for the swallow. The eggs do not exceed 
five, but, except in the extreme north, where they arrive late and depart early, there are two broods in the year, one fledged in June, and the other in August. They are, generally, all gone by the end of September ; but some of the late broods are not capable of the long journey, and so linger in the country, and are found dead, or in a benumbed state, in holes of walls or under hedges, partly, no doubt, from the inclemency of the weather, and partly from want of food.

Swallows are delightful little creatures, not only as they come from a far country, the harbingers of the blooming season; but on account of their industry, the celerity of their motions, and the perfect confidence in which they carry on all their operations.

The most lovely scenes would lose much of their summer interest, if it were not for the presence and lively motions of the swallow. The banks of rivers and the margins of small lakes, are at all times delightful places for quiet contemplation, and for agreeable walks, when the sultry day draws near to a close, or on those stilly and transparent days which immediately precede rain. But there is an excess of repose about them which would soon become monotonous and heavy, except for the evolutions of the swallows, now shooting into nid air, now skimming the surface of the water, and sipping or laving its plumage, as it speeds along, alternately with darting wing and with dart-like glicle. Then, when we think of the myriads of gnats and flies which the teeming waters are constantly giving to the air, to sport (and sting) for their few hours, deposit their eggs and die, making the shores and shallows which are inaccessible even by the minnow, rank with their innumerable carcases, we feel how much the swal.. low contributes to keep sweet and clean those waters over which it glides, quaffing or bathing the while. The air too is so still, that we hear the repeated strokes of its bill as it captures those insects which, to our sight, are viewless.

Though many swallows often build in the same locality if there is abundance of food in the vicinity, the finding of their food and that of their broods, every morsel of which is very 
small, and purchased by a laborious flight, leaves them little time for associating with each other, as do many of those birds which find their food in larger portions and with less labour; and as the young must be fed by the parents for a longer time than is necessary in the case of birds that are not called upon to make so great exertions, the labours of the swallows are thereby further protracted. When, however, the last brood are on the wing, and each has nothing to do but procure its own food, they do assemble together, sometimes in very numerous flocks, over meadows on the banks of streams; and they also roost upon the tops of houses and churches, preparatory to their final departure. As the swallows spend their active powers chiefly over the waters, while they are in the northern and temperate regions, the old story was, that they spent their winters at the bottom of the same; but that is, of course, not true: indeed it is impossible, utterly inconsistent with the spring moult of the birds, and even with their existence. If a swallow remained but for a few seconds under water, it could not be brought out alive. The air is their element-and that too more exclusively than it is the element of any other birds; at least, of any that are common in this country. One of the swallow tribe is rarely seen resting on a solid perch, unless by its nest, till the labour of the season is over, and the time of its departure come.

\section{THE HOUSE-MARTIN. (Hirundo urbica.)}

The house-martin is one of those creatures which associate with man, claim the shelter of his dwelling, and for that purpose, hunt him out in all quarters of the world, and in every latitude, if the places which he chooses will at all afford a supply of food for the martin and its young.

There is not so much romance, or if you will, sublimity, about the martin, as there is about the swallow. The wings are shorter in proportion to its weight, and it wants those singularly-produced feathers in the forky tail, which enable the swallow to wheel round about upon its centre of gravity, 
and to turn here, there, and every where, without almost any perceptible effort. But the martin is a prettier bird, more contrasted and more lively in its colours; and its coming to nestle in the windows (often the very identical bird for a series of years), renders it still more a favourite, Black and white are the colours of the house-martin; the whole of the upper part, except the rump, black, and all the under part white. The tail, which is forked and very stiff at the tip, and the quills and coverts, are brownish black, and the rest of the black part has a trace of blue. The line of separation between the white and black, on the sides of the neck, is finely broken, and the richest blue reflections are close by it. The tarsi and toes are covered with white down. The female has the breast inclining to grey.

The martins arrive in Britain a few days before the chimneyswallows; and, like them, they appear first in the warmest parts of the country, but they soon distribute themselves over the whole of the low grounds, and probably each returns to the place of its nativity, to nestle in the neighbourhood, and hunt in the society of its parents, or to repair the nest in which they were hatched, and continue the race, after the parents have yielded to casualties or to time. But interesting as are the manners of these birds, though as free as that air over which they have so much command, they are yet so truly domestic, that any one can observe them. The nest is more carefully built than that of the swallow ; and if the place where it is fixed has not a projecting cover, the nest is made with a dome, and the only opening is in the side. The nest is made large enough to hold both birds, and may be considered in the light both of a house and a nest. The eggs of the housemartin are never more than four or five; and the birds feed their young with the same assiduity and for the same length of time as the swallows; and light-coloured ones, and even albinos, occasionally occur as in that species. The flight of the martin, though not so rapid as that of the swallow, is still swift, and at the same time easy and graceful.

The house-martin remains a little later in the country than 


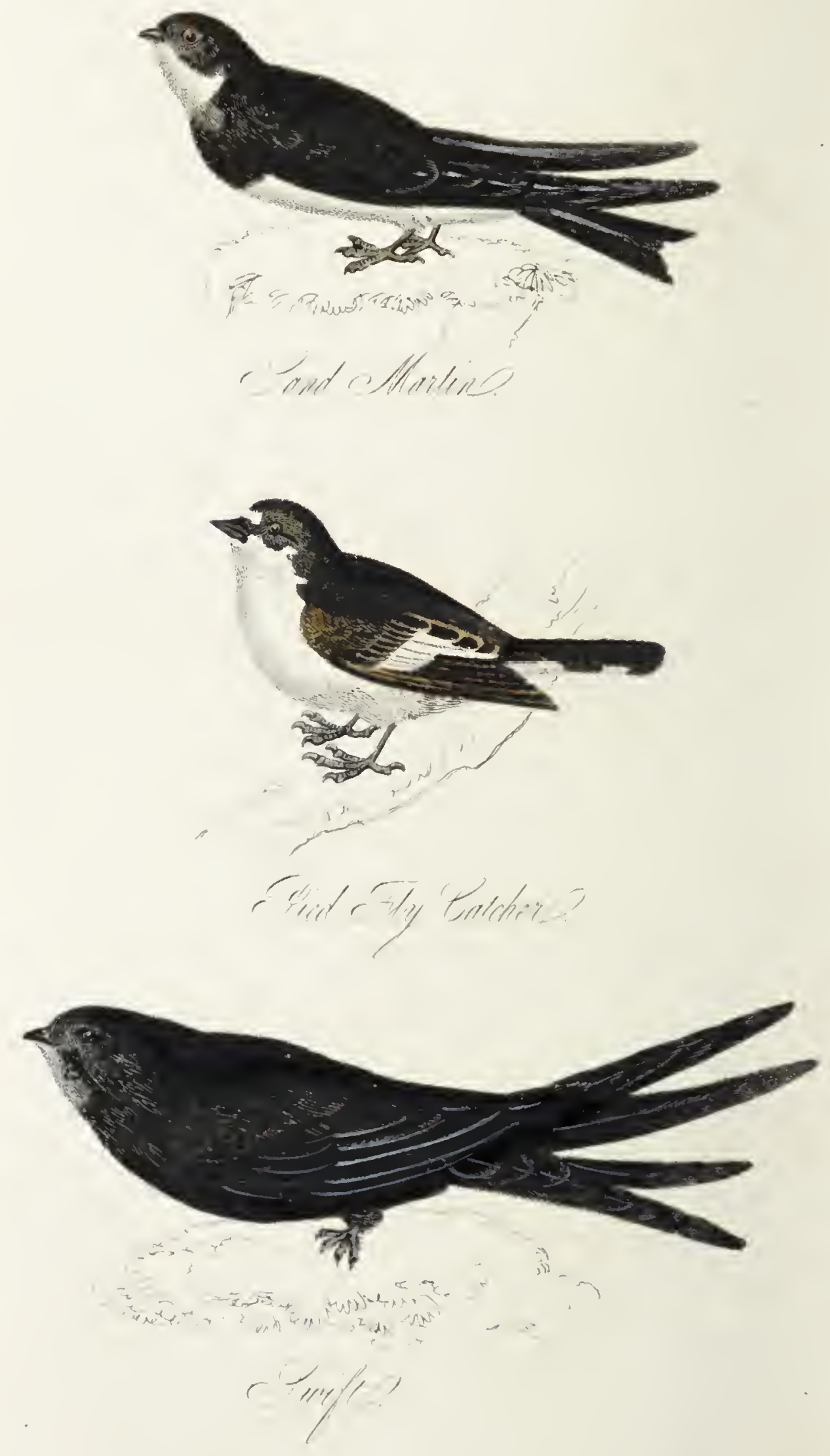
the swallow; but it retires about the time when the housefiles leave the wing, and crowd in numbers inside the houses. It seems that the house-fly is one of the chief attractions for the bird; and that the instincts of the two are so tempered to each other, that the bird retires while the flies are still sufficiently numerous for producing an abundant supply during the following summer. There are, indeed, enough and to spare in that and in all the other races of flies; for by the time that the summer birds begin to take their departure, the autumnal spiders come into full activity, and capture flics (especially males) by millions.

\section{THE SAND-MARTIN. (Hirundo riparia.)}

A figure of this interesting little bird is given on the ad. joining cut, on a scale of one-third of the natural lineal dimensions. It is smaller than any of the other British swallows, rather shorter in the wings, and not so dark in the colour. It is also different in its flight, proceeding more by jerks, and in that approaching the habit of some of the other tribes of little birds; but still, it has all the leading characters of the swallows. It comes, indeed, a little earlier, and remains at least as late, but it is less the associate of man than any of the rest: not that it shuns his neighbourhood, and goes into the wilds; for though there are colonies of sand-martins in lonely places, they are probably more numerous in the cultivated districts. The vicinity of the waters is its huntingground, and gnats and other insects, that sport over the lakes and streams, or their banks, are its chief game; but its distribution is regulated also by the choice which it makes of a nesting-place. Steep banks, or bluff's of sand, which are easily dug into, and yet not subject to crumble by the action of the summer rains, are its favourite places; and in the abrupt faces of these it forms its burrows, using its bill as a pick-axe, and shovelling out the rubbish with its feet, and often working so deep, that it is not easy to reach the nest without digging. In these burrows its young are very safe, 
as the aperture is too small for allowing any predatory bird to enter, and the steep is generally such that none of the small quadrupeds that eat eggs can climb it.

These birds are not found in the rocky districts or on the clays, neither are they partial to gravelly banks that are either very hard or very loose. The fresh-water accumulations of sand are their favourite places, especially where a knoll of these materials has been cut through by a road or the action of a rivulet. There are two reasons for that-the ease of working the bank, and the certainty with which it stands, and the abundance of insect food which, from the warmth of the climate, is found in such places. If the place is otherwise favourable, they do not much heed the immediate vicinity of a village, but will make their holes close to the houses, and beat about with little less familiarity than those species which form their habitations in the chimneys or the windows. The places in which the nests are excavated, generally secure them from inundation; and as all birds that burrow in the ground work with a little slope upwards, the rain does not reach the nests.

A colony of sand-martins, especially when they are in considerable numbers, and forming a new establishment, present a very busy scene, and dig away with much assiduity, relieving each other by turns, the one working while the other feeds; and as they are at work early and continue late, they are not long in having the burrow ready for the withered grass, feathers, or other materials of which the nest is carelessly made. The eggs, which are often as deep as three feet from the face of the bank, are generally one more than those of the house martin; but there are seldom two broods in the year. The young are fed for a considerable time by the parents; and after they have attained as much maturity as to be able to catch insects for themselves, they can be readily distinguished from the old ones, by the rusty colour of the margins of their feathers, an appearance which partially characterizes the female. The deep burrow of the sand-martin, is no more adapted for a winter residence than the mud struc- 
ture of the other species; for by the time that the insects become scarce in the air, partly by the diminution of their numbers, and partly because they are less on the wing, the sand-martin retires to southern counties.

TII COMMON SWIFT. (Cypselus vulgaris.)

The swift, of which a figure is given on tlic plate at page 221, one-third of the lineal dimensions, is perhaps the most powerfully winged, in proportion to its weight, of all British birds, not even excepting the white-bellied swift, or even the storm petrel, which extends its excursions so far from the land as to traverse the surface of the whole Atlantic. But the petrel does not feed on the wing, and in nestling time it of course resorts to the shores; whereas the swift has to hunt in the air, and that too at a considerable elevation, for subsistence both for itself and its brood.

The whole structure of the swift is indeed more adapted to an aërial existence than that of any other bird. Its foot, as may be seen in the figure, bears some resemblance to a little hand, and is not at all fit for walking or for throwing the bird upward with a jerk, as in the case with long..winged birds which occasionally reside on the ground. Place the swift on level ground, and it would be utterly helpless; but let it be in the air, and it is all-powerful. The little foot, too, can lay hold of a small pointed rock, or jutting stone, with so much firmness that the bird can abide on a jutting part of a tower, when it would be unpleasant for a man to stand on the battlement.

The swift is the garreteer of nature; not that it inhabits the highest grounds (for the very altitude of its place presupposes productiveness in its locality), but where it is found it spends its time and finds its food above every other creature. Its place of habitation corresponds: for the highest crevices in steeples, towers, and jutting rocks that rise to a considerable altitude amid fertile places, are the habitations of the swift; and its instinct leads it to adapt the structure of its nest 
to the elements. The straws and other matters of which it is composed, are said to be soldered to the rock and to each other, with a viscid substance, elaborated by glands for the express purpose, though perhaps the same glutinous matter may more assist the bird in the capture of its prey. Those swallows which construct their nests in great part of humid mud (they, too, may secrete less or more of a similar gluten), never build so high or in such exposed situations as the swift; and some of the foreign swallows, which form nests against the tops of caverns, and on the under sides of overhanging precipices, to which it would be difficult to convey ordinary mortar, construct them so generally of glutinous substance that they are sold as a substantive ingredient of soups; but that the nest is wholly a secretion of the birds is only said, not proved. The swift is not so prolific as those swallows which inhabit farther down: its eggs seldom exceed two.

The swifts have not only more labour to perform in order to procure an equal quantity of food, while they are with us, than any other of the tribe; but they also perform a wider and a more hurried excursion in latitude. The same species, and in all probability the same individuals, range from the northern parts of Europe to the Cape of Good Hope, and back again, in the course of about nine months. They seldom appear in any part of Britain before the middle of May, and not in the northern parts till June. The young are hatched, and on the wing about the beginning of July; after that time the whole begin to flock, and they disappear about the middle of August, a little sooner or later according to the state of the weather. Their motions do not depend entirely on the state of the temperature, but on that and the facility of finding food jointly; and warm showers, with gleams of sunshine between, will protract their stay, whereas very dry weather, though intensely hot, rather accelerates their departure.

During the slort time that they remain with us, the swifts are very interesting birds; and duly studied, they would no doubt be equally instructive. Migratory birds are all, of course, from the very same instinct that prompts their migra- 
tions, much more sensitive to atmospheric changes than resident birds, which are tempered by nature to endure those clianges, or to change with them, and on that account they are better indices to those changes. But swifts are the most migratory of birds; their pastures fluctuate more with the state of the weather than tlose of birds that fly and feed lower down, and therefore more delicate but not less certain indications of changes might be drawn from them.

It appears from their mode of flying, that in very dry and settled weather, there are ferver insects at a great height in the atmosphere than when the air is troubled, even when the signs of that trouble have not shown themselves in the deposition of vapour, or in the weight of the ail as shown by the barometric column. It may be (and it most likely is) that the evaporative power of the atmosphere is the first property of it that yields; and that their weak wings, which could not bear the drying influence of the rarefied upper air when dry, can endure it much better when its ardour relents.

In dry weather, the swifts hawk only toward morning and evening, flying lower down than when the air is different, and occasionally skimming the surface of the pools, and sipping and laving themselves as they dash along. At these times, too, they are sportless and silent, and if the drought is of long continuance, they seem fatigued; but when the upper air relents they fly high, appear all day on the wing, accumulate in unwonted numbers, gliding, dashing, wheeling, playing numerous antics, screeching to each other, and apparently acquiring more energy the longer they are on the wing. These sportive dashings in the upper air become more numerous and energetic as the time of their departure approaches, as then their care of their broods has ceased, and they have only their own food to find each for itself. The solstitial showers generally give them a farewell feast; and at that time they may be seen on the wing for sixteen hours in the day without once alighting to rest. Their sight has, by experiment, been found to be so very acute, that from a distance of 400 feet, they can discern an object not more than half an inch 
in diameter, and how much less than that is not known. The same motive of exertion which they often perform in this country without any apparent rest, would suffice to carry them across the widest sea or desert that is in their way, or even from England to Africa, in the course of one flight. Swifts are often seen driving at the smaller birds of prey, as if in derision of their less rapid flight; but they are not quite so furious against them as the swallows, within whose province those birds more frequently come.

the white-Bellied sifift. (Cypselus Alpinus.)

This bird has been found as a rare straggler, near Margate in Kent. It is considerably larger than the common species, being between nine and ten inches in length, and it is different in the colour, brownish with the belly white.

THE GOAT-SUCKer. (Caprimulgus Europaus.)

Few birds have more names than the goat-sucker, and yet there is not a very good one among the number. The MothEater (Phalanavara Europea) has been suggested. Goatsucker does not apply, as, from the impossibility of closing the bill at the sides, the bird cannot suck any thing; but some of the other names (night-jar, for instance,) are even worse.

On the opposite plate there is a figure of the bird, about one-third of the lineal dimensions, from which some notion of the form and also of the colours, which from the minuteness of the markings are not easily described in words, may be obtained. It may be noticed, however, that the sexes are distinguished by the male having oval white spots on the inner webs of the first three quills and of the outer tail feathers.

The length is rather more than ten inches, the stretch of the wings about twenty-one, and the weight nearly three ounces, so that it is not so powerfully winged as the swift, or indeed as any of the swallows, in proportion to its weight, and it is 
less so for its apparent size, as the feathers are much more loose and bulky in proportion.

It is of course improper to call a bird beaked and footed like the goat-sucker an owl, because neither the beak nor the claws are capable of catching either birds or mice; but still, in its habits, and even in the general tints and markings of its plumage, it bears something of the same relation to the swallows, that the owls bear to the diurnal birds of prey. Its plumage is loose and mottled, while theirs is stiff and firm, and more uniform in the colours. As is the case with the owls too, its eyes are very large and prominent, though, as the bird catches its prey on the wing, the eyes have not the concha of produced feathers that distinguish the owls.

There is a remarkable peculiarity in the foot of the goatsucker : the hinder toe is capable of being reversed, so as to be turned forward along with the other three; and that appears to accommodate one particular habit of the bird. The goat-sucker perches lengthways, but generally with its head inwards to the tree, instead of outwards, like the cuckoo; yet it has to glide from its perch in nearly the same manner; only, as it must, from the slope of that perch being the other way, spring more from the toes than the cuckoo, and would find the hinder toe rather an obstacle, that is brought forward in aid of the others, just as one of the two hind toes of the cuckoo are. Like the wood-owl, to which (though their prey is rery different) the goat-sucker bears some resemblance, it makes a noise when flying in quest of its prey. That noise is a compound of hissing and booming, much louder, but still similar to the sound made by the larger beetles when on the wing in the twilight. This sound has been said to be the love note of the beetles, which are thus attracted from a distance by the sound of the birds-their love notes and maternal and filial cries being those by which all animals are most easily allured.

The goat-sucker is a summer migrant, and does not arrive till the middle of May, the time at which the cockchafer flies in the evening; and though it is not plentiful anywhere, it 
contrives to capture vast numbers of those destructive insects. It frequents the woods, and also the banks on the margins of the pastures, where the beetles often settle, previous to depositing their eggs in the ground; and under the tress, it is just as active in the destruction of moths. It departs in the end of August, or the beginning of September, and rears, during the interim, its brood, which are seldom, if ever, more than two. The eggs are deposited upon the ground, under the shelter of a tuft, and without any nest, and the young have sometimes been mistaken for those of the cuckoo, to which they have a faint, though but a very faint resemblance.

When hawking for beetles, which of course it does at beetles' height, that is, within a few feet of the ground, the goat-sucker flies with its bill widely extended, and makes its peculiar noise, but stirs the air but little with its wings. When moth-hunting, its habits are a little different. It glides round and round some tree, below which the moths are often taking wing, on their courtship or predatory flights, and as it catches a glimpse of a moth, it darts in and captures it, the glutinous matter with which the gape is lined assisting in the process.

The goat-sucker occupies alone a peculiar station in Ornithology, - that of hawking on the wing for insects in the dim twilight ; and as those which it chiefly catches are destructive ones, the larva mostly being in the ground, and destroying the roots of plants, or in trees, and consuming their buds and leaves, and sometimes the cambium and even the wood, it must, on the whole, be classed among those birds which are eminently useful to man; and one which comes from a far country to perform its yearly service, and which performs that without doing any thing in the least injurious-for the goatsucker consumes nothing but insects. Indeed, the whole of the chelidonian birds do good only, without the least admixture of evil. 


\section{ORDER X.}

INSECTIVORA.

INSECTIVOROUS BIRDS.

This is not a very accurate name for an order, because the birds, which we have to class under it, are some of them less insectivorous than those of the order immediately preceding, and some of them feed as much upon mollusca and worms as upon insects, if not more; but still, it enables us to bring together birds which have so many characters in common, that a few general sentences enable us to avoid repetition.

These birds mostly inhabit woods, bushes, or reeds on marshy grounds; they do not associate in parties, but each pair have their solitary nest, and many rear two broods in the course of the year. They all feed chiefly upon insects, and other small animals, during the summer, and prefer them for feeding their young; but those which are resident in Britain all the year round, have recourse to berries, seeds, and other vegetable substance, during the season at which animal food is not to be found. Many of them are summer visitants with us, and resort to warmer climates during winter; but a few also breed further to the north, and are winter visitants with us.

Of 37 species that may be considered as belonging to this order, only 12 are permanently resident, 20 are summer visitants, two come in the winter, and three make their appearance only occasionally. The 37 are made up of the following divisions; (but there are probably more).

3 Shrikes: two very occasional stragglers, and one a local summer visitant.

2 Fly-catchers: both summer visitants.

1 Dipper: a local resident. 
6 Thrushes: three resident, two winter visitants, one summer.

12 Warblers: one resident, eleven summer visitants.

2 Wrens: resident.

3 Chats: two summer migrants, one resident.

2 Accentors: one resident.

3 Wagtails: two summer migrants, one resident.

3 Pipits : one summer migrant, two residents.

Though, among such a number of birds, there must be great diversities both of character and habits, yet there are sufficient resemblances among all these tribes to warrant the referring of them all to a distinct, though not a very strongly marked order. There is a softness and indistinctness of the individual feathers in the plumage of their bodies; their bills are slender and compressed, with some tendency to a hook at the tip of the upper mandible, and also a notch; their feet are generally more adapted for perching than for walking on the ground, as they have the middle and outer toe united at their bases; their notes are generally soft, and in most cases melodious; and they nestle in the shade, in trees, in bushes, under stones, or under herbage, and never associate in flocks during the breeding season, though many of the summer migrants do before they take their departure, and the winter ones generally come in flocks. Some of the resident ones change their localities, and partially change their food and some of their habits, during the winter months; but they never congregate in such numerous flocks as those birds which subsist merely on vegetable food. The greater number of them breed more than once in the course of the year.

Though these are not the only birds that feed upon insects and their larva, they are the principal ones that pick them from vegetables when they are in active growth; and therefore they are among the principal conservators of those woods and groves which are rendered lively by their presence, and cheerful with the melody of their songs. Two species, as has been noticed, visit us only in the winter, and ten reside permanently in the country; but still, so great a proportion, both in species and in absolute numbers, come in the spring 
and depart in the autumn, that the whole may be considered as being pre-eminently our summer birds, and as forming no unimportant feature of that season of beauty and activity.

They resort to different localities: some to the open wild or the brake-clad common, and others to the margin of the lake or the bank of the stream; but the majority frequent only the ruder parts of the country, dwell chiefly in the groves, and pour forth their notes while perched on the sprays. Some disperse themselves orer the whole island: but there are others which confine themselves to the warmer localities; and indeed, they may be generally said to be birds of the rich parts of the country, and as such, to increase with the increase of cultivation and planting. In summer, one meets them at erery step; and though the species varies with the place, and the occupation with the time of the day and the state of the weather, yet the place is sadly barren, or the time intensely dry, if we do not meet with or hear these interesting and active creatures. In spring, their appearance, on the whole, keeps pace with the season; for the weather generally changes first in those places that are southward; and the birds are driven by the state of things in the places which they desert, and not drawn by that of the places to which they come. When, however, the spring comes suddenly in a northward place, and before the decay of food and the action of heat southward has sent the usual accompaniment of birds to watch the opening buds, the young year feels dull and desolate. It has been remarked too, that in those years vegetation suffers more than usual from the ravages of insects; though that, no doubt, in part, arises from the checks which it subsequently receives when the young leaves are so far expanded, that they derive little shelter from the hybernaculum, which protects the germ in the winter, and the bird in the early stage before the leaves are so much unrolled as to have much action in the air. But the very same nonconducting property of the albuminous scales of the hybernaculum, which preserves the germ from the winter's cold, prevents the hatching of the insects' eggs, millions of which are gathered by the birds when they first visit the sprays. in 
the opening bud; and if the birds are not there, these hatch apace, and the caterpillars gnaw into the cones of the buds, and spoil the vegetation of the year, as much in the shoots of the forest trees as in the blossoms of the fruit. It is then that the little strangers are peculiarly useful; and, as the males generally come first, and commence their songs after a very short rest, considering the length of their journey, they are as charming as they are useful. A few graminivorous birds do then mingle with them, and eat the small seeds that are sown in borders; but still, the damage done in that way is nothing compared with the general good; and it may be said, that he who kills one of the insectivorous birds in the spring, pays a bushel of apples as a fine to Nature in the autumn.

The spring birds, the spring breezes, and the spring leaves, all come together as parts of the same system; and it is not for us to separate them in their usefulness. But should we not also include the insects? for they too are the children of Nature. Where man does not cultivate, the insects, which keep down the excess of vegetation, are as much part of the system of nature, as the birds which keep down insects, or the magpies, jays, and hawks, which destroy eggs and kill birds; but cultivation alters the case, because the surplus which man takes must be something more than that which satisfies the balancing of uncultivated nature, and because the birds assist in the preservation of that, they are fellow-labourers with man, and deserve his gratitude and protection.

When the summer visitants depart, there is a sort of pause, which may be considered as the great annual breeding time of the insect tribes, though many of them perish in successive generations during the season. There is a minor breeding time during the excess of the solstitial heat, when the birds are silent and repairing their plumage, before they congregate for their farewell feast. But the autumn is the grand time; and as the insects soon die after the eggs are safely cnmmitted to Nature's keeping, the earth would be rank with the bodies of dead flies, were it not for the labours of the autumnal spiders; just as it would be unsightly with rotting vegetables, but for the fungi of the same season. 
After the pause, those insectivorous tribes which remain with us all the year, come home from the wilds. The little wren sits on the Christmas $\log$ as it lies seasoning at the door; and the robin hops about at the threshold, turns up his eye as if lie actually expressed, "I know you :" and hopping on the bush, the last ripe leaf of which falls at the shight vibration, he carols to us the parting song of the year, and continues it till the dark days are over, and many wings are extended in the south wafting hitherward, when the labours of the robin call him again to the wild. So delightfully do these birds mark the year-always changing; and, taken with the other circumstances, every change an improvement.

\section{SHRIKES. (Lanius.)}

Though these birds have the general characters of the order, they feed much upon insects, their feathers are soft, their voices have some music, though little melody, and their feet are formed like the rest of the order; but their bills are larger and stronger, have the tip of the upper mandible decidedly hooked, and that of the lower one fitting a deep notch in the upper; the general opening of the bill slightly curved, the margins of the mandibles strong, and shutting very close, and the whole bill so much compressed laterally, as to have great strength in proportion to its quantity of matter. The sharp points of the mandibles and the notch, enable the bill to pinch much more strongly than that of any of the other insectivorous birds; and they use the bill for killing smaller birds, which is so much "their vocation," that they have got the name of " butcher birds," as they slaughter many, and hang the carcasses, or parts of thein, on the hedges, as if exposing them to other birds. This is, in fact, their object; for as there are many little birds that will peck at dead birds or beetles, which they do not attack when alive, the shrikes literally track the hedges and watch, on an elevated twig, or fly along a little higher than the bushes, and if they observe a little bird below them, they drop down, bear it to the ground, and, seizing the neck between the close-shutting 
margins of their beak, strangle it in a moment. When they hunt on the wing, they capture by surprise rather than speed, and the cry which they utter seems to distract the attention of those birds on which they prey. The smaller graminivorous birds are their chief feathered prey; but they also feed on mice. The margins of woods are favourite places of resort for shrikes; and they are so couragcous, that they drive off crows and magpies, and some of the smaller hawks. The small birds crowd angrily about them, and attempt to beat them with their wings. They are short-winged birds, and bounce or leap along in the air; but they drop down very rapidly. The descent and ascent are much facilitated by the motion of the tail, which is rapid in the vertical direction, strong in its coverts, and capable of being spread out like a fan. The air and attitude are expressive of boldness and activity. These birds have been called "pies," from supposed resemblance to the magpie and the jay, but their characters are quite different: they do not croak or chatter; they cannot be taught to articulate: they do not eat carrion; and it is not ascertained that they plunder the nests of other birds. There are only three species known as British : and one,

\section{THE GREAT ASH-COLOURED SHRIKe, (Lanius excubitor,)}

is merely a straggler, and a straggler not at any usual time of migration, the few specimens that have been found in the country, having been in winter; and certainly not as regular winter migrants, the rare ones of which come late, and after very severe weather. The bird, cannot, indeed, be regarded as much of a migrant in latitude in any country, for it rather follows the habit of the resident insectivora-the woodlands in summer, and the lower plains in winter. The British specimens are, in all probability, blown by east winds from Germany, where they are abundant. The weather which precedes the appearance of these birds that straggle "out of time," wants to be more carefully noticed than it has been.

The great shrike is ash-grey above, white below, has a biack stripe across the eye; the middle of the tail, the bill, the feet, 
and the stiff hair-like feathers, all black. It is ten inches long, fourteen broad, and weighs between two and three ounces. Its habits on the continent are more migratory. Indeed, those of most insectivorous birds are so; as they can range to the polar ocean in summer, but are driven out of great part of Russia in the winter.

\section{RED-BACKED SHRIKE. (Lanius collurio.)}

The red-backed shrike is a summer migrant, arriving in May and departing in September, and differing from the rest of our local summer visitants, in being more numerous toward the centre, or even the western side of the country, than on the south-east. The larger beetles appear to be the principal food of these birds, though they are also said to eat mice, and to kill little birds, much after the fashion of the great shrike. There is, however, a want of precision in the description of their habits, as they seem to have been mixed up with those of the other, and they are given by British ornithologists more at second-hand than from observation.

They are lively birds, and so far resemble the birds of prey, that the female is larger and darker-coloured than the male; but they live, upon the whole, in harmony with other birds, and do not appear to excite so much ill-natured attention as even the cuckoo. The male weighs an ounce; Dr. Fleming says two : but he has either copied the wrong book, or it is a misprint. The female weighs about an ounce and a quarter. The male is rather more than six inches long, and about ten and a half broad; the dimensions of the female are seren and twelve inches. The prevailing colours of both birds are reddish-brown on the upper part, and dull greyish white on the under; but the white in the male is tinged with pale rosecolour, and that in the female marked by dusky lines.

When these birds sit watching on a twig, they appear prepared for an instant start upon whatever prey may come in their way. The tail is spread, the wings partially expanded, the bill open, and the eye in a state of active excitement. It 
is said that, upon some occasions, these birds will, by imitating the cries of other species, sometimes allure young birds to their destruction: but this is probably only said, not seen.

The nests are carefully hidden in close hedges or bushes, generally where the soil is rather humid, and near the margins of woods. The nest is formed of moss and fibrous roots, intermixed with wool, and finished with a lining of hairs. The eggs are five or six, of a colour something resembling the under part of the male bird, and marked with brown spots. The young, in their first plumage, resemble the female; but the upper part is not nearly so red. When the birds are in full plumage, the red, though a brown red, is very rich; and when the bird jerks along the air, it has the appearance of flashes of dull fire; on which account it has been called the "flasher," and that has been corrupted to "flusher."

The locality of the red-backed shrike is the most remarkable part of its natural history. It is short-winged, and of course gets through the air with more labour than many of those summer birds that are found only in the south-eastern part of the country; but it leaves the gravelly and clayey districts, and takes up its abode in a central zone, beginning at the channel, and terminating at the light soils in the valley of the Dee. The climate of that zone is warm, and the soil peculiarly adapted to the habits of the larger beetles, which seem the natural and peculiar food of these birds. The habits of the red-backed shrike, and also the characters of those districts which it prefers, deserve to be studied.

\section{WOOD-CHAT SHRIKe. (Lanius rutilus.)}

As a British bird, this species is rare, though common enough on the continent, where it is a migrant, resorting, as is the case with many of the common birds of central Europe, to the delta and valley of the Nile in the winter. With us it is a rare summer visitant, and may be said to be only an occasional one; but the nest having been found more than once in Norfolk entitles it to a place among British birds. 
The length of this shrike is about seven inches, and the extent of the wings eighteen. The bill is dusky with a tinge of blue, very strong and notched toward the tip. The irides are hazel, the legs dusky, the claws black, short, and very crooked. The forehead a stripe down each side of the neck to the shoulders, the lesser coverts, and part of the quills, black or dusky. The base of the primaries and tips of the secondary quills white. The back of the head rufous, the scapulars white, the back dark ash-colour. The tail, which is rather long, strong, and a little rounded, is dusky, the rump somewhat paler and mixed with white. The throat, fore part of the neck and breast, dull white, passing into dull ochre, yellow on the belly and vent.

It is a bold bird, partaking much of the characters of the other shrikes; but with us it is rare, and only seen occasionally in the woods. It does not follow the same zone as the others.

THE FLY-CATCHER. (Muscicapa.)

There is some little perplexity in the natural history of the fly-catchers. They are smaller than the shrikes, and their bills are less formidable, as their prey is softer, not having the same horny covering as the beetles. They are also larger in the wings, because their prey flies more swiftly, and plays more tricks in the air than the beetles are capable of doing on their " drowsy flight." Still, the fly-catchers hold a sort of intermediate place between the swallow-tribe, which catch their insect food by strength of wing in the free air, and those summer birds which pick it from the leaves, buds, and bark of regetables, in the larva state.

the Pied fly-CAtcher. (Muscicapa luctuosa.)

The history of this species is also a little confused. No good cause has been shewn, either by fact or analogy, to establish the assertion, that the birds reside in any part of England during 
the winter: and as they resemble the shrikes more in character than the spotted fly-catcher does, which is a summer migrant, the presumption is, that they are summer migrants also. They follow nearly the same zone in longitude as the shrikes; but they are found farther to the north, chiefly beyond the heights on the confines of Stafford and Derby, where the principal locality of the shrikes terminates. They are found thence along the hills between York and Lancashire, and so into the hilly parts of Westmoreland and Cumberland; but there is no account of their breeding or even being found in Scotland; and they are very rare on those champaign parts of England over which they must pass in order to arrive at the interior and hilly districts. But that, though an important fact in their history, and in the history of migration generally, is no argument against their arrival in the spring and their departure in the autumn. The same instincts which adapt birds to certain districts, guide them to those districts, without any reference to the country which lies between. Like the occasional shrike, these are upland birds, and they find their way to the uplands, just as the softer-billed summer migrants find their way to the lower and richer places, where the larvæ of lepidopterous insects are more abundant.

A figure of the pied fly-catcher, one-third of the lineal dimensions, is given on the plate at page 221 , on the same scale with the sand-martin and the swift, and the three together showing the gradation of fly-catching birds, from the swift, which dashes after them with great celerity, and at the highest elevation to which little birds extend their hawking, to the fly-catcher, which watches for them on the hedge or the branch of a tree, and pounces on them as they pass. The colours of the male plumage are subject to some variation with age and with the seasons: when old, the tail-feathers are black: but when young, they have some white on them. In winter, the upper parts incline more to grey, and in summer they incline more to black. The birds breed in holes of trees, or in thick and close bushes, forming their nests of dry vegetable matters, and lining it with hair or feathers. The eggs 
seldom exceed five; they are pale-greenish blue. The incubation begins about the end of May, the birds being supposed to arrive about the middle of that montl. As they do not previously flock, the time of their departure is not very accurately known.

The pied fly-catchers are very pretty and lively little birds; and as they are constantly hopping in and out of the bushes at those bright and sultry hours when the flies are on the wing, they give an interest to times at which the greater number of the summer birds are still as well as silent. In the mornings, before the flies begin to come out, the male birds are generally perched and singing, and the females are on their nests. The songs of the males have not much variety or compass, but they are soft, and not destitute of sweetness. Their fly-catching is, however, the most interesting of their habits; they hold themselves so constantly prepared, their eye is so keen, and their motions so quick. Their wings, though well fitted for the leaping flight which they perform in catching their food, are not so well adapted for long journeys, especially if they have to contend with gales of wind, which of course blow them to leeward in the pauses during which the strokes of their wings are exhausted. This may be one of the reasons why the east winds of May carry them out of what may be considered as the line of their migration. When the weather blows hard, they are so ex. hausted, that they are obliged to alight, and rest for some time near the coasts, although they do not stop to nestle there. But many migrant birds have resting places, within many miles of which not one nest is to be found.

the SPotted fly-Catcher. (Muscicapa grisola.)

This is a larger bird than the other, softer in appearance, less active in its manners, and having the bill less convex on the upper part, and less looked and notched at the tip. The upper part is brown, redder on the shoulders, and with a pale streak over the eye; the top of the head mottled with darker; 
the quills and tail feathers very dark. The under part brownish white, with dusky patches and shafts to the feathers on the breast. It arrives late in the season, not till near the end of May, and it departs toward the end of September, but, sooner or later, according as the season is less or more farourable to the continuance of insects upon the wing.

It remains in the low districts, being most abundant in the south of England, diminishing both northerly and inland, and being rare in Scotland, if indeed it at all reaches that country. It is a familiar bird, pursuing its labours close to the dwelling of man, and even building in the shelter of outhouses. But it is a very quiet little bird, as silent in its manners as it is sober in its plumage; and therefore it spends its laborious summer in clearing the gardens and copses of flies unnoticed and unsought for. Its nest is formed of moss and small fibres, lined with hair, wool, or feathers; and the eggrs, which are bluish white spotted with red, are seldom more than five. The nest is usually so placed as to be sheltered from the weather, but it is not so studious of concealment as the other species. It does not perch so much on those trees that are covered with foliage as on stumps and posts, which are not above the ordinary flight of the flies, and which command the horizon all round. It will often occupy one of these for hours, though people are at work around it; and its habit is to dash at the insects, capture them and return to its perch, all in perfect silence.

The time when the early cherries and berries begin to ripen is one at which flies throng to the gardens; and as it is also the time at which the broods usually take wing, and feed with great activity, the birds are very numerous and active among the trees. They are then actually preserving the fruit from myriads of insect destroyers; but they have been (as is not unfrequently the case with birds) accused of perpetrating the very mischief which it is the business of their lives to prevent, and because some one called it the "cherry sucker " "and the consequence is that the bird is often driven off, in order that the choicest of the fruit may be spoiled by the 
wasps and flies. This bird has little or no note, save a clirp). It comes, performs its appointed labour, and goes, peaceably ; but it is one of the birds that accompany cultivation, and become more numerous as that extends.

\section{THRUShes. ('Turdus.)}

The thrushes are the largest of all the British insectivorous birds: those which remain permanently with us are among the most mellow-toned of our wild songsters; and the whole are very interesting in their manners, and, when in proper condition, they are wholesome and palatable food. Though the thrushes have a melodious song, of which the omnivorous birds are wholly destitute, their alarm note partakes a little of the scream of these, and like them, they can be taught to articulate, though not quite so readily, or with so much perfection. They have the bill of mean length, a little curved, bent at the tip, and with a notch in the upper mandible; and their whole plumage is close and compact, so that they dart through and under the bushes and low branches with great celerity. They have also considerable command of themselves, both on the perch and the ground, in the last of which situations they find a considerable portion of their food. They are not so exclusively insectivorous as some others of the order, but they are chiefly so during the summer; and in the winter, when the state of the weather excludes them from their animal supplies, they have recourse chiefly to wild berries. Snails, slugs, and worms, form a principal part of their food, and in the capture of these they do very valuable service to the gardens, orchards, and shrubberies, and even to many of the field crops. The three resident British ones are all inhabitants of the groves and thickets of the low grounds, or just on the borders of the wilds, and they generally remain in the neighbourhood of their nesting places all the year round. 
THE MISSEL-THRUSH. (Turdus viscivorus.)

There is a sort of double naming in this bird; it is called the missel-thrush because it " missels" (soils) its toes with the viscid slimy juice of the mistletoe berries, of which it is very fond in the winter; and the mistletoe gets its name because it "soils" the toes of the bird. The missel-thrush is the largest of the British species, being nearly a foot long, ahout eighteen inches in the stretch of the wings, and five ounces in weight. It is not a very gay bird in its plumage, neither is it remarkable for the briskness of its expression; but still it is a beautiful bird, light in its form and soft ir the tints of its plumage. Its ground colour above is grey with a trace of buff, and that below whitish with a lighter trace of the same. Quills and greater coverts, greyish brown, relieved at the margins with pale ash colour and white, and occasionally a trace of buff. Tail deep ash grey, the tips of the outer tail feathers, and their inner webs white. The throat, cheeks, and chin, marked with three-cornered spots of brown, and the rest of the under part with larger patches of the same. The bill black except the base of the lower mandible, which is pale yellow; the sides of the head brown, but the eye surrounded by a white circle. The female is more rusty on the under side; and the young have the top of the head and upper part of the neck greyish white, and the wings and tail more inclining to brown. The colours vary considerably, and some specimens are nearly white.

The missel-thrush, being found chiefly in those wooded and sheltered places where the winter is neither the longest nor the most severe, and meeting with berries at the times when the snow keeps it from the ground, is much better fed at that season than many of the other birds. In ordinary seasons indeed, it is never very long without animal food, because it is very persevering and very adroit in finding snails and slugs in their winter retreats; so that it is among the first birds to feel the turn of the year, and though its 
note is not so mellifiuous and varied as that of the song thrush, it is still both powerful and musieal; and as it is the first that is heard in the woodland after the howling of the wind among the leafless branches, and heard even during the fitful pauses of that, when the February or even the January sun flings a momentary ray of hope upon the doubtful year, it is perhaps hailed with more fondness than the song of the nightingale itself, which is never heard till the season has so far budded and bloomed, as to be full of life and hope without the nightingale.

Perehed upon some leafless tree, and haply near a braneh of that mistletoe, whieh has been a bone of eontention between the bird and the rustics, the one for his Christmas dinner, and the other for his Christmas sport, the missel-thrush shakes the surrounding air with his melody; and while we listen to the strain, we feel that the promise of nature's bounty for another year is amounced, at the very time when we have been sharing most plentifully the fruits of the year which has gone by. For some time the song of the bird alternates with those varying winds whieh at that season shake the earth, and sometimes uproot the trees, though they also mollify the elods. When the blaek cloud eomes over, and the sleet pelts, or the snow drives, the bird glides down to his shelter; but as soon as it is over, he is again on his perch and at his song, nor does he ecase till other ehoristers have eome to bear their part in that morning song with which the ehildren of nature welcome in the year.

The breeding time of course varies a little, both with the situation and the season; but the average periods may be reckoned about the middle of Mareh for the building of the nest, and April for the hatching of the eggs. The male continues his song till then, after which it is heard no more during the summer.

The nest is usually made in the fork of a tree, the more moss-grown the better; because that harmonizes with and helps to coneeal the nest itself, which is formed of lichens, mosses, and twigs externally, partially eombined with, and 
rendered more close and substantial by, an intermixture of earth. The interior is lined with softer materials-fine dry grass, hair or wool, according as the one or the other is more easily procured. The eggs rarely, if ever, exceed five: they are flesh colour, mottled with rusty brown; and the birds do not seek the seclusion of the deep and lonely woods, but will build in the orchard, or the garden, though very near to the house, if they find there the tree best suited to their purpose.

The male of the missel-thrush is not a mere idle songster. He takes turn with his mate in the labour of incubation; he feeds her, and assists in feeding the young; and he is equally vigilant and bold in the defence of his family. The call note which he utters in case of danger, and which is answered by the female as if slie were expressing her confidence of safety while he is on the watch, is harsh and grating, and has the tone of a note of defiance. And, with the missel-thrush, the defiance is no idle boast; for the sneaking magpie, the light. winged kestrel, and even the sparrow-hawk, are at those times compelled to keep their distance, as the thrush is too vigilant to be surprised, and under the sprays where those birds must contend with him upon equal terms, he keeps them all at bay. Nor is he the guardian of lis own family only, he is in some measure the warder of the whole grove; and when the harsh but shrilly sound of his bugle note of alarm is heard, all the warblers take heed of the danger, and the chorus is mute till he again mounts the highest branch, and raises the song of deliverance.

If the nest despite his watchfulness, is robbed, the male continues his song, till preparations are made for a new brood, and if he loses his mate, he continues in song all the summer; and therefore, his note, which is any thing but a note of sorrow, partakes somewhat of that character of a lament in solitude, which has poetically, but not really, been considered as characteristic of the song of the nightingale and the moan of the trutle.

The purpose which the song of birds answers in the eco- 
nomy of nature, is one of those mysteries which, like the differences of tint in their plumage, human ingenuity has not yet been able to explain. It is not, however, a mere pairing cry, because it is continued till the birds break the shell, and in some instances, till they are able to fly. We may be sure, however, that it has its use; and, as we can observe that the females of all birds which have that cry, whether it be what we call song or not, are excited when it is uttered by the male, it may be that it produces in the female that heat which is necessary for hatching the eggs. In ourselves, there are many sounds which make the heart beat, the blood dance, and the whole body glow, we know not why; and thus we have at least no ground for denying without proof, that the other animals may be affected in a similar manner. Perhaps the more philosophical way of considering it is to suppose that it produces general excitement, and a power of more energetic performance in all the labour which the birds can undertake.

The connection between the song and the plumage, and the silence and the moult, is also a curious matter, and shows that the whole bird is subject to some general law, which though it lies deep beyond the power of our divination, governs even the minutest circumstance,- - the production of a new spot or gloss on a feather, the reddening of a comb or a wattle, or the inspiration of courage into birds naturally timid. The birds, in fact, blossom in the spring as well as the plants, and when the purpose of nature is accomplished, the bloom of the one is shed as well as that of the other. But if the purpose of nature in continuing the race is not accomplished, the bloom lingers. If the east wind shrivel the anthers of the peach blossoms, the petals do not come down perfect in that powdery shower which is the sign of a plentiful crop, they cleave to the tree, and languish slowly there. "Wo be to the wind of the bleak north-east," says the cultivator, "it sheds no blooms;" and so also may the lover of birds lament, if the songs of his favourites are continued through the summer. If the bird continues its song, it 
at the same time continues its plumage; and the moult, when it does takes place, partly because it is at a later and colder season, and partly from that part of physiology which has not yet become a science, the new plumage has less of the peculiarity of the male, and more resembles that of the female and the young, than if the bird had been mute and had moulted, in due course.

That song of sorrow (though to the bird it is rather a song of hope delayed) has not the spirit of the natural song. It is true, that by midsummer, nature is muffled, by drooping leaves, and fallen blooms, and downy anthers; and it waxes fat and rank, so that though it may murmur it will not "ring clear" (like a moistened flute) as it does in the season of vernal song, when all is fresh and full of sap; but we also can perceive a falling off in the note itself; and we have a corroboration in caged birds, which never give their song with the full glee and power of that of the woodlands. Even in the most admired song that is warbled from the prison-house of wire, an ear tuned and habituated to the free strains of nature, can recognise a blending of the cry of irritation and distress. Nor can it be otherwise. The bird is the child of Nature as much as man is, and it loves liberty as well-better, for it will not voluntarily exchange that to be a pampered slave in a palace. It puts one in mind of that exquisitely muurnful delineation of the children of Israel, in painful servitude and restraint, even on the palmy shores of the widerolling Euphrates; and one cannot contemplate the imprisoned bird, without thinking on the mossy tree, the little nest, and the chirping brood, and feeling the force of the unanswerable interrogatory- "Alı! how can we sing the song of our God in the place of our captivity?"

If matters fare prosperously, the missel-thrush has moulted, and is partially in song in the early part of autumn; and by the time that the second brood is fledged, the animal supply for the year is nearly over, and the family flock together in quest of berries, at which time they do not hesitate to lay the gardens under contribution. Thence till they sing again, is the 
time when they are best in flesh and in flarour; and when the fruit of the service tree and the mountain aslı may be repaid by a clelicious meal, without any injury to the economy of Nature, and with some saving of the crop on the late vines.

That is the only season cluring which even a small flock of these birds assemble in peace; for, during the busy time, the males are as pugnacious toward each other, on the score both of partners and pastures, as they are resolute in defending their families from predatory birds.

East winds, whether they waft the cold humidity of the fen or come withering with drought, are equally unfavourable to the food, and consequently to the presence, of the misselthrush. It is accordingly less plentiful on the east coast than on the south and west, and in that zone which has been mentioned as particularly favourable to birds that feed on the larger insects. But improved cultivation has brought it to many places in which it was formerly unknown; and a continuation of the same will extend it. The larger snails, nemoralis, hortensis, and aspersa, and a variety of others, are always concomitants of the missel-thrush, and those snails are somewhat dainty, and will not eat the austere produce of the marsh. The missel-thrush is thus a sort of tell-tale, showing how cultivation goes; and the way to build him in is the same as that by which the ague is built outbuilding drains below ground, and not walls above it.

THE SONG-THRUSH. (Turdus musicus.)

This bird is much more generally distributed over the country than the former; and though there is some resemblance between them, more especially in the markings on the under part, the colours of the song-thrush are not nearly so delicate. The whole of the upper part is brown, with a trace of grey, the under part cream colour, darkest on the breast, and mottled with triangular dusky spots. The length is about nine inches, the stretch of the wings thirteen and a 
half, and the weight about three ounces. It is, however, subject to considerable variations in colour-to more, perhaps than the missel-thrush-and it is also subject to considerable variations in size: those which inhabit the high grounds are smaller than the tenants of the richer pastures.

The thrush is so familiar a bird every where, that there are few to whom any description of it is necessary. It does not like marshes, or countries that are very open and bare; but in all places where hedges, thickets, and young plantations, or even orchards and gardens with trees are to be found, there are sure to be thrushes. They feed on slugs, worms, and snails, of the last of which they destroy vast numbers, but they are not so exclusively confined to the districts in which the larger species of snails abound as the missel-thrushes. They are found in many upland parts where shelled mollusca are ferv and confined to the smaller species: and in those, snails and earthworms are their chief food in the early summer; and as the season advances, they have recourse to wild berries - the whortleberry in preference to any of the others. The soils where that thrives best are generally well suited for plantations or natural copses; and copses there are sure to be inhabited by thrushes. In winter the birds come down to the warmer lands, and beat about under the hedges and in the gardens.

In the richer districts, their labours in destroying snails are equally incessant and successful. Before these have opened the winter curtain which they spread over the mouth of the shell, so as to completely exclude the air during the time that they are dormant, the thrushes and their associates the blackbirds find them out in their hiding-places, and by this means do great service to the winter and early spring crops, especially in those places where culinary vegetables are much cultivated. In these places, the snails nestle by hundreds, under the hedges, and by the foundations of the walls. In the former, which is their favourite winter abode, the hedge preserves them in a great measure from the rain, and the dry leaves from the cold; but so industriously do the 
thrushes and blackbirds search them out, that the hedge side is marked by a line of broken shells, as the birds fetch the snails out, and batter the shells to pieces with their bills. In the dead of winter this is carried on, in open weather, during the whole day; but if January is open, and warm, and sunny, they may be seen suspending their labours about mid-day, perching on the hedges, or hedge-row trees, and warbling their clear, melodions, and variable song; yet a change of weather-a fall of snow especially-makes them mute again for a space: and they have recourse to their vegetable food, which does not appear to stimulate them so much, as those that are in situations where they must depend chiefly on that, do not come into song till the season is farther advanced, and the slugs and worms have begun to make their appearance.

When the situation and the season are both favourable, the birds are in full song early in February; and as there are generally two, and not unfrequently three broods of young in the year, the song continues till the beginning of October: and though the same bird does not sing during the whole time, yet there are always thrushes in song from the middle of January to that of October, if the weather is favourable. Indeed one or two very fine days are sufficient to excite the thrush into song at any time of the winter.

During the hatching of the young, the male is as attentive and industrious as the missel-thrush : and as the birds are more numerous, they have to bustle more for food. They are then up betimes. Their favourite prey finds its food during the night, and retires before the heat of the morning is too severe for the slimy secretion, which it uses not only as glue, but also as a cable, and sometimes as a highway. The distance to which it can contrive to crawl is not small, considering that it has only one foot, and is burdened with its house; but the coming drought invariably sends it home, and the thrush is in the way to intercept it. When collecting food for the young, the birds carry it not in the bill, but in the stomach. The membranous upper part of the stomach is, in all those birds which are not furnished with a pouch, a very convenient 
pannier for carrying food to their young; and though there are not many in which a milky secretion, like that mentioned in the pigeons, is produced, yet, in all, the food may be so far acted on by the gastric fluid of the parent, as to be more easily digested by the young birds.

The song-thrush builds in the middle of a hedge, tree, or bush, but it builds lower than the missel-thrush; and as the nest of the missel externally resembles a lichen-crusted stump, so the nest of the song-thrush resembles a mossy tuft. Internally it is strengthened with mud, said to be water-tight, and therefore destructive of the eggs in rainy seasons. Rainy seasons are destructive to the nests of many birds; but they must be less so to that of the thrush than to many others: the thrush does not build in situations where the nest has much chance of being inundated by floods; and it may be said that the nests of all birds are about equally secure from falling rain, while the process of incubation is going on. If the nest is not so choscn as that the eggs are sheltered from the weather by other means, it will generally be found that the mother herself affords them sufficient protection by her plumage and her mode of setting. 'A water-proof nest is no more a necessary means of drowning than a water-proof boat: it is the preventing of watcr from getting in, not from getting out, which is the grand means of security; and if the eggs of a bird were for any length of time continually wet with falling rain, they would be cooled more, and therefore rendered less likely to be fertile than if they were as long immersed in water. The birds whose nests suffer the most from rain, are those that build on the flat uplands, where the rain falls in torrents, and stagnates among the herbage; and if there be any season more perilous to the thrushes than another, it is that which is excessively dry, at that time when they feed most exclusively upon animals, which are, for the most part, below the ground when the weather is in that state.

The song of the thrush is unquestionably the finest of any of our permarient woodland songs, and superior in power and clearness, though not in variety, to that of any of the warblers. 
But the very abundance of it, perhaps, makes it less prized than it should be. The nightingale heard in the depth of groves and during the soft and balmy stillness of the summer's night, may have more of the lusciousness of romance about it; but there is a bold, natural, and free feeling of rustic vigour, enjoyment and endurance, about the thrush, which gives it a more home and hcarty interest in all parts of the country, than can be commanded by any mcre bird of passage, whatever may be its charms while it stays. The thrush is, especially one of the birls of plenty: its blithe and varied song is never heard amid desolation; and if you hear a thrush you have not very far to go ere you come to a human dwelling. When its animal food, which it at all times prefers to that which is vegetable, fails, the thrush may commit more devastations among the fruits than many other birds; but when the snail-shells by the hedge-side are counted, and it is gravely considered how completely these and their broods would have eaten all the early vegetables as they got above ground, and the strawbcries and peaches, as soon as they began to ripen, it is at least an undetermined question, whether the good done by the thrush may not far more than counterbalance the evil. The creatures on which the thrush feeds are destructive; they have no song; and they are at least not more pleasant to look at than thrushes.

\section{THE BLACKBIRD. (Turdus merula.)}

The blackbird is as long as the missel-thrush; but more slender in its form, and weighs an ounce less. Its form and also its plumage are remarkable for compactness; and it is very quick-sighted and lively in its motions. The male is entirely black except the bill and circle round the eyes, which are orange ycllow, and the feet which are brown. The fcmale has the bill and circle round thc eyes, and the upper part of the body blackish-brown; and the lower part light brown passing into white on the chin, and mottled with dusky. The young birds are like the females, and do not accuirc the 
yellow bill which is the sign of maturity, till after the second moult.

The haunts and habits of the blackbird are nearly the same as those of the thrush, only it is more familiar, and in proportion to its numbers, less seen. The disposition of the bird is slyy and solitary, more so than the thrushes, as the blackbirds separate as soon as the young are able to provide for themselves, and never again assemble except in the breedingtime. It has been said that they do not all associate even then, but that therc are many solitary blackbirds which pass the whole year in a state of sulky celibacy. There is no reason for carrying the matter quite so far as that; the blackbird is as attentive to its nest and young as any other of the tribe; and its evasive habit, or simply the facility with which it slips through hedges and in below bushes, not probably so much from the wish of hiding itself as in mere search for its food, is the foundation of the whole. The blackbird nestles quite close to the house, on ivied walls, in old trees, and thick bushes, and at a moderate height from the ground. The nest is made of moss and sticks, plastered inside with mud, and lined with soft and dry matters. The brood is from three to six, but rarely the latter number; and the eggs are of a greenish blue, with very obscure dusky markings. But as is the case with most birds that frequent cultivated districts, the colour both of the birds and eggs is subject to variety.

The blackbird sings early; and though there is not nearly so much spirit and variety in his song as in that of the thrush, it is soft and clear, and has a sort of flute-like tone, which makes a pleasant variety among the number of more sharp and trilling voices. There are usually two and frequently three broods of blackbirds in the year; and thus the song continues through a great part of the season, though it is not heard so continually, so long at a time, or from so lofty a perch as that of the thrush. Notwithstanding its solitary and hiding habits, the blackbird is more easily tamed and more patient of restraint than the thrush. 

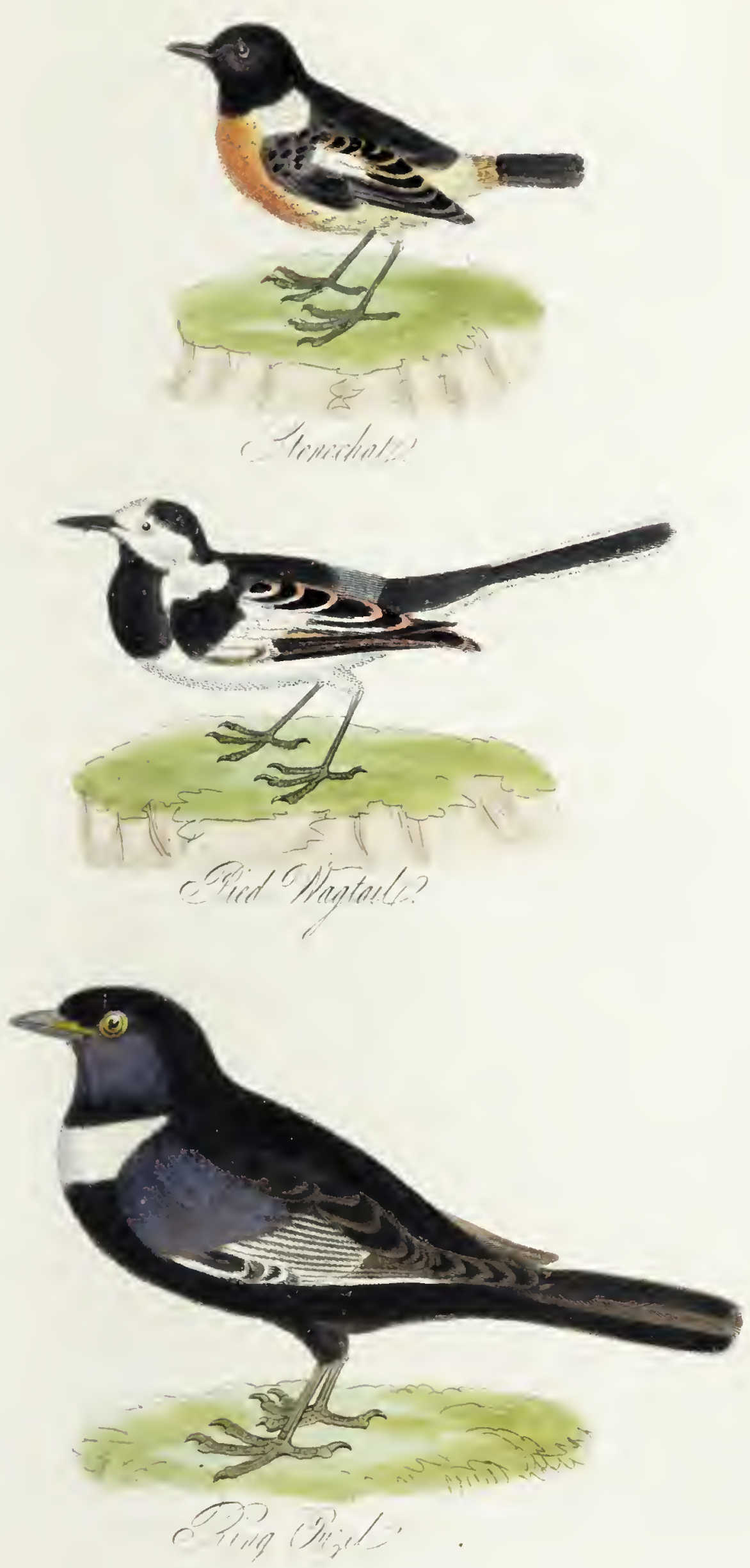

THE RING-THRUSH. (Turdus torquatus.)

The ring-thrush is a very beautiful bird, half an inch shorter than the blackbird, but having about the same extent of wings and nearly the same weiglit. It is much more firm and compact in the fore-part, and altogether better formed for long flight, or for contending with the weather, though not nearly so well for gliding through bushes.

The figure on the opposite plate, which is one-third of the lineal dimensions, will give an idea of the form, general colours, and expression of this bird. It may not, however, be amiss to remark, that the grey on the edges of the feathers above, and also on the greater wing-coverts, varies considerably in different individuals, and also at different ages and seasons. The pure white gorget is always a character of the mature males. The young males have it reddish; the old females clouded with brown and grey, and in the young females it is barely visible.

The ring-thrush is a summer migrant, arriving in Britain in the spring, rearing its broods in the wilds, and disappear. ing in the autumn for warmer climates, in which it spends the winter; and, as is the case with many seasonal birds, its migrations on the continent are much more extended than with us, though it is not very rare, in its season, in some parts of the Scotch highlands, and has an original Gaelic name.

Like the resident thrushes, it avoids the fenny parts of the country; and it does the same on the continent, as it is rare in Holland and the flat parts of the Netherlands, and along the low sandy shores on the east of the German sea. Hence it comes to us across the channel, and rarely or ever across the eastern sea. Whether these birds migrate over low dis. tricts, ol thefer hilly ones, such as Normandy, is a point worth attending to in studying the habits of our migratory birds; because, if they prefer the former countries, we may expect stragglers on the east coast; but if the latter, we can in general receive them only by the south. The Alps, too, 
divide the birds in their migrations, by driving them nearer botlı to the western and the eastern seas.

Though the ring-thrush is better formed for flight than the resident thrushes, it does not appear to proceed by very long flights, for considerable numbers alight on the shores near the channel in the spring, and remain there for some time to rest and recruit, though they always resort to more inland, or at all events more alpine or upland places, to breed. As they are shy, and betake themselves to the heathy and rocky places, which are not much visited in the early part of the season, the times of their arrival in the different localities in which they breed, have not been so far ascertained as to establish the fact, that all of them make the tour of the country from the channel northward. It is probable, however, that they do. The south-eastern part of England-the paradise of the warblers-is not well adapted to their habits; and they range westward into Cornwall, Wales, and Ireland, and northward to the hills on the border, to the south of Scotland, and at lcast to the southern slopes of the Grampians.

Cold moors, stony places, but still where a good deal of rain falls, and there are springs and pools if not lakes, are the nesting grounds of the ring-thrushes. Their food has not been so well ascertained as that of the more lowland species; so that we are less able to say what takes them to their peculiar localities; but whatever that food may be, they ncstle far apart; and unless by quartering the ground on purpose, it is not common to see above one pair in crossing the place where they reside. It must, however, be borne in mind, that their habits are very shy and retiring.

When alarmed, by your coming suddenly upon them at the turning of a rock (it is not very easy to get near them on the open moor), they utter the same alarm note as the blackbird; not quite so loud however, though tlæat may be from the want of trees which magnify sounds. [The snapping asunder of a stick, which you would not hear at the distance of twenty yards on the open heathy hill, will make a rcport like a pistol in a wood, especially one of pines, which is the 
most sonorous of all forests.] The song which it does not appear is uttered while the bird is on the coast, is given, though not very copiously, in the wilds. But though a short song (a miniature of that of the missel-thrush), it is a sweet song in those wild places where there are screams and whistles, but not many songs. It is given as the bird sits on some point of the low rock or an clevated stone.

The nest varies a little with the place. A tuft or bush especially if against a bank, gets the preference, but a tuft of grass or heath, or a projecting part of a mossy stone will do where better is not to be had. The nest is formed of moss and lichen, plastered with mud, and lined with soft dry grass. The cggs are four, rarely six, about the size of those of the blackbird, but rather greener in the tint, and the spots more decidedly marked.

When the business of nidification is over, the birds again retire to the south; and, as they have a farther flight than those which they require to take on their journey into the interior, they rest longer. They are more noticed on their southward march, as they collect by the way. They come into the low country about the end of September, and generally linger there for three weeks or a montlr. Hence they are called Michaelmas blackbirds. They are beautiful birds, and have something very peculiar in their habits; but we want information respecting them, especially their favourite food. I am inclined to think that mountain beetles form a considerable part of it, but I cannot say positively. If one will stand to look at you on the dark heath, where little else comes definitcly out but the bright white crescent on the breast, the sight is very pretty.

\section{THE FIELD-FARE. (Turdus pilaris.)}

The field-fare,--of which a figure is given on the plate at page 26, along with the ptarmigan and the quail, on the same lineal scale as the latter, and half as much as the former, that is one third of the size,-is in many respects the rery 
antipodes of the last-mentioned species. Like that it is a migrant, and upon the continent has a considerable range in latitude, but with us it is a winter migrant, arriving late in the autumn, and remaining till the season is considerably advanced.

Field-fares are said to breed chiefly in the woods within and near the arctic circle; and as insects are very abundant, there in the summer, which does not fairly set in till June, and wild berries are equally plentiful, in what may be termed the arctic autumn, which is merely a few weeks during which the winter pauses, ere it collect its storms and whelm the whole country in that snowy covering which is to remain till summer, there is food for them there.

These circumstances of the native regions (for the native place of migratory birds is, of course, that in which they are hatched), give them some peculiarities which are not observable in birds that come from, or gradually pass through, countries in which the changes of season are less abrupt.

In consequence of the abundance of food during the short but very active season, when the whole or nearly the whole twenty-four hours are daylight, the field..fares are very numerous, and build near to each other; and as the proportion, making allowance for the casualties of the breeding time, is nearly tripling the numbers, they swarm very thick by the end of the season. They begin to move in September or October, according as the cold weather sets in; and, as that is earlier if the summer has been wet, they sometimes, though very rarely, reach the north-eastern part of Scotland by the first of October, but they are, in general, later : and according to the state of the weather, they come occasionally all the winter. They seem, indeed to take short stages on the continent, and move southward as the storm drives them, often in incredible numbers, and subjected to the greatest hardships; and if those dreadful storms are from the northeast, they are drifted to our shores, often in an exhausted and famishing condition when they land, and subjected to still greater peril if it continues. 
In the winter of 1798 (I forget the day, but shall never forget the weather), there was one of the most dreadful snow storms that ever visited the British isles. It was the harbinger of those years of oppressive severity with which the close of the eighteenth century was marked. I cannot say that I was out on the fearful Friday, when the north-east was flinging mountains of snow on the forests, but I was so placed that I could hear the crash of the rending trees, and also the thunder of the ocean against a rocky shore, which was dreadful; and I had occasion to pass along the coast line from the Tay to Aberdeen, as soon as the road was at all practicable, on the tops of the dry stone or mud fences, or leg-deep in snow, or any way. That road commands not a little of the coast, and the quantity of wreck, cast high on the beaches, or appearing ragged out of the sands, was most melancholy.

Now, in the early part of that week, the field-fares were coming in absolute clouds; and I remember an old countryman disliking the omen, and saying, "There will be news of this, though many that are in health now will never tell the tale." And the news did come, and if I mistook not (for it was not a day for calm observation), it must have caught the birds on their voyage; for snow and birds were drifting together. My observation, remembered through the checquered lights of so many years and chancings (it never was worth much), may go for nothing; but it stands recorded that, during that storm, which was as far extended as it was fierce, the field-fares were driven diagonally over the island; that vast numbers of them were found dead in Dorset and Devon; and that the Atlantic threw back the dead bodies of many more along the western coast.

The places of the island where these birds come in the greatest numbers are those that have a north-east aspect. My personal observation does not reach Caithness, or south of the Spurn; but in the intermediate parts, the southern shore of the Moray Forth, East Lothian, Berwick, Northumberland, and the line of coast on to Flamborough Head, are the places where they appear in the greatest numbers; and they come first to those places which are farthest to the north. 
During the day they spread over a considerable extent of surface, though rather in an expanded flock than in detached individuals; but they collect together towards night, roost in the fields in open weather, and in the plantations of timber when there is snow. They continue in the country till May and even till the beginning of June, in some instances; and though they usually continue in flocks, they sometimes pair before their departure; but it has not been ascertained that they nestle or rear their broods in any part of the British islands.

THE RED-WING THRUSH. (Turdus iliacus.)

The red-wirig is the smallest of the British thrushes, measuring cight inches in length, about fifteen in the wings, and weighing about two ounces and a half. The red-wing has a considerable resemblance to the song-thrush, only, besides being smaller and less heavy, it seems a thicker bird, from being more closely feathered. The markings on the head, and the red on the flanks and under the wing, however, easily distinguish it from the thrush. The bill is longer in proportion, more pointed, darker at the tip, and yellower at the base of the lower mandible; a dusky streak extends from the gape to the eye; a white one extends from the bill over the eye to the hinder part of the head; and there is a corresponding one on the side of the throat. Double rows of dusky spots from each side of the lower mandible, form a sort of gorget under the chin, the space inclosed by which and the ground colour of the breast are the same dull white; but the breast is much marked with dusky spots, larger but less distinct than those on the thrush. The belly and neck are white with dusky markings, and the flanks and under the wings are brownish red. The upper part is brown, with more of a greenish tinge than the thrush. The female has the under part more dusky and the red less bright.

The whole habits of the red-wing are very similar to those of the thrush; like that it builds chiefly in low bushes; and in the breeding countries, which are principally those around 
the Baltic, it sings sweetly in the breeding season, though with us it has only a sort of plaintive piping note. The birds come to our shores in September, sooner or later, according to the state of the weather in the places whence they come, and of the wind which aids them in their passage across the sea.

Red-wings appear in flocks, are lovers of peace, and mingle freely with the field-fares; the two, indeed, seem alike at the mercy of storms during the winter, though the redwings usually come first, and occupy the ground. While the weather continues open, they remain on the pastures and fields, in those places where they land, and roost for the night in the liedges, or on the ground, according to circumstances; but when they are "frozen out," they betake themselves to the hedges and copses, in search of wild berries, and continue till these also are exhausted ; and if they are then overtaken by a storm, many of them perish, as, like the field-fares, they seem to have but little command of themselves in a gale. If the season is variable, they work their way southward, but suffer very much from hunger and fatigue; and many of thern are smothered in the snow, if overtaken by heavy falls in their attempts to pass the central heights.

Red-wings, as well as field-fares, are often found lingering in those parts of Britain which have the greatest resemblance to the countries where they nestle, as late as the middle of May, or even the first of June, detained, no doubt, chiefly by the east winds, which blow dry and cold at that season; but the same instinct-the same obedience to the state of the weather which retains them with us, prevents them from breeding, or even singing in this country. Bullock mentions their breeding in the island of Harris; but that is out of the line of their ordinary migration; and though it may be true in the instance which he gives, it is certainly not true as a general feature of the ornithology of that island. The song of the red-wing is not known there, any more than it is on the coast of Northumberland or East York; but where any singing bird breeds regularly, its song is sure to be known, not to naturalists merely, but also to the country people. 
Such are a few remarks on the thrushes-a well defined and a very interesting family of birds, whether they remain permanently with us, come only in the summer, or take their fate along with our field birds during the dreary and tempestuous season.

\section{CHats. (Saxicola.)}

Though the chats have the general characters of birds of the insectivorous order, yet their particular characters, and also their habits and haunts, are so well marked and distinct, that they form a very convenient and well-defined group. Their bills are straight, with a slight keel on the upper part, which runs into the line of the forehead, and the upper mandible is margined, and slightly bent at the tip. The bill is wide at the base, partaking there a little of the character of that of those birds which hawk for insects on the wing. The tarsi are long, and the feet well adapted for running; but the toes are not so much extended as in those birds which walk upon very soft ground, or the hinder claws so much as in birds which tread upon soft and thick herbage. The wings are of moderate length and light, the coverts not lying so far over the quills as in many other birds, so that they are not very well fitted for lofty and prolonged flights.

Their habits agree with the peculiarities of their structure; they dwell in the wilds, nestle under stones and bushes, fly low, seek their food upon the ground, run with much celerity in quest of it, and, from the pliable structure of their wings, they can drop immediately from the wing under the cover of a stone or a bush. Most of the males have some song in the breeding season, soft and musical, but not of much power. Their ordinary note is peculiar, something like the sound made by striking or rubbing one pebble against another. They are dispersed and solitary in the breeding time, and the families do not keep together after the young are able to shift for themselves; but the migratory species collect in numbers before they take their departure in the autumn. As their 
mode of life requires them to be constantly arising and alighting, in order to catch the insects and worms on which they feed, they have very great command of the tail, and keep it flirting upwards and downwards, even when they are perched on a stone, a clod, or the top of a low bush, and uttering their peculiar cry. They do not frequent the bare and open parts of the wilds, but rather places where there are heaps of stones, furze bushes, or any other substances which are calculated to retain those fatter and richer parts of the soil which are drifted by the winds, and are more favourable for insects and worms than the exposed parts. They do not feed wholly on the ground, but occasionally dash after insects on the wing, something after the manner of the fly-catchers, to which they bear some resemblance in their shape. They are, however, rarely found in marshy or very humid places. The chats have some of the characters of the thrushes, more especially of the ring-thrush, only they inhabit places that are more open and exposed, and they are far more easily seen, as they perch on the top of the heap of stones or other shelter that covers their nests.

\section{THE stone-chat. (Saxicola rubicola,)}

This is the only resident British species; it is a bird of the dry, but not the most barren moors, being found only where there are thick brakes of furze, or other close bushes which do not rise high above the surface, but are close, and afford concealment to the nests, and also to the birds themselves, who reside there, and find a warm and sheltered habitation, and, in all probability, food, when the ground is covered and the sheltering bush nearly buried with snow.

A furze bush on a wide moor, over which the winds sweep with unbroken fury, is a sort of menagcrie in the desert; it catches and retains all the lighter mould which the wind drives, together with seeds of plants and larvæ of insects; and though furze does not grow, where water stagnates, breeds mosses, and converts into peat, even the matters which 
the wind drives, yet there is always some moisture under its close shade, so that there are worms there, and all sorts of crawling and creeping things of the wild; and, as is also the case with the snails and slugs under hedges in the cultivated lands, they do not require to make their winter habitations deep below the surface under the furze. Thus, though the stone-chat is a smaller bird, and feeds upon smaller prey, it feeds much in the same manner as the thrush and the blackbird, and does not, unless the winter is very severe, need to shift into other grounds. This bird is, indeed, most truly and characteristically the "whin" chat, as it summers and winters among whins, though the name is appropriated to a migratory species, which does not so exclusively inhabit bushes even in the summer. The young are, indeed, said to "go on their travels" the first year, and not to acquire that fondness for the place of their residence which characterizes the species, till they have had a nest and a family of their own; but as they are not seen on the low grounds, except in very prolonged severe weather, and as they live apart at all times, the autumnal dispersion of the young may be nothing more than a local distribution orer the waste, in quest of unappropriated bushes; and as there is little to call them out till the season of song, it is probable that the individuals living apart under their bushes are more numerous than, from the few that are seen, one would be led to suppose. Their safety is in the bush, as well as their food, and they fly in, instead of out, when they are alarmed.

From the figure at page 221, which represents the male in summer plumage, one-third of the lineal dimensions, it will be seen that the stone chat is a very beautiful bird, compact in its form, and rich, though not gaudy in its phmage. In winter, the orange brown on the under part is less bright, and the feathers on the head and neck are partially mottled with brownish yellow: these appear to be decaying feathers, which drop off, and are replaced by pure black ones. The spring moult of our hill birds is seldom any thing more than that portion of their old coat, which remains for additional 
warmth in the winter, and which answers the purpose better from being dry and nearly dead. Dead hairs and feathers are much worse conductors of heat than live ones: the case of house birds does not apply here. The female has the whole of the upper part brown, and the under part pale brown, with no whitc on the rump; and that on the wings and sides of the neck much smaller and less distinct than in the male.

In early spring, these are very delightful birds. The furze brakes are mostly upon the southern slopes, and above the light fogs and exhalations of the spring; so that they are among the first places on which the sun of the young year shines out. The green and gold of the furzc itself are exccedingly gay and cheering, and the scent of it breathes a vernal exhilaration which never tires. The black, white, and brown of the little bird contrast beautifully with the colours of the furze, as he sits on the topmost and luxurious branch, which is too elevated for being clipped and rounded by the browsing of sheep, or the nibbling of hares and rabbits; and he is ever and anon flinging himself a few feet into the air, hovering over the bushes, flitting now here, now there, like a butterfly over a bed of flowers, or a dragon-fly over the margin of a brook, and chaunting his little song, sweet and persuasive, but low, and tuned to the short distance at which it, may be heard by his mate under the shade of the evergreen bower.

That soft but sweet song is almost the first that is heard on the buslry margins of the extensive heaths. The robin and the wren are, indeed, before it; but when they depart from the cottages, they are in the wild woods; the thrush is in the grove, and the sky-lark is hovering over the fields below; so that the stone-chat alone supports the vernal song in thosc places which it is peculiarly healthy and pleasant to visit at the opening of the vernal season. It sings, too, till you are almost close upon it, and then drops so perpendicularly, that you imagine you have no more to do than stoop, lift the side branch, and pick it up; but it glides through the bushes like magic, and before you have examined the half of one bush, it 
rises from another part, hovering and singing again, and foils all attempts at capture, or at a near view of it, otherwise than on the wing.

The nest is under a bush, secured from the rain, and hidden from sight; and though if you start a female from a bush, after the male has begun to sit on the tops, and "chert" his peculiar note, you may be sure that there is a nest, you cannot discern, from the escape of the bird, which part of the bush it is in, or whether it is at all in the one from which she rose. The nest is of moss and dried grass, lined with hair or feathers, or very frequently with wool. The eggs are never more than six; they are greenish blue, with small spots of reddish brown at the thick ends.

If there are young plantations near, especially of pine or spruce, under the shade of which the ground is not unlike what it is under furze bushes, the stone-chat resorts there in the cold months, and even in autumn if that is dry; but it does not build there, or at least very rarely, and only when the plants are young, and the lateral branches near the ground.

THE WHIN-CHAT. (Saxicola rubetra.)

The whin-chat is smaller than the stone-chat; it is five inches long, and weighs about four drachms; the other is five and a half, and weighs fivc, and the whole appearance of the whin-chat is feeble. It is a migrant, arriving in the south of England about the middle of April, and migrating northward rather slowly, so as not to reach its northern limit till the middle of May; and even then it does not reach the northern parts of Scotland, although it ranges much farther than the stone-chat. Its habits, and also its song, have a considerable resemblance to those of the former species, only it sings more frequently on the perch, and comes nearer to the cultivated fields, nestling in thick tufts of grass as well as under bushes; but it is as shy as the others, and, if possible, more careful in the concealment of its nest. That is approached by a laby- 
rinth, to which the rising of the bird affords no clue; and one may seck long for it in vain, while it may not be a yard distant all the time. The nests of all the chats are so placed under cover, that they cannot be looked down upon; but those of the stone-chat are often placed in situations apparently less calculated for concealing a nest, than that from which the bird rises, and which is generally an ontwork to the nest, and approached by a zig-zag path under cover. In that outwork the bird often turns, so as to fly back again over the nest, or off at an angle, which renders the discovery of it still more difficult. The eggs are bluish green, without any spots, and they do not exceed six.

The range of the whin-chat extends at least as far as the furzy and broom-clad slopes, which are particularly abundant on the secondary hills to the south of the Grampians; but it does not appear generally, or in any great number, to cross those mountains. It may, however, be found in the eastern parts of the county of Ross, especially along the northern shore of the Cromarty Firth, where the climate is peculiarly genial for the latitude, the lower grounds rich, insects very abundant, and the country accessible across Aberdeen and Moray, without any long flights over the sea or high mountains. The whole of that line from the sea to the central mountains, is well worthy of the attention of ornithologists.

It is probable that the whin-chat retires, in the latter part of the season, from all its more northerly breeding places; but that a few pass the winter in Kent and Sussex, even in places where they rarely breed in the summer, - as a passage from the central parts of Scotland to the south of England, is as great a change, both in climate and latitude, as one from the central parts of England to the other side of the channes; and though birds of powerful wing and long and rapid flight can migrate from hemisphere to hemisphere, it is reasonable to suppose that birds of comparatively weak wings, like the chats, have their migrations shorter; and that those which gro far to the north in summer, do not go so far south in winter.

VOL. I. 
The whin-chat is not so compact or thickly feathered on the neck and shoulders as the stone-chat, but is intermediate between that and the warblers. The colours are not so boldly contrasted: in the male, the head and ear coverts are dusky brown; a line over the eye, the chin, a line down each side of the neck, the bars of the quills and tail-feathers, and the crest white; the rest of the upper part blackish brown; the throat and breast very pale orange brown, fading through dull yellowish white on the belly to the white on the vent. In the female the white is less and dull, and the young birds have the brown less or more mixed with white and grey.

As these birds do not affect high grounds or long flights, they come to Britain more to the south-east than bolder flying birds; and hence they are not common in the south-west of England. They belong to the same migration, in direction, as the warblers, only their habits and kind of food lead them farther inland.

THE WHEAT-EAR CHAT, (Saxicola onanthe,)

Is another summer migrant, but it comes at least a month earlier, and in much greater numbers than the other species; it is by far the most abundant of the tribe, ranging over every latitude in the British Islands, and resorting even to the inhospitable shores of more northern lands; it is also distributed farther up the wilds, and lower down on the cultivated grounds, than any of the other species. Their perch is on clods, and especially on stones, beneath which they form their nests, and probably expel the toads from their dwellings; at least $I$ have seen a toad in a hole under a stone, and afterwards a wheat-ear's nest under the same. They do not, of course, always nestle under stones; they resort to those places where there is most food for them, and nestle under whatever suits their purpose best. They love a dripping sky and misty atmosphere, because these are favourable to the growth, and also to the appearance of those earth-worms which form their principal food; and these circumstances have, of course, more 
influence in the determining of their localities, than the places under which to shelter, or the materials whereof to construct their nest. Indeed, the materials of a bird's nest are not a character upon which to found a dispute; because they are minor parts of the bird's accommodation; and, in nature, minors must always yield. If there is a loose heap of stones, natural or artificial, a dry stone wall, a rugged stony bank, or a single stone on the common, below which a hidden shelter for the nest either exists naturally, or can be formed with little trouble, the wheat-ear will prefer that; and as they are not in the habitual sight of man, it has no objections to the crumbling masses that have fallen from a ruined tower or abbey, or even to the shelter of a tombstone which has been partially filled beneath witl weeds and rubbish. It is worms that entice the wheat-ear, and wherever the place of worms is, more especially if deserted by man, there the wheatear is sure to come, heedless of whatever tale of ghost or goblin may keep the rustic in fear of its haunt, and occasionally make the pretender to a more daring philosophy at little sceptical of his own scepticism.

As the wheat-ear always nestles where it can feed both itself and its young with the least exertion of its wings, of course its nesting-places are different in those districts where stones are not to be found. In these, the slovenly agriculture of "fallowing," makes the best substitute for stones; and as the rugged furrows of that rude hushandry lie encouraging weeds, they seem so like ruins that they are selected as nesting-places by the wheat-ear; and as they are left alone in their desolation, unoccupied by crop and useless as pasture, till the broods are hatched (which is not later than June), and as the birds then begin to resort to the downs and open commons, the "fallow-chat," "wheat-ear," and "clodhopper," are not unappropriate names. But the bird, though bordering onit, is not quite a bird of cultivation ; and therefore the names are rather uncomplimentary in an agricultural point of view. Wheat-ears breeding in the cultivated lands, are not so expressive of desolation as bitterns in a city; but one N 2 
would rather hear warblers in the copses, and shoot pheasants and partridges.

In the north, the wheat-ear is generally found on heaps of stones, by ruins, or on the dry stone walls of burial-grounds; and though it is a very handsome bird, and in the early season sings sweetly, its haunts have gotten it a bad name. Its common alarm note is not unlike the sound made in breaking stones with a hammer; and as it utters that note from the top of the heap which haply covers the bones of one who perished by the storm-or his own hand, or the mound beneath which there lie the slain of a battle-field, magnified through the mist of years, or the rude wall that fences in many generations, it is no very unnatural stretch of the pondering fancy which dwells in such places to associate the wheat-ear with all the superstitions that, unphilosophically but not irreverently, belong to the place of graves. It comes onward too, to meet the traveller, and now running, now flying, seems to pilot him to a place beside the "cairn," as if his own bones were soon to be gathered there; and in that, its note of solemn warning, it is more than usually energetic; it is seen in the fog too, and from the contrast of its colours it is particularly conspicuous even in that. In a highland glen, during a highland mist (which wets but warms you), you hear the clacheran before you see it; you meet the clacheran before you see the cairn: so you are at perfect liberty to believe that it is busy breaking the stones that are to cover you-if you choose; and really there is no accounting for what people will believe in such places_or in any place.

Now, the said clacheran has merely selected that spot, as you would select some sunny and south-turned nook, sheltered northward by trees continuing upward to the hill, and bordered southward by a sparkling river rolling onward to the sea- $\mathrm{a}$ spot where no plant would fail, no blossom be barren, and no blight or blast could invade; but where plenty would attend on every labour, and the beauty of the scene, would bloom full and fair, mingling confidence with hope, that the colony which you had founded would con- 
tinue generations unnumbered to enjoy the bounty and bless the bestower. If the land were all before you where to choose, and you were as much the unsophisticated child of nature as the bird, the probability is that you would act thus, and that is just what he does. Beneath that heap of stones, there is a little nest, formed of moss and grass, and carefully lined with hair, feathers, or wool, with five or six eggs of a delicate bluish white, and there is a mate of whom and her promised brood the bird is as fond, and for them he has as much forsaken the society of other birds, as the most exemplary of the human race could possibly do. He watches early and late, and endeavours to divert any one that passes, from the retreat of his charge. He renders it unnecessary for the dam to leave the eggs when they might be injured by the cold and damp, for he feeds her morning and evening while the air is cold; but in order that she may not suffer by the confinement, he takes her place a short time during the warmth of the day, while she exercises her feet and wings for a little, and picks a snail fresh from the all-supplying earth.

Yet, for these assiduities to his brood, the wheat-ear has been made, in the northern parts of Britain, and in places further to the north, the victim of superstition. Old and young continue to kill and persecute the birds, and to destroy their eggs, considering the service as one of more than ordinary merit. Nor, though the warfare on them there be a little more rational, do they fare better in the southern parts of the country. When they collect in numbers on the southern downs, which they do about the middle of July, they are caught in horse-hair nooses in vast numbers, which are set between two turfs turned against each other. At that time they are very fat and of exquisite flavour; as indeed all the chats are in the latter part of the summer. It appears that the broods when matured so as to be able to shift for themselves, have the same disposition to resort to new ground which was noticed in the other species; for those taken on the downs are chiefly young ones. 
The wheat-ear thus appears to be a bird of most hapless lot. It is persecuted to death by superstition in the one end of the island, and killed and eaten by the cravings of luxury in the other; and yet the wheat-ear does nothing but good, for its habits do not lead it in the slightest degree to destroy any one thing that is useful to man. On the contrary, the numbers which are scattered over the country, destroy an incredible number of animals that are really hurtful. But the birds themselves appear to be indestructible; from the situations in which they build, and the industry with which the callow young are fed by the parent birds, together with the general watchfulness of the whole, fewer casualties befal the wheat-ear than most of the other birds, and a dead one is rarely seen, neither are they much destroyed by birds of prey. From the situations which they choose, they are exempted from famine in dry seasons; and those humid rains that are lestructive to so many other species of birds, are seasons of extraordinary plenty to them.

The wheat-ear is the largest of the British chats. It is six inches and a half, and the weight about six drachms, but rather heavier when fat, and the female is a little heavier than the male. The bill, legs, claws and gape are black, and so are the quilks, the middle tail-feather, the tips of the side ones, and a streak from the bill under the eye to the ear-cover; but the black on the wing has a slight bluish tinge. The rest of the upper part is bluish grey, with the exception of the rump, which is white: all the under part is white, with the exception of the breast, which is buff orange. The colours of the wheat-ear are very pure; and the bird has a remarkably clean appearance.

As is the case with many, or most of the migrants that come to Britain to breed, the males come before the females; and as the instinct of the season leads each pair to separate, they come singly, though many are often seen near the southeast after they land. The song of the male wheat-ear is very sweet, but it is low and heard at a very short distance. They have been occasionally seen late in the season, so that it is 
possible some of them may winter in the southern parts; but if they do, they hide themselves in the copses or other sheltered places, and are seldom if ever seen, at least by those who would be disposed to notice and record their appearance. The distance to which their northern migration extends, and the weakness of their wings (though they are better winged than any of the other chats), would lead to the conclusion that they do winter in some parts of the country.

\section{Wagtails. (Motacilla.)}

The wagtails get their name from the remarkable, rapid, and almost incessant motion of their tails. There are many other birds that flirt the tail upwards and downwards, but perhaps none that do it so habitually as the wagtails; and the elevation is accompanied by a jerking spread, which relaxes when it is depressed, so that it appears to have two simultaneous motions.

These birds, which all either leave the country in the winter, or migrate to different places within it, are natives, and while they sojourn with us, inhabitants of peculiar localities. They frequent the margins of waters, especially clear streams and pools in retired places, and form their nest under projecting stones or in holes near the banks. They feed chiefly upon aquatic insects and upon worms.

The principal characters are,- the head small and pointed; the body slender, but firm at the shoulders, and tapering backwards; the tail very long, and well fortified by coverts, both upper and under, and the wings rather short, but also well supported by coverts, and pointed, the second quill being the longest. The bill is slender, awl-shaped, has a ridge or keel on the upper part, and margins to the edges of both mandibles at the middle. The tarsi long and strong, and also the hinder toe, the claw upon which is considerably produced. The whole air is expressive of energy and varied motion, whether in the air or on the ground.

They run with great rapidity, and do not hop or require N 4 
the aid of their wings in running; they can run upon the surface of very soft ground without sinking, and over slippery pebbles by the brooks without any unsteadiness; and when it is necessary for them to change from running to flying, they can take wing from either of those surfaces with great ease. The following cut will show the difference in structure between a foot adapted for running upon or rising from grass, and one adapted for such places as those on which the wagtails run.

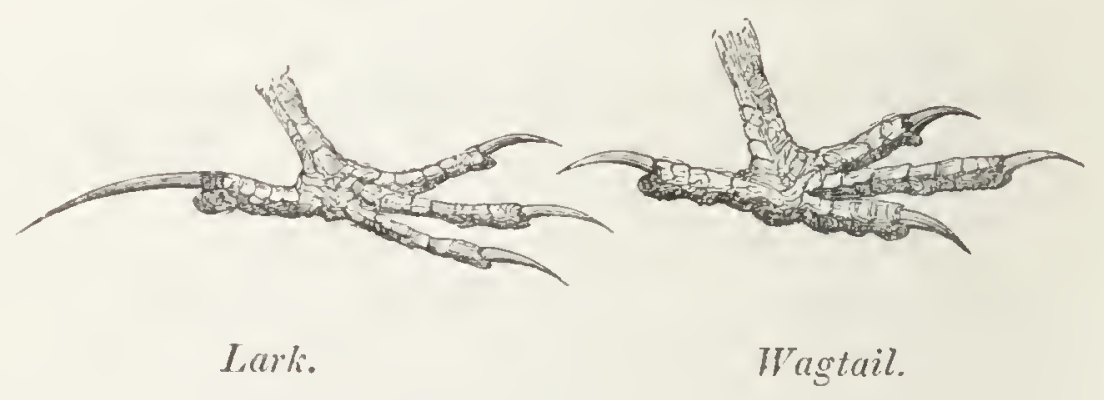

These characters are remarkably well suited to the haunts of the wagtails and the modes in which they acquire their food. They live beside the waters, upon the soft muddy banks, or the pebbly strands, where they run and capture such land or aquatic insects as present themselves; or they quarter the surface by short but rapid flights, and snatch those that play on the surface of the water or hover near it in the air.

The legs of the wagtails are placed behind the centre of gravity of their bodies, as is the case in all birds which run rapidly, in consequence of which they would have difficulty, or at least labour, in recovering themselves by mere muscular exertion when they bring their bills to the ground, as they must often do in picking up their food. The tarsi, as has been noticed, are long in proportion to the size of the birds; but the neck and bill, instead of being so long as to enable the latter to reach the ground while the axis of the body is horizontal, so that the shoulders must dip much when the bill is brought to a level with the feet. A bird so formed would be very apt to tumble forwards, if it had not some means of working a counterpoise; and that counterpoise is the tail. 
When that is expanded and struck forward against the air, it acts in nearly the same manner as a wing, and pulls the body of the bird backwards, so that the head is raised with comparatively little effort. All birds that liave the same length of tarsi in proportion to that of the neck and bill, have a similar action of the tail; but as that structure, and also the habit of picking up food on a level with the feet is more remarkable in the wagtails than in any other British birds, the motion of the tail is more powerful in them; and the tail is also longer in proportion. But the habit may be seen in very many birds, both in enabling them to raise the head and to retain it in an erect posture. The magpie is a familiar instance, and so is the peacock-which would tumble backwards if he were to raise the body in the same manner when the tail is down as he does when it is erected and spread.

\section{PIEd Wagtail. (Motacilla alba.)}

A figure of the male bird in its summer plumage is given on the plate at page 261, on a scale of one-third the lineal dimensions. The female has the throat and breast white, and the plumage on the back more inclining to grey, which are also the colours of the males in the winter, at wlich time the sexes are not easily distinguished.

The pied wagtail is a very generally dispersed bird; and there are few pools and streains in any part of the British Islands near which it may not be seen in the summer, though it prefers those that are near trees, fertile grounds, or any cther accompaniments that bring numbers of insects upon the water. Hence it is not so much found by the cold, dingy, and peat-encircled pools on the naked heights; and lower down, a favourite brook for the wagtail is always a successful one for the young trout-fisher.

In summer, the wagtails hawk over the surface of the water, and catch winged insects, not by straightforward speed, like the swallow tribe, but by short and jerking flights, 
after the manner of the fly-catchers. When the water subsides during the droughts of summer, they may be seen scouring the margins and picking up the larva that are still alive in the mud and sludge which remain wet. At other times, they may be seen wading in the shallows, and picking up the larvæ and aquatic insects that are between the pebbles, their motions while doing so being so rapid, that only the flitting of the tail is noticed. They also follow the plough, and pick up larva and worms that are exposed on the turned furrows; and they come about barns, and examine horseponds, and generally all places where water stagnates or the earth is turned up. Inhabiting, as they may be said to do, the border between the land and the water, they conduct themselves as borderers generally do-they levy their contributions upon the one or the other, as may be most conducive to their own interests; but they do it with this difference, that all their inroads and forages are useful to man, as the number of insects which they capture, if allowed to remain and breed, would make the waters rank and the land unsightly.

As the wagtails subsist wholly upon insects, they are unable to pass the winter months in the northern and elevated parts of the country, because the ground is frozen up; but even there they may be found among the discharges of those copious and deeply-seated springs, which maintain nearly a uniform temperature all the year, and thus keep their rivers open, even when the rest of the ground is skirted with snow and ice. In such situations, the wagtails may be seen even in the month of January, hopping under the banks of snow that have been undermined by the discharge of the spring. The change in the under part of the male bird to white, is an adaptation of the bird to cold, in consequence of which there is no doubt that they could bear the climate, and only change their residence in order to find food. Many of them retire to the sea-coasts, where they may be observed running along the beaches, after the tide has ebbed, and picking up the small marine animals that are left on the sand. They linger 
long also about those fields where turnips are fed off by folded sheep; and may be seen there in considerable numbers after they have all left their summer haunts by the upland brooks.

In the southern counties of England, they remain nearly stationary all the year round; and though, in many other places, they leave their summer quarters, the probability is, that they only disperse to more suitable places, and do not, in any great numbers at least, leave the country. It is true that, in the north, they are not seen inland from the time that the cold weather sets in till the storm breaks; but as that takes place a month sooner in some seasons than in others, without any alteration of weather in the south; yet as the birds visit the northern brooks as soon as they are open, and are on the fields as soon as the ploughs can be got in, they cannot come from a very great distance, unless we suppose that some messenger sends them word that the northern country is fit for their reception. It must never be lost sight of, that birds-all animals - are affected only by present circumstances, by circumstances present both in time and in place; and though Iceland were heated like a furnace by the action of its volcanoes, that would not occasion the migration of one bird from the south. Besides, the pied wagtail undergoes a considerable change of plumage preparatory to the winter; and birds require that, in order to temper them to the climate, and having done so, they never migrate farther than is necessary in order to find food.

The wagtail sings early, and sweetly, though its song is neither very long nor very loud. It sings from a low perch, -the point of a rock by the water's edge, the parapet of a bridge, on an old stump of a tree, a mill, or even the top of an outhouse or cottage. It is a very familiar bird, and, at the same time, very lively and very pretty, so that it is a general favourite. A meadow of short soft herbage by the brook, or a well-mown lawn near the bank of a river, is a very favourite morning or evening pasture for the wagtail, and it will run about there with great alacrity and glee, ever 
and anon dipping its head, and again recovering its balance, by the peculiar motion of the tail, as if it took pleasure in a place neatly kept. But the fact is, that the short grass, more especially if it is newly mown, enables the bird to see its insect prey readily and capture it with ease.

The situation of the nest is varied according to the haunt. It may be in a bank of stones by the brook, a shelf of the bank, a hole in the wall, or a thick old tree. The external structure is composed of vegetable fibres filled with wool, and the internal lining hair; but these, of course, vary with the materials that are to be had. The eggs are four or five, very small, greyish white, with minute light brown speckles. They are not unlike the eggs of the cuckoo; and that strange, anomalous bird is said often to inflict upon the wagtails the labour of feeding her ungainly and voracious offspring.

THE GREY WAgtail. (Motacilla boarula.)

This is not so common as the last species, and it is more migratory in its disposition, though there is reason to believe that its migrations, like those of the other, are chiefly performed within the island.

The grey wagtail is about the same size as the pied, that is, seven and a-half inches long, and about a foot in the stretch of the wings, and six drachms in weight; but it is lighter and more elegant in shape, more fitted for getting through the air, and the tarsi are not quite so strong, or the toes quite so much produced. The colours, though distinct, are soft and delicate.

The male in the summer or breeding plumage, has the upper part a fine delicate grey, except the rump and tail coverts, which are bright sulphur yellow. The white lines, proceeding from the gape, one over the eye, and the other on the side of the neck, joined by a white line across the eye, impress the side of the head with a mark resembling the letter $\boldsymbol{D}$. The throat, between the white lines is black, circular toward the breast; and from that the whole under part 
is yellow, very intense on the breast, and becoming paler backwards. The wings are greyish black, and the coverts tipped and margined with white, which forms a white spot, and two longitudinal white streaks on the closed wing. The tail (which is very long) has the outer feather, the inner web of the second, and a streak on the inner web of the third white, and all the rest black. The bill and gape are black; the feet dusky brown, with the exception of the joint of the tarsus which is yellowish.

In the breeding season, the colours of the female are nearly the same, only a good deal paler and less distinct, the yellow being whiter, and the grey having a shade of black, while in the male it inclines more to blue. In winter, the male, in a great measure, loses its distinguishing colours. The black on the throat gives place to pale greyish white, and the whole under part becomes very pale; the female also loses the black on the chin, which is, indeed, never so pure and conspicuous as that on the male.

Those changes of colour indicate an adaptation to the temperature of the season, so that the migration of these birds may, like that of the pied wagtails, be regarded chiefly as a migration for food: indeed, the want of food in the polar climates may be considered as the grand operating cause in all equatorial migrations.

The grey wagtail leaves the southern parts of the country (in which it is called the winter wagtail) about February or the eariy part of March, the cause which changes the plumage appearing to operate simultaneously in prompting the migration, as the sexes resemble each other as long as they remain in the south. Many of them halt by the upland streams in the central and northern parts of England; but others pass into Scotland, where they penetrate to a considerable distance north, although as they keep to more retired situations, they are not so often seen in proportion to their numbers as the pied wagtails. They are also more confined to the clear streams in the open wastes, where they feed upon water-flies, insects, and larvie. They nestle chiefly in rocky banks, 
seldom in any vegetable cover. Nest like the former, eggs not exceeding six, larger than those of the former, yellowish white, and mottled with brighter blotches. The first brood is usually fledged by about the first of June, and the second (when they have two), about the middle of July; but in the most northerly places, they seldom have more than one brood, which is fledged about the end of June. In the north they are, of course, summer wagtails; and they take their departure earlier than the pied, though some of them linger by the rims of the deep-seated springs, and may continue there during the winter, in more northerly places than they have yet been found in at that season.

It does not appear that they ever summer or nestle in the south; and, it is worthy of remark, that these indigenous water-insect consuming birds, retire northwards in summer, and leave the waters of the south and south-east to the aquatic warblers. Those resident insectivora are suited to the open air, and the warblers to the shade; and, accordingly, they alternate with each other in the seasons. The warblers retire to climates in which they find shade in the winter; and the resident birds betake themselves to the north in the summer, where the deep shade and the rank vegetation by the sides of the pools and streams do not interfere with their pedestrian habits.

the yellow wagtajl. (Motacilla flava.)

The name of this bird, though accurate enough as to the under part being more entirely yellow than that of most birds, is an inapplicable one and apt to produce confusion; for it really has less yellow upon it than the summer plumage of the species called grey, the rump not being yellow, but a dull yellowish green; and the habits of the bird are less those of the pied wagtail, which we naturally (being most familiar with it) take as the type of the genus. If it is to be called a wagtail (for wagging the tail, the one of the characters, is not the distinguishing one, as it applies to many birds - and to dogs when they are 
pleased), it ought to be the GREEN wagtail, as the green upon it bears some resemblance in locality to the grey on the other. The spring or summer wagtail, is also a bad name for all Britain, as there are places where all the three are spring or summer birds.

The following is the summer plumage of the male:-Top of the head and ear-coverts pale yellowish olive green; shoulders, back, and rump, the same but darker: and the green advancing in a point at each side of the lower part of the throat, as if fragnents of a collar. The whole under part pale gamboge yellow, still paler towards the vent. Wings and tail dusky; less white in the tail than the other wagtails; and very little in the wings, and the little that there is dull and obscure. The female has the yellow below so pale as to be almost white, and a blackish tinge in the green on the back. As the birds are regular summer migrants, they have no winter plumage as British birds; and, as might be inferred from the fact of their seasonal migration, their plumage is not so much subject to change as that of the others.

The air of these birds, and their haunts and habits, differ so much from those of the wagtails, that they have been with propriety separated as a genus, though the generic name "Budytes" (associator with cattle) is not a very happy one, or the characters well made out. Our business, however, is merely with the popular appearances and characters of birds.

In that point of view, the yellow wagtail wants the active expression of the others. The neck is longer, and the tail an inch shorter, being less necessary for balancing the bird. The hind toes are also longer, and the claws on these more produced and straighter, approaching more to the character of a foot for walking upon elastic surfaces, such as grass. The bird accordingly frequents the cultivated lands, the pastures and ploughed ficlds indiscriminately more than the margins of the waters. Its proper character with us is that of a summer visitant of the open fields, and it prefers inland places to those on the coast. Its nesting corresponds; for 
the nest is built on the ground, and not under stones or in the shclves of banks. The nest is formed of dry vegetable fibres, and lined with hair ; and the eggs, which are not more than six in number, have the prevailing colour of those which are laid in ground nests. They arc light brown, with darker brown spots. The nest is, howcver, generally placed under some cover, as in a tuft of grass, or at the root of a tree. The young birds resemble the female.

These birds, which are by no means uncommon, makc their appearance in March; and, as they are then most abundant in those elevatcd parts of the country which arc better adapted for the growth of oats than of wheat, they have been called "oat seed" birds. They ply their labours, both assisting in the nest, and the male crying shrilly but not singing; and by the end of July the broods are fully fledged. In August they accumulate in flocks on the stubble lands, and especially on the richer pastures, and about the pens and folds; and by September they leave the kingdom generally, though it is probable that a few may pass the winter on the warm downs near the channel.

These birds occupy a particular zone (the edge of the cultivated country, but within it), a zonc not exactly occupied by any other migratory species; and, therefore, they want to be more carefully studied, not as wagtails (which they really are not), but as migratory birds connected with that particular zone, and depending chiefly upon the insects, the larve, and the worms, which are peculiar to that. There is no satisfactory knowledge of birds (or of any animals), unless it comprehend the places which they chiefly inhabit (that is, the places in which they are produced), and the peculiar matters which in those places constitute the greater part of their food. Food for themselves and their young is the grand necessary with birds, to which temperature and nest-building are very subservient; and many of the errors of which ornitlology is full, both as a science and a popular employment, recreation, and source of pleasure, have arisen from the elevation of minor circumstances over the major ones. 
The blue breast, (Motacilla Suecica of Linnæus, )

Has reccntly been caught in the vicinity of Newcastle-uponTyne, and therefore it must be admitted into the list of stragglers. Its characters arc as follow:-the crown of the head and rest of the upper parts are brown, the latter tinged with greyish, and paler on the margins of the scapulars and wing-coverts; feather's at the base of the bill and streak over thc eye, yellowish white. The chin, throat, and upper part of the breast, rich azurc, with a silky white spot in the centre; the blue bordered beneath with a narrow gorget of black, which is succeeded by another of reddish brown. Under parts, dirty white inclining to grey. The two middle tail-feathers brown, the remainder having their basal half of a bright ferruginous, or brownish orange colour. In the female, the upper parts are paler, the chin pale azure blue, mixed with black, streak on each side of the neck, and upper part of the breast, black intermixcd with azure blue, and surrounding a large spot of white. The young are, in their first plumage, mottled. This bird has been classed with warblers, but it does not appear to have much song.

THE DIPPER. (Cinclus.)

There is only one British specics of dipper; but it has so many peculiar characters, that it cannot be properly included in any other genus, as therc is no other British bird that much resembles it in shape, in colour, or in habits. The bill is slender, with a slight bend upwards, the mandibles bent inward at the edges, and the upper one margined and very slightly hooked at the tip. The head is small, and the forehead remarkably low; the body short and compact, the wings very short and rounded, the tail also short, but very stout and strongly fortified by coverts. The whole is what one would call a "dumpy" bird, but there is an expression of great energy and activity about it. Its plumage also is remarkably 
thick and close, resembling that of the water birds. Like these, it is amply supplied with oil for its feathers; and, though a considerable time in the water, the plumage on the living bird does not become wet. The head, back, and sides of the neck are deep brown; the rest of the upper part is black, with some variations of brownish grey. The tail-feathers and quills are quite black. The throat, chin, and breast are white, passing into reddish brown about the middle of the belly, and becoming gradually deeper and blacker toward the end of the tail. The bill is dark brown, the irides brownish yellow, and the feet yellowish grey. The sexes are like each other in their markings, only the brown on the head of the female is darker, and the white on the breast less pure. The young birds have that part of the head and neck grey which is brown in the old birds; and they have the under part white almost to the vent, but marked with grey and yellow on the portion which afterwards becomes brown. They are, of course, seen with the plumage of the changeable parts in all its intermediate stages; and, as it may change differently in different birds (as is the case in all birds that change much of their plumage either with age or with the seasons), there may be very different markings even in the same brood in the autumn; but probably there are distinct species, or at least, varieties.

When the bird is standing in its usual position of quietude, the length from the point of the bill to that of the tail is not more than five inches and a half, of which the bill and tail take two inches and a half, measured on the horizontal line, so that the body of the bird, in that position, is shorter than that of any other species of equal weight. The weight is two ounces and a half. The curve along the under side is, however, nearly nine inches.

The dipper inhabits more romantic places than those that are the almost exclusive haunts of any other British bird; and its manners, taken altogether, are among the most singular. It is not confined to any particular latitude, being found near the Channel, in Wales, in the mountainous parts 
of the centre of the island, and also in the north. Cold and heat seem indifferent to it, so that it can be near water which is not frozen. The ravines on the slopes of the mountains where the perennial streams have worn themselves deep and rugged channels through the strata, with here an opposing rock, there a dimpling pool, and in another place a brawling rapid, with loose stones, overturned trees, ne plus ultra precipices, and all the et ceteras which annoy while they astonisle a guideless stranger in such places, are the favourite haunts of the dipper. The bird fits before him from stone to stone to chirping, and with a wing so apparently helpless, that he imagines it unfledged, utterly incapable of gaining the sky, of which a mere stripe appears over head, and thus " a something," which he can easily catch and carry home as a triumph of his victory over the wild. As he gives chase, with all the confidence of one who drives deer into a tinchal, or ducks into a decoy, the dipper flits on from stone to stone, flirting its tail, and ever and anon jerking round as if half astonished, half inviting. So onward they fare, till they come to a bolder and tougher stratum which has obstructed the stream, but at the same time given it fall and force to scoop out a pool below, which though it boils where the cascade plunges (or rather where it rises again), is placid compared with the brawlings that have been passed. The water merely laves a beach of clean pebbles; the rocks on the other side are "sky high," without footing even for a bird; and the breast. over which the water dashes, seems too high for a thing so hopping and badly-winged. The bird halts on the beach; and the sportsman rushes forward hat in hand to the capture; but the wet stones are treacherous, endlong he falls, dips himself, and rising, sees the hat which was to capture the bird, whirling round and round in the eddies. The bird too, has vanished -it is "a sprite" to wile him into peril. But it soon "bobs" to the surface, at the lower end of the pool on the other side, with its feathers dry without any shaking off of the water, and, leaping first on one stone and then another, it descends the ravine with the same nonchalance that it ascended. To 
rccover the hat is a mueh more arduous matter than to lose the bird; but that, too, may be aecomplished with one of the long suckers of hazel which grow from the tangled and gnarled stool on the bank, though if the hold be not taken warily, and kept earefully, there may be a seeond dippingand yet no dipper to boast of.

The dipper is, in faet, a very curious bird, and it is more gratifying to watch the mancuvres of one, than to be in possession of the bodies or skins of fifty. Its food is water flies, water larvæ, water inseets, worms, and dragon-flies, water beetles, and, in short, a variety of animals and animal matters found in the waters. The fry of the trout and salmon, while still in their eradle pools, numerous as motes in the sun, and each not an ineh long, form a supply for it, and its young while these are in the nest. Nor is it at all ehary of the nests of the fishes, - of those nests under the sand and gravel, each eontaining thousands, to form and fill which the fish aseend as far as they ean by the help of the autumnal floods, and the nests (or rather " plantations") of young sprout up in the spring, like young onions in a garden. While the water is unfrozen the sun acts upon these, and they pass through their stages; so that while the thrushes, with whieh the dipper has sometimes been associated in systems, are frozen, out on land, the dipper feasts in plenty under the water.

The dipper eatches part of its food standing on land, and some even on the wing, as well as floating on the surfaee of the water; but it also eatehes a considerable part under the water, and the water is its retreat from terrestrial danger. It eannot skim the water so well as if its feet were webbed. Wings, though they help a web-footed bird in rumning along the water, as may be seen in the case of a duek or goose, are of less use for progressive motion along the surfaee, if there are not webbed feet to aet as fulera. But the dipper walks into the water, or lights on it from the wing, and in either way gets under the surfaee, and rises, deseends, moves laterally, or appears to walk (aetually does walk) along the bottom; in 
short, has ahnost the same eommand of itself in that singular element for feathers, as other birds have in the air.

A question has been raised (I do not say among "those out o' their wits," beeause there are "impossible cases" in that problem), how the dipper can eontrive to keep "beneath a fluid so infinitely more dense than itself." That is a strange use of the word "infinitely," unless infinitely small be meant. An owl to an owl's bulk of air, is a stone to a pound, as eompared with the dipper's bulk of water to the dipper; and if birds rise and descend in the air at pleasure, by the motions of their wings it is only reversing those motions to enable them to descend or keep themselves down in water. The compression of three feet of water is nearly two pounds and a half on the inch of the feathers, and that, when they are unruftled, as they are in the dipper, will bring them to very nearly the specific gravity of water. The difference of specific gravity between the bird and the water, is indeed so trifling, that very little effort suffices to move it in any direction, upwards, downwards, or laterally. Bircls do not fly upon the principle of specific levity, as with equal wings the heavy bird flies best; they fly because they strike the air more forcibly in the opposite direction to that in which they wish to go, and, under water, the dipper does just the same: if it wishes to go down, it strikes upward the wings and tail ; if to come up, it does just the reverse. The only difference is, that the wings are held " recovered," as running birds use them, and that gravitation has even less to do in the matter than in flying. Any one who has ever seen a dipper under water, or has the slightest knowledge of the mere elements of meehanics, can understand the whole matter in an instant. The dipper is, indeed, often adduced as an instance of the beautiful simplicity of animal mechanics. The curious habits of the bird will perhaps be an excuse for this digression, which, after all, is more apparent than real.

From its not being solely dependent upon atmospherical temperature for its food, the dipper is, considering the upland character of its haunts, really an early bird. It sings in 
January, and its note, which is very sweet, and peculiarly varied, may be heard before the frost has relented on the banks between which the stream of its habitation runs.

The nest is also begun early in the season, and considerable labour and ingenuity are bestowed upon it. It is large for the size of the bird, formed of such materials as the ravine or other banks of the stream furnish, covered over with a sort of dome, and having an opening in the side. It is usually placed but a little above the highest level of the water, and the water is generally high from the spring rains and floods about the time that it is building. The angle between two fragments of stone, or between an old root and the bank, is no uncommon place for it. Externally it is generally of moss, which the humidity of the place keeps partially green, so that it looks like one of the natural mossy tufts; internally it is lined with more dry matters,-leaves or fibres, as the situation may best afford. The first brood is fledged in May; but as the birds have a perennial pasture, they have two or three in the course of the season. The eggrs are not more than five, and of a beautiful white. [There are, no doubt, exceptions ; but the eggs of many birds partake of the colour which the breast of the male has in the breeding season.] The young dippers grow fast, are great feeders, and are incessantly chirping in the nest, in the absence of the parent birds. It does not appear that the dipper inhabits situations so high as that the running waters are liable to be frozen over in ordinary seasons, though it comes farther down in the winter, not to the wide and slow rivers, however, for these are apt to be close, while the brawling ones are clear. A pair of dippers with their nest are given in the vignette to this volume.

THE Titling. (Accentor.)

There is one species of this genus a resident British bird, and a very common and familiar one-the "hedge-sparrow," "hedge-warbler," or dunnock (uccentor modularis.) It is neither a sparrow nor a warbler, and it is certainly not the 
only "dun-coloured" bird in the country; so that titling is the least exceptionable name, and it also partly expresses the common cry of the bird, which is teet, sounded short.

The word "tit" means "little," and is used as part of the names of some other birds, as tit-mice, tit-larks; but it is applicable pre-eminently to the bird under consideration, not on account of its diminutive size, for, leaving the tail out of the estimate, it is as large and heavy, and from its thicker plumage, it appears a larger bird than the wagtail; but because of a very frequent habit, or rather, perhaps, misfortune. The nest of the titling is one of those which the cuckoo chooses for depositing its exposed egg. It shares that burden with some other birds, especially with the meadow-pipit, which has, on that account, been also called the "tit," or "tit-lark." Both birds follow the cuckoo : it may be sometimes from hostility, and sometimes in the character of fostermothers; at all events, they do it voluntarily, and often blithely. It is the small following the great; and "the cuckoo and the titling," or, better still, from the double meaning of the first name, "the gowk and titling" of the Scotch, has become not an uncharacteristic and, in some instances, a very biting expression for the little of mankind dancing a senseless and thankless attendance on the great.

In. form, the titling has some resemblance to the redbreast, only it is larger, more lumpy, and not nearly so energetic in its expression, or so lively in its motions. Its habits are also a good deal similar to those of the red-bieast; it comes about the farm-yards and cottages, and into the gardens and shrubheries, in the inclement season, not in flocks, but hopping about singly, and picking up any food, whether animal or vegetable, it may find. In these gloomy times, it utters its peevish cry with an apparent feeling of suffering and desolatioll. If the weather is at all favourable, these birds begin to sing about the middle of January, and by the middle of February they pair, and retire to a greater distance, though not so conpletely into the depth of the woods as the redbreasts. Both birds labour at the nest, which is composed 
externally of moss and vegetable fibres, and lined internally with hair. (Birds that line their nests with long hairs, do not build in the depth of large forests.) The nest is at no great elevation, but it is in general hidden among sticks, or in a thick bush or close hedge. The external part is rather loose, like a natural tuft of green moss: but the interior is more elaborately worked, the hairs being interwoven with each other; and the friction of the bird and eggs during the process of incubation, produces a sort of felting, which very little action will produce in hairs interlaced with each other. It has, very naturally, no doubt, occurred to some who have mentioned this bird, that the internal part of the nest is put together with paste,-(as some books are, and, of course, that the materials are obtained with scissors, ) - which is a process to which magpies will resort, though, instead of paste, they are apt to daub with more vulgar mortar, as the manner of some is-among ourselves. The nest, laborious as the construction of it is, is generally finished by the end of March, and the depositing of the eggs requires only four or five days; so that the first brood in the south of England would be too early for the cuckoo; but probably there is a second brood there, and in the same nest. Farther to the north, the cuckoo is said to prefer the nests of birds that build later.

The colours of the titling are sober; the upper part is brown, relieved with ash colour on the head and neck, and with rust colour, or reddish brown; the second coverts of the wings tipped with white; quills and tail-feathers blackish brown, margined with red brown; sides of the neck, throat, and breast bluish grey; the rest of the under part greyish white. Female with the head more grey, and spotted with brown; the colours on the other parts less bright. The song is continued for a considerable time in the winter quarters of the birds, as they do not formally begin the construction of their nests, during which they have little time for singing, till the weather is somewhat settled. They do not return to the neighbourhood of houses so soon as the red-breasts, so that their song is not so frequently heard in the autumn. 
Another species, the Alpine accentor, grey above, with brown spots, has occurred in England; but it is comparatively rare.

\section{PIPITS. (Anthus.)}

If the natural locality of the birds could be strictly adhered to, the titling would lead to the red-breast and the wren, which are our only sylvan warblers that remain the whole year, and the pipits would follow them, as partaking partly of the characters of the insectivorous birds, and partly of those of the lark; but there is an interesting race of strangers that come in, partaking of the characters of our resident warblers; and as these, though strangers when they come to us in the spring, are really native birds, inasmuch as they are hatched in the country, we must alter the arrangement of those birds which are suited to all our seasons, in order to deal as shortly as possible with these most interesting prodigals, which leave us in the autumn, to return to the feast in our renovated fields and groves in the summer. We shall therefore very briefly notice the pipits.

'Their general characters are more decidedly insectivorous. The bill a little conical at the base, but awl-shaped at the point, with a keel and slight notch on the upper mandible, and much more slender and produced than that of the graminivorous birds. The wings are blunt; the feet well adapted for running, but not having the hind toes and the claws (which are curved) so much produced as the larks, they are not so well fitted for running over long herbage. They nestle on the ground, but sometimes use hair for the lining of their nests, which is seldom, if ever, done by the larks, with which they have been confounded. The plumage of the old birds changes after the breeding season, so as to resemble that of the young, but the change is not very striking. There are three of them ; two resident, and one migrant. 
THE MEADOW PIPIT. (Anthus pratensis.)

This bird, which is a resident, might, with as much propriety, be called the moor-pipit, or the marsh-pipit, for it is found abundantly in places so upland and naked, that hardly any other bird will resort to them. In summer, it frequents the naked places of the moors, where it nestles in the tufts of grass, and picks up worms and insects for itself and its young; in winter it comes down, but still prefers marshy places. Its colour is very sober, and its appearance is as poor as its pasture, while its short and complaining note tends to deepen the impression.

The length of the meadow-pipit is rather less than six inches. The prevailing colours are dark olive brown, with a slight greenish tinge on the upper part, and dull brownish white on the under, with a pale reddish tinge on the breast of the male. The markings above are dull greyish white round the eyes and on the ear-coverts, and lighter margins to the feathers on the back, and scapulars; those on the under part have indistinct blotches of greenish brown, two of which form obscure lines from the gape down to the sides of the neck. Wings very dark brown with dull white margins to the lesser coverts, tail the same, with a white margin on each exterior feather, and a few white spots at the end.

Contrary to the usual habit of birds, the meadow-pipit is more gay in its winter than in its summer plumage. The sides of the feathers above become olive green after the moult, and the under part acquires a yellowish hue.

The moult takes place in the higher and more retired situations in which the birds nestle, and the new plumage, and plumage of the young, which are very like each other, as also are the sexes at that time, and during the early part of the winter, and the birds come to the lower pastures, turnip fields, and sometimes but more rarely to the stubble land, in small flocks, in September and October. At these times, they generally roost on the ground, not so close together as 
some of the other species that have that habit; and as they are different in colour from the more solitary birds that are seen in the spring, and also fly differently, they are a little perplexing to those who do not attend to their annual clanges.

In the autumn they have only their common flight, which is performed by jerks, in the course of which the birds rise and fall, and continue uttering their feeble and complaining " peek." In the course of the winter they gradually acquire more of that brown which may be regarded as the field colour of British birds, and the shades of which vary from dry sand, through all the earth-tints to humid peat; and with the colour (which however is duller than in the true larks) they acquire something of the speckling of the larks; and though they do not soar with the majesty or sing with the power of the lark, they do mount up in a manner different from that which they display at other seasons, and they have not an unpleasant though a feeble song. Their motion in ascending is a curious combination of leaping and fluttering, the wings being perpetually in motion to prevent that descent after the stroke which is so conspicuous in their common flight. The labour of ascending, though they do not go very high, appears to be enough for them without the effort of voice; and therefore they do not sing till they have got to the top of their height, or rather are on the descent, which is performed in an easy sliding manner, and sometimes perpendicular.

That ascent and song are commenced early, as early as those of the lark; but they cannot be mistaken for each other ; and besides, the pipit sometimes lights on a hedge, the sky lark never; the larks remain over the rich fields, the pipets retire to the wilds, and continue their song there. The nest is on the ground in a tuft, the eggs are never more than six, sometimes light and sometimes dark brown with reddish brown specks. The bird runs swiftly, catches insects and worms readily, and is very industrious in the feeding of its own young; and also in feeding the young cuckoo, which, it is said, is often committed to its care. There is one point in the curiously anomalous history of the cuckoo, which has 
not been so well authenticated as the rest, (and these may be the exceptions not the rule, as they are not evidence of one to ten thousand of the cases); and that is whether the male falls into the same dupery as the female, and aids in rearing the cuckoo. The domestic cock scorns to assist in rearing a brood of ducklings, even when they have been hatched by his favourite hen; and it would be curious to ascertain whether the males of those bircls that hatch and feed the cuckoo, are equally zealous for the honour of their species. But the point can be settled by observaiion only, experiment takes animals out of nature; and so there is an end to all legitimate conclusion. The meadow pipit is the titling in many places.

\section{THE SHORE-PIPIT. (Anthus aguaticus.)}

The shore-pipit is considerably larger than the meadow species. It is seven inches long, nearly a foot in the stretch of the wings, and weighs about seven drachms, and the upper part is without the greenish tinge, and the under has a brace of dull ochre yellow. The breast also is browner, the vent whiter, and the bill is yellow at the base. The hind claw is also more curved and shorter in proportion.

This bird, as its name imports, inhabits the sea shores, especially where there are beaches of sand or mud, from which the tide recedes to some distance, and where there are low rocks, or benty downs where it can nestle. In those situations it is very plentiful, though always solitary. It finds the principal part of its food at and within the high water mark; but never in the water except in those shallow pools, which it can easily wade. It has thus a perennial pasture like the dipper in the brawling rivers; and so does not quit it for any other haunt, during any time of the year. Its manners, its song in spring, and its chirip at all times. bear a very close resemblance to those of the last species. It runs with great ease along the sand, picking up its food; and when alarmed, it hops onward with a bouncing flight. In the early part of the season, when most of the shore-birds 
have gone inland to nestle, and the sca-birds also have gone to their farourite rocks and islands, the pipit is almost the only winged creature that is met with upon long stretches of beach; and in passing along during a May mist, when the sea is hissing unseen on the one hand, and the land obscured on the other, the cry of the pipit adds not a little to the melancholy of the scene; but on the other hand, it is pleasant to see so small a bird "bobbing" about and braving the storm in the winter. As the haunt of the shore-pipit changes less in temperature with the seasons than that of most birds, the seasonal changes of its plumage are not so considerable. The nest is formed of bents, or other plants growing near the sea, and lined with finer fibres, or with hair, if its haunts are such that that substance is within its reach. The eggs are not more than five, yellowish grey with reddish brown spots, especially at the thick ends; but there are, from the constant supply of food, and the uniformity of the temperature, two broods or more in the course of the year. The shore-pipit does not frequent the wild and precipitous parts of the coast, neither is it ever observed at any considerable distance from the sea.

\section{THE TREE-PIPIT. (Anthus arboreus.)}

The tree-pipit is so like the meadow one, both in the tints of its colours, and in the marking and distribution, that if they are seen alternately it is not easy to tell the one from the other. But if seen together, they are at once distinguishable. The tree-pipit is larger than the other, and heavier; but it is more compactly feathered, and more slender at the shoulders (the last of these is, by the way, no bad distinguishing mark between the resident and migratory birds-the last always appearing the more slender and elegant), flatter in the head, more produced in the bill, and gayer in the tint on the under part. The claw on the hinder toe is also much shorter, and more crooked, so that the foot is fully as well adapted for perching as for walking, and much better than for walking on grassy surfaces. 
The tree-pipit is a summer migrant, arriving in May, and taking its departure in September. Its locality is intermediate between those of the other pipits, more inland than the shores, and less upland than the wilds. It frequents the rich country; but more on the margin of the woodland than that of the open wild. It has in consequence some resemblance in its habits to the sylvan warblers upon whose domain it borders, and with which it makes its appcarance and takes its departure.

Its single cry, though " peeking," is more musical and less melancholy than that of the other pipits, and its song is also sweeter, and being warbled from a greater elevation, and in places that are more frequented, it is more generally heard. It ascends with the single cry, and sings either perched on the top of a tree, or whilst it is descending. It generally if not always nestles upon the ground, constructs its nest of vegetable fibres, and lines it with finer fibres and hair. But it never builds far from trees; and when the male is in song he generally makes use of a tree as an intermediate station both in rising into the air, and in descending to the ground. By successive leaps, he gains the top of the tree, and after having rested there for a little, he leaps higher into the air in a similar manner, and chirping as he leaps. When he has gained the top of his ascent (which is not very lofty,) he begins his song, and while uttering it, he slides down the air with expanded wing, and tail erected and spread, till he again reaches the tree, where he pauses a little and then descends to the ground in the same manner. Many of the weakwinged birds that feed chiefly upon the ground, have the same habit of getting to a height, and resting a little there before they take their flight from place to place; but there is perhaps none in which it is so marked as in the tree-pipit. That habit does not extend to birds that find their food in trees, but only to those which have the feet better adapted for walking than for perching. That is the case with the treepipit. It can walk or run very easily, and at the same time pick up its food; but when it perches it can do little else than 
balance itself; and those birds which feed in trees have generally just as little command of themselves on the ground.

The part of a tree on which a bird perches is not a bad means of ascertaining whether it be a surface bird or a tree bird. Surface birds, even when they flock, so as to cover the whole top of the tree, akways perch on the top or the topmost part, while tree birds hop into the tree and leap about from one twig to another. The sparrow and the red-breast are familiar, though not the most striking illustrations. The sparrow merely rests in the leafless tree in winter, the redbreast hops about in it as if quite at home. That habit is well worth attending to, especially in the winter, when both tree and surface-birds come near the houses, and perch on the leafless trees.

\section{RIChARD'S PIPIT, (A. Richardi, )}

Has been found in England. It has the tarsi and the hind claw long, and the bill strong. Upper part brown with pale edges; under part, white.

WRENS,

The birds popularly called wrens, have so few appearances in common that they can hardly be described as a tribe, and therefore they cannot be classed according to their structure. But, leaving out a few migrants which are sometimes called wrens, and including the red-breast, to which the name "wren" is never given, a popular tribe, founded on habits, though not in appearance, might be instituted and described. It is not our intention to interfere with names or with classes, but merely to place in juxta-position such birds as have their habits so much alike, that the description of the one may in part serve for the other, and thus save repetition.

The birds which we would include in this popular section, are the red-brast, the common wren, the golden-crested wren, and the fiery-crested wren, more recently added to the British 
Fauna. We do not call them wrens, or have the slightest wish that any body should call them so, but there is a family likeness among them, as well as a similarity in some of their leading habits; and which is not a little remarkable, these are more striking between the common wren and the redbreast than between the common wren, and those other birds that are called wrens. So much so, indeed, that popular opinion, which in such cases is always founded upon observation-habitual and without bias, has "time out of mind" associated Robin Red-breast and Kitty Wren, as husband and wife.

They are both resident even in the very coldest parts of the country; they both breed in retirement, for though the wren sometimes builds under the eaves of thatched houses, it never does so if there are plantations near, thick with underwood and soft with moss; and both come close to the dwelling of man in the winter, though the red-breast, which is by far the most familiar at that season, retires to the greatest distance in the summer. Thus the red-breast so far partakes of the character of the warblers (with which it is often associated) that is more of a woodland and a migratory bird, only it does not emigrate from the country, or appear much to change its latitude, with the seasons.

As both of this species sing very sweetly though not loud, and very early when there are few other notes, and sometimes when the frozen earth rings back again even to their small voices, they are among the most delightful of our little birds, especially in those parts of the country to which the summer warblers come sparingly, or not at all. The goldencrested wren, which is more a "bark bird" than the others, does not with us so often leave its native forests, or seek the shelter and subsistence that are found near the dwellings of men; but as it is without that habit as a resource, it migrates to greater distances, and far more completely during very violent storms.

Violent storms, indeed, often carry to great distances, and in vast numbers, birds, which, in ordinary seasons, can hardly 
be said to migrate, and that is perhaps more the case with the dwellers in the northern forests. In those cases they are literally driven southward or obliquely, as the wind may set; and not only that, but as the wind often changes from the northern to the southern half of the horizon in the course of a winter storm, especially one on the eastern coast of Britain, and when it comes near to the middle latitude, by the cold air from Holland and the northern part of Belgium, " taking the Norwain blast in its wane," the birds are often caught, exhausted in the eddy, and whelmed in the sea, or cast, fatigued and perishing, on the coast between St. Abb's Head and the Spurn. That happens, lowever, only when the snow-drift gives note of its coming, in the intensity of cold; for if it break at once, the birds remain in thcir arctic dwellings, and perish by thousands there. The golden-crested wren is one of those which suffer much in that way.

\section{THE COMMON WREN. (Trogiodytes vulgaris.)}

The wren is not literally a "dweller in caves," as troglodytes imports, but it is a hideling, both in its nidification and in its habits. In winter it comes near the house, and even when snow lies thick upon the ground, it may be seen hopping about under the plants, in the garden or the shrubbery. If there is a pile of wood which has lain for some time, and is not snowed over, it may be seen on the top when the sun comes out, or the day is otherwise at the brightest, but it hops under cover the instant that it is approached. The farm-yard is also a favourite place with it in severe weather, and there it will seek its food very confidently among the domestic poultry and domestic animals. If there are mud walls, very thick hedges, or any other deep cover near the house, it makes that its habitation all the year round, and seeks shelter, in very severe weather, in the same nest in which it has reared its brood. If the weather is more than ordinarily severe, numbers will get into the same shelter, and 
they are often found chilled to death by the cold or suffocated by the snow. At those times, and indeed, soon after the young are reared, there does not appear to be any society among wrens. Not that they evince the slightest hostility to each other, but they are quite passive till the heat of the weather puts them in mind of the labours of the season : and very little heat suffices; for even when the frost is still seen, if the mid-day sun gleam out warmly, the wren will chant his song; and even when the sky is suddenly overcast, he will continue his notes till the snow drive him into some hidingplace.

Considering the diminutive size of the wren, its song is loud, and it is clear and very sweetly modulated; so that, upon first hearing it, one has some scepticism of its being the song of so tiny a musician. It is more clear and heard farther than the song of the red-breast, though that too is a pcculiarly agreeable one, as the young birds come to the vicinity of houses, and renew it as early as they are in full plumage, which is about the middle, or towards the end of September. The song of the wren is not so continuous, but in peculiarly farourable situations and weathers, it may be heard as early as Christmas, or earlier. It is, however, liable to be again interrupted, more especially in those middle latitudes of Britain, where, in the inland places, heavy falls of snow often occur after the new year, and remain till the end of March. There is reason to believe that, owing to culture, drainage, and planting, those falls will not hereafter be so frequent as they have been; but there are remembered instances in which the wren sung in the early part of January, and not again till the middle of April; though, in ordinary seasons, the birds pair in February, and begin their nests in March.

The nest is constructed with much care and neatness, but varied in its materials, and also a little in its form, with the place. Moss, lichen, or withered grass, is the external material, intermixed with wool, if the place afford it. The lining is hair or feathers, according as the one or the other is most 
easily procured. The nest generally has a dome-covering, formed by the birds; but if there is a natural one, they avail themselves of it, and under the lower branches of "backgoing Scotch firs," which are generally rough and hoary with lichen, the nest may be found, constructed of moss, with a lichen roof. The entrance is always at the side, and the approach such, tliat the bird does not immediately enter the nest or leave it. So much has been written on the subject of wrens' nests, that one would be almost tempted to believe that the witches had been consulted as architects; but when there are fifty conjectures to one fact, any body may make descriptions.

The eggs, where the birds are undisturbed, are seldom fewer than six or more than eight; they are of a pure white colour, mottled with small reddish specks. The young return to lodge in the nest for some time after they are fledged; and it is said that while the female is performing the incubation, the male makes a few clumsily-constructed nests for the accommodation of the brood after they disperse too widely for returning to that in which they are hatched. That would be curious if true; but it wants confirmation: and birds are subject to so many casualties in the breeding time, and they are so liable to abandon lialf-constructed nests, that finding a young wren in such a nest, would be no evidence. Wrens nestle in holes and hiding-places at almost all seasons.

The wren is a very small bird, about four inches and a quarter long, six and a quarter in the extent of the wings, and rather less than three drachms in weight. The prevailing colour is reddish brown, darker above and lighter on the under part. The quills and tail-feathers are dusky brown, the former spotted on their outer webs and the latter barred with reddish brown. The bill is nearly the same colour as the dark part of the quills; and the feet, and also a streak over the eye, are pale brown. The bill is rather long, very slender, and a little curved. It has an insect-catching bill; and the bird catches the smaller ones with great quickness, either when they pass or by darting at them. 
In form, the wren has somc resemblance to the dipper; it is short and dumpy, and wears the tail, which though short is very strong for the size of the bird, in an ercet posture. That structure of tail enables it to balance itself, with the centrc of gravity before the points of support; and thus it can drop down, which is its most important motion, with considerable celerity.

THE RED-BREAST. (Sylvia rubicola.)

The red-breast, though it associates more familiarly with men than almost any other free bird, is really a native of the woods. It is unnecessary to describe the red-breast, as every body knows it. It is about an inch and a half larger, and two inches and a half more extensive in the wings, than the wren; but though rather a thick-looking bird, it is not so weighty in proportion to its length, as that proportion (the cubic of the lengths) would give three quarters of an ounce, whilc the bird weighs little more than half an ounce. The bill is short, nearly straight, thick and broad at the base, and strong for the size of the bird. Forehead, sides of the neck and breast, reddish or orange, with grey at the lateral margrins; the upper part alone intermediate between green and brown, and with a tinge of yellow; belly and vent, dull whitc; wings and tail, dark greenish grey, with a reddish brown hue on the middle coverts of the wings, The breast of the fcmale is dull yellowish brown; and the young birds are dull brownish green, spotted with reddish brown, and want the orange red on the breast.

Though it has sometimes been so stated, it does not appear that the red-breast is any where a migrant; and there is no reason to believe that it is an emigrant in any part of Britain, though in countries where the districts suited to its winter and summer habits run in larger tracts, as they do on many parts of the continent, it may range much farther in the course of the year than it does with us. Most birds that are migratory are also social, at least when they are preparing for their 
southward flight; but the red-breast, though very familiar with man, is shy with all little birds, even those of its own species, and also disposed to be pugnacious. It does not appear that they battle for their mates; they are too wary and solitary even for that; but when they have retired to the breeding places, and begun their nests, they "keep their ground" with much resolution.

The nest is on the ground, at the roots of trees, and in other concealed places, formed of the same materials as the nest of the wren, but not so elaborately put together, and without a dome to the nest. If, however, there is not a natural concealment of foliage, the birds contrive to form an artificial one of dry leaves, under which they may reach the nest without the precise spot being known; and when the dam leaves her eggs, she sometimes covers them in the same manner, so that the strewing of leaves mentioned in the old ballad of "the babes in the wood," is true to the habits of the red-breast. Red-breasts, like wrens, often nestle near houses; but, from the caution with which they approach and leave the nest, it is rarely seen in proportion to the numbers of the birds. The eggs are yellowish grey, mottled with chestnut colour, and rarely exceed seven.

The red-breast is not only a very interesting bird, but it is also an exceedingly useful one about gardens, orchards, and shrubberies, and plantations near houses generally. The young birds come first, because they are soonest in condition, their plumage not being changed by a moult, but ripening into its tints, as is the case with many young birds which assume a new livery in the course of their first winter. Thus they arrive in time to capture myriads of insects, when these are alighting to deposit their eggs on the embryo buds; and they continue that labour as long as there is a fly to be found; and when the flies are gone, they attack the eggs. It is highly probable that the common house-fly is the first object that attracts them so near to houses, though they come for crumbs, or any thing eatable that they can pick up, when the severe weather sets in. 
They also render considerable service in the capture of worms. Young earthworms are very plentiful in the earlier months of the autumn; and when the weather is humid, they come out in vast numbers, and are carefully watched by the red-breasts. They approach the worms, or indeed, any prey that is on the ground, by very light and rapid hops; and when they have got within their distance, they pounce on it with great certainty. The worm is seized by the head and beaten against a stone or the hard ground, till all the earthy matter in the canal is discharged, before it is eaten.

By the time that the red-breasts come into the shrubberies and gardens in the autumn, the flies have become rather dull and heavy in their flight; and thus the birds can pounce upon them with not much more difficulty than they find with the worms, whose sense is so acute, that they would escape even at the concussion produced by a red-breast, if it were to alight close beside them from the wing. But in summer, the capture of flies is a little more arduous; and when the bird observes one upon a leaf, it hovers round and round, somcthing in the same way that a buttcrfly does round a flower, till it has got near enough for making its pounce. At that time also, worms form a considerable part of the prey; and as the young birds are rather numerous and grow fast, the labour of the old ones is incessant. Though shy to his neighbours, the male is very attentive to his mate, never goes to any great distance, and continues to encourage her with his song during the whole period of incubation.

THE GOLDEN-CRESted Wren. (Regulus auricapillus.)

A figure of the golden-crested wren, the male in full plumage, is given on the opposite plate, on a scale of one-third of the natural dimensions. The female has the colours of the crest paler, and a greenish tinge over the whole body. It is rather shorter than the common wren, though a little longer in proportion in the wings, and only about half the weight, being lcss than a drachm and a half. It is the smallest of 
British birds, but it is one of the most aetive, and one whieh endures the winter better than very many larger birds. It is a forest bird, nestling in trees, residing on them, and not paying an annual visit to the neighbourhood of houses, like the eommon wren. Its bill is very slender, straight, and awlshaped; and it is presumed that, at all seasons, it feeds upon insects. Indeed, there is little vegetable food fitted for so small a bird in the places which it chiefly inhabits.

It is found in all wooded parts of the country, rather plentifully in most places, and very much so in the larger pine forests, which are its favourite haunts, though it is not confined to them. But it is so small, generally so far from the ground, and always so quick in its motions, that it is not easily seen, and never long at a time. It is continually hunt. ing both on the rough bark of the boles and main branches and on the twigs; but it appears to prefer the latter. The command which these little birds have of themselves in the trees, is really astonishing. They whisk about more like meteors than like beings of solid matter. They are now on this side, now on that; now above the twig, now hanging inverted under it - the body never at rest, and the head having generally an additional motion.

The male sings early, though the time of the year of eourse varies with the season. In warm situations it sings in February, and the young are sometimes fledged in April. The nest is not very easily diseovered, as it is always in a thick branch if in a pine forest, and if in other trees, it is in a elosely-tufted place, or between ivy and the boie, where that exists. The birds enter to the nest under the branch; but they enter the nest itself at the upper side, as it is never (at least in the pine forest.s) eovered by a dome, but is in the shape of a cup, very deep, and neatly constructed; green moss forms the external part, and is sometimes interwoven with wool, when that is within the range of the birds. The interior is very small feathers, but in considerable numbers, so that the eggs can hardly be seen. The eggs are numerous, sometimes as many as ten or eleven, but not mueh larger than peas. Whether it 
be owing to the number of the brood, the uncertainty of finding a regular supply of food during the early season at which these little birds begin to breed, or to some other cause which has not been ascertained, has not been made out; but it is true that more nests and eggs of the golden-crested wren are left to perish, apparently from the death of the mother, than of almost any other species of British birds. On that account, as well as from the number of the birds that die in severe winter's, more especially in the deciduous forests, which do not afford the same shelter as pines, the increase is by no means in proportion to the number of eggs. Golden-crested wrens are also liable to be driven, en masse, from their habitats, by severe winters; and there are recorded instances of vast flocks, evidently continental ones, being stranded on our eastern shores, as well as the native ones being driven from their northerly liaunts with us for an entire season; or rather as being swept from those haunts, not to return, but to be replaced by a fresh colony from the north; as the birds, in those cases, re-appear in the autumn-a time at which there is no northerly migration in our hemisphere.

The birds are, however, so minute, and generally so hidden among the branches, and shift about so much, that they are not easily seen even in places where they are abundant. They are, however, so beautiful and so lively in their action, that they are well worth looking for. That is best done with a small pocket telescope, an instrument which no accurate observer of the forms and actions of the smaller birds should be without. By its means, the birds may be seen without the least alarm or disturbance, and all the tints and markings may be as well made out as if the bird were in the hand, at the same time that it is showing all its attitudes with that perfect freedom which alone can bring out its true character. That applies to all birds, but more especially to those that inhabit trees, and pass the greater part of their time in hopping from twig to twig, and seldom come down to the ground, or take long flights in the air. 
THE FIERY-CRESTED WREN. (Regulus ignicapillus.)

This species which, though by no means uncommon on the continent of Europe, is a very recent addition to the known birds of the British islands, is resident as well as the other ; and though it has hitherto been observed only in some parts of England, as in Cambridgeshire and Sussex, it is in all probability pretty generally diffused, and may have, in many instances, been confounded with the former.

The discovery of it as a British bird is in itself rather a curious matter, as the honour of it belongs to a cat, in the possession of a gentleman at Swaftham. Puss and her master are both fond of birds, though for different reasons, no doubt; but puss studies her master's interest as well as her own, and affords another proof that the feline race are, by a little attention, fit for other purposes than mere mousing. The old prejudice that "cats are attached to places only," which, though a vulgar prejudice, is not of popular origin, meets with contradiction every day. One would not formally lay it down as a maxim, though in truth it has very much the force of one, that " the more carnivorous any animal is, it is the more gentle and docile if you only keep its hunger satisfied." Even among men, beef..eater's are proverbially goodtempered, if they get their beef; and parched lentils and potatoes certainly raise the malignant and murderous passions, more than beef-steaks or black-puddings, in spite of the poetical allegation that " he who feeds on blood must be cruel."

Well, the cat in question is a very notable bird-catcher. At first, no doubt, for the supply of her own appetite; but her master and she now so well understand each other, that when she catches a bird she brings it to him. If it suits his purpose, she is fondled or fed; and, if not, the bird is returned to her and she does with it as she likes. In that way she brought the fiery-crested wren to her master, a young bird, and just at the season when the young, if 
hatched in the country, would have begun to fly. That afforded a hint, which was followed up; the old birds were observed in the neighbourhood, and very soon after they were observed near Brighton; and altogether there is no room for doubting that they are native and resident birds.

Hitherto they have not been seen in the northern parts of the island; and their history, as a species, is rather too short for furnishing any satisfactory data as to how they and the golden-crested species may divide the land. The probability is, that the fiery-crested is less an upland bird than the other; but that is only a probability.

No question that the two species have been often confounded, as their size, habits, and general appearance, are very much alike. But upon a closer examination, the specific differences appear. The crest, which is golden-orange in the one, is bright fire-red in the other. The golden-crest has one black streak along the margin of the crest; the fiery-crest has three, alternating with two white ones. The yellow on the shoulders of the golden-crest has a greenish tinge; that on the fiery-crest is pure or inclining to orange. The bill of the fiery-crest is rather stronger and broader at the base, and the size of the birds is a shade larger. The manners and habits of the two are so nearly the same, that in discriminating them it is necessary to pay particular attention to the tints of the crests, and especially to the stripes above the eye. The two lastmentioned species are the "pets" among our resident forest birds; and it will be a pleasing office to " settle the boundaries" between them, and find out the portion of the country which the newly-discovered ones can claim as their rightful heritage; and if the observations necessary for that purpose are properly carried on, fresh discoveries may be confidently expected, as the birds in question are so minute, that where they are found, no others are likely to be passed over. 
the dartford warbler. (Sylvia Provincialis.)

The Dartford warbler might perhaps more accurately be called, "the brake warbler;" as it is not quite correct to name after one place in England, and that not the place where it is most frequently seen, a bird which is more abundant in Spain, Provence, and Italy, than in England. Though generally classed with the warblers, and resembling them in some of its characters, it differs in others; and the points of difference are certainly more numerous and at least not less striking than those of agreement.

This bird has been observed only in the southern counties of England-those that lie southward of the Thames and the Bristol channel; but as it has been observed at points widely distant from each other, and as its immediate haunts and its habits both tend to concealment, it is probable that the actual numbers are very great in proportion to those that have been seen. The birds have been seen only on dry places, in the neighbourhood of bushes, more especially close furze-bushes, under which they nestle, and through which they glide, with apparently as much facility, and not much farther from the ground than mice. Nor are they very unlike mice in colour. The whole upper part of the body is dark reddish brown, with dull grey on the cheeks, and a trace of the same on the sides of the neck; the throat and breast are brownish red, passing into deeper on the under part, but with a line of white on the middle of the belly; the quills and tail feathers are dusky, relieved with rusty brown on the margins of the webs, except the tips of the exterior and second feathers of the tail, and part of the outer webs of the former, which are white; the bill is pale yellow at the base, and black at the tip; the irides and naked spaces round the eyes reddish yellow; and the feet dull yellow. The colour of the female is a little duller: and the young have the throat and breast streaked with white, which gradually wears off as they advance to maturity.

The length is about five inches and a half, or an inch more 
than that of the common wren; but the tail, which is straight and wedge-shaped, takes up fully half the length, so that the body is not longer than that of the wren, and it is more slender; the extent of the wings is also less, and the whole bird lighter, being only two drachms and a half. There is a faint trace of resemblance to the wren in the shape of the body, but none in the head, neck, and tail. The head is rounder; both that and the neck are more darkly feathered, the bill is less produced and less pointed, and the expression is not so lively as that of the wren. The form of the head and tail, as well as the expression of the bird, are however less like those of the true warblers.

The nest is not placed immediately on the ground, but in the very thickest part of the bush, which, in furze-bushes, is higher or lower according to age and other circumstances. The materials of the nest are chiefly vegetable: the withered spines of the furze, and other small vegetable bodies, sometimes united with a little wool, and lined with the withered culms of the small hard grasses which grow on the dry wastes; but it is rather loose and rude. Indeed, the care with which it is concealed and sheltered, render the structure of the nest a matter of minor importance. The eggs are four in number, of a greenish colour, marked with olive brown spots. The nests have been observed only late in the season (July), but it is possible that these may have been second broods.

The male often hovers about the bushes, uttering his chirping song, which is rather feeble and hurried for being called a genuine warble. The height at which that is done is inconsiderable; and from the thickness of the head and neck, the long tail, and the short and rounded wings, the bird bears then some resemblance to a large dragon-fly. The glass must be used in observing it; for if one venture near, he instantly drops into the bush, where it is vain to search for him; and the alarm note which he then utters, is not very unlike the cry of some of the field-mice. The well-feathered body, the short wings, and the long tail of these birds, 
enable them to thread their way among the close bushes witl great celerity, whether the sinuosities be vertical or lateral. Grasshoppers, flies, and the smaller moths, are understood to be their chief summer food, to which, perhaps, the seeds of the furze, after they have been softened by lying for some time on the ground, may be added in the winter, as the birds do not appear to quit their haunts; at least, they have been seen on the furze-clad places as late as Christmas; and, though they vanish during very heavy falls of snow, it is probably only by retiring into the thick bushes, where the seeds alluded to may supply them with food. At all events, their structure is not well adapted for long migrations; and they do not resort to the neighbourhood of houses during severe weather.

The Dartford warbler is one of those birds of which the habits require to be more carefully studied; and when that has been done, and an arrangement of birds founded on their structure, haunts, and habits comes to be formed, it will probably be found advisable to drop the name, both parts of which are calculated to mislead. The white-throat warbler nestles in a manner somewhat similar; and has some analogous habits, but the form and character of the two birds are quite different: the shape of the body in the white-throat is well suited for long flights; that of the Dartford warbler is the reverse. Barnes Common is not the worst place in the vicinity of London to search for these local birds.

\section{The Grasshopper warblet. (Sylvia locustella.)}

Though this bird is called a warbler, and has latterly been classed with the aquatic warblers, it is not, if names and classifications are to have any meaning, either the one or the other. It does not warble, or so far as observation has gone, utter any sound save a hissing chirp something similar to that of the grasshopper or the mole cricket, whence it has got the name of the former of these insects. Neither is it an aquatic bird, though it may sometimes be heard in thick 
bushes near water. Hedges and brakes are its favourite resorts; and its nest is usually hidden in the very closest bushes upon dry places. Its tail is wedge-shaped in the same manner as that of the aquatic warblers; but the wedged tail is not an aquatic character, but one which adapts the bird to glide easily through thick foliage. The dipper, which is much more aquatic than any of the warblers, as it feeds in the water, has the tail square; and the aquatic warblers have their's wedgeshaped, to adapt them, not to the water but to the thick aquatic vegetation in which they chiefly reside. The woodpeckers, the creeper, and indeed all birdș whose habit it is to thread their way among close twigs or thick foliage, have the tail wedge-shaped or rounded; and that gives them the same facility over birds with forked or square tails, in turning laterally, that a vessel with a round stern has over one that is square.

When birds are classed upon any particular character, the name should apply to the use of that character, otherwise it either has no meaning or a false one. In some of the books, the bird under consideration stands classed as a lark, and that name, which was no doubt given to it from the slight similarity in the mottled plumage on the back, induced some of the older authors to add also the produced hinder claw of the lark; but that claw of the grasshopper bird is short and crooked, well adapted for perching upon twigs, but not for walking on the ground. A long straight claw would be as inconvenient in close bushes as a forked tail; and no bird whose habit jt is to thread the sprays has either the one or the other. Even in the larks and pipits, the round or partially wedged termination of the tail, at once distinguishes the wood lark, or the tree pipit. The end of the tail and also the tips of the wings are always good indices to the general haunt. If the tail is wedge-shaped, the bird is woodland bred, or rather a bird of the close sprays and bushes, and in that case, the wings are rounded; if the tail is square, the haunt is in more open places, and if much forked, it is in the free air, and the wings are pointed. 
The grasshopper bird (" the brakehopper," would not be an inappropriate name for it) differs from the aquatic warblers, and indeed from all the true warblers, in plumage and expression as well as in haunt and habits. The true warbler's, whether aquatic or sylvan, have the colour on the back entire, even when there are strong markings on the other parts; but the upper part of the grasshopper bird is mottled brown, and the whole dress has a tinge of that hue which characterizes the field birds. When all together, however, it is not like any of them; but stands alone, in appearance, in roice, and in habits. There can be no harm in callinig it Sylvia, because that name may include birds of the brake as well as the tall forest; but Curruca which some have used, is not very appropriate. Names that have no precise meaning may be used in any way; but error is always the consequence of an unskilful use of significant ones.

The grasshopper bird is about five inches and a half in length, and rather more than seven inches in the stretch of the wings. The bill is a little more produced, and passes more immediately into the line of the forehead than in the sylvan warblers, but less so than in the aquatic. The bill is dusky above and dull white at the base of the lower mandible. The irides are hazel, the legs pale brown, and the claws, which are strong, sharp, and hooked, of the colour of dark horn. The upper part has the centres of the feathers dusky, and the margins brown with the least trace of green, which brings out each feather distinctly. The tail and primary quills are the same a shade darker; and the middle of the wing rather lighter, with a faint trace of yellow. The sides of the neck and the breast are pale yellowish brown, which brings out the forepart of the closed wing. The colour passes into greenish white on the belly, and there are a few lines and spots of pale brown on the vent feathers and under tail coverts. A dull whitish streak extends from the gape to the eye; and there is a gorget of the same colour on the chin and point of the neck, which is better defined by being margined with pale brown spots. In the female, the colours 
are duller, and the gorget on the breast is not so well defined. The forepart is very thickly, and the whole bird very closely feathered, presenting no point that can be broken, and no place that can be easily ruffled on a forward motion; so that the bird slides unhurt through places where birds of different form and plumage would be torn to pieces. The closest hedge or brake presents no barrier to it; so that it slips into the hedge one knows not where; and threading along without stirring a twig, it will apparently in an instant slip out again at the distance of several yards. It does not often leave its cover; and one may watch and even beat the brake, hearing it, but without being able to see either it or its nest, for the nest is as well hidden, as the bird is expert at hiding. In position, the nest is very similar to that of the Dartford warbler (or rather the "furze warbler," as that leads one to its haunts, and it is not met with in Dartford) ; but as it inhabits wilder places, the materials are not quite the same. In the hediges and branble brakes, the materials are the withered stems of trailing plants; and in furze bushes, where those plants are not so abundant, they are more mossy. The eggs are four or five, of a bluish white, with very obscure rust-coloured mottlings.

The males arrive on the south coast of England about the middle of April, and gradually proceed to distribute themselves over the lowland and warmer parts of the country, though they are always most numerous in the counties on the south. That is the best time for seeing them, as they then perch on the tops of the brakes and hedges, and utter their cricket.cry, which is their only song of love. When the females arrive, and the nest-building begins, there is no more perching on the top; but the cry continues till about the beginning of August; and as the moult is probably completed in that month, the birds may take their leave of us about the beginning of September.

That the whole of our summer visitants moult in the very hottest month of the year, is a point which, duly worked out, would throw much light on many of the habits of birds, and 
more especially upon the relation between the economy of nests and the progress of plumification. I would offer a few hints, but one of our ablest practical physiologists, whose demonstrations, I am proud to say, have in many instances verified conjectures at which I had previously arrived by virtual analysis, has taken up and demonstrated the same view, but has not yet published it; so that I can only recommend the reader to notice the connexion between temperature and the growth of feathers, and also the influence which light has upon eggs. There is a corroborative circumstance in the human body: the hair and nails grow faster when the body is leated, as in fever, than when it is cool.

The obscurity to the sight, and the very peculiar note of the grasshopper bird, give it very considerable interest; and the resemblance which the note has to the sounds emitted by the grasshopper and the mole cricket, often lead to the belief that the bird is in situations which it never visits, and vice versis.

All the jarring and hissing notes of birds, which probably partake of the nature both of love-calls and of hunting cries, have something peculiar in them; they are in so far allied to ventriloquism, that one cannot tell very readily from what precise direction they come. That is one of the reasons why the grasshopper bird is so seldom seen; it appears to $\mathrm{cl}^{2} \mathrm{y}$ in one part of the brake, while it is really in another; and the same thing happens with the crake in the corn-field, the nuthatch on the tree, and several other birds. The direction of the sounding body, whether a bird or any thing else, or, indeed, even the fact that there is a sounding body, is not an immediate perception of the organ of hearing, but an act of mind founded on experience; and that easily explains what is called ventriloquism, (an absurd name, by the way,) either in man or in birds. Men acquire it by pitching the tone and quantity of the voice to those of an echo returned from the distance of the object from which they wish the sound to appear to come: they do that by measuring the distance with the eye, just as a speaker does when addressing some particular

VOL. I. 
person in a crowd; in which case the tone and quantity of the voice alter, and that person hears better than even those between him and the speaker. But the distance can also be measured mentally, as sailors who have come to the buoys in a fog, can " halloo a harbour" to the pilot. The voice of the birds is instinctive; but it is also made up partly of echonotes, in all cases where it is ventriloque, or varies in apparent place, while the bird remains in the same; and it is a curious property of those echo-notes, that they cannot be well returned in a real echo.

\section{WARBLERS. (Curruca.)}

Though all the little birds are interesting, as associated with nature, with innocence, and with beauty, there is a peculiar interest about the warblers. The birds which remain constantly with us, and come round our dwellings in the inclement season, give that season sprightliness by their appearance, and hail with their songs any warm day that breaks out. But the constancy of their appearance takes off some of the interest which, if they were as novel as they are beautiful, they would more certainly command; and as their songs, breaking out as they do in the intervals of the storms, are no certain signs that the life of the year has begun, we do not listen to them with the same attention and satisfaction as to the migrant warblers.

The song, or the other demonstration of spring, given by the resident bird, tells us merely of the state of the season in our own country, of which we have other means of judging; but the summer or rather the spring migrant brings us tidings from afar-intimates that the plains of Africa are burned up with drought, or that the season of growth is adrancing in the south of Europe, and will speedily reach us. They are visitants from afar, but they are not strangers; they are our own native birds, that retired during winter, leaving the groves, the fields, and the river banks to other races, driven from our own wilds, or from more inclement regions 
further to the north, so that in the season of penury there might be plenty for those whose structure and powers did not adapt them for flights so far to the soutliward; and now, when the time of plenty is again coming round, and vegetation is approaching that state in which there is danger to it from those creatures on which birds feed, they return to resume those labours which are alike useful, and those songs which are alike cheering, to themselves and to us.

They come also to be our near associates, when those that we had with us in the winter are beginning to seek their way to the woods and the wilds. All the warblers love shade and shelter; but with few exceptions, they seek these among the cultivated lands, or close on their margins. Some are in the grove, others in the coppice; some by the sedgy stream, or the reedy pool, and others in the brake; but they are not found on the wide waste, or in the upland forest; and, generally speaking, man always partakes in the benefit of their labours, and may hear the melody of their notes. The spaces over which they extend vary, and so do the characters of those places which they most frequent; but it is a general rule, that where the air is most pure, and the soil most fertile, and in the highest state of cultivation, there the warblers are found, in the greatest variety of species, and the greatest number of individuals. Even their voices partake of the characters of their localities. The nightingale sings more sweetly over the gravel in Surrey, than over the clay in Middlesex.

There are considerable differences of appearance in the warblers, answering to the haunts in which they are found; but there seems a general likeness through all the genera. They are delicate in their outlines, without any of the full or abrupt curves that are found in many other genera. Their plumage is delicate, and, though there be some exceptions, their colours are subdued, and without any very strong markings or contrasts. The feathers on the shoulders and the wing coverts are short, so that the wings are light. Their whole expression is soft, but not dull; and their manners, though gentle, 
arc rather sprightly. They have not, indeed, any organs which can be regarded as offensive weapons: their bills are tender, suited only for the capture of insects and their larvæ, or for bruising berries or other small pulpy fruits. They are not all song-birds, but they comprise the finest of our songsters, and their notes run rnore on the minor keys than those of any other birds.

Their general characters are: the bill of moderate length, straight, slightly awl-shaped, a little compressed at the base, and the upper mandible with a small bend and margin at the tip. Feet with three toes bcfore and one behind ; the outer one articulated on the middle one, so as to be capable of perching upon very slender supports. The first quill of the wing is very short, and in some species merely rudimental; the second and third are nearly of the same length, which gives the wing a blunt appearance. The tail is of moderate length, but strong in proportion to the size of the birds; in some wedge-shaped, in others nearly even, and in others again slightly wedgeshaped; but, in all cases, without any sharp points when spread. There are two divisions of warblers, aquatic and sylvan, which are easily distinguished by their appearances, as well as by their haunts.

AQUATIC WARBLERS.

Of these there are two; the sedge warbler and the reed warbler : they are little birds, and summer birds only.

Their general appearances are,-the forehead low; the body long and slender; the tail strong and wedge-shaped; and the prevailing colours brown above, and yellowish white on the under part, without strong contrasts in any part of their plumage. While they residc in Britain, they frequent the reedy or sedgy banks of stagnant pools and slow running rivers, or the bushes and brakes in the vicinity of such places. They do not range far from their nestling places, neither does it appear that they flock previous to their departure in the autumn. 


\section{THE SEDGE WARBLER. (Curruca phragmitis.)}

The sedge warbler, called also the sedge bird and the sedge wren; but it has no other resemblance to the wrens, properly so called, than being about the same weight as the common wren. It is about five inches and a half long, rather more than seven in the extent of the wings; the head slender, the bill pointed, and the tail wedge or lancet-shaped: the whole well fitted for gliding between the tall aquatic plants, among which it chiefly resides and finds its food.

The colours are sober; brown on the upper part, with a slight tinge of olive; the quills and tail darker, and the edges of the feathers relieved with rusty. The side of the head is peculiarly marked, and is an easy means of distinguishing the sedge warbler from the other small birds which haunt similar places: a white streak proceeds from the line of the upper mandible over the eye, and a pale brownish one from the eye a short way down toward the side of the neck, so that the two have a faint resemblance to the letter $\mathrm{Y}$, with the bottom above the gape, and the fork at the eye. The parts immediately adjoining are deep brown; the chin and throat are dull white, which passes into dull brownish yellow on the breast, and becomes paler again toward the belly and vent; but, with the exception of the streak over the eye, the colours are all softened into each other. The bill is dusky at the tip and on the upper part, and whitish at the base on the under; feet dusky brown, and the claw on the hinder toe rather short, but hooked.

The sedge warbler arrives in England about the middle of April, and silently, but in considerable numbers, takes possession of the sedgy and reedy banks of streams and pools, of osier holts, and of shrubs and bushes on the edges of marshes and moist places. It does not inhabit the very high grounds, but it appears throughout the whole range of England, and partially, though perhaps only as a straggler, in the southern parts of Scotland. 
It is not a loud songster, but it is a very constant one; and though it sings best in the morning and toward night, it may be heard at most times of the day, and not unfrequently during the night. Its song is hurried, but varied, not so much in the single stave, as in its having several of them, which would lead one to imagine that there are different birds : they have been compared to the notes of various other birds, but the resemblance is not close. It sings in the throat, and gives a sort of guttural twist to all that it utters. It sings from within the reeds or the bush, from the top of it, or when it is leaping from one bush to another.

The mode of building depends something upon the locality : if among reeds, it is united to two or three of these; if in a holt, where the young osiers do not afford convenient forks, it is on the side of some stool that stands above the flooding of the place; if in $\dot{a}$ bush, it is placed in the centre; and if the only cover for the bird be rushes, the nest is placed in the centre of a tuft. The materials are vegetable fibres and moss, with occasionally a few hairs, if the locality can supply them, which is not often, so that the chief lining is fine fibres of dry grass or roots. The eggs are five or six in number, of a light dull brown, mottled with darker spots of the same.

So far as has been observed, its food consists chiefly of those winged insects which frequent humid and watery places, which it captures by leaping from its perch; but it probably also picks up larvæ from the leaves, although its feet are not so well adapted for giving it command of itself upon very flexible ones, as those of the next species.

\section{THE REED WARBLER. (Curruca arundinacea.)}

A figure of one-third of the lineal dimensions, is given on the plate opposite, by which the bird can be readily distinguished from the sedge warbler. The upper part is brighter and more uniform brown, and the under part more inclined to yellow. The streak on the cheek is obscure, and extends only to the eye. 


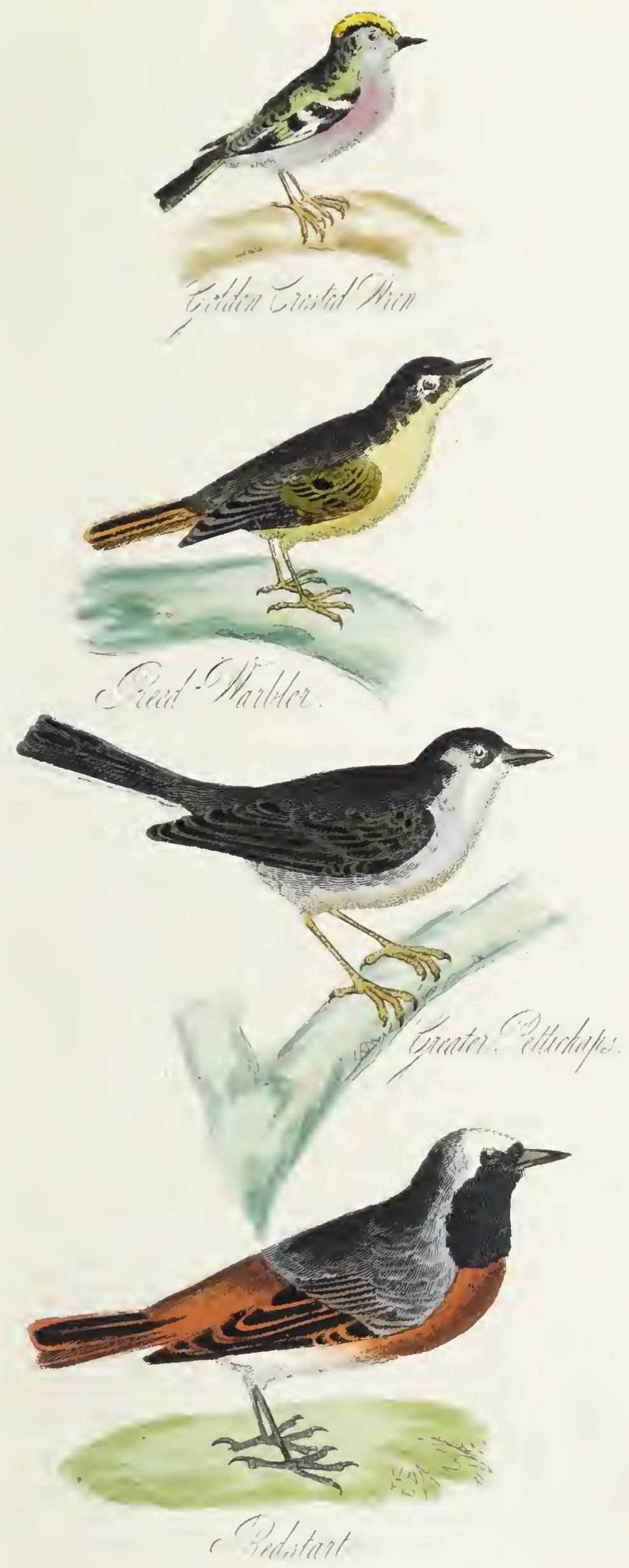



This bird, which has sometimes been called the reed-wren, comes rather later than the other, and is more confined to the southern parts of England. It is also more exclusively an inhabitant of reedy places, at least in the breeding time; for it is a more active bird than the other, and sometimes approaches houses before its final departure.

The nest, which is always fastened to reeds, flexible upright twigs, or upright stems of some kind, is constructed of vegetable matters, well united together, and very deep, so that it can bear to be rocked upon its bending supports without ejecting the bird or the eggs. The eggs are four or five in number, but they are easily distinguished by their colour from those of the sedge warbler, even though the nests should be found in similar situations. The egg of the sedge warbler is smaller than that of the reed warbler, and generally a pale and nearly uniform brown, or with very obscure mottling; that of the reed warbler is very pale greenish white, closely mottled with darker green and brown.

The note of the reed warbler, though decidedly a warble, consisting of a melody of several hurried notes, is a very subdued warble, and heard only at short distances.

That the bird is not adapted for so many situations as the sedge bird, might be inferred from the different form of the tail; it is more produced, and not wedge-shaped; so that while it answers better as a balance on the bending reeds, or other flexible aquatic plants, it would not be so convenient among the unyielding sprays of a hedge or brake. The bird rarely, if ever, perches on the top of the reeds, even on its first arrival, and when the song of invitation to a mate is given, its place is on a leaf, or on a leaning stem, though, upon emergency, it can cling to an upright one, the stiff feathers of the tail acting as a sort of prop. It is not easily raised, and remains a very short time on the wing; but it is by no means timid on its perch, upon which, if very flexible, it sits with its wings not quite closed, but recovered, so as to have a little hold on the air, and thereby either prevent its fall, or be ready, when a gust comes, to bear it to a more 
secure footing. Its food is found wholly over the stagnant waters.

By no means the worst place, in the neighbourhood of London, for observing the habits of this local and very interesting bird, is between Shepherd's Bush and Hammersmith. The soil there is a retentive ague-provoking clay, which has not been improved in any thing-save perhaps the herbage during drought, by the oozings of the Grand Junction canal on the height to the north. The ground there has been much dug for brick earth; water stagnates in the excavations, and soon becomes thick with reeds : those reeds are useful to the brick." makers in covering the "hacks" and "clamps" of bricks, as a protection from rain, and also from wind, which would make the clamp burn unequally: and thus the reeds are cherished as a crop. The warbler does not come till the reeds are considerably advanced, and it departs before they are cut ; so that it dwells in peace, and, especially in the mornings about the end of May and the beginning of June, it may be observed with the greatest ease.

\section{SYLVAN WARBLERS.}

These excel the tenants of the marsh in their size and the power and melody of their songs, as much as the forest and the grove, from which the majority of them sing, rise above the brakes and beds of reeds. They are not equal to many other birds in the brightness of their colours or the liveliness of their motions; but there is a softness in their plumage and a gentleness in their expression, which at once distinguish them from the resident birds which they resemble the most in shape and colour.

With the deductions that have been made in the birds that have been described, there are about nine species of warblers. They are all summer visitants, nestling with us, and being consequently native birds. They are also frequenters of the warm and rich lands, more numerous on the southern part of the island, and the greater part rare, or only occasionally 
straggling into Scotland, and rarely found in the more mountainous parts. The only one which has a name in the original language of the Scotch Highlands, is the red-start. Some prefer the close forest; others the copse; others again, the hedges; and others still, the wild bush : though of those that sing and seek their food in thick trees, there are some that nestle on the ground, but always in shady places, or otherwise under cover.

Their general characters are,- the bill more slender, and the forehead more rounded than in the aquatic warblers; the throat full and inflated while singing; the tarsi and toes slender, and the latter with the claws considerably crooked, and much better adapted for perching than for walking. The wings longer, and not so much rounded as in the aquatic species; the tail in general longer than in the aquatic ones, but not so much fortified by coverts, and rounded square, or slightly forked, (rather lobed) according to the haunt of the species.

THE RED WARBLER. (Curruca phœnicurus.)

As might be inferred from its boldly-contrasted plumage, which, though the cause has not been satisfactorily investigated, is always in the inverse ratio of the power of song, the red warbler (called, from one of its habits, red start, ) is not the finest songster of the warblers, ) but it is one of the earliest visitants, and one of those which, though not the most abundant perhaps in any locality, is most generally distributed. It is found in the richer parts of the country, and in woods; but it is not confined to those parts, and the wood is not its peculiar abode.

A figure of the male in summer plumage, one-third of the lineal dimensions, is given on page 318 , from which it will be very easy to recognise the male bird. The remarkable expanding and closing of the tail, which is rapidly and also very frequently done, is another character which taken in conjunction with the colour, cannot be mistaken. 
The female is also easily known, though very different in plumage from the male. The upper parts are brown, the head and sides of the neck a greyish tinge, and the back yellowish. The rump and tail reddish orange, except the two middle feathers, which are brown; but neither colour is so bright as in the male bird. The throat where the black is in the male, is a pale reddish white, which passes into pale reddish orange on the breast and flanks. The light streak over the eye is dull in the female, and does not reach farther back than the eye. The young males have the breast mottled with the colours of both male and female; but it is probable that the colour changes without a moult, although in the same feather: upon mature birds, the change to a darker colour is less frequent than that to a lighter one.

The red warbler is altogether about the same length as the red-breast, a bird to which it bears a slight resemblance in its general air; but it is longer in the body, considerably more slender, and better adapted for long flight. In form, as well as in colour, it is one of the handsomest of our summer birds, and it is at the same time one of the most interesting in its manners. It is lighter than the red-breast, weighing less than half an ounce. Its tarsi are shorter in proportion than those of the red-breast, which mark it more as a bird of stony places, as these in general have the tarsi short. The time of its coming varies; sometimes it appears in March, and sometimes not till the middle of April.

Its habits are peculiar; and though very lively in its appearance and motions, it is the bird of ruins in the warmer districts, as much as the wheat-ear is the bird of sepulchral cairns in the wilds. Deserted houses, mouldering walls, and the hollow remains of trees, are its favourite nesting places; the nest being formed of dry moss or grass, lined wholly or with a mixture of hair or feathers. The eggs are numerous, sometimes as many as eight. They are of a very light, but clear greenish blue.

The bird is both familiar and shy: familiar as to general hunting place, for it visits gardens and courts, and even the 
close vicinity of towns, and the squares and less frequented streets. But it is continually hopping about, so that it is not easily got sight of ; and that has led to the supposition that it is not so generally diffused as it really is. The "blink" of reddish orange displayed by the flirt of the tail, even when there is not time to notice the peculiar motion of that organ, is, however, sufficient to distinguish it from every other bird.

Its song is sweet though plaintive, and has some resemblance to that of the nightingale, only very inferior in compass and power, and audible only at a short distance. The song is uttered from the perch, on a ruin, a tall post, the trunk of a blasted tree, or some other situation from which it can see around it; and one who has heard the plaintive strain of the redstart from the top of a ruined abbey or crumbling fortalice, would be inclined to call it the bird of decay, rather than the "wall-nightingale," as Buffon did. It is not a nightingale at all even in time, for it usually begins its song about the time when that of the nightingale ceases. Early morn is its favourite time, but not till the dawn has made considerable advances. When the males arrive, they sing from elevated perches; but after the operations of nesting are begun, he sings lower, and always within a short distance of the nest. Among other birds, his song is not always easily detected, for he is partially an imitator of other birds. The flirting of the tail is accompanied by a very short and plaintive chirp. From the habit which both birds have of hopping about, the nest is not easily discovered, even though it be known to be near; and when it is discovered, considerable liberties may be taken with it, without making the birds desert it.

As is the case with most of the other warblers, the red warbler lands on the eastern portion of the south coast of England. The flight of these migrants is rather from the south-east than on the meridian-by the valley of the Seine rather than from Brittany; and they do not land much farther to the west than Dorset, and indeed, chiefly in Kent, Sussex, and Wilts, and partially on the east coast as far as about 
Yarmouth. The high grounds in the midland countiss divide them, and the eastern divisions are in a great measure stopped by the heights in Yorkshire or on the borders of Scotland. The western divisions, which are fewer in number, pass by the valleys of the Severn and Dee; and as the climate is more humid and productive of insects in Westmoreland and Cumberland than on the corresponding parts of the eastern coast, they straggle farther in that way; and though interrupted by the hills in Dumfries and Galloway, some of them gain the valley of the Clyde, and probably pass that way into Lothian, and even farther to the north. Of course these observations do not apply equally to all the warblers; but they do apply to the redstart, which follows the line of the stony places on the margin of the rich lands; and, unless there are decaying trees, it avoids the level and dry plains.

Its food consists of insects and larvæ, especially the larvæ of coleopterous insects, and the other tenants of crumbling stone and rotting wood. When these are thinned by capture, maturity, or drought, the birds (which have generally then reared their broods) come to the garden and gather soft herries and other small summer fruits. Insects are, however, the principal food of these birds; and their bills are not well adapted for bruising the harder seeds, although, being, like those of the red-breasts, more enlarged at the base than those of most of the other warblers, they are probably more capable than those living upon vegetable diet.

Besides its singular vibrating motion, which appears as if outwards and inwards, upwards and downwards, all at the same time, the tail is a curious organ, and aids in very peculiar leaps or short flights. When completely shut, it is rounded at the extremity, so that the bird can thread intricate places, as the brake birds do. When opened a little, it is slightly forked, or rather terminates in two circular lobes, so that the bird can wheel in the air; and the sort of rotatory motion that it has, and the oblique positions in which it can be exerted, enable the bird to change into an echellon motion, the result of which is forward, sideways, and upward or downward, 
all at the same time. The straight-forward flight is rather rapid, and all the motions of the bird are graceful.

$$
\text { THE BLUSH RED-START, (C. Tithys, ) }
$$

Has occurred as a British straggler. It is much more rare even on the continent, than the common red-start. Its colours are ash and grey above, cheeks, throat, and breast black, flanks dark ash, middle of the belly white, vent and under coverts of the tail bright red.

\section{THE White-THROAT WARBLER. (Curruca cinerea.)}

The white-throat is the best known, the most numerous, and the most generally distributed of all the warblers; and though its stave is somewhat brief, it is so unsparing in the repetition, that it gives abundant quantity of no despicable song. The dwelling of the white-throat is comparatively humble : a hedge, a solitary bush, or failing that, a tuft of nettles, or of any other rank herbaceous plants. Still, it is a bird of the rich districts, and not found in the wild and elevated moors, though it migrates farther to the north than any of the other warblers.

The plumage is as sober as its dwelling is humble. The bill, which is not so enlarged at the base as that of the redstart, is dusky above and at the point, and light on the under part. The feet are pale brown, and the irides yellowish brown. The upper part is a mixture of brown, yellow, and grey, the grey more conspicuous on the sides of the head and neck. The lesser wing coverts are pale brown, the larger and the quills and tail.feathers dusky brown, the coverts margined with rich colours, and the outer curb of the first quill and the outer tail-feathers, and also the tip of the latter, white. The chin and throat white, passing into very pale rose colour on the breast, and into white again on the belly, vent, and under tail coverts. The female wants the rosy tinge on the breast, has all the colours less perfect, and the upper 
part more inclining to brown, Their young are browner above than the old birds, have a pale streak from the gape to the eye, and the outer web of the first quill reddish brown, instead of white. The feathers on the head are a little produced, and capable of a slight elevation when the bird sings, so that the forehead and crown of the head appear higher than in any of the other warblers.

The white-throat is not so elegantly formed as the redstart, and it is about half an inch shorter and narrower in the wings in nearly the same proportion; but it is more compact, looks stronger, and weighs about the same. Its attitude is different on the perch. The axis of the body is more horizontal, and the neck elevated with a shorter bend, which, with the produced feathers on the top of the head, gives it a brisker aspect.

In the nesting season, the white-throat keeps much in the retirement of its hedges and bushes, not leaving the cultivated grounds, but choosing those parts of them where the cover is thickest or most retired. When disturbed, the birds flit about in the hedge, uttering a grating and querulous sort of chirp; but when they are undisturbed, the male continues his song even in the heat of the day, when most of the other birds are mute. That song is sometimes given from the perch, but more frequently on the wing, not during an onward flight, but rising to a small elevation, and again gliding slowly down. When it sings, the feathers on the head are erected, and the anterior part of the throat distended so as to show the white very conspicuously. It sings " with all its might," and when there are other birds singing near, it appears to sing against them, though only when they are tolerable singers. The lark or the hedge-accentor excite it; but not the bunting.

The nest is loosely formed of the withered stems of those annual plants which trail under hedges and bushes, lined with finer fibres, or if the place furnish them, with hairs, The eggs are four or five in number, of a greyish white colour, mottled with deeper grey and dull browll. 
At that season of the year when caterpillars are so apt to disfigure the hedges and hedge-rows, and spoil the orchards and gardens, the white-throats are very serviceable birds. Caterpillars are their principal food, and the feeding they collect for their young while in the nest; and as the birds are so numerous and widely distributed, the numbers which they destroy are very great. But the supply of caterpillars does not last beyond the nesting time; and the foliage of the hedges, bushes, low trees and other vegetables, which the birds are so instrumental in preserving, become comparatively barren pastures some time before the birds take their departure. They then throng to the gardens; and though they continue useful in the destruction of the later swarms, as well as in that of the insects which are depositing their eggs in the garden plants, they levy contributions on all the early small fruits. In market gardens especially, where these are interspersed with hedge rows, and patches of tangled brake, they do a good deal of mischief; but still, if the service which they have previously rendered be fairly thrown into the other scale, it is probable that the balance of good is on their side.

THE BRAKE-WARBLER, OR LESSER WHITE-THROAT.

(Curruca garrula.)

The lesser white-throat is a smaller bird than the other; it comes later in the season; is more local in its distribution, and probably not so numerous, though from its diminutive size, and its retiring habits, it is also less frequently seen in proportion to its numbers. It is about an inch shorter than the white-throat, and proportionably smaller in all its dimensions; but it is only about one fourth less in weight, so that it is stouter, and not so well adapted for flight. The weights of similar birds should, of course, be as the cubes of their lengths, which, comparing this bird with the white-throat, would give a weight of only about two drachms and a quarter, whereas it weighs rather more than three. The power of 
flight in birds is not however, always directly as their lineal dimensions and inversely as their weight, though, in birds of similar habits it approximates to that ratio; for the power of flight depends on structure, spirit, and many other elements, which are not easily brought within the scope of calculation, The lesser white-throat is, lowever, a more hideling bird than the white.throat, and more sparing in the use of its wings, both in migration over the country, and in common flight where it does inhabit. There is no well authenticated instance of its being seen in Scotland, or even to the north of the midland heights in England: but still it may be in both places.

The distribution of its colours is nearly the same as that in the white-throat, only the whole of the under part is purer white, the head and upper part are more ash coloured, and the coverts are relieved with ash colour instead of rusty brown. The bill is wholly dusky, the irides greyish yellow, and the feet dark smoke grey. The exterior feathers of the tail are white on their outer sides, and light coloured on the inner.

The bird inhabits the hedges and bushes much more closely than the white-throat, and does not sing on the wing. Indeed it can hardly be said to sing at all, as its note consists of two whistling chatters, the second delivered a little more quickly than the first: but while it flits about in the hedge, bush, or brake, seldom exposing itself to view, and then only for a moment, it is not sparing of its voice; and on that account, it has got the appellation of "garrula," or " chatterer." It is a summer bird of passage, inhabiting the same places which the warblers inhabit, and having some of the manners of the white-throat; but, if the name is to be applied as a significant one, it cannot with very strict propriety be called a warbler.

Its nest is not very unlike that of the white-throat. It is concealed in a hedge or thick bush, rarely in a tuft of annual herbage, formed of vegetable fibres, loosely but not clumsily put together, and lined with finer fibres, generally mixed 
with wool or hair. The eggs, which are smaller than those of the white-throat, are not exceeding five, of a bluish colour, and mottled with ash colour and pale brown. The materials of nests, and the colours of eggs are not, however, very certain characters of birds. It is the food that brings birds to particular localities, and they must build their nests of materials which those localities furnish. The depth of tint and the markings of eggs also vary considerably, not only in the same species of birds, but in the same nest; and it would seem that, in general, those that are last deposited, and especially those of a second brood, are paler than the first ones.

\section{THE WOOD WARBLER. (Curruca sibilatrix.)}

This bird has sometimes been called the wood wren, but with very little propriety, as it has not the expression or the habits of the golden-crested or fiery-crested wrens, which nestle as well as hunt in the woods, and inhabit them all the year round.

The wood warbler is one of the more beautiful of our summer visitants. The general tint of the upper plumage is a soft and very peculiar shade of green, produced by the blending of sulphur yellow on the points, and ash grey on the basis of the feathers. A streak of the same colour passes across the eye; and the ear coverts are slightly tinged with it. Over the eye there is a bright and well defined streak of gamboge yellow, and the same colour appears partially on the chin and sides of the neck, and the under parts of the shoulders; but it soon passes into pure silvery white, which, unbroken by spot or stain, is the colour of the whole under part of the bird, except the thighs, which are pale yellow, as far as the tail feathers. This beautiful whiteness of the under part preserves the bird, in some places, the local name of "linty white." The wings and tail are dusky brown, the coverts margined with greenish, and the quills and tail feathers, except the two outer ones of the latter, are mar- 
gined with sulplur yellow. The upper mandible is dark yellowish brown, and the under one the same colour but paler. The irides are hazel, the feet greenish brown, and the claws the same colour, only a shade paler. The colours of the female bird differ little from those of the male; and even the young before they leave the nest are so distinctly marked as to be easily distinguished from the young of any other.

The shape of the wood warbler is particularly handsome, light without being feeble; and the wings and tail indicate very considerable command of the air. The wings are long, reaching when closed to nearly two-thirds the length of the tail; and the tail is slightly forked or rather lobed. The length is rather more than five inches, the weight not quite three drachms.

The wood warbler has sometimes been confounded, in athe descriptions of authors, with the lesser petty-chaps or hedge warbler, and the field warbler or willow warbler, from both of which it is however easily distinguishable in plumage, in expression, and in manners.

The lesser petty-chaps is about a quarter of an inch shorter, the upper part yellowish brown, and the under dull greyish white, with some pale orange brown speckles on the sides of the neck, and an obscure pale patch round the eye instead of the bright streak over it. The tail and wings, especially the latter, are also shorter in proportion, and they want the greenish and yellow margins, the feathers being relieved with yellowish brown instead.

The lesser petty-chaps is about a quarter or three-eighths of an inch shorter than the wood warbler, has a brisker, or as one would say, a perter expression, and is not so elegant in shape. It also perches with the axis of the body more in the horizontal line, is thicker backwards, has the tail more fortified by coverts, and shows altogether more the air of an "up-and-down" bird, and less one of forward flight. The position of the axis of the body when perching, or otherwise in a state of repose, and the way in which the body of a bird 
tapers toward the tall, are always good characters, not only in distinguishing one bird from another, but as indicating the habits of birds.

The field or willow warbler is aiso easily distinguished from the wood warbler. It is larger in about the same proportion as the petty-chaps is less, and the tint of the back is intermediate, yellower than the petty-chaps, and not so green as the wood warbler. The belly only of the field or willow warbler is white. The under tail coverts, the breast, sides of the neck, chin, and throat, a dull streak over the eye, the lesser wing coverts, and the edges of the greater coverts, quills and tail feathers, being pale whitish yellow. The wings reach only half the length of the tail; the tail is thicker, and the whole expression of the bird is softer, but not so elegant. Neither of the birds, however, has the slightest resemblance to the wrens in form or in general habits, although they have both got the name.

The difference in note between the wood warbler and the two birds with which it has been confounded, is as perceptible as the distinction in appearance. The note of the wood warbler is the single syllable twee; but it not only varies that so as to make almost an octave of it; but runs the last repetition of the stave into a peculiar hissing and whistling trill, from which it has got the specific name of sibilatrix (the hisser or siffler); and in the delivery of that the bird is agitated in a very peculiar manner. The lesser petty-chaps has also only a single note; but it repeats that twice with different intonations, so that it has got the name of "chipchop," or " chiff-chaff." Indeed, it is accused of falling into the habit of the people of the district which it frequents, in substituting one for another of those letters that belong to the same organic expression with $f$; being "chiv-chov," "chiffchaff," " chib-chab," or " chip-chop," according to the locality.

That is not unlikely, as birds have great flexibility of voice, and great powers of imitation; and, as there is unquestionably an unexplained something in the air and climate of 
different districts which influences the pronunciation of the people, it is natural to suppose, that it should also affect, not the songs of birds only, but the voices of all animals. The voice of a dry chink or a dry leafless tree, is harsh and sharp to the wind, compared with the same when they are humid; and it is open to observation, that the voices of the inhabitants of dry places are not so soft as those of moist. Compare Westmoreland and Cumberland with Durham and Northumberland; and compare the whole western side of Scotland with the eastern; nay, compare Essex with the maritime part of Somerset, and they are both champaign counties, though Essex is by much the drier of the two. The provincial tones of birds are well worthy of study, not only as they are curious in themselves, and might help bird fanciers to procure birds of the finest voice, and also to improve that by artificial means; but as throwing light upon the very curious subject of the varieties of local pronunciation. The inquiry would involve, not the mere difference of tone, but the difference of cadence and inflection; the interchange of sounds both of consonants and vowels, and the predominance of jarring and hissing.

The note of the willow warbler is also easily distinguished from that of the wood warbler, it is sweet and varied, not unlike that of the red-breast, but not nearly so powerful. It is a murmuring note, while that of the wood warbler sounds querulous.

The males of the wood warbler arrive in the south of England toward the end of April, and diffusing themselves very generally over the country, they reach the north in May.

They resort to the woodlands, the margins chiefly, and not the depth of the forest, as they do not generally nestle in trees. When they have chosen their locality, they perch on the tops or points of the high branches, and begin their song, labouring to "win their dames" by dint of glee, and often twee-ing and trilling against each other, as if they would shiver themselves to pieces.

The nest is usually made in the close foliage of a bush or 
tuft, on or near the ground, or failing such cover, in the lower parts of the lateral branch of a pollard, or on the branch of any other tree that affords a bush near the ground. The nest is formed of dried leaves and grass, and well lined with fibres and hair. In structure it bears considerable resemblance to the nest of the lesser petty-chaps, only that lines with feathers, and its eggs, though of nearly the same general colour, are not so much spotted, and have not the spots at the larger end so much run into a zone as those of the wood warbler. The ground colour is white, the markings reddish purplc. The young are easily distinguished by their resemblance in tilit to the old birds.

The song of the wood warbler continues during the nesting time, and ceases only with the moult, at which time it is partially continued by the earlier broods of the young birds. During the nesting time, it is often delivered during flight, while the bird is rising from its perch and returning again; but it is easily distinguished from that of other birds which have a similar habit in singing.

But though this warbler does not nestle in trees it is always in their vicinity, they form its pasture, and it gives the preference to such as are lofty. But it is a leaf bird and not a branch bird (in which again it is altogether different from the wrens); and its food consists of the caterpillars which curl, roll, and otherwise injure the leaves of deciduous trees, and the flies and moths by which these are deposited in the egg state and into which they are changed. Its short flights from and to the tree are no doubt made for the purpose of discovering the retreats of those caterpillars; and its habit of thus beating round the foliage of the tree agrees with its structure as being a flying and not a leaping bird, as all birds are which hunt among the stems and branches.

Though this bird is not, perhaps, quite so abundant, or resident so far to the north as the lesser petty-chaps, and does not come so early in the spring, or tarry so late in the autumn, it is in all probability far more plentiful than is gencrally supposed; but it is apt to be overlooked, as there is nothing very 
striking about it, as it does not come so close to houses as many other birds, and as it is hidden even from those that walk under the thick trees in the foliage of which it is hunting. It is one of the most active preservers of the foliage of trees; and as such it claims the protection of all the lovers of those highly useful and ornamental productions of the soil.

\section{THE WILLOW WARBLER. (Curruca trochilus.)}

The description of this bird has been partially anticipated in the course of that of the former. It comes a little earlier than the wood wren, and is either more abundant, or from the nature of its haunts, better or more generally seen. It nestles on the ground, under dry banks, or at the roots of close bushes. The nest is constructed with a dome covering and lateral entrance. The materials used in the external parts are dry vegetable fibres, and rarely, if ever, moss. The fibres of course vary with what the locality supplies; but the culms of the wild grasses of the former year, together with the slender wiry leaves which have faded in the winter, are the predominating ones, so that the nest is externally like a little clot of hay, and hence the vernacular name of " haybird." The inner lining is downy feathers. The eggs do not exceed seven: they are white with rusty brown spots, thinly dispersed except at the larger end.

The willow warbler feeds lower than the wood warbler, though the character of its game is nearly the same. Hedges, copses, bushes, willow beds, and other collections of deciduous shrubs are its haunts; and among those it captures larvæ, moths, and flies. It does not fly to a distance for discovery so often as the former species; but it is very active in leaping upward and downward, for which its shorter wings, and its more strongly fortified tail better adapt it. Its habits, indeed, resemble those of the wrens and creepers a little more than the former species, as it is found running among the branches, and partially on the stems.

When the males of these birds first arrive, which in the 
south of England is very early in April, they perch on the tops of hedges, bushes, and willows, and raise their song, to which there is a very peculiar prelude. First, there is a sort of broken chirp, then a retiring tinkle, and after that the song, consisting of three distinct notes, but modulated into many more.

Like most of the early visitants, those birds come in small flocks; but they separate soon after their arrival, form their pairs, and commence their building, which is rather a laborious operation. If the weather prove kindly, they go on well; but if frost set in, as it often does (on the east coast in the first or second week of April), they suffer considerably by the cold, and probably also of hunger: several are found dead if such weather continue, and the song of the remainder ceases for a time.

All the warblers, when their song has ceased, have a peculiarly soft chirp, as they fly about, either on the wing or from spray to spray; and though they resemble each other much more in that than in their proper songs, yet an attentive ear may distinguish them even by that. Those that have varied song generally shut their single chirp by a sort of consonantal turn, while the single noted ones do not, unless their first note has that sort of ending. Thus the willow warbler's single note is tweet, the wood warbler's is twee; and there is a shake in that of the finer warblers.

THE HEDGE WARBLER, OR LESSER PETTY-CHAPS.

\section{(Curruca hippolias.)}

The description of this bird also has been partially anticipated in that of the wood wren.

Though the smallest of our warblers, being generally about four inches and a half in length, and about two and a half drachms in weight, this is the most hardy, coming as early as March, remaining as late as October; and, if the autumn is mild, remaining as a straggler in the warmer parts of the country all the winter. In situation and structure its nest 
very much resembles that of the willow warbler; but the eggs are not, perhaps, quite so numerous, and the markings are purple red, which easily distinguishes them from the rustcoloured markings on those of the others.

It is very abundant in all parts of the kingdom, being found farther to the north, and also in more bleak and exposed situations than any of the other warblers, nor does it appear to suffer like the former species from the spring frosts. From the length of time that it not only remains in the country but continues in song, it probably has two broods in favourable situations; and that may account for the consider. able differences in size and weight that are found in different specimens, and also for the fact of some remaining over the winter.

In the early part of the winter it feeds upon insects, and is peculiarly serviceable to those bushes and low trees, which are subject to have their leaves and young shoots destroyed by aphides: but before it finally leaves the country, the insect supply is greatly diminished; and as it has been known to eat small seeds in confinement, it probably also does so naturally, in the latter part of the season.

The difference in habit of the two broods of those migrant, and native insectivorous birds that breed twice in the year, is worthy of investigation. The supply of seeds and berries, which is the kind of vegetable food to which insectivorous birds first resort in the autumn, is most abundant at that season, while winged insects are fewer, and there are no larvæ, except the birds can dig them out of wood, or of the ground, or seek for them in humid places, which would not agree with the structure or the other habits of the sylvan warblers. The second broods must, therefore, be brought up differently from the first, at least, they must feed differently when they begin to feed themselves. Now, as difference of food has as much influence upon the character of animals as difference of soil has upon those of vegetables, it would be of much importance as well in the individual history of birds as in the physiology of animals generally, to see what influence 
that difference in the early feeding has upon the future habits of the bird. The probability from the analogy of domesticated poultry is, that that treatment when young tempers them more to the climate; and that, as the country becomes more and more improved by drainage and culture, those birds which now retire during the winter, may remain the whole year. Consequently the appearance of those birds more northerly or upland than they had wont to come, is a testimony of what cultivation has already done towards the increased productiveness and salubrity of the place, in which they sport and sing for the first time.

Birds, and those insects upon which birds feed, are as true to climate and fertility as the vegetable tribes are. The summer butterfly or moth, and the summer bird, are alike children of the sun; and, if they come into any place in which they were not previously to be found, we may rest assured that some change favourable both to the subsistence and the health of man has been effected there; that some dimimution has taken place in that evaporation from bog and marsh, which chills, stunts, and sours the vegetation, and nourishes carex and rushes, with their accompanying mosses, and all the elements of peat-bog, - - and that the earth is in a condition to feel and to profit by the whole influence of the season, nursing a more sweet and kindly vegetation upon which the caterpillar can feed; and where these again can supply food for the warblers and their broods.

That all these birds are now spreading northward and upland, there can be little doubt, independently of the greater attention which (on the part of some), has been paid to the feathered tribes. That alone would not explain the difference, for though there are now more professed students of birds, the country people, from more constant labour, and other changes of habit, study them less than in former times; and so, if they had existed, they would have got names as well as the other birds. The white throat has been "Charlie Muftie," and the hedge warbler the "white wren," in the midland parts of Scotland, from time anterior to record, and 
there is no doult that, if the garden warbler had fre.. quented that country in the olden time, its more enchanting notes would have won it a name, especially in a land not unknown to song. There is little question that this delicious songster has now penetrated to the warm glens in the southern verge of the Grampians; and so the folks of Scotland may make sure that they have only to cultivate away till they deserve the nightingale, and they shall have him-and more and better.

THE BLACK-CAP TVARBLER. (Curruca atricapilla.)

The black-cap warbler is one of our most delightful songsters; and it is more abundant, more generally distributed, more hardy, and less exclusively insectivorous, than some of those which are very inferior in song. The male black-cap is barely six inches in length, and about eight and three-quarters in the stretch of the wings, and it weighs barely half an ounce; the female is fully six in length, and nine in breadth, and weighs a little more than half an ounce; but as the birds range over a variety of soils, and are both reared and subsequently fed on pastures of varied productiveness, they are subject to considerable variations, both in weight and dimensions. I believe it will in general be found that the bird of the poorer pasture is lighter and longer in the wings. It is a general law, that where an extra production of appendage to the cuticle is required in the same species of animal, there is more than a corresponding diminution in the quantity of flesh, yielded by an equal and equally nutritious species of food. It has been already noticed that heat has a tendency to produce those appendages; and thus the exertion of flying tends, in some measure, to produce or enlarge the instruments of flight.

The black-cap warbler is a bird of sober attire: the male has the head, from the forehead to the occiput, dull black; the rest of the upper part grey, with a tinge of dull blackish green; the throat and breast grey, and the rest of the under part pale 
ash-grey. The bill is bluish brown, the irides dark hazel, and the naked parts leaden grey. The quills and tail feathers are inclining to dusky, relieved with dull greenish on the margins. The female has the head redaish brown, and the general tint of the plumage darker, and more inclining to green than the male. The young of both sexes, when first fledged, resemble the female.

The nest is near the ground, in hedges, bushes brakes, or tufts, formed loosely of dry vegetable fibres, and lined with the same, and often with a few long hairs. The eggs are four or five in number, pale reddish brown, rather obscurely marked with a deeper shade of the same colour and with grey; but their colour, as well as the material of the nest, is subject to variation. The young black-caps are said to leave the nest sooner than most other birds of the order, and they and the old ones roost for some time afterwards on the same perch.

Hedges, copses, bushes, and trees, but not the depth of forests, are the favourite haunts of the black-cap. It seldom comes till toward the end of April, and is soon dispersed over the country, fluctuating to a considerable distance northward. As is common with the tribe, the males come first, and feed for some time on any berries that have been spared by the winter birds; at that time, it sometimes also nips off the $h y$ bernaculi of buds upon trees in gardens and other places, though probably only those in which the eggrs of insects are lodged. While confined to regetable diet, it does not sing with its full power.

Its song is generally given from a high perch, or an elevated branch, or the top twig, if the tree be not very lofty. While it sings, the axis of the body is very oblique, by the elevation of the head, and the throat is much inflated. While the bird is trilling, in which it excels every songster of the grove in rapidity and clearness, and in the swells and cadences which it gives to the same trill, the throat has a very strong convulsive motion, and the whole bird appears to be worked into a high state of excitement. It has, indeed, the wildest and most witching notes of all our warblers; it has not, certainly, 
the volume and variety of the nightingale, neither has it the ineffably sweet chant of the garden-warbler; but its notes take one by surprise, and the changes, and especially the trills, are finer than those of any other bird. The song, when the bird is at rest, appears to be, by turns, like those of several birds; but it transposes them into a lower or rather a minor key, and finishes off with variations of its own; and, as is the case with the works of some of the more impassioned musical composers, the very genius (so to speak) of the bird interferes with the melody, and a sort of indescribable wildness is the character of the whole.

When the supply of insects, in the destruction of which, while they last, the black-cap is very assiduous, fails, it levies its contributions pretty copiously upon currants, raspberries, and other soft fruits; but, as is the case with most of the tribe, the harm which it does is, in all probability, very small in proportion to the good, as one day of the ravages of caterpillars, at the time when the black cap is most active in their destruction, would prevent the coming to maturity of ten times the quantity of fruit that the bird ever consumes.

As the black-cap does not extend its winter migrations far to the southward, and as it is capable of subsisting upon that vegetable food to which our residents have recourse in the winter, it is probable that the whole never leave the country, but that some linger during the winter in those wild and lonely places of the south, where wild berries are abundant in the brakes and hedges; but as the lingerers of the migrant species are of course less lively, and less liable to be excited into song by a fine day in the winter, than those resident birds which are better clothed and fitted for the climate, it may remain unheeded. It has been seen in Surrey in December, and shot in Kent in January. On the continent of Europe it is rare on the south of the mountainous ridge that may be traced from Cape Finisterre to the mountains of Albania; but it is found in the Atlantic isles; that, however, is no proof of its migrating thither from any part of Europe. The climate of these beautiful islands is mild, and the seasons 
are so very uniform, that the laws both of vegetable and animal life are very different from what they can be expected to be in the range of a large continent, which is parched at one extremity, and frozen at the other.

the Garden warbler. (Curruca hortensis.)

The garden warbler, or greater petty-chaps, of which a figure of the male in the summer plumage, and one-third of the lineal dimensions, is given on the plate at page 318 , is, perhaps, a sweeter songster than the black-cap, though not so wild.

The plumage of the female is not unlike that of the male, only less bright, and with less of the greyish tinge which appears to be the nuptial livery of the male. The young have more of a yellowish brown tinge on the upper parts, the fore part below pale amber colour, and the belly and vent white; the feet also want the bluish tinge which is perceptible in the mature birds.

The garden warbler is larger than the black-cap, and longer in proportion in the wings: the length is more than six inches, the breadth more than ten, and the weight about fiveeighths of an ounce. It is also a more extensive migrant, ranging as far as the north of Africa. In Brifain, it arrives about the same time with the black-cap, or perhaps a little later; and as it frequents richer and warmer places, it is not so generally distributed. As is the case with all the sylvan warblers, it is more common in the south and south-east of England, than in any other part of Britain, and it is certainly not plentiful so far to the north as the black-cap; but from its power of flight, it is probable that it ranges much farther in that direction than has been stated by authors. I have heard reports of it near Balgonie, on the Leven, in Fife, and in the romantic dell between the castle of Airlie and Ruthven, in Strathmore; and, as these are both warm places, and abound in brakes and brush-wood, it is not unlikely to be true, though I cannot certify the fact on my own observation. 
In Lothian it has been both heard and seen upon each of the rivers Esk, which are confluent in Dalkeith park; on the Northern one, between Lasswade and Roslin, and on the Southern at Newbattle and Dalhousie; nor is there much doubt that, if looked for, it would be found in many of the warmer wooded districts of the lowlands. When summer migrants once cross the border,-indeed when they get regularly into Durham and Northumberland,-there is much to entice and little to impede them till they reach the Grampians. It is true that the plantations are more of fir and less of deciduous trees, but the number of the latter is on the increase.

The hideling manners of the bird may prevent it from being known, even where its song is heard. It is a hedge, copse, and thicket bird, and does not, like the black-cap, sing from a high perch, but from the close cover; and as that cover is in foliage all the time that it remains, it is not very often seen, even by those who search for it. Its notes are perhaps the softest of any that have equal volume and compass; they want that clear silvery tone which pierces the ear so much in the song of the nightingale; but they are exquisite flute notes; and the whistling part of the stave, which is almost as full and mellow as that of the blackbird, has an unbroken swell, which is at once characteristic and peculiar.

Its nest is formed in the same manner, and nearly of the same materials, as that of the black-cap; but it builds more exclusively on the ground, though it always chooses a cover of close herbage. The eggs are about the same in number as those of the black-cap, but they are easily distinguished by their colour : they are pale yellowish brown, with dull brown blotches, rather crowded at the larger end, and obscure over the rest of the surface.

The birds inhabit even closer to houses than the black-caps, though they do it more stealthily. The nests are sometimes found in gardens; and in these cases the birds beat for food in the hedges, and the male sings from them. Like the others, they can subsist upon succulent vegetable food, and 
they plunder the berries when insects cease to be plenty. They retire from Britain in September ; and it does not appear that any of them remain during winter, or if they do, they pass their time in solitude and silence, unseen and unheard; indeed they are not much seen at any time, unless come upon by accident, or that the observer remains close while they are singing.

THE NIGHTINGALE WARBLER. (Curruca luscinia.)

The nightingale is the most celebrated of all the warblers, but it is the one of which it is necessary to say the least; first, because its liabits are so concealed, and so much has been written on the subject of its song, that there remains little to be added; secondly, because there is no mistaking the nightingale, as no otlier bird sings at the time when its song has the greatest effect; and, thirdly, because, though the bird often sings when there is light enough to see it, it is jusi as much concealed as during the night.

The nightingale is the largest of all the warblers, being about seven inches in length, between ten and eleven in the extent of the wings, and three-quarters of an ounce in weight. In shape and expression it resembles the garden warbler, only it seems a little softer and heavier, and its plumage is inferior in tint.

The colours of the nightingale are: the bill wood brown, with the basal end of the lower mandible pale yellowish brown, and the tarsi (which are long) and the toes of the same colour; upper parts deep yellowish brown, inclining to reddish brown; the quills and greater coverts dusky brown, with reddish brown margins; and the tail deep reddish brown, and very slightly forked; sides of the neck, ear-coverts, breast, and flanks, pale ash-grey, passing into greyish white on the throat and middle of the belly; an obscure dusky streak passing from the grape down the side of the neck, and passing imperceptibly into the grey on the breast. The colours of the female nearly the same as those of the male. The 
nest is a simple structure, formed on the ground below brakes, underwood, or hedges, composed of withered leaves and fibres, and lined with withered grass. The eggs are from four to six, of a plain olive brown, often varying a little in the intensity of the tint, but without markings.

The male nightingales arrive in Britain about the beginning of May, and, as is the case with some of the other warblers, they may be seen in the open places near woods for a few days; and it is then that the bird-catchers are most successful in making prize of them.

About two weeks after their arrival they betake themselves to the woods, and are soon in full song, continuing the greater part of the night with little intermission, and evidently singing against each other. They do not sing from the very depth of cluse forests, but from the tall and thick trees that are near open places, abounding in underwood or other cover upon the ground. After the incubation begins, the song is less incessant, and as the broods come to maturity, it gradually ceases. In severe drought, it does not begin till dark, and it ceases at an early hour in the morning; but when the air is moist, it begins earlier, and is continued longer. A very dry season, after the nesting has been some time in progress, will cause it to cease altogether ; but if a shower comes, it will break out anew; and it will do so the more readily and the more powerfully, if the shower has fallen during the day, with just a blink of clear before sunset.

From their retiring disposition, the habits of nightingales, in a state of nature, must always be, to a very considerable extent, conjectural, because instead of being able to follow them in the details of their history, it is not easy to see the same one twice. I watched them very carefully for more than five years, in a place where they are very abundant, and at the end of that time, I was-about as wise as at the beginning.

It appears that the principal food of nightingales is the caterpillars of night-moths, and probably also of some of the night-beetles. It is the habit of these larvæ to feed only, or 
chiefly, during the night, and to retire during the day. In damp weather, when vegetation is succulent, they of course come out in the greatest numbers; a much shorter interval suffices for the nightingale satisfying himself, or procuring a meal for his mate or his brood, and then he has time to sing; but in different states of the atmosphere, the task is more laborious, and then the song ceases. It is true that, even at those times, a solitary one, here and there, may be heard singing with all his might; but the probability is, that that is some one who has been unsuccessful in his wooing, or widowed of his mate. Even in the latter case, however, the song is any thing but a lament. The poets have, indeed, said so, and given it to the female, as the most pathetic way of putting it; but poets are not the best of philosophers, and the song is one of invitation, which will slacken whenever it has answered its purpose. We sing in many moods, but birds sing only when they are merry. It is probable that the loss of the brood may also bring the male a second time into song; but the subject is one upon which it is exceedingly difficult to get accurate information. What we know of nightingales, farther than that which we " hear from themselves," is collected chiefly from the observation of them in a state of confinement, and that can throw but little light upon their habits as denizens of the wild woods.

It is just as difficult to get a fair estimate of the song of the nightingale, compared with the songs of other warblers, as it is to get a satisfactory account of the manners of the birds.

Under every circumstance, the song is a delightful one; and, with the exception of the time at which it is heard, it is perhaps the most spirit-stirring and gleesome in nature, much more so than that of the skylark, though the lark has the odds of the bright sun and the clear sky, against the gloom of the woodland shade and the night. To hear it in the morning, especially for the first time, and to be awakened by it upon one of those balmy mornings in May, when every leaf is freshness, and every breath young perfume, is indescribableworth more than a whole musical festival; but yet it owes 
much to the time, and the absence of other sounds. Every one knows how sweet the music of the "waits" is, when it breaks one's sleep in a long December night, though if day were dawned, and the musicians were seen, it might prove to be sorry or even intolerable scraping. The song of the nightingale, heard as above mentioned, (the most favourable way of hearing it,) borrows something from the same cause, although it certainly has less need to borrow.

The nightingale is local, confined to the chalky, gravelly, and partially to the clayey soils, and shunning the rocky country and also the marshes. The cause of this restriction is rather obscure, and in all probability it is complex. The places which it frequents are certainly those that abound most in lepidopterous insects, whether moths or butterflies, and within them it affects most the places where those insects appear in the greatest abundance and variety. But we are not warranted in concluding that food is the only circumstance that regulates its distribution; for within the places that it does frequent, there are favourite spots, and they are always those spots at which the air is most balmy, and the whole vegetation the most moist and kindly. To the margins of waters it has no objection, but rather the reverse; but it does not so much affect marshy grounds as those where the soil is retentive, the evaporation rank, and the vegetation austere. Indeed, the clearness of its song is said to vary much with the character of its locality.

Tits. (Parus.)

Though the tits (or tit-mice) are often classed with graminivorous birds, and have hard bills, harder, indeed, than many of the species which deserve to be so classed, as feeding more upon the seeds of vegetables than upon animal substances, yet they are not more entitled to the appellation of gramini. vorous than some of the warblers, if, indeed, they be as mucl. They are, in fact, omnivorous, and might, without impropriety, be placed among the birds to which that name 
is given, only they are small birds, and insects in some stage of their existence form their chief food.

It may seem a very secondary matter, in so far as popular and practical knowledge is concerned, in what part of the system any genus of birds may happen to be placed; but in the case of the tit it is not unimportant. A bird that eats seeds is a marked bird with the cultivator. Whenerer it makes its appearance on the ground in gardens, it is in quest of the newly-sown small seeds; and if it happens to twitter about among the sprays in the spring, then it is nipping off the buds and destroying the beauty of the summer and the wealth of the autumn. The tits do come to those places at those times: and though they come to preserve rather than to destroy, they come with the brand of seed and bud-eating birds affixed to them, and as such, they are destroyed. Justice to the birds, and also to those who unwisely persecute them, thus demands that they should be called by the name of that food to which they are most partial, or in search of which they are not only more assiduous and successful, but employed more in the proper season than many of the birds which stand on the muster-roll as insectivorous, and especially more than any of the warblers. These retire, leaving the insects to deposit their eggs in the buds; and before they return, these eggs have been hatclied, and the mischief both to shoot and blossom has been done. The tits, on the other hand, watch the buds, more especially the fruit buds, from the time of their formation in the autumn, till they begin to expand in the spring; and the number of the eggs and larva of the tortrices and other insects, which they pick up, would, if left, be quite sufficient to ruin the crops and disfigure the trees.

The larva of those lurking moths not only do mischief themselves, but are also the cause of mischief being done by others. The injury which they do to the young buds, in the very cores of which they batten, gradually brings on that languid action in the tree, in consequence of which the influence of the sun, which, in healthy plants, would bring out 
a rich and luxuriant foliage, induces a saccharine condition of the sap, which fosters the congregating caterpillars, so that they appear upon the tree in swarms, secure, during the day, in their silken tents, but eating voraciously at night, till not a particle of green is left; so that if the tree does not perish, it renuains actionless for the year,

Nor is the mischief confined to the leaves; for, without their action, the sap does not change into a healthy cambium, fit for producing the new layers of wood and of bark, which, when a tree ceases to produce, its decay is begun. The whole active surface of the tree thus becomes saccharine, and is infested with swarms of insects of different kinds, down to the very roots; and in the course of the summer, the bole and branches become full of ulcerated and cankering sores; half the top dies, branch after branch, and the miserable remnant of the erewhile fruitful and ornamental tree, becomes equally unproductive and unsightly.

When a tree is thus attacked, its recovery is always doubtful, and generally hopeless. Wood and bark, that have stood more than one winter, are much less fit for vegetable action, even though they have received no direct injury, than when they have stood only one. But in a tree which has been injured as above described, the continuity of even the stiffened vessels is broken, and the new production, even if the tree lives, is wasted in unsightly gnarls and knobs, which give further shelter and protection to insects, and also form lodgments for water, which stagnates and rots the wood. Heading down and grafting is generally only loss of time and labour; and the diseased remains inoculate other trees.

Such would be the natural course with most trees, and with all the finer fruit-trees, especially if the buds were not cleared by birds ; and among these birds, the garden-frequenting tits stand as eminent as rooks do among those larger birds which clear the fields from insects. Indeed, different as they are in size and in many of their characters, the tits and the crows resemble each other not a little in the form of their bills, as well as in their miscellaneous and indiscriminate feed- 
ing, and also in the firmness of their plumage, the strongly contrasted tints of their plumage, and their disposition to kill and eat young and weakly birds.

The bills of the tits much more nearly resemble miniatures of the bill of the magpie than they do that of either of the insectivorous, or the seed-eating little birds. They are small, short, rather compressed, very firm and strong, and pointed at the tip. The birds have very free, and in proportion to their size, powerful action of the neck, and they strike with the point of the bill as with a pick-axe or chisel, and do not peck or strike as the insectivorous birds do, or grind hard substances between the oblique tomia, like the birds which feed on grain.

By this action of the beak, they can dig very successfully into the crevices of bark, or the folds and hybernacula of buds, and extract thence the larvæ, of which they are such incessant and general destroyers. When they eat seeds which have hard testa or coats, they do not crush them, but tear them in pieces by repeated strokes of the bill, as is done by the nuthatch; and they also kill young and weak birds by striking them on the head till they have broken the skull, the contents of which they immediately devour. Some of their habits and also the command which those species that frequent trees, have of themselves upon the bark would lead to their classification with the creepers and nuthatch, only their feet are different, and they have other habits that do not belong to those birds. They also capture prey by the snap of the bill, and some of them are very successful fly-catchers and bee-eaters.

Their flying feathers are very firm and stiff; the wings rather rounded, the third or fourth quill being the longest, and the first in some of the species, merely rudimental. The tails are in general strong and stiff, so that those species which hunt on the bark of trees, can use them as supports; and they are more or less produced, and square or forked, according to the habit of the species.

In fact, the tits have habits of so mixed a character, that they do not accord well with any of the orders into which the 
feathered tribes have been arranged; though, as insects form their prevailing food, they may perhaps, in the present state of the science, be with more propriety classed with the insectivora than with any other order. Their very name has been objected to by some. Not the syllable " tit," which is so general in its meaning that it might be applied equally to any genus of "neat little" birds; but the syllable "mouse," which is as descriptive of their habits as the name of a quadruped can be of the habits of birds. One regrets the introduction into natural history of that small verbal criticism, which has no sense or meaning even in an etymological sense; because, when the public find that the professors of any science are merely triflers, it is difficult to prevent them from concluding that the science itself is a trifle, and avoiding it accordingly.

There are eight species of tits enumerated as British birds; and they are probably all resident, though some of them are much more common and generally distributed over the country than others; but there is one species about the habits of which, as a British bird, very little is known.

the gReat tit. (Parus major.)

The great tit, " ox eye," or " tom tit," (the latter name is also given to others of the genus,) is a woodland bird, very general in all parts of Britain where trees abound, but rare on the open champaigns, and unknown in the open wastes. It is bright and well marked in its plumage, handsome in its form, and brisk and lively in its manners; and altogether one of the most easily distinguished, most beautiful, and most energetic of our forest birds.

When full grown, its length is about five inches and a half, the extent of its wings about eight and a quarter, and its weight about an ounce and a quarter. Its air has a considerable resemblance to that of the magpie; but its motions are much quicker. The bill is stouter and more produced than that of any of the other species; both mandibles are curved in their outline, and the upper one is very strong at the tip. 
The bill and claws are black, the latter strong in proportion to the size of the bird, and the hind claw is long and strong, and much crooked. The irides are black, and the feet and toes blackish grev. The colours are black, olive green, bluish grey, sulphur yellow, and white, rich in their tints, glossed with reflections in the male bird, and disposed in the following manner: the head and throat, as far as the middle of the neck, glossy black with some purple reflections, and the black continued in a mesial line down the under part, as far as the lower part of the belly. A bright white patch on each cheek, pointed at the gape, passing under the eye, and rounded at the other extremity, but with the black forming a sort of collar beyond them on the sides of the neck. A patch of pure white on the nape. The back and shoulders olive green, passing into bluish grey on the rump and the tail and wing coverts. The greater coverts with white tips, which form a bar across the wing. Quills, deep greenish grey, the prima. ries edged with greenish white, and the secondaries with greenish grey. Tail dark greenish grey, with the exterior webs of the outer feather's white. Under part, with the ex.. ception of the black mesial line, sulphur yellow; and the under tail coverts white. The colours of the female are similar, only less brilliant in their tints.

The great tit has a chattering rather than a singing voice; but it has considerable flexibility of utterance. As it hunts in the trees, its chatter, though not loud, is harsh and grating resembling that which is produced by the filing of iron; but in the pairing time it has a note not very dissimilar to that of the chaffinch; and the alternation of the note with the chatter, makes a sort of rude song, but that song continues only for a short time.

The birds pair in February, and soon after retire to a little greater distance from houses than that at which they are found in the cold weather; but they may still be found in gardens and copses, though they keep more in the close foliage than many other birds.

As during summer trees are the abode and pasture of the great tits, they prefer holes in trees as nesting places, when 
these are to be found in their locality; and if the tree be in a state of decay, so that it can be chiselled by the stroke of their bills, they trim, and probably sometimes wholly excavate, nesting places for themselves. If the trees do not afford a proper place, they will nestle in the holes of walls, and trim the mortar, if there, to suit their purpose; and in young plantations which afford neither, they sometimes form their nests in the thick herbage which surrounds the root of a young fir; but in these they nestle less frequently than in the others. The quantity of materials in the nest varies with the situation. In a deep hole of a tree, which is warm and sheltered, there is sometimes little else than chips of wood which the birds have detached; but in more exposed situations, the nest is formed of moss, and lined with hair and feathers. The eggs are numerous, often as many as ten or twelve, and seldom fewer than eight: they are white, mottled with rust colour, especially towards the thicker ends, and bear much resemblance to those of the nuthatch, only they are more numerous, and the ground colour has a slight yellowish tinge. There are often two broods in the year, so that the birds have a laborious summer. The young come out of the egg in a much less advanced state than many other birds. They are blind, and remain so for a few days; but as they eat heartily, and both parents are equally industrious in feeding them, they grow fast, and in the course of two or three weeks they are able to fly. The brood are of a social disposition, and continue hopping about in the trees adjoining the nest till the moult, which takes place in about six weeks. When spring comes, the family society breaks up by the pairing of the young: the pairs are very attached and attentive to each other. It is supposed that the attachment is for life; and that, if they are not disturbed, they use the same nest for many successive broods. Both birds assist in the building of the nest, and also in the incubation. The two hatches, and the number and voracity of the young in each, keep the birds fully employed during summer, so that they have less time for sport than many of their fellow-tenants of the trees. As, during that period, they are wholly insectivorous, the 
number of insects and larva of which they clear the trees is very considerable; and during the time that the young birds are in rapid growth, the activity and industry of the old ones are worthy of admiration. They are in continual motion, now running along the branches, again leaping from twig to twig so swiftly that their motions can hardly be discovered, and ever and anon darting out a little to catch any winged inscct that may happen to come within the range of their very acute vision. In extracting their smaller prey from the chinks of the bark, the great tits, in all probability, use the tongue as a prehensile instrument, for the point of it terminates in four filaments, by which a very small object could be embraced. It is also probably used in picking aphides from the leaves and tender shoots.

Trees growing near rank places are preferred to those that stand upon a clear surface, as they abound more in insects; and the great tits may often be seen watching an opening through which there is a current, or even attacking the bees as they leave or return to a hive; but the little thieves are so clever that, even on the latter occasions, one can hardly bear to drive them off.

When the house-flies become languid in the autumn, the tits capture them in rast numbers; and when insects fail, they make prize of the autumnal spiders. In the dead season, when insect life is chiefly in the egg, though they hunt for the eggs with great diligence, yet they do not find in them a sufficient supply of food. At that time they pick up nuts, acorns, and the capsular fruits of other trees, hold them in their claws, and hammer away with the bill, till the hardest shell or toughest capsule is opened. They also eat the seeds of the grasses, especially those that are of an oily nature, and of such size that they can hold them in the foot, and pick them open, for they do not grind or bruise with the edges of the bill. They feed greedily upon carrion; and when they come upon other birds in a benumbed or exhausted state, they dispatch and eat them, first breaking and then emptying the skull.

When the snow lics heary on the ground they approach 
houses, and hunt about for any offal that may come in their way. They are very partial to thatched roofs, as numbers of the insects which remain dormant in the winter hide themselves there. The birds cling to the eaves with their back undermost, and draw out the straws very dexterously and expeditiously one after another, scrutinizing the whole length as it passes; and dropping them as soon as they are cleared, or it is discovered that they present nothing eatable. So successful are they in that operation that they soon bring out a heap of thatch; and, though that is, of course, no part of their purpose, assist in forming a nestling.-place for the sparrows. They also sometimes draw straws from corn-stacks; but they do that much more rarely than some of the birds which feed more exclusively upon vegetable matters. While engaged in these labours they continue repeating their grating cry; but as soon as the weather begins to relent, they resort to the trees, preparatory to the labours of the summer, which, in their case, is no idle time.

the Cole-tit. (Parus ater.)

The cole-tit is a woodland bird, as well as the former species; but it inhabits colder places, where the trees are of more stunted growth, and is also more abundint in copses and young plantations on the margins of the wilds. It is found in all the wooded parts of Scotland, even to a considerable height in the mountain glens; and is indeed much more abundant in that part of the island than in England. In both countries, perhaps, it has been confounded with another species, that which is, not with the strictest propriety perhaps, called the marsh tit. But though the two are often found as neighbours, their appearance, their habits, and their haunts, are all perfectly distinct. The cole-tit has the black on the liead extending to the lower part of the neck, but pied with three bright and very conspicuous patches of white; an oblong one from the gape to the lower part of the neck, on cach side, pointed forward at the upper extremity and back- 
wards at the lower, and in some positions of the head extending to the white on the shoulder, and one on the nape wholly within the black at the lower edge. The black on the head of the marsh-tit does not comc below the eye, but forms a remarkably well defined cap extending from the bill to the nape; and the black on the throat is much narrower, so that it is visible only in certain positions. In the coal-tit the head is rather flattened on the crown, while that of the marsh species is a full and remarkably graceful curve. The other colours are equally different, but there are sufficient to distinguish the spccies both in the males and the females, as the sexes differ little from each other in their plumage.

The cole-tit sings, and the marsh one is comparatively silent, or at least only chatters. The song of the cole-tit is not indeed one of many notes, or of mellifluous inflexions; it is little else than the same note repeated four or five times, but with so much variety of pitch and tunc as to form a sort of cadence, which would make a good variety any where, as it is shrill and clear; and which is particularly welcome and cheering in those mountain woods which the summer warblers but rarcly visit. The bird sings in the noon-tide heat when most birds, and especially those on the open wastes, with which the haunts of this species are usually interspersed, are silent. While the cole-tit is singing away in the plantation of half grown pines, often heard, but seldom seen, the marsh species may be seen flitting about among the long and fragrant broom which often grows thick in the neighbourhood; but as the one is heard while the other is seen, that causes them to be sometimes confounded.

As the cole-tit is found, though in very different degrees of abundance, in most wooded parts of the country, and (to my observation) least plentifully in the richer and norc humid districts, it is not easy to say what description of woodland is its favourite locality. I should feel inclined to say, in fir plantations, upon places that are rather elevated and dry, and while the trees are so young as to be closely branched nearly to the ground, or on thc outskirts of the natural forests, where the trees are more apart than in the centre, and never 
so completely lose their lateral branches, and where young ones have space and air to spring up.

In a fir plantation, which is neither so low as to partake of the mushroom growth of pines (especially pinus sylvestris) upon too rich soils, or too inland and upland, there is a succession of birds. Linnets and other brake birds come to them as long as they are mere bushes; but the note of the cuckoo is not heard in them. After a while, the cole-tit becomes one of their most plentiful inhabitants; and by that time the cuckoo perches and sings on the margin. A few years longer and the ring-dove moans in the tops of the trees, which have then begun to open toward the surface of the ground, and the cover for the brake birds, and nesting-places for all birds that breed hideling and near the earth, is gone. The cuckoo is then heard less frequently, unless there are coppices of deciduous trees, or young pines come up in succession in the vicinity. If the trees form a belt between rich grounds, the magpie, though he loves the " home" trees better, will sometimes come a little after the wood-pigeon; and if the plantation is deep and secluded, the jay will, perhaps, come a little earlier. To all these succeeds the rook, which nestles in the mature trees, with the long boles clear of branches, and he quits them not till they are cut down, or perish in the lapse of time.

The cole-tit is usually described as nestling in the holes of trees and of walls; but in the above mentioned places, which as they are those in which the birds are most abundant, must be considered as the most natural to them, there are 110 such holes in which they can nestle. Walls there are none; and pines do not fall into holes in which birds of any kind could nestle. When they do decay it is always first in the alburnum, and they are generally barked and bleached before then. In these situations it nestles something in the same manner as mice nestle; but not in their holes, because young pine plantations upon erewhile moors being but bare pastures for murine quadrupeds of any sort, there are not many mice in them. The nest is in the close shrubby vegetation near the ground, formed externally of moss and wool, and lined 
with hair. Where there is no cover of underwood, it, of course, must build in other places; and, as it always hides its nest, the holes of walls and of trees are, no doubt, the best and readiest places that it can find. The eggs in a hatch vary from four to ten, they are of a purer white than those of the great tit, but mottled in the same manner.

The birds come less frequently near houses than the former species, and when they do they are not so shy, though they are to the full as quick and lively in their motions. Their food is not quite so well known; but their bills are so well adapted for digging into the fissures of bark (and these appear very early on pines toward the roots), and their air and expression so much resemble those of the fly-catchers, that insects and larvæ must form their chief food in the summer. and probably they dig out the larva that burrow in the bark in winter.

The cole-tit is a very small bird, the length being not quite four inches and a half, and the weight little more than half an ounce. The wings stretch seven inches. The bill, head, and neck, with the exception of the patches of white on the cheeks and neck, are deep glossy black. The upper part of the breast, and the shoulders in a line bordering the black, are white, passing into yellowish white in the lower part, and deepening in the yellow tint, and tinged with grey toward the rump. Back and scapulars (from the white margin) greenish grey, wing coverts bluish grey, with pale ashcoloured tips to the feathers forming two bars on the wing. The colour of the back passing gradually into a yellowish grey on the rump. Quills and tail feathers ash-grey, the former with the margins paler: feet and toes bluish grey. The tail is a little forked, and stouter in proportion than that of any other of the genus.

THE marsh-tit, (Parus palustris.)

The marsh-tit is one of those birds which, from seeking their food under cover of brakes, copses, and other underwood, and being seldom on the wing, except while flitting 
"from bush to bush, and otherwise lideling in their habits, are sometimes described as being much less abundant than they really are.

It is about the same length in the body as the coal-tit, but the tail is at least half an inch longer, the body is thicker, and the weight one half more, or about three drachms, the other being about two. The wings, too, are an inch longer, being at least eight inches in extent.

The plumage is more downy and free from gloss than that of the former species; and the black on the head is not so deep, though from being entire and having no lustre, it shows better. The bill is dusky, the head as far as the nape and eyes, and the centre of the chin, black. The rest of the upper part smoke grey, with a slight yellowish tinge; the under part cream colour, with traces of pale brownish buff. The wings and tail feathers bluish grey, with the margins a shade lighter. The feet and toes bluish grey. The colours, and also the lustreless surface, which makes them appear the same in all lights, are sober and soft, with the exception of the well-defined black-cap on the head, but they harmonize very pleasantly : and as the shape of the bird, especially that of the head and neck, is very handsome, there are really few more classically beautiful birds in the brake.

Its haunts appear to be different in different parts of the country, those in which it finds tall brakes or low copses; but it can hardly be considered as a marsh bird. It is found in broom brakes and in copses of deciduous trees, and rarely in furze or other prickly evergreens. A hollow stump near the ground is preferred for the nest, and as that is abundant in willow grounds, and also in the stools of oak copses that are cut for bark, it is found among them; but finding a tree fit for its accommodation, it nestles in the thick of the bushes; and in the broom its nest is found near the roots. The nest is formed of moss and vegetable down, the latter, of course, varying with the haunt. The eggs are about the same in number as those of the coal-tit, but a little larger, and the spots more numerous and rather closer together at the thick ends. 
In summer these birds consume a great number of flies, bees, wasps, moths, and all winged insects generally; and when the animal supply fails, as the birds do not resort so much to the holes, high branches, and buds of trees as most others of the genus, they feed more on seeds, especially those of the composite flowers; but they also resort to the farm yards in winter, and do not refuse carrion or any other animal garbage, if it comes in their way.

the long-tailed tit. (Parus caudatus.)

This species (which from the peculiar form of its nest, is called the "bottle-tit," or " bottle-tom," though these names are local, and have little truth of application) is the smallest, but, at the same time, one of the most active and beautiful of the genus.

The whole length of the bird is about five inches and a half, of which the tail occupies three; so that the body is really shorter than that of any other British bird; but it is thick and firm in proportion to the length, and the weight is nearly equal to that of the cole-tit. The bill is very short, and as the feathers on the head are rather produced, it appears shorter than it really is; and the lively attitude, and peculiar markings of the plumage, give it a fiercer aspect than any of the others. The bill and feet are dusky, inclining to black; and the irides dark hazel, with a ring of reddish orange margining the orbit of the eye. From the bill to the nape there extends a prominent band of white feathers, which are pointed, and stand half erected, hiding anteriorly the nostrils and basal part of the bill, and more or less tinged with rosecolour toward the nape, and less or more marked with grey or dusky at the tips. Below these there is an arch of black feathers, pointing upwards, which extend from a little before the eye to the nape, where they meet, and the black con. tinues on the anterior part of the shoulders, and along the middle of the back, in a line gradually diminishing in breadth. Around the eye a radiated patch of white, narrow between the eye and the gape, but extending, with pointed feathers, 
backwards on the cheek, downwards on the side of the neck, and forwards to the throat, till it blends with the white upon that and the breast. The feathers on the throat are rather produced and pointed, and some of them marked with grey or dusky on the points. The sides of the back and the scapulars are pale rose-red, with some of the feathers margined with white, and others with black or dusky on the central parts. The quills are black, and the secondaries black or dusky, margined with white. The white on the throat and upper part of the breast passes into pale ash-grey, which is more or less blended with pale rose-colour, especially on the flanks, but partially along the whole of the under part, as far as the under tailcoverts. The tail, which is as remarkable for its straightness as for its length, has the four middle feathers entirely black, and longer than the rest, and the others margined with white on their outer webs, and white at the tips, excepting the two next the black ones, which are white at the tips only.

The sexes very much resemble each other in their plumage, but the colours in different individuals are subject to considerable variation. In some, the dark arch orer the eye is wanting, and in others the greater part of the cheeks are dusky, with only a few white feathers radiating from the eye. But the form and size of the birds are so peculiar, that they are at once known from every other species, whatever may be their colour.

They are tree birds, or more strictly bush birds, and keep so closely to their cover, that they appear much less numerous than they really are. That is not owing to any deficiency in wing; for though the wings are short in proportion to the tail, they are not so in proportion to the weight of the bird.

The flight is vigorous for such small birds, and the length of tail gives them a very peculiar appearance.

Long-tailed tits are among the most active and even laborious of birds; and diminutive as they are in size, they are so well knit in their little bodies, that it appears as if no degree of fatigue could wear them out. Their food appears to be the very smallest species of insects in the hedges and copses; and though the number of these be great, the individuals are 
so minute, that it requires many of them to form a meal even for a long-tailed tit. The birds are accordingly incessantly in motion among the twigs the live-long day, and never use their wings in sportive flight, but in leaping from spray to spray, or posting from bush to bush. Saw-flies and their larvæ, and eggs, aphides, ants, small spiders, and generally all the minute creatures with which the twigs and branches swarm in summer, constitute their food at that season of the year; and as the first races of these make their appearance, even with a mid.-day gleam, in the very early part of the sea.. son, and continue race after race, till the very latest period of the autumn, there is plenty for the birds for at least nine months of the year, only that plenty is not procurable with. out incessart activity. When the insects in the larva or the winged state, and the little spiders, fail, there still remains a plentiful supply of eggs; and the absence of the leaves makes the niches in which these are concealed, whether that be a silken nest or a gummy case, much more easily seen than during the season of even that decaying verdure in which the eggs are deposited. Thus, the concealment of the leaves while the grerms of broods for the future year are committed to the trees, is of advantage both to the preyers and the prey. While the foliage remains, the birds cannot easily find the eggs; and thus they are obliged to hunt for the grown insects, many of which they capture merely in time to save them from perishing in the course of nature, which they in general do very soon after the eggs are deposited. The insects are so much more numerous than the birds, that notwithstanding the captures which these make, the eggs that are deposited would produce probably a hundred times more than the stock of the former year; and minute as the indivichuals are, and few as are all the races that are found in the haunts of the long tailed tit, as compared with those in the whole country, yet, if the whole deposit of one year were to come to maturity, the injury which they would do to vegetation would be very great, and their numbers would bring about their own extermina.. tion; but when the leaves and herbage, under cover of which

VOL. I. 
the eggs are depositcd, are in the course of nature cleared away, as many of these are disclosed to the acute vision of the bird as serves for a winter supply; and in procuring that, the birds display the same energy, and the same curious attitudes, as the crested wrens, with which they are not unfrequently found in company.

It is probable, however, that though the bird is a little larger than the golden-crested wren, (it is very nearly the same as the fiery-crested,) it feeds upon smaller prey. From the centre of the eycs to the tip of the bill, is only four-tenths of an inch, while that in the golden-crested wren is one onehalf morc, or six-tenths. Hence it is probable that, in its vision, the long-tailed tit is the most microscopic of birds. Now it accords with analogy, and with observation, as far as that can be carried, that the shortest focal length of the eye, that at which minute objects can be distinctly seen, is never much longer (if longer at all) than the distance from the eyc to the tip of the bill; and nearer than that would be useless.

Hence we havc a very easy means of judging of the relative power of vision in those birds which feed upon very small substances, and which, bcing hard-billed, as the tits are, or not having the bill covcred with a sentient membrane, or the nasal groove continued to the point of it, as is the case in that most singular of all birds, the apteryx, or wingless bird, of New Zealand, must feed wholly, or chiefly, by sight.

In the average of human eyes, of good formation, and in a healthy state, the common focal distance for small objects, such as for reading very small print, is about seven inches and a half; and the microscopic distance, such as that at which a very delicate engraving is examined, (and that requires a little time for the adjustment of the eve), is about one-third less, or five inches. The bird must often strike its prey without any time for adjustment, and therefore the distance from the eye to the bill may be taken as the ordinary short focal length; but call it microscopic, and the magnifying power in line being inversely as the focal length, the 
lineal dimensions of an object seen by the long-tailed tit, will be, to that of the same seen by the human eye, as five inches to four-tenths of an inch, or as twelve and a half to one. The surface will of course be as the square, or as $156 \frac{1}{4}$ to 1 ; and the body, or solid of an object, as the cube, or $1953 \frac{1}{8}$ to 1. Thus an aphis, or any other small insect that can come wholly within the field of vision, will appear very nearly as large to the long-tailed tit, as two thousand of the same would do to the human eye.

As the subject is one of considerable interest, and not generally noticed by authors, it may not be amiss to state the relative magnifying powers, as compared with the human eye, of the eyes of some of the other birds that subsist chiefly by picking their prey from the bark and the buds of trees.

RELATIVE MAGNIFYING POWERS OF THE HUMAN EYE AND THE EYES OF BIRDS.

\begin{tabular}{|c|c|c|c|c|}
\hline & $\begin{array}{l}\text { FOCAL } \\
\text { LENGTH }\end{array}$ & LINE. & SURFACE & BULK. \\
\hline & Inches. & Times. & Times. & Times. \\
\hline MAN (standard). & $5^{\circ}$ & $1 \cdot$ & $1 \cdot$ & $1 \cdot$ \\
\hline Green Wood-Pecker . & $2 \cdot 25$ & $2 \cdot 2$ & $4 \cdot 84$ & $10 \cdot 648$ \\
\hline Nut-hatchi $\ldots$ & 1 . & 5 . & $25^{\circ}$ & $125^{\circ}$ \\
\hline $\mathrm{W}_{\mathrm{RY} \text {-NECK}} \ldots \ldots$ & $\cdot 85$ & $5 \cdot 8$ & $2 S \cdot 64$ & $166 \cdot 112$ \\
\hline Creeper, and Larae Tit & $\cdot 7$ & $7 \cdot 1$ & $50 \cdot 11$ & $355 \cdot 781$ \\
\hline Crested Wrens .... & $\cdot 6$ & $8 \cdot 3$ & $68 \cdot 89$ & $571 \cdot 787$ \\
\hline Cole Tit ...... & $\cdot 5$ & $10^{\circ}$ & $100^{\circ}$ & $1000^{\circ}$ \\
\hline Blue Tit ...... & $\cdot 45$ & $11 \cdot 1$ & $123 \cdot 21$ & $1367 \cdot 631$ \\
\hline Long-tailed Tit . . & $\cdot 4$ & $12 \cdot 5$ & $156 \cdot 25$ & $1953 \cdot 125$ \\
\hline
\end{tabular}

This table will be easily understood. The first column of numbers is the focal lengths of the eves in inches and deci1 2 
mals, and it is found by actual measurement. The second column is the number of times, and decimals of a time, that the eye of each of the birds, whose names are prefixed, magnifies in line, as compared with the standard of the human eye, at five inches' distance; and the numbers are found by dividing five inches by the focal length of the eye as stated in the first column. The third column is the magnifying powers in surface, and the numbers in it are found by multi. plying those in the second column by themselves. The numbers in the last column are the magnifying powers in bulk, and they are found by multiplying together the corresponding numbers in the second and third columns. In consequence of the greater magnifying power, an insect a quarter of an inch long will appear as large to the eye of the long-tailed tit, as the common mouse does to the eye of man, when held as near as it can be seen.

The microscopic power of the eyes of those little birds which seek for minute prey on the bark of trees, is, therefore, as wonderful as the telescopic range of the eyes of eagles and other birds which soar aloft, and scan a horizon of miles; and not the least wonderful part of the whole matter is, the ease with which the eye changes from telescope to microscope. The eye of the eagle, which can discern the motion of a small quadruped at the distance of more than a mile, can shorten its focus, so as to be keen and perfect, at the distance of a few inches: and the tit, to whose near vision the eggs of flies must appear as large as musket bullets do to us, feels no difficulty at seeing a bush at the distance of more than a hundred vards. We may admire, but we cannot imitate, that wonderful mechanical skill which can, in an organ not altogether larger than a pepper-corn, produce so many focal lengths in the same crystalline lens, instantly adapt the retina, or sentient tissue, to all of them, manage the admission of the proper light by the iris, and remore the colours and correct the aberrations by the other humours-all, as it were, in an instant, without effort, and (to use the common, though un. philosophical terms) without will or eren consciousness on the 
part of the owner. But curious as the subject is, and wide and wonderful as is the ficld of investigation to which (if properly followed out) it would lead, we must leave it, with our warmest recommendation, to the attention of even the common reader, (to the scientific it needs no recommendation,) and return to the individual bird in which the microscopic power is so very great.

But though the vision of these little birds is thus remarkably nice and microscopic, capable of discerning clearly objects which to our cyes are not at all visible, yet it is not to be supposed that they depend wholly upon the eye in all their motions. Eyes have, no doubt, a wonderful flexibility in their focal length, so that the same eye is to a very considerable extent both a microscope and a telescope. But still their flexibility, or power of adaptation, in that way, has a limit; and as the focal length of the long-tailed tit's eye is not a twelfth part of that of the human eye, we may suppose that it cannot see so well at the distance of half a mile as man does at the distance of twelve miles.

Indeed the estimate should be taken somewhat differently; the mean range of near distance in the human eye is probably about half the length of the arm-say about fifteen inches, as that is the medium point to which the eye guides the hand; and thus the acting focal length of the human eye is between thirty and forty times that of the long-tailed tit's eye, so that one furlong is as telescopic to it as five miles art to man; and that man would be sharp-sighted who could distinguish a loaf of bread from a grey stone at the distance of five miles.

But the tits find out carrion at long distances, probably at the distance of several miles, and therefore we must suppose that they are, on their long flights, guided by some other means than sight. What these means are, whether scent or some other species of perception, to which, as a sense, we can give no name, we do not know, and it is neither useful nor wise to speculate. In matters of reasoning and inference we are free from the trammels of the body, but, in matters of 
mere animal sensation, we can know nothing beyond the power of our own organs of sense, or of the artificial means by which we can contrive to improve these. Science has yet found out no contrivance by which the sense of smelling can be improved. Indeed, as the sense of smell is in a great measure " a feeding" sense, the probability is that our acuteness in the use of it diminishes as the comforts of society improve. At all events, we are far less acute than man in the savage state; and we say proverbially, "A hungry man smells meat afar." No doubt the saying is allegorical; but when we find an allegory made a proverb, we may in general depend upon the literal foundation being a well-known fact. The subject is an exceedingly curious one; because it involves not only the flights of birds from place to place within the same country, but also the means by which they are guided upon their longer migrations. So far as the bird is driven from the place which it leaves, we can and do understand; but how it is directed to the place to which it comes is beyond our philosophy, because the data by means of which alone we could work it out, are beyond the cognizance of our senses. Where knowledge is attainable, it is our own fault and misfortune if we remain ignorant; but there are subjects which appear to be under the taboo of natire, and to waste our time and labour on these is among the worst species of idleness. But let us return to the bird.

It is not in the procuring of its own food alone that the long-tailed tit has to labour diligently; its brood is very numerous, and they are as assiduously fed, and far more comfortably, nay, elegantly lodged, than those of any other birds.

The nest of this species has always attracted notice as the model of neatness and warmth among nests, and we have very accurate descriptions of it handed down from times at which the habits, and even the forms of birds, were but imperfectly known.

The nest is a structure formed by the patient and incessant lisbour of both birds for at least a month, even in those places 
where materials are most abundant, and requiring five or six weeks where these are more scanty. It is placed in the fork of a small mossy tree, or among the thick twigs of a shrub, often of a hawthorn, and sometimes of an evergreen; but it is seldom more than three or four feet from the ground, and generally, if not always, more or less within the cover of the sprays. In form, it is an elongated spheroid, or rather that of an egg placed on the larger end; and in appearance and texture it is very like a short decayed stump which has become coated over with lichens, and it is as firm in texture as it is neat and regular in form. The main fabric is closely made of moss, taken in very small pieces, and matted together with animal fibre, rarely with wool, as the bird does not range so far from the bushes as to be much of a wool-gatherer, but principally with what may be called tree or bark silk; that is not the thread of spiders, either those that are spun for snares, or as gossamer, to waft the spinners through the air, for the last of these hardly stand a shower, and the first disappear during the winter; but the silken cocoons, indiscriminately, perhaps, of the crysalides of insects and the eggs of spiders, both of which are much less perishable, and consequently much more abundant in the early part of the season, when the birds build.

These materials are firmly interwoven. But, though the term is sometimes applied, they are not felted, as they are not of a feltable nature, even though the birds could perform that operation; and as it is an operation which no bird can perform, the name ought never to be used in describing the texture of nests. The two materials form a stronger fabric than could be made of any of them singly. The moss gives bulk and stiffness, and the silky filaments cohesion; and as the birds are microscopic in their vision, have perfect command over their short bills, and apply these materials by very small portions at a time, the fabric is beautifully put together, and when there are twigs in the way, the nest is so closely worked upon these, that it cannot be removed entire unless they are taken along with it. Externally it is coated with 
lichens and liverworts, applied in small pieces, but so close as to hide all the substantive materials, and so firmly worked in, that not a bit falls off. The inside is carefully lined with feathers, the tubes or quills of which are worked into the fabric, so that nothing can be felt internally but the down and sides, of which there are several falls, as there are in the clothing feathers of a bird. The whole nest, dome and all, is lined in this manner; so that the nest, when finished, is equally secure against rain and change of temperature.

The entrance is by an aperture in the side, toward the top of the structure; and there are, in some instances, two such apertures, the one nearly opposite the other, the feathers around which are so worked into the fabric as, when not pushed aside by the birds, to form a sort of curtain. The interior is usually of sufficient size to contain both birds during the night; and they, in the case of two apertures, sit with the head of the male out at the one, and the tail of the female out at the other, so that both apertures are partially closed, and the male is ready to start out, as soon as there is light enough for hunting. But, notwithstanding these precautions, the long tails of the birds are often so much bent, torn, and otherwise injured, during the incubation, that they do not regain their peculiar flight, which is something resembling that of a short dart armed with a long feather, till after the moult.

The nest is altogether one of the most extraor linary of animal structures. It is built wholly of gathered materials, without any secretion by the birds either as a cement or otherwise. That any bird uses a secretion of its own body in the construction of its nest, cannot indeed be regarded as an absolutely demonstrated truth, and in the case of the longtailed tit, rational hypothesis does not go so far even as to lead to the belief that any of the materials adhere to each other by being glutinous, because in that case they would be as likely to adhere to the dry surface of the bill, or at least to the produced feathers at its base, as to ary thing else. Thus the nest in question must be regarded as being wholly a me- 
chanical structure, owing its compactness to the manner in which the materials are put together; and, in the mere mion of its parts, perhaps it is the finest mechanical structure, independently of living structures, that is any where to be met with. The best of human workmen would find more difficulty in imitating the execution of a long-tailed tit's nest, than in imitating any work of human art.

Nor is that at all to be wondered at, when we consider the implements with which it is made. The power which the bird has of perching on one foot, if necessary, so as to have perfect command of its whole body; the nice, yet powerful forceps formed by the firm, short, and pointed bill; the innumerable motions that may be given to them by their own peculiar muscles, and the motions of the neck, and of the whole body, if necessary ; and the high magnifying power of the eye, which guides the whole; are altogether vastly superior to any set of tools with which man can be furnished. A power of four, or one inch and a quarter focal length, is inconvenient even in very small works, and a power of six has so small a field, that it can hardly be used; but the bird has a power of more than twelve in its natural sight-so that, with that power, it commands any extent of field, fully better than we can do, with the naked eye, at the distance which answers to a power of eight. When we reflect upon these adaptations, we may cease to wonder that the work itself excels our art.

In the early part of the season, the male of these birds has a weak, but not an unpleasant song; but when the season has advanced so far that the labours of it are in vigorous progress, there is little leisure for singing. While the nest is building, the birds have barely time to feed; and when the eggs are laid, the one sits while the other feeds, the male going out first in the morning, and the female last at night. The eggs vary in number, from eight or ten to twelve or fifteell, of a clear white ground, more or less marked (but always sparingly) with small red specks towards the thick ends; but they appear of a pink colour when held up against 
the light: they are not much larger than peas. Unless the eggs are removed and the feathers carefully examined, the total number is not easily discovered, as they are always in part buried in the soft lining of the nest.

When the young are fledged, they continue for the remainder of the season together, and with the parent birds; and in the cold weather they roost for the night all huddled together on the same twig, and indeed, seldom quit the bushes even at that season. The latter circumstance has led some to conclude that they are migratory, which, however, does not appear to be generally the case, though they may, under certain circumstances, shift their ground. They are birds of rich and rather humid situations, where the seasons are mild, and small insects abound in summer and their eggs in winter, and where the foliage is close during the former season, and the leafless sprays thick during the latter. Their peculiar form, their diminutive size, their lively action, their laborious lives, their beautiful nests, the number of their broods, and their strong and lasting family attachments, render them among the most interesting of our little birds.

\section{THE BLUE TIT. (Parus caruleus.)}

The blue tit, of which a figure is given on the plate opposite, on a scale of one third of the lineal dimensions, is a very beautiful and lively little bird; and few of the British species are either so generally distributed or so numerous in their localities. In some places of the country it is called the tom-tit, and in others the "ox-eye;" but as both of these names are, in other places, given to the great tit, it is better, for general purposes, to avoid them altogether, and retain only that trivial name which is expressive of the prevailing colour of the upper part of the bird, and thus can lead to no mistake in any district.

The colours, though different in their tints from those of the great tit, bear some resemblance to them in their disposition. The forehead, sides of the head, and cheek, are 
white, divided by a black line across the eye; the crown of the head is blue; the nape, and collar round the neck, bright azure; the back a mixed tint of azure, grey, and green, the azure generally predominating, but all confluent without mottling; the wings and tail are pale blue, the greater coverts of the former with white tips; the throat and mesial line on the under part, deep blackish blue; the breast pale yellow, passing into darker and greyish yellow on the sides; the bill and feet blackish grey. The colours of the male are subject to some variations, in all probability climatal ones, as in hot countries the blue on the back, which has always a tinge of greenish grey, becomes olive green, and even inclines to dusky, or black, and the yellow on the under part becomes paler. The female is a little paler in the tints than the male, has less blue on the head, and is rather smaller in size. The young birds have the light parts more inclining to yellow, and the dark more of a greyish and greenish cast, than the birds in mature plumage.

If the length of tail in the last species be included, it is longer than the present; but as the tail is not half the length, the body of the bird is longer; and it is also more stoutly formed, and one, half heavier, being rather more than threeeighths of an ounce. The length from the eye to the point of the bill has been already stated as being the shortest of any British bird, excepting the long-tailed tit. It is considerably shorter, in proportion to the size and weight of the bird, than that of the great tit; and hence the blue one is the most expert in the capture of very small game; and its stroke and bite are sharper in proportion.

The blue tit is a tree or bush bird, like most of the other species; but it is an inhabitant of the cultivated lands and their margins, rather than of the wilds. It nestles, and indeed generally lodges for the night, in holes of trees or of walls, and it is said to vary them with the season, choosing warmer ones in winter and colder ones in summer, though that wants confirmation; but the trees may be considered as its native pastures, in which, during the greater part of the year, it hunts 
for insects and larvæ. It is, perhaps, more incessant than any other bird in hunting the buds and branches of trees, especially of fruit trees near houses, for its insect prey. But it is not confined to these. It will eat any animal matter either in a recent or putrid state; and it appears to scent animal remains at a considerable distance, as it hovers about slaughter-houses, dog-kennels, and other places where there are animal scraps or carrion. It also haunts the neighbourhood of louses, and picks bones, eats bits of fat or any refuse that it can find; and when opportunity favours, it kills other birds by punching them on the head, and picks their bones as clean as if they were cleaned by the thousands of an anthill. Dead birds are, of course, lawful prize, for which it searches under trees and hedges after severe weather. It is, in short, a very omnivorous bird, and plays the scavenger with equal diligence and grace. It is also very bold and familiar, and will alight among the poultry in the farm-yard or the dogs in the kennel; nor does it much heed the presence of people under the trees upon which it is hunting.

The last trait of its character makes it easily studied; and the best trees for watching it in are standard apple trees which are partially injured by insects. Dull days, threatening rain, in the summer months, and the mornings in the autumn and spring, are the best times for observing it. In summer it lurks more within the trees than at other times, though not so much upon the bole and larger branches as the nut-hatch and creeper. In autumn and spring, as well as in winter, (though at that season it sometimes finds the ground a better pasture than the trees,) it is more among the buds, and though it may sometimes drive off clean buds in the bustle and activity of its search, it probably does not pick off any with its bill, except such as contain the eggs or the larva of insects.

Granting that it does sometimes take off buds which would produce shoots or fruit notwithstanding the insects that are in them, or even buds in which there are no insects, it must not be supposed that the effect is always mischievous. Whether the beauty of trees can or cannot be improved by pruning 
is a matter of taste; but it is matter of fact, that judicious pruning does improve the value both of timber trees and forest trees, by producing long straight boles in the former, and more abundant or larger fruit on the latter. There no doubt remains a question as to the quality of the timber and the flavour of the fruit, but there is none as to the market. able appearance. If the pruning is delayed till the shoots that are regarded as injurious be grown, all that part of the action of the tree which went to their formation is lost; and in the case of forest trees the wound made by the removal of a large branch injures the timber, and in fruit trees it hastens the decay of the tree. Insects do not generally deposit their eggs on the most forward and principal buds; and thus the ones which they do attack are those which can be best spared - spared with advantage, if the destruction were to be confined to them; and it is no exaggeration to say that, in many instances, the valuable part of the tree grows twice as much in the course of the year, in consequence of the pruning which the inferior parts have received from those birds which nip off the tainted buds for the sake of the insects they contain. Among these birds, especially in gardens and orchards, the blue tit holds a conspicuous place; and therefore it ought to be hailed as a welcome, and cherished as a most useful servant.

It also has recourse to vegetable food, to the oily seeds at all times when the supply of insects fails, and to grain, especially oats, when the ground is covered with snow, and food is not to be had either in copse or field. On such occasions it draws the oat ricks, and perching on a bush with one foot, holds the grain with the other, till it has divided the husk by repeated strokes of its bill. It will also attack a pea or nut, but does that on the ground. The activity and resources of the bird, during the inclement season, are not less interesting than its action in the trees at other times.

The blue tits feel the influence of the season early, and although the male can hardly be said to have a song, he testifies his feeling by two chirping notes, that are lively, 
though not musical, and he is much more bustling than at other times. The nest is formed in holes of trees or walls, and sometimes among the thickly matted herbage at the root of a bush. The body of it is composed of moss, and the lining of hair or feathers. A hole, when it can be had, is preferred to any other situation, and it is often trimmed by excavation. The eggs are from six to eight or ten, of a white ground with rust coloured specks at the thick end. In the latter stage of the incubation the female is a very resolute sitter; and, as she has no back door for retreat, she defends the entrance to the nest with great boldness and determination, erecting her feathers, hissing and biting very sharply, and no doubt offering successful resistance to predatory birds, secured as she is from attack every where save in front. It is not personal safety that induces her to be thus bold; for if taken forcibly from the nest, she will fly straight back to it, and offer the same resistance as before. It is only in the later stage, however, when exposure to the air would be most injurious, that she is so resolute. At other times, if an egg is broken, or the nest is otherwise altered or deranged in her absence, she will abandon it and commence anew; but if no accident happen, the pair (generally at least) rear only one brood in the scason, with which they resort to the gardens (if these have not been their nesting places) rather early, and commit depredations by digging into the wormed fruit. The birds are of rather pugnacious dispositions, and very forward in the attack of any strange bird, however large, that may appear in their haunts.

The above enumerated species comprise all the birds of the genus parus, which are generally or popularly known as British; but there are two others, one of which is certainly a resident, and analogy is in favour of the residence of the other. Residence is, indeed, so much the habit of the genus, that we could hardly look for even a straggler. The omnivorous disposition of the birds enables them to live at all seasons in the same latitudes, with only a slight change of their ground with the seasons; and, as the species which 
remains doubtful as a British bird belongs to the zone of the pine forests, and is found both on the continent of Europe and in America, it is at least worth seeking for as a British bird. The two species in question are, "the crested tit," a woodland bird, and " the bearded tit," a marsh bird.

the CRested tit. (Parus crestatus.)

The title of this beautiful little bird to a place in the British Faunæ, rests upon rather slender direct evidence, - that of a single specimen received by Dr. Latham from the forest of Glenmore in the eastern Grampians.

These birds inhabit, abundantly and permanently, the pine forests and the adjoining or interspersed jungles of juniper or other shrubby evergreens, in Scandinavia, the countries on the south of the Baltic, the Carpathian mountains, and the hilly districts of France ; and they are also found in the pine forests on both sides of the St. Lawrence in North America. But in all their localities they are hidling birds, never seen out of the forests, and but seldom there in proportion to what, from the eggs, (which are as many as ten,) may be presumed to be the total number of the birds.

The proper places to look for these birds are the natural pine forests, the juniper brakes, and the fir plantations in Scotland southward of the Moray Firth, on the borders of the great glen of the lakes, and in Strathglass between the river and Mam Suil ; the last of which deserves more minute observation than it has hitherto met with, from its proximity to both seas, and the mildness of its climate as compared with the elevation of its surface-there being a rich sward upon Mam Suil at a greater height than that at which all vegetation but lichens ceases on Ben Nevis, which is nearer the Atlantic, and farther to the south, though the small lake in the north-east gorge of Mam Suil remains frozen to the bottom even in the warmest summers, and the mountain is very copiously deluged with rain. 
I have been much in those forests, and in them at different seasons, and never saw or even heard of the crested tit. That, however, is no proof of its not being there, because the golden crested wren, which inhabits the same places, and is presumed to be abundant, is rarely seen. To search an extensive pine forest for a little bird is no very promising matter. If the trees are young and close down to the ground, as they generally are when they are in that state, it is impossible to discover any bird except one which rises, because the rustling of the branches is unavoidable, and sufficient to keep all the feathered tribes beyond view of the tardy and laborious observer; and, if the trees are aged, the branches are so far from the ground that little birds are nearly out of view. The time at which they would be best seen, would be when they resort to the juniper bushes for winter feeding: but then both ground and bushes are either covered with snow, or the former is so sludgy as not to be easily walked on. Besides, there are more than three hundred square miles of forests to examine, and consequently one cannot very safely conclude that any little bird whose habits are in perfect accordance with the climate and locality may not be there. In matters of natural history observation tells us what there $i s$, so far as it goes; but we have no guide whatever to what is not.

The length of this species is rather more than four inches and a half, the breadth about eight inches and a half, and the weight between two and three drachms; the bill is nearly black, the feet lead-coloured, and the irides hazel. The upper part of the body is olive brown, passing gradually into yellowish white on the under part. The wings and tail are dusky, the chin black, the cheeks hoary, or white mottled with dusky. A black line passes above the eye, round the ear covert, and returns under the eye; and there is another black line margining the produced feathers on the cheek. The feathers on the hind head form a crest, which is partly hoary, but black on the top, and bends forward something in the shape of the Phrygian bonnet. The bird is said to nestle in hollow trees (though these are not common in pine forests): the eggs are white with reddish spots. 
THE BEARDED TIT-Or lather BEARDED ROAD-BIRD.

(Parus

\section{biarmicus.)}

This species differs from the rest of the genus, in its appealance and its locality, so much as to make it doubtful if it should in reality be classed with them. It is a marsh bird, and inhabits more deeply and more silently in the reeds than either the reed-warbler or the reed-bunting. It inhabits the marshy zone of country which extends from the great saltlakes of Asia a considerable way up the valley of the Danube, and again in Holland; in all of which places it is a resident bird, feeding upon insects and mollusca among the reeds in summer, and upon the seeds of the aquatic plants in winter. It has the same command of itself upon a waving perch as the other tits and the buntings; but it is seldom seen, unless when the reeds are cut down, and then the family, which consists of six or eight besides the parent birds, flit onward before the reed-cutters, not taking high flights, but generally lurking huddled together when the cold weather sets in. It is but recently that these birds have been ascertained to be resident natives, and they have been met with only in the fenny parts of the south-east of England; nor is it likely that they are to be found in Scotland, unless, perhaps, in the reeds which skirt some parts of the Carse of Gowrie.

This species is between six and seven inches long, of which the tail occupies fully half, the two middle feathers being longer than the others, and lancet-shaped at the points. The body is more slender in proportion than that of the other tits; the first quill of the wings is nearly rudimental, and the bill is orange yellow, more pointed and conical than that of the other tits, very slightly bent, and altogether more of a graminivorous character.

Its plumage is beautiful: head, nape, and breast bright bluish grey, paler and with a tinge of lilac on the chin and throat; hind part of the neck and back bright orange brown, paler on the scapulars; belly, sides, and thighs like the back. 
only a shade lighter. Quills dusky; the inner webs of the primaries white; the secondaries margined, and the tertiarics tipped with the same colour as the back. Tail the same colour as the back, with white tips to three exterior feathers on each side: vent-feathers black. In the male bird, a tuft of soft black feathers originates between the bill and eye, and is pendant by the side of the neck, terminating in a point; the female has merely a dusky spot, in the place of the tuft of produced feathers, and has the head mottled with orange-brown and dusky. The nest is formed of the leaves of reeds and aquatic grasses, and lined with the tops of the same; it is carefully hidden in the reeds, or, if the ground is not solid enough there, in a tuft upon the margin. It has not been ascertained that the bird has any song, but its single note is more shrill and ringing than that of most of the genus : it is one of the subjects which equally demand and deserve farther observation.

There are still remaining many miles of the marshy parts of the country at home, of which wonderfully little is known, because they are not inviting under any circumstances, and very often they are not accessible. In summer they are not firm enough for the foot, and one has some reluctance at taking the chance of drowning, or even of sticking fast in the foul water or fenny mire of a "deep bed of whispering reeds;" which are not ungraceful as they play in the wind, but they grow in places of which we are suspicious. In winter again, even in the floods, there is no passage for a boat; and as the frost in England is seldom so severe as to consolidate the surface of those places, they are less inviting then than even in summer.

The fact that, till within these few years, the bearded tit was not admitted into the list of resident British birds, or even into that of regular migrants, while it has been found that it is not only resident, but far from rare in those parts of the country which are favourable to its habits, points out pretty strongly the necessity of scrutinizing those places which have been neglected, and also of not coming to any hasty 
conclusion, that a bird which is rarely seen, is only a strag. gler and need not be sought for. If, indeed, the habits of the bird in any other country be well known, so that from its haunts, its food, or any other circumstance, it can be clearly inferred that no part of Britain is well adapted for it, and that the adaptation is worse at the seasons at which it has not been found, than in those in which it has; or if the bird is a migrant, and belongs to a migration which is distant in longi." tude, and ranges over a great extent in latitude, then we may safely conclude that it is only a straggler. But if those circumstances do not apply; if the bird inhabits nearly the same climate as that of Britain, does not change far in latitude seasonally, is a bird of rare occurrence, concealed habits, and obscure history in other places, though we ought not to decide without proof that it is a British bird, we are as little entitled to decide the other way without proof. In such cases, it is always of use to examine; and if the young be found early in the autumn, and before the supply of food shall have failed, or the cold weather set in, in places farther to the north, that is an additional inducement to examination. The labourers in the field of British ornithology are now many, and the harvest which has been reaped since fresh ardour and improved science were brought to the task, show that the field is not yet exhausted. 
LON D ON :

GILBERT \& RIVINGTON, PRINTERS, ST. JOHN'S SQUARE. 


\title{
CUVIER'S NATURAL HISTORY,
}

\author{
COMPLETE IN SIXTEEN VOLUMES,
}

Illustrated by upwards of EIGHT HUNDRED ExGRAVIXGs, mally of them from

Original Drawings, by LANDSEER, BASıKE, and other Engravers.

PUBLISHED BY WHITTAKER \& CO. AVE MARIA TANE, LONDON.

\section{THE ANIMAL KINGDOM,}

DESCRIBED AND ARRANGED IN CONFORMITY WITH ITS ORGANIZATION,

BY THE LATE

BARON CUVIER,

MEMBER OF THE INSTITUTE OF FRANCE, \&c. \&c.

'Translated, with large additional Descriptions of all the Species hitherto named, and of many not before noticed, and with other Original Matter,

By E. GRIFFITI, F.A.S., Lt-CoL.C. HAMILTON SMITH, F.R.S, E. PIDGEON, J. E. GRAY, F.R.S., AND OThERS.

'Tне translation of Baron Cuvier's inestimable work on the Animal Kingdom was undertaken with the intention of supplying the great and acknowledged want in English literature of any treatise on Zoology possessing even tolerable pretensions to completeness. While continental nations were rapidly enlarging the bounds of Natural Science, and minutely examining the details of its several departments, we continued to look on with apathy, though England possessed the greatest facilities for the cultivation of zoological knowledge, and the deepest interest in its advancement. The dawn of improvement commenced with the publication of the first part of this work, and has since gone on steadily increasing. The first object of the conductors of this great undertaking was to give a complete translation of the Baron's " Regne Animal," as close and accurate as the idioms of the two languages would admit; thus affording, for the first time, to their countrymen, a scientific synopsis of the varied living tribes that tenant earth, water, and air, arranged according to the laws of their conformation: they could not avoid perceiving that the low state of zoological science in England was owing to the prevalence of systems, in which arbitrary character's and accidental resemblances, instead of structure, were made the basis of classification; and they but followed the opinion of all the enlightener men in Europe, when they adopted a system founded mainly on organization, " a system of zoology," as Cuvier himself describes it, " that may serve for an introduction and a guide in anatomical researches, and such a body of anatomy as may tend to develope and explain the zoological system." 


\section{CUVIER'S NATURAL HISTORY.}

Had their labours terminated here, the conductors of the work felt, that though they would have performed services of no inconsiderable magnitude to British science, still the sphere of their utility would be limited; for a mere catalogue of the divisions of the Animal Kingdom, however ably constructed, however valuable to the working zoologist, and comparative anatomist, must, of necessity, seem dry and repulsive to the general reader. They, therefore, have added to the Baron's classification, a vast body of authentic information respecting the instincts, habits, \&c., of animals, collected from the works of the most observant travellers, and the researches. of the most eminent naturalists, conveyed in a popular form ; containing, therefore, all the interest that belongs to treatises on the remarkable productions of nature, without any sacrifice of scientific accuracy. Their plan received the sanction of Baron Cuvier himself : a little before his lamented decease, he expressed his great satisfaction at seeing, from the portion of the work then published, that he was about to be introduced to the British nation under more favourable auspices than he could reasonably have anticipated.

The conauctors felt that, in a country whose prosperity depends so much upon its trade, it was of the utmost importance to supply accurate information respecting the commercial value of animals, and animal productions; and to this subject they have devoted a very large portion of the supplementary matter. 'The salt-provision trade, the fur trade, the various branches of the fish and fish-oil trade, \&c., have been carefully examined, the former causes of fatal errors minutely investigated, and the suggestions of experienced practical men diligently collected, both to extend present good, and to prevent the recurrence of former evils.

They have also paid much attention to the possibility of increasing the number of domesticated animals, especially the poultry tribes, of which it is probable that a much greater variety might easily be brought under the dominion of man.

The connexion between Zoology and the new science of Geology, which is daily increasing in interest and importance, induced the conductors to direct their attention to the fossil remains of extinct species of animals, that seem the relics of a former world. They have devoted an entire volume to this interesting object of enquiry, detailing the structure and organization of these wondrous objects, the strata in which they are found, and the order in which they are arranged; but they have car efully aroided adopting any peculiar geological theory, and strictly confined themselves to a lucid statement of facts.

Aware that general, and not ungrounded objections, have been urged against the zoological treatises of the continental naturalists, who too frequently make their theories the vehicles of the insidious poison of infidelity, sedulous care has been exercised to remove not only what was positively dangerous, but what was capable of being distorted to the prejudice of religion, by the careless, the ill-judging, or the malevolent. 'The conductors feel that Natural History, properly considered, is replete with the strongest evidence of the omniscience and benevolence of an Almighty Creator. "How 
wondrous are thy works, O Lord, in wisdom hast thou made them all!' 'They have, therefore, taken every fair opportunity to direct attention "from nature up to nature's God," whose power, whose goolness, whose skill, is shown in man's complicated structure, and in the simple organization of the meanest mollusca that drags on its almost vegetating existence in the coral cares of the ocean.

A work of such magnitude is designed, of course, to be one of standard reference : great care has, consequently, been used to secure the completeness and accuracy of the Index, which is now published.

\section{The following Extracts are from an elaborate Criticism in the Trues of the 24th of January last.}

"The cultivation of Zoology, that vast and interesting branch of natural history, which had languished principally through the want of a well-grounded system of scientific arrangement, has of late years been pursued in this country with considerable ardour, which is sufficiently apparent from the number of works now publishing on zoological science. The facilities for analogical research have much increased; travellers are more observant and more skilful than heretofore, and the menageries in our Zoological Gardens aflord ample and ready opportunities for investigating the properties and characters of animals. But the strongest impulse has probably been given by Baron Cuvier's magnificent work, the Règne Animal, the systematic arrangement in which is, perhaps, almost as great an improvement upon that of Linné as that eminent philosopher's was upon Aristotle's

"The Règne Animal, however, is little more than a scientific catalogue, compendium, or synopsis, arranged on peculiar scientific principles, and, although it is the completest and most scientific zoological arrangement the world has ever seen, it is deficient in popular and entertaining details relative to the habits and instincts of animals, and it contains only a partial selection of the various species in the different genera. In fact, it was meant as an introduction to the Baron's still more elaborate work on comparative anatomy. As a naturai history, the Règne Animal is an extremely, meagre work, adapted to the study of professional students, and as a grammar of zoological science.

"'The outline sketched by Baron Cuvier has been admirably filled up in the splendid work under consideration. 'The whole of the Baron's Rìgne Animal has been translated, with a vast addition of supplementary matter, including full descriptions of all the species, calculated to render the work " not merely useful to the naturalist, as a book of pure science, but also interesting to the public at large, as general zoological biography, and ornamental, as containing original and well-executed illustrations.' 'The gentlemen who have been associated with $\mathrm{Mr}$. Griffith in this arduous undertaking are Mr, Edward Pidgeon, Colonel Charles Hamilton Smith, Mr. John Edward Gray, and Mr. George Gray. 'Iheir competency and qualifications are sufficiently well known." 
"Without entering into a more elaborate examination of the work, we may confidently characterise it as one which cannot fail to recommend itself to a very high rank in public estimation. It appears to have been executed with much care; it evinces a large share of scientific talent and research in the editors; and the plates, some of them from drawings by Landseer, are distinguished by great reatness and fidelity.

" We must not omit to observe, that all superfluous details, which might offend fastidious delicacy, are excluded in this edition; and that, whereas passages in Baron Cuvier's work have been distorted to the prejudice of religion, it has been the particular care of the authors to show the utter inapplicability of zoological science to such an end."

The ANIMAL KINGDOM consists of 16 volumes, at the following prices, in extra cloth boards, viz.

\begin{tabular}{|c|c|c|c|c|c|}
\hline & vols. & $\begin{array}{l}\text { Demy } \\
\text { 8vo. }\end{array}$ & $\begin{array}{l}\text { Royal } \\
\text { 8vo. }\end{array}$ & $\left|\begin{array}{c}\text { Royal } \\
\text { 8vo. } \\
\text { coloured. }\end{array}\right|$ & $\begin{array}{l}\text { Demy4to } \\
\text { India } \\
\text { proots. }\end{array}$ \\
\hline 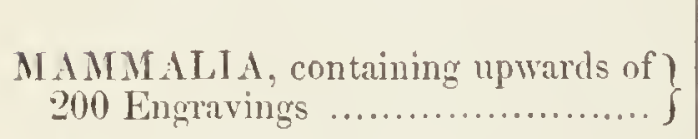 & 5 & $\begin{array}{cc}\mathcal{E} . & s . \\
7 & 4\end{array}$ & 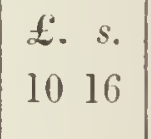 & $\begin{array}{ll}\mathfrak{L} . & s . \\
14 & 8\end{array}$ & $\begin{array}{ll}\mathcal{E} . & s \\
14 & 8\end{array}$ \\
\hline A VES, with 180 Engravings ............ & 3 & 58 & 82 & 1016 & 1016 \\
\hline REPTILI $\Lambda$, with 60 Engravings ..... & 1 & 116 & 214 & 312 & 312 \\
\hline INSECT $A$, with 140 Engravings ...... & 2 & $4 \quad 4$ & $6 \quad 6$ & $8 \quad 8$ & 88 \\
\hline $\begin{array}{l}\text { ANNELID } A \text {, CRUSTACEA, and ) } \\
\text { ARACHNID } A \text {, with } 60 \text { Engravings }\end{array}$ & 1 & 116 & 214 & 312 & 312 \\
\hline 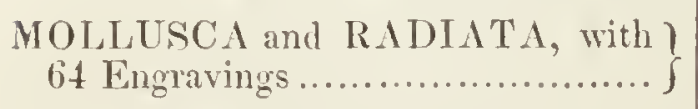 & 1 & 116 & 214 & 312 & 312 \\
\hline 1'ISCES, with 60 Engravings ............ & 1 & 116 & 214 & 312 & 312 \\
\hline FOSSIL REM A INS, with 50 Engravings & 1 & ] 16 & 214 & $\underset{\begin{array}{c}214 \\
\text { coloured. }\end{array}}{214}$ & 31 \\
\hline CLASSIFIED INDEA.. & 1 & 012 & 018 & 018 & 14 \\
\hline & $\begin{array}{c}\text { Vols. } \\
16\end{array}$ & $\begin{array}{ll}\text { f. } & s . \\
26 & 8\end{array}$ & $\begin{array}{cc}\mathfrak{E} . & s \\
39 & 12\end{array}$ & $\begin{array}{cc}f & s . \\
51 & 12\end{array}$ & $\begin{array}{ll}f . & s . \\
52 & 16\end{array}$ \\
\hline
\end{tabular}

'The Publishers beg to draw the attention of Subscribers to the necessity of immediately completing their sets, there being but few remaining of many of the parts.

* * Printed Prospectuses, with further particulars, and extracts of numerous criticisms, may be had of all Booksellers. 



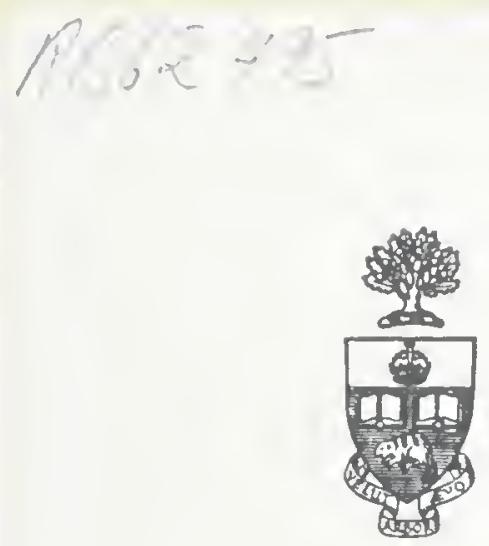

Library

of the

University of Toronto 


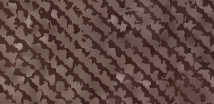

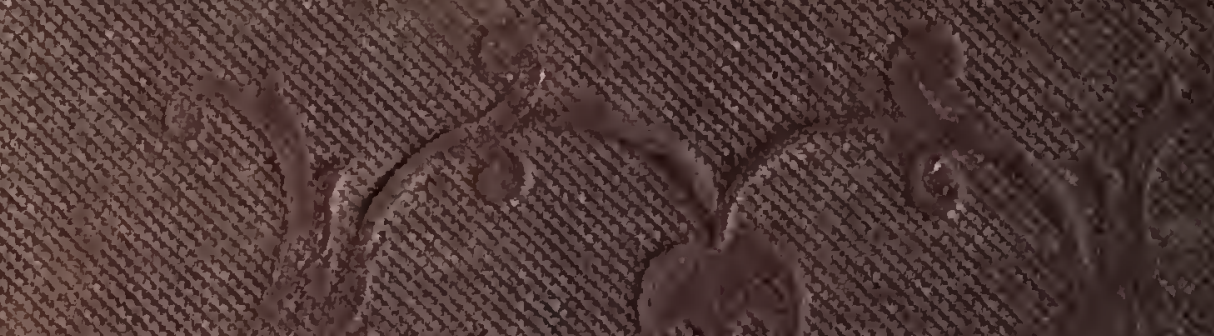

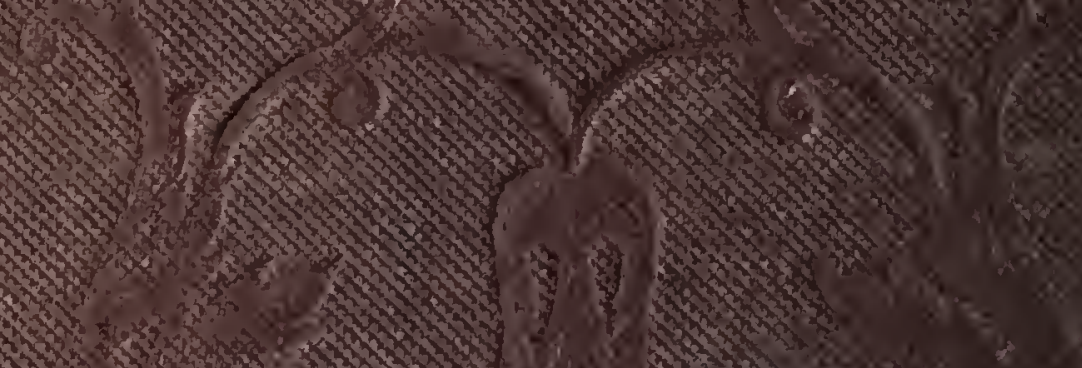

3

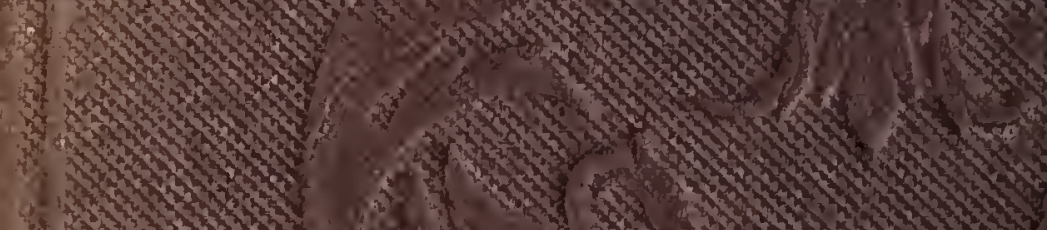

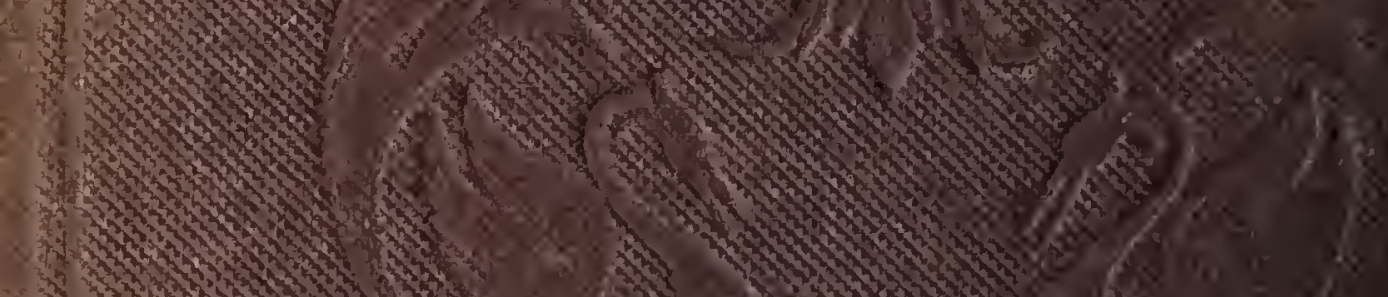

\section{(3)}

H.

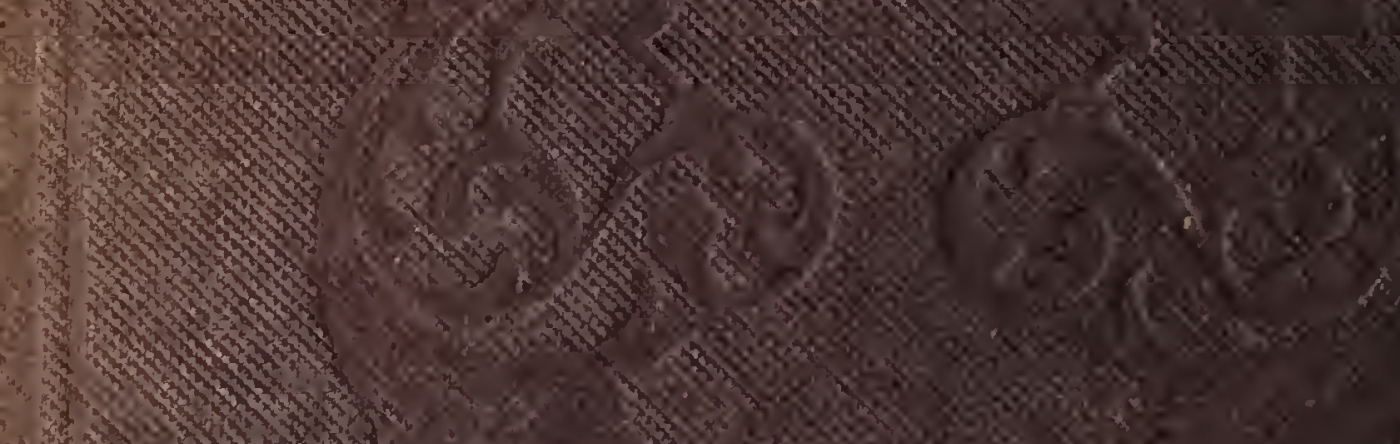

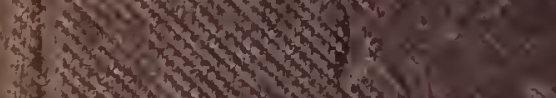

and

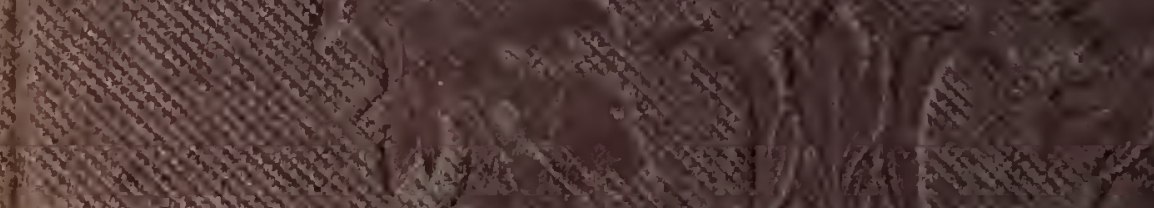

1.1.

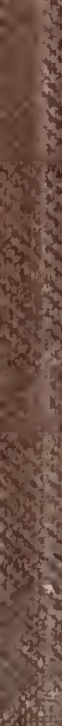

- t.

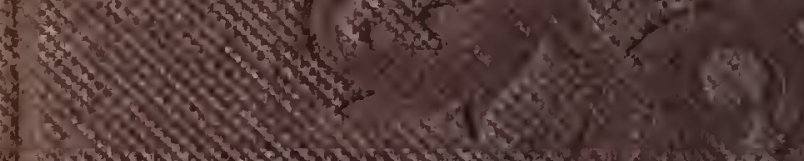

$6 e^{2}$

? 